\title{
Gout, uric acid, and cardiovascular disease : know your enemy
}

Citation for published version (APA):

Wijnands, J. M. A. (2014). Gout, uric acid, and cardiovascular disease : know your enemy. [Doctoral Thesis, Maastricht University]. Maastricht University. https://doi.org/10.26481/dis.20141211jw

Document status and date:

Published: 01/01/2014

DOI:

10.26481/dis.20141211jw

Document Version:

Publisher's PDF, also known as Version of record

\section{Please check the document version of this publication:}

- A submitted manuscript is the version of the article upon submission and before peer-review. There can be important differences between the submitted version and the official published version of record.

People interested in the research are advised to contact the author for the final version of the publication, or visit the DOI to the publisher's website.

- The final author version and the galley proof are versions of the publication after peer review.

- The final published version features the final layout of the paper including the volume, issue and page numbers.

Link to publication

\footnotetext{
General rights rights.

- You may freely distribute the URL identifying the publication in the public portal. please follow below link for the End User Agreement:

www.umlib.nl/taverne-license

Take down policy

If you believe that this document breaches copyright please contact us at:

repository@maastrichtuniversity.nl

providing details and we will investigate your claim.
}

Copyright and moral rights for the publications made accessible in the public portal are retained by the authors and/or other copyright owners and it is a condition of accessing publications that users recognise and abide by the legal requirements associated with these

- Users may download and print one copy of any publication from the public portal for the purpose of private study or research.

- You may not further distribute the material or use it for any profit-making activity or commercial gain

If the publication is distributed under the terms of Article $25 \mathrm{fa}$ of the Dutch Copyright Act, indicated by the "Taverne" license above, 
Gout, uric acid, and cardiovascular disease

\author{
know your enemy
}


CJosé Maria Andreas Wijnands, Maastricht 2014

Cover picture: Colchicum autumnale (autumn crocus) by Gert Ettes

Colchicine is a medication used to treat gout and originally extracted from the Colchicum autumnale.

Cover design: Hilarius Design

Layout: Tiny Wouters

Production: Gildeprint

ISBN: 978-94-6108-824-6 


\title{
Gout, uric acid, and cardiovascular disease
}

\author{
know your enemy
}

PROEFSCHRIFT

ter verkrijging van de graad van doctor aan de Universiteit Maastricht, op gezag van de Rector Magnificus, Prof. Dr. L.L.G. Soete volgens het besluit van het College van Decanen, in het openbaar te verdedigen op donderdag 11 december 2014 om 10.00 uur

door

José Maria Andreas Wijnands 


\section{Promotores}

Prof. dr. A. Boonen

Prof. dr. I.C.W Arts

Prof. dr. C.D.A. Stehouwer

\section{Beoordelingscommissie}

Prof. dr. C.P. van Schayck (voorzitter)

Dr. A. Dehghan, Erasmus Universitair Medisch Centrum Rotterdam

Prof. dr. M.A.F.J. van de Laar, Medisch Spectrum Twente

Dr. K. Reesink 


\section{Dialogue between Franklin and the Gout}

\section{Benjamin Franklin, 1780}

FRANKLIN. Eh! Oh! eh! What have I done to merit these cruel sufferings?

GOUT. Many things; you have ate and drank too freely, and too much indulged those legs of yours in their indolence.

FRANKLIN. Who is it that accuses me?

GouT. It is I, even I, the Gout.

FRANKLIN. What! my enemy in person?

GOUT. No, not your enemy.

FRANKLIN. I repeat it, my enemy; for you would not only torment my body to death, but ruin my good name; you reproach me as a glutton and a tippler; now all the world, that knows me, will allow that I am neither the one nor the other. 



\section{Contents}

$\begin{array}{lll}\text { Chapter } 1 \text { General introduction } & 9\end{array}$

Part I Classification, prevalence and incidence of gout 25

Chapter 2 Large epidemiologic studies of gout: challenges in diagnosis 27 and diagnostic criteria

Chapter 3 Determinants of the prevalence of gout in the general population: 41 a systematic review and meta-regression

Chapter 4 Individuals with type 2 diabetes mellitus are at an increased risk of gout but this is not due to diabetes: a population-based cohort study

Part II The role of uric acid in the aetiology of cardiovascular disease

Chapter 5 The cross-sectional association between uric acid and atherosclerosis, and the role of low-grade inflammation: the CODAM study

Chapter 6 Association between serum uric acid, aortic, carotid, and femoral stiffness: The Maastricht Study

Chapter 7 Uric acid and skin microvascular function: The Maastricht Study

Chapter 8 General discussion

Samenvatting

Valorisation addendum

Dankwoord

Curriculum Vitae 



\section{Chapter 1}

General introduction 
Chapter 1 


\section{General introduction}

Gout is the most common form of inflammatory rheumatic disease and is caused by the deposition of monosodium urate crystals in the synovial fluid ${ }^{1}$. The disease receives increasing attention by clinicians, researchers, and healthcare authorities. First, as gout is related to lifestyle and obesity, it has been suggested that the incidence and consequently the prevalence of the disease increased in the last decades and will rise further ${ }^{1}$. Second, patients with gout often have a broad spectrum of comorbidities including the metabolic syndrome and cardiovascular disease (CVD) ${ }^{2}$. Although common risk factors might explain this association, accumulating evidence shows that there may be a causal relation between gout and CVD. It has been suggested that high uric acid levels in patients with gout play an important role in this increased risk ${ }^{3}$. Various mechanisms have already been proposed that link uric acid to CVD ${ }^{4}$. However, the precise underlying mechanisms are still unknown. Assessing the influence of uric acid on the different processes that may lead to CVD, i.e. atherosclerosis, arteriosclerosis and arteriolosclerosis, may provide a better insight in the role of uric acid. If uric acid is proven to have an independent role in the development of CVD, uric acid concentrations should be a treatment target in the management of CVD.

This thesis comprises two main parts. In part I, the classification, prevalence, and incidence of gout are studied. In part II, the role of uric acid in the aetiology of CVD is explored. Accordingly, some background will be provided regarding gout, uric acid, macro- and microvascular disease, and the role of uric acid in cardiovascular disease.

\section{Gout}

Gout was first described by the Egyptians in 2640BC. More than 2000 years later, Hippocrates referred to gout as "the unwalkable disease" and developed the term "podagra" ${ }^{5}$. Podagra is a descriptive term referring to the sudden painful inflammatory arthritis of the metatarsophalangeal joint of the hallux, and is a key pointer toward gout diagnosis ${ }^{6}$. For centuries, gout was known as the "disease of the kings" due to the association with an intemperate lifestyle $e^{5}$. Risk factors include beer consumption and the intake of certain dietary products such as meat and seafood ${ }^{7}$. These products are high in purines and thus may increase uric acid production. Sugar-sweetened beverages and the associated fructose intake may also increase uric acid concentrations ${ }^{8}$. Fructose is rapidly phosphorylated to fructose-1-phosphate, during which adenosine triphosphate (ATP) donates phosphate. Phosphorylation of fructose is not as tightly regulated as that of glucose ${ }^{9}$. This results in ATP depletion, and consequently, in the generation of adenosine diphosphate (ADP), which is further metabolized to adenosine monophosphate (AMP) and to uric acid ${ }^{10}$. Furthermore, the fructose-induced decrease 
in phosphate activates AMP deaminase, which catalyses AMP to inosine monophosphate ${ }^{9,11}$. Inosine monophosphate is further metabolized to uric acid (Figure 1.1). Next to dietary products, risk factors for gout include male sex, age, genetic factors, the presence of other chronic diseases and use of certain medications (please see paragraph "Uric acid as an epiphenomenon").

Several clinical manifestations of gout can be distinguished ${ }^{12}$. After a period of asymptomatic hyperuricaemia, characterized by high uric acid concentrations, uric acid may crystalize and form urate deposits around a joint. Consequently, an inflammatory response can be initiated, resulting in a first attack of monoarthritis that is generally located in the first metatarsophalangeal joint. This attack usually resolves within 14 days $^{13,14}$. After the acute monoarthritis has subsided, the patient enters an intercritical period with a clinically inactive disease. Flares of arthritis can recur at highly variable intervals. When the disease progresses, the periods in between flares become shorter and more joints get involved. Finally, usually after a long period of intermittent flares $(5-10 \text { year })^{12}$, a patient can develop chronic arthritis. It is characterized by chronic joint inflammation and disabling gouty erosions or tophi, which are deposits of monosodium urate crystals in the skin, tissue or bony parts of the joints ${ }^{2}$. Although the different manifestations normally occur in this order, patients can also present with severe tophaceous gout without having had episodes of acute arthritis.

Despite our understanding of the pathophysiology of gout and the availability of effective therapy, the disease remains a challenge to diagnose and to manage ${ }^{15}$. Gout is in most cases diagnosed and managed by general practitioners ${ }^{16,17}$. The diagnosis in primary care is often based on clinical signs and symptoms solely ${ }^{18}$. Although recurrent podagra in combination with hyperuricaemia is reasonably accurate for the diagnosis of gout, demonstration of monosodium urate crystals in synovial fluid or tophus aspirates is the only method to permit a definitive diagnosis ${ }^{17}$. As a result, the disease may be misdiagnosed or diagnosed late in its clinical course ${ }^{17}$. Next to late diagnosis, studies show a low adherence to treatments guidelines ${ }^{19}$ and low compliance with uratelowering drugs ${ }^{20}$. As a result, the disease places an economic and social burden on society ${ }^{21}$ with substantial costs of productivity loss ${ }^{22,23}$ and an effect on physical-healthrelated quality of life ${ }^{24}$.

\section{Uric acid}

Uric acid is an organic compound composed of carbon, hydrogen, nitrogen and oxygen $\left(\mathrm{C}_{5} \mathrm{H}_{4} \mathrm{~N}_{4} \mathrm{O}_{3}\right)$. It is primarily formed by the liver from the breakdown of purines, i.e. adenosine and guanine ${ }^{25}$. The purine nucleotides are broken down into the purine bases guanine or hypoxanthine, after which they are catabolised to xanthine and, ultimately, to uric acid by the enzyme xanthine oxidase ${ }^{26,27}$ (Figure 1.1). 


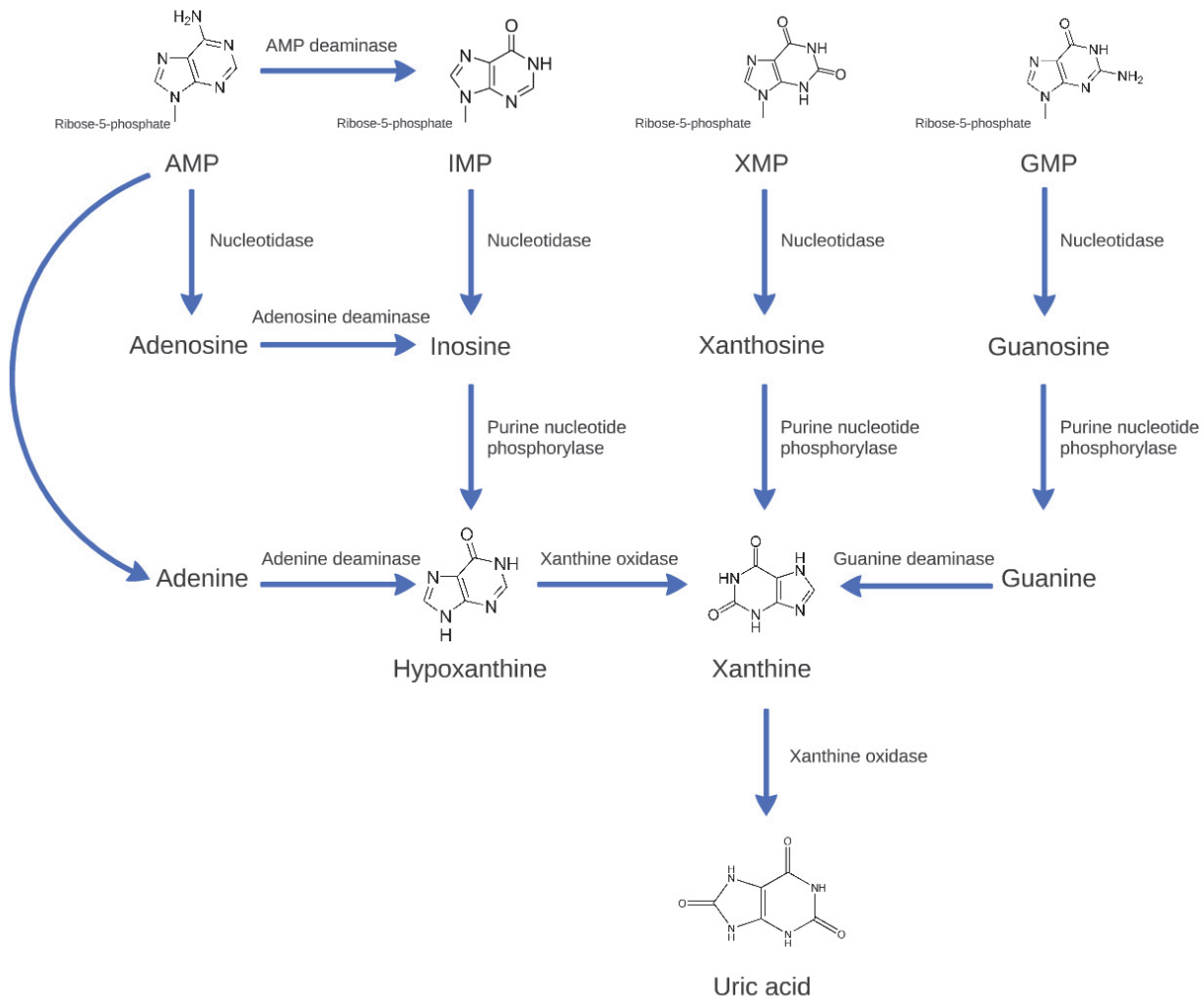

Figure 1.1 Purine catabolism. AMP=adenosine monophosphate; IMP=inosine monophosphate; $\mathrm{XMP}=x$ anthosine monophosphate; $\mathrm{GMP}=$ guanosine monophosphate.

In most mammals, uric acid is converted to the more soluble allantoin by the urate oxidase enzyme uricase ${ }^{28}$. However, in humans, uric acid is the end product of purine catabolism due to a mutation in the urate oxidase gene that occurred nearly 15 million years ago ${ }^{29,30}$. Since uric acid is a weak acid, it predominantly circulates as urate anion at physiologic $\mathrm{pH}^{31}$.

Uric acid concentrations are determined by a balance between uric acid production and excretion. In general, individuals maintain a relatively stable uric acid concentration with a total body uric acid pool of approximately $1000 \mathrm{mg}^{32}$. In $15-20 \%$ of the general population, a disbalance may exist resulting from overproduction and/or underexcretion of uric acid. Overproduction can be caused by excess dietary intake of purines, a genetic tendency towards high uric acid production or conditions with a high cell turnover ${ }^{33}$. Underexcretion, responsible for $90 \%$ of the hyperuricaemic $\operatorname{cases}^{34}$, can be caused by reduced renal function, genetic polymorphisms in renal urate transporters 
or certain drugs such as diuretics ${ }^{35}$. Excretion of uric acid occurs via the kidneys ( $70 \%$ ) as well as the intestine $(\sim 30 \%)^{36}$. The disbalance between production and excretion will elevate uric acid concentrations. Without any clinical signs or symptoms of gout these individuals are classified as having asymptomatic hyperuricaemia. Currently, there is no consensus on the definition of hyperuricaemia ${ }^{12}$. Several methods exist, often depending on the outcome of a study. Hyperuricaemia can be defined based on a statistical definition, i.e. uric acid concentrations lying more than two standard deviations above the mean ${ }^{12}$. Since women have generally lower uric acid concentrations, a lower cut off value in women than in men is used. An alternative method is to use the saturation point of uric acid in body fluids. However, the saturation point in joint tissues is not precisely known ${ }^{12}$. In addition, hyperuricaemia can be defined as the threshold at which the risk of developing gout or CVD increases. Experts propose to define hyperuricaemia as uric acid concentrations above $6 \mathrm{mg} / \mathrm{dl}$ $(\approx 357 \mu \mathrm{mol} / \mathrm{l})$, which is the concentration above which gout may appear ${ }^{12}$. Note that hyperuricaemia is not considered a disease state, and only a small percentage (10-15\%) of individuals with hyperuricaemia will develop gout ${ }^{29,37}$.

\section{Macro- and microvascular disease}

CVD remains among the leading causes of mortality and morbidity worldwide. Degenerative changes of the large arteries, i.e. atherosclerosis or arteriosclerosis, are the main causes of CVD. Atherosclerosis is a disease of the intimal layer of the vascular wall (Figure 1.2) and is initiated by a series of cellular events within this wall ${ }^{38}$. Traditional risk factors include unhealthy blood cholesterol levels (i.e. high triglyceride, high low-density lipoprotein (LDL) cholesterol, and low high-density lipoprotein (HDL) cholesterol concentrations), hypertension, smoking, overweight, and diabetes mellitus. The disease is characterized by the thickening of the wall and narrowing of the lumen of the large arteries as a result of the build-up of fatty materials (plaques) ${ }^{38}$. The buildup of a plaque is a slow process and may take many years. However, if a plaque ruptures, a thrombus may form that potentially causes ischaemia of the heart, brain or extremities, resulting in infarction ${ }^{38,39}$.

Arteriosclerosis or arterial stiffening refers to the loss of the elastic properties of the arterial wall and is one of the hallmarks of arterial ageing ${ }^{40}$. It is primarily characterized by changes in the medial layer of the wall (Figure 1.2). These changes include a dysregulation of the balance between collagen and elastin fibres ${ }^{41}$. Furthermore, stiffness is affected by disturbed endothelial cell signalling and increased vascular smooth muscle cell (VSMC) tone ${ }^{41}$. Stiffer arteries impair the cushioning capacity of the wall, leading to an increase in systolic blood pressure and a decrease in diastolic blood pressure ${ }^{42}$. In turn, these changes contribute to left ventricular hypertrophy, heart failure, stroke and myocardial infarction ${ }^{42}$. 
Next to macrovascular disease, CVD include a microvascular component. The microcirculation is composed of all small blood vessels with a diameter of less than $150 \mu \mathrm{m}$, including arterioles, capillaries and venules ${ }^{43}$. These small vessels regulate organ perfusion, vascular tone and transport of blood solutes ${ }^{43}$, and are therefore an important part of the vascular system. Impairment of one or more of these functions is called microvascular dysfunction, which is affected by endothelial and/or smooth muscle cell dysfunction. Risk factors include ageing, hypertension, dyslipidaemia, smoking and diabetes ${ }^{44}$. Severe abnormalities in microvascular function may result in microvascular disease (arteriolosclerosis) which can affect several organs, including the muscle, skin, heart, kidney and/or brain.

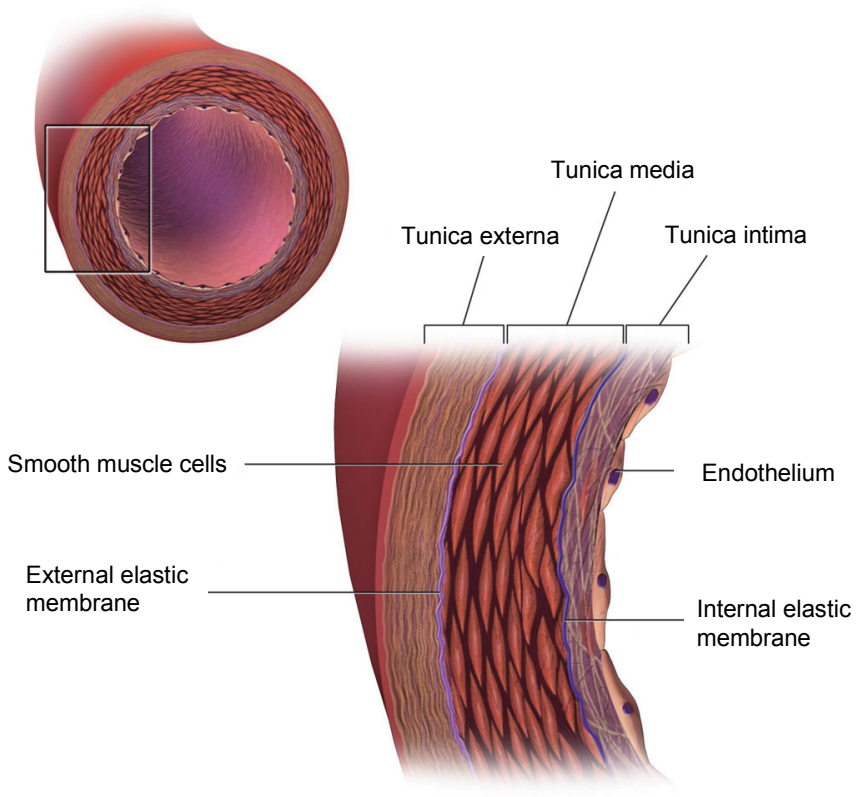

Figure 1.2 Schematic representation of the artery wall (Blausen Medical Communications).

\section{Uric acid and cardiovascular disease}

The exact nature of how uric acid relates to cardiovascular and metabolic diseases is complex and still not completely understood. High uric acid concentrations may be a consequence of these diseases (epiphenomenon), represent increased antioxidant activity as a response to oxidative stress and/or may play a causal role the development of CVD. 


\section{Uric acid as an epiphenomenon}

Hyperuricaemia is often observed in individuals with obesity, hypertension, kidney and/or CVD. In these individuals, hyperuricaemia has been regarded as an epiphenomenon ${ }^{45}$. One of the main underlying mechanisms for the association between these diseases and increased uric acid concentrations is insulin resistance and its compensatory hyperinsulinaemia. Excess insulin concentrations are known to stimulate urate reabsorption in the proximal tubule ${ }^{46}$. Furthermore, hyperinsulinaemia can play a role in the development of hypertension and lipid abnormalities (increased small dense LDL cholesterol and triglycerides, and decreased HDL cholesterol) ${ }^{47}$. Increased uric acid concentrations in individuals with hypertension or hyperlipidaemia may thus be explained by the often coexisting insulin resistance. However, hyperuricaemia in hypertension may also reflect early renal vascular involvement as increased uric acid concentrations have been associated with low renal blood flow and high renal and total peripheral resistance ${ }^{48}$. An alternative mechanism that has been postulated to explain high uric acid levels in individuals with a high cardiovascular risk profile is ischaemia. During tissue ischaemia, ATP is broken down to ADP and AMP, which can be further catabolised to uric acid ${ }^{49,50}$. Finally, high uric acid concentrations can results from certain drugs ${ }^{51}$. The best known examples are loop and thiazide diuretics $^{52}$ that may cause hyperuricaemia due to circulating volume depletion ${ }^{53}$ and the competition with the tubular secretion of urate in the kidney ${ }^{54}$, but also cyclosporine and tacrolimus (immunosuppressant) and low concentrations of salicylic acid derivatives (anti-inflammatory agents) can decrease uric acid excretion ${ }^{54,55}$.

\section{Beneficial effects of uric acid}

After filtration of uric acid by the kidneys, a large percentage ( $90 \%)$ of filtered uric acid is reabsorbed, suggesting uric acid is not a waste product ${ }^{26}$. It has been hypothesized that loss of the uricase enzyme, the enzyme that catalyses the conversion of uric acid into allantoin, may have had an evolutionary advantage and that uric acid may counteract oxidative stress found in individuals with CVD and increased longevity ${ }^{26}$. Uric acid has been brought forward as one of the most important water-soluble antioxidants in humans with the ability to scavenge radicals such as peroxyl and hydroxyl radicals ${ }^{56}$. A major site of the antioxidant activity of uric acid is the central nervous system ${ }^{56}$, where uric acid may protect against multiple sclerosis and neurodegenerative diseases such as Parkinson's disease and Alzheimer's disease by scavenging peroxynitrite ${ }^{57-60}$.

\section{Detrimental effects of uric acid}

Accumulating evidence suggest that high uric acid levels may precede the development of weight gain ${ }^{61}$, hyperinsulinaemia ${ }^{62}$, hypertension ${ }^{61,63}$ and the metabolic syndrome ${ }^{64}$. 
In addition, studies suggest that hyperuricaemia can modestly increase the risk of CVD independently of these traditional cardiovascular risk factors ${ }^{65,66}$. Several underlying mechanisms have been identified through which uric acid may contribute to the development of $\mathrm{CVD}^{4}$.

First, it has been proposed that VSMCs have organic anion transporters that allow the uptake of urate ${ }^{67}$. After entering the cells, uric acid may cause cell proliferation ${ }^{68}$. One pathway involves the activation of mitogen-activated protein kinases ${ }^{69}$, which is one of the signalling pathways involved in $\mathrm{CVD}^{70}$. An additional mechanism for smooth muscle cell proliferation relates to the stimulation of the renin-angiotensin system and thus angiotensin II production in VSMCs ${ }^{69}$. VSMCs are responsible for arterial contractile tonus, regulation of blood pressure, and redistribution of blood flow ${ }^{71}$. Hypertrophy of VSMCs can result in a decrease in elastin content, which reduces the elastic properties of the arterial wall ${ }^{71}$. This may eventually lead to arterial stiffness.

Second, during the production of uric acid, xanthine oxidase generates oxidants. These oxidants may react with nitric oxide (NO), decreasing NO availability and consequently induce endothelial dysfunction. In addition, uric acid itself may have a direct effect on the endothelium by decreasing NO production independent of oxidant generation $^{72}$. Endothelial cells are involved in platelet activation, leukocyte adhesion and thrombosis ${ }^{73}$. Dysfunction of these cells can result in several manifestations that promote the development of atherosclerosis such as an altered vascular reactivity, increased lipoprotein permeability and oxidation, and dysregulation of the haemostatic-thrombotic balance ${ }^{74}$. The endothelium may also control the relaxation and contraction of VSMCs and thus be involved in arterial stiffness ${ }^{75}$.

Finally, soluble uric acid has been associated with low-grade inflammation. It has the potential to up-regulate C-reactive protein (CRP) expression in smooth muscle cells and endothelial cells ${ }^{76}$. Furthermore, epidemiologic studies have shown that uric acid is associated with inflammatory biomarkers such as interleukin-6 (IL-6) and tumour necrosis factor (TNF)- $\alpha^{77-79}$. Inflammation plays an important role in CVD, especially in atherosclerosis $^{80}$. IL-6 is a procoagulant cytokine which can promote thrombosis ${ }^{81,82}$. CRP and TNF- $\alpha$ can induce the expression of cellular adhesion molecules that play a role on the adhesion of leukocytes to the endothelium ${ }^{83}$. Adhesion of leukocytes to the endothelium is proposed to be a critical step in the initiation of the atherosclerotic process $^{39}$.

\section{Outline of the thesis}

This thesis consists of two main parts: 1) classification, prevalence and incidence of gout as described in chapters 2-4; and 2) the possible mechanisms for the association between uric acid and CVD in chapters 5-7. 
A wide range of research is performed on the epidemiology, pathophysiology and treatment of gout. However, the episodic character of the disease provides some hurdles in epidemiologic research. In chapter 2, we critically appraised definitions and criteria of gout regularly used in epidemiologic studies. In addition, a number of additional challenges when interpreting results of epidemiologic research on gout were addressed.

Difficulties in classifying gout might have resulted in the large variation of estimates of the prevalence and incidence. Although it is known that gout prevalence varies with age, gender and ethnic background, clear insight in methodological sources of heterogeneity is lacking. In chapter $\mathbf{3}$, we performed a systematic review and metaregression analysis on the prevalence and incidence of gout, and investigated the contribution of a series of methodological and clinical sources of heterogeneity to the variety in reported prevalence.

In chapter 4, we explored the complex relationship between type 2 diabetes mellitus (T2DM) and gout. On the one hand, individuals with T2DM are characterized by various clinical features that are known risk factors for gout, such as high BMI, hypertension and kidney failure ${ }^{84,85}$. On the other hand, the decreased inflammatory response $^{86}$ and the uricosuric effect of glycosuria ${ }^{87}$ might protect against the development of gout. The objective of this study was to understand the role of diabetes itself and its comorbidities within the association between T2DM and gout. The study was performed in the Clinical Practice Research Datalink (CPRD) GOLD. This is world's largest database of anonymised, longitudinal primary care medical records, with 678 general practitioners having collected data of approximately $8 \%$ of the UK population as part of their routine clinical practice.

Studies examining the association between uric acid and CVD have yielded inconsistent results. A possible explanation may be a difference in the underlying pathophysiological mechanisms through which uric acid may contribute to the development of CVD. We considered three different processes in the development of $C V D$, i.e. atherosclerosis, arterial stiffness and microvascular dysfunction.

In chapter 5, we examined the relationship between uric acid and atherosclerosis in predefined subgroups according to glucose metabolism status. It has been suggested that the association between uric acid and CVD may differ according to glucose metabolism status due to the biological interaction between uric acid, insulin and glucose $^{88}$. In addition, we investigated the mediating role of low-grade inflammation. The study was performed in the cohort study of diabetes and atherosclerosis (CODAM), which is a longitudinal cohort study of individuals at an increased risk of CVD in the Netherlands.

Only a small number of studies have assessed the association between uric acid and arterial stiffness. Studies that used the gold standard for arterial stiffness, i.e. carotidfemoral pulse wave velocity, are scarce and show inconsistent results ${ }^{89-96}$. Furthermore, studies that examined the association with local stiffness indices are lacking ${ }^{97,98}$. In 
chapter 6, we therefore explored the association between uric acid and arterial stiffness in the general population and assessed the possible interaction between uric acid on the one hand and sex and glucose metabolism status on the other. The study was performed in The Maastricht Study. The Maastricht Study is a prospective population-based cohort study that focuses on the aetiology and pathophysiology of T2DM, its classic complications (CVD, nephropathy, neuropathy and retinopathy), and its emerging comorbidities.

Studies on the association between uric acid and microcirculatory function have only scarcely been performed. A limited number of studies have reported an association between uric acid and microvascular dysfunction in the heart ${ }^{99-101}$, kidney $^{102}$ and eyes ${ }^{103}$. Since the cutaneous microcirculation is considered a representative model of microvascular function in general ${ }^{104}$, we investigated the relation between uric acid and cutaneous microcirculatory function in chapter 7 . In addition, we assessed the possible interaction between uric acid on the one hand and age, sex and glucose metabolism status on the other. The study was performed in The Maastricht Study.

Finally, in chapter $\mathbf{8}$ the main findings of the studies presented in this thesis are summarized and discussed. Moreover, the clinical relevance and directions for future research are addressed. 


\section{References}

1. Roddy E, Doherty M. Epidemiology of gout. Arthritis Res Ther. 2010;12:223.

2. Stamp LK, Chapman PT. Gout and its comorbidities: implications for therapy. Rheumatology (Oxford). 2013;52:34-44.

3. Fang J, Alderman MH. Serum uric acid and cardiovascular mortality the NHANES I epidemiologic followup study, 1971-1992. National Health and Nutrition Examination Survey. JAMA. 2000;283: 2404-2410.

4. Johnson RJ, Kang DH, Feig D, et al. Is there a pathogenetic role for uric acid in hypertension and cardiovascular and renal disease? Hypertension. 2003;41:1183-1190.

5. Nuki G, Simkin PA. A concise history of gout and hyperuricemia and their treatment. Arthritis Res Ther. 2006;8 Suppl 1:S1.

6. Taylor WJ, Grainger R. Clinical Features of gout. In: Terkeltaub R, ed. Gout and other crystal arthropathies. Philadelphia, PA: Saunders; 2011:105-120.

7. Singh JA, Reddy SG, Kundukulam J. Risk factors for gout and prevention: a systematic review of the literature. Curr Opin Rheumatol. 2011;23:192-202.

8. Choi HK, Curhan G. Soft drinks, fructose consumption, and the risk of gout in men: prospective cohort study. BMJ. 2008;336:309-312.

9. Johnson RJ, Sanchez-Lozada LG, Nakagawa T. The effect of fructose on renal biology and disease. J Am Soc Nephrol. 2010;21:2036-2039.

10. Hallfrisch J. Metabolic effects of dietary fructose. Faseb J. 1990;4:2652-2660.

11. Smith CM, Rovamo LM, Raivio KO. Fructose-induced adenine nucleotide catabolism in isolated rat hepatocytes. Can J Biochem. 1977;55:1237-1240.

12. Bardin T, Richette P. Definition of hyperuricemia and gouty conditions. Curr Opin Rheumatol. 2014;26: 186-191.

13. Zhang $\mathrm{Y}$, Woods $\mathrm{R}$, Chaisson $\mathrm{CE}$, et al. Alcohol consumption as a trigger of recurrent gout attacks. Am J Med. 2006;119:800.e813-800.e818.

14. Hunter DJ, York M, Chaisson CE, Woods R, Niu J, Zhang Y. Recent diuretic use and the risk of recurrent gout attacks: the online case-crossover gout study. J Rheumatol. 2006;33:1341-1345.

15. Sundy JS. Gout management: let's get it right this time. Arthritis Rheum. 2008;59:1535-1537.

16. Rott KT, Agudelo CA. Gout. JAMA. 2003;289:2857-2860.

17. Zhang W, Doherty M, Pascual E, et al. EULAR evidence based recommendations for gout. Part I: Diagnosis. Report of a task force of the Standing Committee for International Clinical Studies Including Therapeutics (ESCISIT). Ann Rheum Dis. 2006;65:1301-1311.

18. Janssens HJ, Fransen J, van de Lisdonk EH, van Riel PL, van Weel C, Janssen M. A diagnostic rule for acute gouty arthritis in primary care without joint fluid analysis. Arch Intern Med. 2010;170:1120-1126.

19. Wall GC, Koenigsfeld CF, Hegge KA, Bottenberg MM. Adherence to treatment guidelines in two primary care populations with gout. Rheumatol Int. 2010;30:749-753.

20. Harrold LR, Andrade SE, Briesacher BA, et al. Adherence with urate-lowering therapies for the treatment of gout. Arthritis Res Ther. 2009;11:R46.

21. Trieste L, Palla I, Fusco F, et al. The economic impact of gout: a systematic literature review. Clin Exp Rheumatol. 2012;30:S145-148.

22. Edwards NL, Sundy JS, Forsythe A, Blume S, Pan F, Becker MA. Work productivity loss due to flares in patients with chronic gout refractory to conventional therapy. J Med Econ. 2011;14:10-15.

23. Kleinman NL, Brook RA, Patel PA, et al. The impact of gout on work absence and productivity. Value Health. 2007;10:231-237.

24. Roddy $E$, Zhang W, Doherty M. Is gout associated with reduced quality of life? A case-control study. Rheumatology (Oxford). 2007;46:1441-1444.

25. Rose WC. Purine metabolism. Physiol Rev. 1923;3:544-602.

26. Alvarez-Lario B, Macarron-Vicente J. Uric acid and evolution. Rheumatology (Oxford). 2010;49: 2010-2015.

27. Moriwaki Y, Yamamoto T, Higashino K. Enzymes involved in purine metabolism: a review of histochemical localization and functional implications. Histol Histopathol. 1999;14:1321-1340. 
28. Hayashi S, Fujiwara S, Noguchi T. Evolution of urate-degrading enzymes in animal peroxisomes. Cell Biochem Biophys. 2000;32:123-129.

29. Richette P, Bardin T. Gout. Lancet. 2010;375:318-328.

30. Oda M, Satta Y, Takenaka O, Takahata N. Loss of urate oxidase activity in hominoids and its evolutionary implications. Mol Biol Evol. 2002;19:640-653.

31. Neogi T, George J, Rekhraj S, Struthers AD, Choi H, Terkeltaub RA. Are either or both hyperuricemia and xanthine oxidase directly toxic to the vasculature? A critical appraisal. Arthritis Rheum. 2012;64: 327-338.

32. Laster L, Muller AF. Uric acid production in a case of myeloid metaplasia associated with gouty arthritis, studied with N15 labeled glycine. Am J Med. 1953;15:857-861.

33. Ngo TC, Assimos DG. Uric Acid nephrolithiasis: recent progress and future directions. Rev Urol. 2007;9:17-27.

34. Anzai N, Endou H. Drug discovery for hyperuricemia. Expert Opin Drug Discov. 2007;2:1251-1261.

35. Taniguchi A, Kamatani N. Control of renal uric acid excretion and gout. Curr Opin Rheumatol. 2008;20:192-197.

36. So A, Thorens B. Uric acid transport and disease. J Clin Invest. 2010;120:1791-1799.

37. Perez-Ruiz F. Treating to target: a strategy to cure gout. Rheumatology (Oxford). 2009;48 Suppl 2:ii9-ii14.

38. Ross R. Atherosclerosis: an inflammatory disease. N Engl J Med. 1999;340:115-126.

39. Ross R. The pathogenesis of atherosclerosis: a perspective for the 1990s. Nature. 1993;362:801-809.

40. Lakatta EG, Levy D. Arterial and cardiac aging: major shareholders in cardiovascular disease enterprises: Part I: aging arteries: a "set up" for vascular disease. Circulation. 2003;107:139-146.

41. Zieman SJ, Melenovsky V, Kass DA. Mechanisms, pathophysiology, and therapy of arterial stiffness. Arterioscler Thromb Vasc Biol. 2005;25:932-943.

42. O'Rourke MF, Hashimoto J. Mechanical factors in arterial aging: a clinical perspective. J Am Coll Cardiol. 2007;50:1-13.

43. Levy BI, Ambrosio G, Pries AR, Struijker-Boudier HA. Microcirculation in hypertension: a new target for treatment? Circulation. 2001;104:735-740.

44. Crea F, Camici PG, Bairey Merz CN. Coronary microvascular dysfunction: an update. Eur Heart J. 2014; 35:1101-1111.

45. Mazzali M, Kanbay M, Segal MS, et al. Uric acid and hypertension: cause or effect? Curr Rheumatol Rep. 2010;12:108-117.

46. Facchini F, Chen YD, Hollenbeck CB, Reaven GM. Relationship between resistance to insulin-mediated glucose uptake, urinary uric acid clearance, and plasma uric acid concentration. JAMA. 1991;266: 3008-3011.

47. DeFronzo RA, Ferrannini E. Insulin resistance. A multifaceted syndrome responsible for NIDDM, obesity, hypertension, dyslipidemia, and atherosclerotic cardiovascular disease. Diabetes Care. 1991;14: 173-194.

48. Messerli FH, Frohlich ED, Dreslinski GR, Suarez DH, Aristimuno GG. Serum uric acid in essential hypertension: an indicator of renal vascular involvement. Ann Intern Med. 1980;93:817-821.

49. Woolliscroft JO, Fox IH. Increased body fluid purine levels during hypotensive events. Evidence for ATP degradation. Am J Med. 1986;81:472-478.

50. Patschan D, Patschan S, Gobe GG, Chintala S, Goligorsky MS. Uric acid heralds ischemic tissue injury to mobilize endothelial progenitor cells. J Am Soc Nephrol. 2007;18:1516-1524.

51. Scott JT. Drug-induced gout. Baillieres Clin Rheumatol. 1991;5:39-60.

52. McAdams DeMarco MA, Maynard JW, Baer AN, et al. Diuretic use, increased serum urate levels, and risk of incident gout in a population-based study of adults with hypertension: the Atherosclerosis Risk in Communities cohort study. Arthritis Rheum. 2012;64:121-129.

53. Gibson TJ. Hypertension, its treatment, hyperuricaemia and gout. Curr Opin Rheumatol. 2013;25: 217-222.

54. Sica DA, Schoolwerth AC. Renal handling of organic anions and cations: excretion of uric acid. In: Brenner BM, ed. The kidney. Philadelphia, PA: Saunders; 2000:680-700. 
55. Kanbay M, Akcay A, Huddam B, et al. Influence of cyclosporine and tacrolimus on serum uric acid levels in stable kidney transplant recipients. Transplant Proc. 2005;37:3119-3120.

56. Sautin YY, Johnson RJ. Uric acid: the oxidant-antioxidant paradox. Nucleosides Nucleotides Nucleic Acids. 2008;27:608-619.

57. Zhang YJ, Xu YF, Liu YH, et al. Peroxynitrite induces Alzheimer-like tau modifications and accumulation in rat brain and its underlying mechanisms. Faseb J. 2006;20:1431-1442.

58. Hooper DC, Spitsin S, Kean RB, et al. Uric acid, a natural scavenger of peroxynitrite, in experimental allergic encephalomyelitis and multiple sclerosis. Proc Natl Acad Sci U.S.A. 1998;95:675-680.

59. Scott GS, Hooper DC. The role of uric acid in protection against peroxynitrite-mediated pathology. Med Hypotheses. 2001;56:95-100.

60. Ebadi M, Sharma SK, Ghafourifar P, Brown-Borg H, El Refaey H. Peroxynitrite in the pathogenesis of Parkinson's disease and the neuroprotective role of metallothioneins. Methods Enzymol. 2005;396: 276-298.

61. Masuo K, Kawaguchi H, Mikami H, Ogihara T, Tuck ML. Serum uric acid and plasma norepinephrine concentrations predict subsequent weight gain and blood pressure elevation. Hypertension. 2003;42:474-480.

62. Carnethon MR, Fortmann SP, Palaniappan L, Duncan BB, Schmidt MI, Chambless LE. Risk factors for progression to incident hyperinsulinemia: the Atherosclerosis Risk in Communities Study, 1987-1998. Am J Epidemiol. 2003;158:1058-1067.

63. Gaffo AL, Jacobs DR, Jr., Sijtsma F, Lewis CE, Mikuls TR, Saag KG. Serum urate association with hypertension in young adults: analysis from the Coronary Artery Risk Development in Young Adults cohort. Ann Rheum Dis. 2013;72:1321-1327.

64. Goncalves JP, Oliveira A, Severo M, Santos AC, Lopes C. Cross-sectional and longitudinal associations between serum uric acid and metabolic syndrome. Endocrine. 2012;41:450-457.

65. Kim SY, Guevara JP, Kim KM, Choi HK, Heitjan DF, Albert DA. Hyperuricemia and coronary heart disease: a systematic review and meta-analysis. Arthritis Care Res (Hoboken). 2010;62:170-180.

66. Kim SY, Guevara JP, Kim KM, Choi HK, Heitjan DF, Albert DA. Hyperuricemia and risk of stroke: a systematic review and meta-analysis. Arthritis Rheum. 2009;61:885-892.

67. Price KL, Sautin YY, Long DA, et al. Human vascular smooth muscle cells express a urate transporter. J Am Soc Nephrol. 2006;17:1791-1795.

68. Kang DH, Han L, Ouyang $X$, et al. Uric acid causes vascular smooth muscle cell proliferation by entering cells via a functional urate transporter. Am J Nephrol. 2005;25:425-433.

69. Corry DB, Eslami P, Yamamoto K, Nyby MD, Makino H, Tuck ML. Uric acid stimulates vascular smooth muscle cell proliferation and oxidative stress via the vascular renin-angiotensin system. $J$ Hypertens. 2008;26:269-275.

70. Zhang W, Elimban V, Nijjar MS, Gupta SK, Dhalla NS. Role of mitogen-activated protein kinase in cardiac hypertrophy and heart failure. Exp Clin Cardiol. 2003;8:173-183.

71. Lacolley P, Regnault V, Nicoletti A, Li Z, Michel JB. The vascular smooth muscle cell in arterial pathology: a cell that can take on multiple roles. Cardiovasc Res. 2012;95:194-204.

72. Kanellis J, Kang DH. Uric acid as a mediator of endothelial dysfunction, inflammation, and vascular disease. Semin Nephrol. 2005;25:39-42.

73. Kuvin JT, Karas RH. Clinical utility of endothelial function testing: ready for prime time? Circulation. 2003;107:3243-3247.

74. Gimbrone MA, Jr., Garcia-Cardena G. Vascular endothelium, hemodynamics, and the pathobiology of atherosclerosis. Cardiovasc Pathol. 2013;22:9-15.

75. Bellien J, Favre J, lacob M, et al. Arterial stiffness is regulated by nitric oxide and endothelium-derived hyperpolarizing factor during changes in blood flow in humans. Hypertension. 2010;55:674-680.

76. Kang DH, Park SK, Lee IK, Johnson RJ. Uric acid-induced C-reactive protein expression: implication on cell proliferation and nitric oxide production of human vascular cells. J Am Soc Nephrol. 2005;16: 3553-3562.

77. Lyngdoh T, Marques-Vidal P, Paccaud F, et al. Elevated serum uric acid is associated with high circulating inflammatory cytokines in the population-based Colaus study. PLoS One. 2011;6:e19901. 
78. Ruggiero C, Cherubini A, Ble A, et al. Uric acid and inflammatory markers. Eur Heart J. 2006;27: 1174-1181.

79. Ruggiero C, Cherubini A, Miller E, 3rd, et al. Usefulness of uric acid to predict changes in C-reactive protein and interleukin-6 in 3-year period in Italians aged 21 to 98 years. Am J Cardiol. 2007;100: 115-121.

80. Willerson JT, Ridker PM. Inflammation as a cardiovascular risk factor. Circulation. 2004;109:II2-10.

81. Kerr R, Stirling D, Ludlam CA. Interleukin 6 and haemostasis. Br J Haematol. 2001;115:3-12.

82. Libby P, Simon DI. Inflammation and thrombosis: the clot thickens. Circulation. 2001;103:1718-1720.

83. Ridker PM, Hennekens CH, Roitman-Johnson B, Stampfer MJ, Allen J. Plasma concentration of soluble intercellular adhesion molecule 1 and risks of future myocardial infarction in apparently healthy men. Lancet. 1998;351:88-92.

84. McAdams-DeMarco MA, Maynard JW, Baer AN, Coresh J. Hypertension and the risk of incident gout in a population-based study: the atherosclerosis risk in communities cohort. J Clin Hypertens (Greenwich). 2012;14:675-679.

85. Krishnan E. Reduced glomerular function and prevalence of gout: NHANES 2009-10. PLoS One. 2012;7:e50046.

86. Rodriguez G, Soriano LC, Choi HK. Impact of diabetes against the future risk of developing gout. Ann Rheum Dis. 2010;69:2090-2094.

87. Choi HK, Ford ES. Haemoglobin A1c, fasting glucose, serum C-peptide and insulin resistance in relation to serum uric acid levels--the Third National Health and Nutrition Examination Survey. Rheumatology (Oxford). 2008;47:713-717.

88. Kramer CK, von Muhlen D, Jassal SK, Barrett-Connor E. A prospective study of uric acid by glucose tolerance status and survival: the Rancho Bernardo Study. J Intern Med. 2010;267:561-566.

89. Chen X, Li Y, Sheng CS, Huang QF, Zheng Y, Wang JG. Association of serum uric acid with aortic stiffness and pressure in a Chinese workplace setting. Am J Hypertens. 2010;23:387-392.

90. Liang J, Li Y, Zhou N, et al. Synergistic effects of serum uric acid and cardiometabolic risk factors on early stage atherosclerosis: the cardiometabolic risk in Chinese study. PLoS One. 2012;7:e51101.

91. Vlachopoulos C, Xaplanteris P, Vyssoulis G, et al. Association of serum uric acid level with aortic stiffness and arterial wave reflections in newly diagnosed, never-treated hypertension. Am J Hypertens. 2011;24:33-39.

92. Gomez-Marcos MA, Recio-Rodriguez JI, Patino-Alonso MC, et al. Relationship between uric acid and vascular structure and function in hypertensive patients and sex-related differences. Am J Hypertens. 2013;26:599-607.

93. Hsu PC, Su HM, Lin TH. Association between coronary collaterals and serum uric acid level in Chinese population with acute coronary syndrome. Angiology. 2013;64:323-324.

94. Lim JH, Kim YK, Kim YS, Na SH, Rhee MY, Lee MM. Relationship between serum uric acid levels, metabolic syndrome, and arterial stiffness in korean. Korean Circ J. 2010;40:314-320.

95. Tsioufis C, Kyvelou S, Dimitriadis K, et al. The diverse associations of uric acid with low-grade inflammation, adiponectin and arterial stiffness in never-treated hypertensives. J Hum Hypertens. 2011;25:554-559.

96. Cicero AF, Salvi P, D'Addato S, Rosticci M, Borghi C. Association between serum uric acid, hypertension, vascular stiffness and subclinical atherosclerosis: data from the Brisighella Heart Study. J Hypertens. 2014;32:57-64.

97. Cipolli JA, Ferreira-Sae MC, Martins RP, et al. Relationship between serum uric acid and internal carotid resistive index in hypertensive women: a cross-sectional study. BMC Cardiovasc Disord. 2012;12:52.

98. Oikonen M, Wendelin-Saarenhovi M, Lyytikainen LP, et al. Associations between serum uric acid and markers of subclinical atherosclerosis in young adults. The cardiovascular risk in Young Finns study. Atherosclerosis. 2012;223:497-503.

99. Gullu H, Erdogan D, Caliskan M, et al. Elevated serum uric acid levels impair coronary microvascular function in patients with idiopathic dilated cardiomyopathy. Eur J Heart Fail. 2007;9:466-468.

100. Kuwahata S, Hamasaki S, Ishida S, et al. Effect of uric acid on coronary microvascular endothelial function in women: association with eGFR and ADMA. J Atheroscler Thromb. 2010;17:259-269. 
101. Erdogan D, Tayyar S, Uysal BA, et al. Effects of allopurinol on coronary microvascular and left ventricular function in patients with idiopathic dilated cardiomyopathy. Can J Cardiol. 2012;28:721-727.

102. Oh CM, Park SK, Ryoo JH. Serum uric acid level is associated with the development of microalbuminuria in Korean men. Eur J Clin Invest. 2014;44:4-12.

103. Yuan Y, Ikram MK, Jiang S, et al. Hyperuricemia accompanied with changes in the retinal microcirculation in a Chinese high-risk population for diabetes. Biomed Environ Sci. 2011;24:146-154.

104. Holowatz LA, Thompson-Torgerson CS, Kenney WL. The human cutaneous circulation as a model of generalized microvascular function. J Appl Physiol. 2008;105:370-372. 


\section{Classification, prevalence and
incidence of gout Classification, prevalence and
incidence of gout

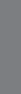 \\ Classification, prevalence and
incidence of gout .}

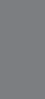 \\ Part I}

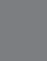

.

.

\section{(}




\section{Chapter}

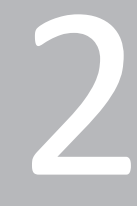

Large epidemiologic studies of gout:

challenges in diagnosis and diagnostic criteria

J.M.A. Wijnands, A. Boonen, I.C.W. Arts, P.C. Dagnelie, C.D.A. Stehouwer, Sj. van der Linden Curr Rheumatol Rep. 2010;13:167-174 


\section{Abstract}

Large epidemiologic studies of gout can improve insight into the etiology, pathology, impact and management of the disease. Identification of monosodium urate crystals is considered as the gold standard for diagnosis, but its application is often not possible in large studies. Therefore, under such circumstances, several proxy approaches are used to classify patients as having gout, including ICD coding in several types of databases or questionnaires that are usually based on the existing classification criteria. However, agreement among these methods is disappointing. Moreover, studies use the terms acute, recurrent and chronic gout in different ways and without clear definitions. Better definitions of the different manifestations and stages of gout might provide better insight into the natural course and burden of disease and can be the basis for valid approaches for correctly classifying patients within large epidemiological studies. 


\section{Introduction}

Epidemiology can be defined as the study of the occurrence and distribution of disease and its determinants ${ }^{1}$. In a broader approach, the areas of research in epidemiology include disease definition, occurrence, causation, outcome, management, and prevention. The occurrence of a disease may be studied in relation to factors that can identify or predict the disease (diagnostic factors) or are thought to influence its occurrence (eg, prognostic or etiologic factors). Furthermore, the association between a particular intervention and a change in the occurrence of the disease is of importance ${ }^{2}$.

In a recent review on rheumatic diseases, Gabriel and Michaud ${ }^{3}$ acknowledged that until recently, very few studies had been conducted on the epidemiology of gout. Notwithstanding the rising incidence ${ }^{4,5}$, the burden of disease associated with gout and the frequency of gout as a comorbidity in patients with multiple morbidities highlight the importance of gaining a better understanding of the etiology, pathology, and management of gout through epidemiologic studies.

This article focuses on the challenges of epidemiologic studies that aim to estimate the occurrence of gout in terms of prevalence or incidence. Such studies require large sample sizes, especially in heterogeneous populations. However, it is not only sample size that needs consideration when conducting epidemiologic studies on the occurrence of gout. This article considers some other deliberations. First, the definitions used in studies of gout are discussed, as well as the differences between diagnostic and classification criteria. Next, the criteria regularly used in epidemiologic studies are reviewed and critically appraised. Finally, several additional challenges encountered when interpreting results of epidemiologic research on gout are addressed.

\section{Definition of disease}

The gold standard to diagnose gout is to demonstrate the presence of monosodium urate monohydrate (MSU) crystals in synovial fluid at the time the patient experiences a gout attack ${ }^{6}$. However, this is easier said than done in clinical practice, as gout patients are often seen by general practitioners ${ }^{7}$ or specialists other than rheumatologists, who rarely perform a synovial fluid analysis to demonstrate urate crystals $^{8}$. Reasons for nonperformance include lack of expertise, limited access to polarizing microscopes, lack of time, or the concern of getting a "dry tap" ${ }^{9}$. If a joint aspiration is performed, several difficulties remain, as both false-positive and falsenegative results may occur ${ }^{10}$. In some cases, cholesterol crystals may appear as needleshaped birefringent crystals ${ }^{11,12}$. Furthermore, it is debatable whether one can diagnose 
a patient as having gout when only one or two MSU crystals are seen, or whether one should perform a second joint aspiration if no crystals are detected the first time. On the other hand, Lumbreras et al. ${ }^{13}$ showed that when observers are trained in crystal detection and identification, their results are usually consistent. Although in clinical medicine synovial fluid examination remains best practice in clinical medicine, in the context of epidemiologic studies, this might not be feasible, especially in view of the intermittent nature of gout and the sample sizes that are needed in population studies.

In studies, the terms gout flare, chronic gout, and acute gout are regularly used. However, comparing their definitions, if they are provided at all, these terms seem to be used inconsistently by different authors. To facilitate the comparability of study results, clear definitions of the various manifestations and stages of gout therefore are needed.

Taylor et al. ${ }^{14}$ proposed key components of a standard definition of gout flares using the Delphi methodology. The final list of elements includes a swollen, tender, and warm joint; patient self-report of pain and global assessment; time to maximum pain level; time to complete resolution of pain; functional status; and an acute-phase marker. This definition specifically aims to be used in clinical trials.

Another frequently used term is chronic gout. Interestingly, although a core set of outcome domains to be used in clinical trails was proposed by OMERACT (Outcome Measures in Rheumatology Clinical Trials), the group did actually not provide a clear definition of chronic gout but agreed on serum urate, gout flare recurrence, tophus regression, joint damage imaging, health related quality of life, musculoskeletal function, patient global assessment, participation, safety and tolerability as core outcome domains to be assessed in trials on gout ${ }^{15}$.

For Choi et al. ${ }^{16}$, acute gout is typically intermittent, whereas chronic tophaceaous gout develops after years of acute intermittent gout. However, they point out that tophi can also be part of the initial presentation. This is in line with the American College of Rheumatology (ACR) criteria for acute gout, which incorporate the item "more than one attack of acute arthritis" as well as suspicion of a tophus. Others state that after a certain undefined number of attacks, a patient has reached a stage called recurrent gout. Then the attacks come more frequently and stay longer. If a patient cannot recover from the flares, it becomes chronic gout. In that case, there is an almost permanent state of inflammation and pain. Some authors have a more inclusive definition of chronic gout, incorporating all patients who have had more than one attack of acute gout. Acute gout, in that case, is synonymous with gout flare. The underlying reasoning is that once a patient has had a flare, a persistent metabolic disorder exists.

In addition to these deliberations, one might think of gout as a continuum of increasing severity. Currently, a clear definition of severity is lacking. A first step would be to define the domains that are of importance when deciding on the severity of gout. Of interest is a recent study that explored which variables are associated with patients' 
as opposed to physicians' assessment of gout severity ${ }^{17}$. It was found that physicians base their judgment of severity on the presence of tophi, frequency of gout attacks during the past year, recent serum uric acid levels, and rheumatologist utilization, whereas patients' judgment of severity is associated with concerns regarding gout during an attack and the time since the last gout attack. It will be a challenge to try to measure each of these domains and to define thresholds to distinguish levels of severity based on the selected domains. This may also include addressing issues such as total load of uric acid and total load of tophi.

In summary, the question remains whether intermittent or recurrent gout must be distinguished from chronic gout and, if so, at which point acute or recurrent gout develops into chronic gout. Can we speak of chronic gout after a number of attacks or after a specific period of recurrent attacks, or only when a patient has bone destruction and chronic synovitis, even during remission of acute flares? Should we make a distinction between chronic gout and tophaceous gout, and should we distinguish different levels of severity of gout?

Currently, no clear answers to these questions exist, and the lack of insight into the natural course of gout among all patients complicates this issue. Some patients may not recall attacks of symptomatic gout, and patients with tophaceous gout may no longer experience acute attacks. This underlines the problem of assessing the true prevalence of gout. Moreover, the gold standard for diagnosing gout does not discriminate between different "stages" of gout. Clearly, a need exists for consensus on definitions that help distinguish the different manifestations of the disease.

\section{Diagnostic criteria versus classification criteria}

The title of this article may seem contradictory because in epidemiologic studies, no diagnostic criteria other than classification criteria are applied. Classification criteria aim to define homogeneous groups of patients with a particular disease. These criteria can be used to select patients for clinical (interventional) studies, to compare the results of clinical trials, or to assess the occurrence of a disease in epidemiologic studies $^{18}$. In contrast to diagnostic criteria, classification criteria do not have the purpose of early detection of a disease in an individual patient ${ }^{19}$. Instead, classification criteria are used to detect established cases.

As for diagnostic tests, calculating the sensitivity and specificity assesses the usefulness of criteria. Sensitivity is the percentage of individuals with a certain disease correctly classified as "ill" (true positives). The percentage of individuals without the disease correctly labelled as "not ill" is the specificity $(100 \%$ - percentage of false positives). If the sensitivity and specificity of criteria are both $100 \%$, diagnostic and classification criteria are the same ${ }^{19}$. Note that diagnostic criteria would require sufficient sensitivity in early stages of the disease to enable early diagnosis. However, 
the nature of medicine makes it unlikely that there will ever be tests that offer $100 \%$ sensitivity and specificity. Therefore, misclassification poses a challenge, and the type of misclassification that is least desirable will depend on the setting in which the test is applied.

In health care, physicians must identify which disease a patient has rather than whether a disease exists at all ${ }^{19}$. They do not want to misdiagnose a patient and may prefer high sensitivity against acceptable specificity. In contrast, in epidemiologic studies in large populations, to study homogeneous groups that are likely to have the diagnosis of interest but do not include many false positives, the researchers must balance specificity and sensitivity and will often sacrifice part of sensitivity against better specificity.

Of course, any misclassification, which is common in classification criteria, is undesirable $^{19}$. An approach to minimize misclassification is the use of cut-off points. In deciding on a cut-off point, one has to choose between a sensitive approach, involving false positives, and a more specific approach that results in a more homogeneous group and more false negatives ${ }^{19}$.

Classification criteria often are developed by comparing groups with the disease of interest with control patients having other (usually related or resembling) diseases that should be taken into account in the differential diagnosis. However, one must keep in mind that if these criteria are applied in population studies, the positive predictive value (PPV) may decrease, especially when the prevalence of the disease of interest is low. The PPV is defined as the number of individuals with a true positive test result divided by all individuals with a positive test result (true positive + false positives). In other words, it indicates the probability that in case of a positive test, the patient truly has the specified disease. The value of PPV depends on the prevalence of the disease of interest in the particular setting and will decrease when the prevalence goes down, due to the increasing number of false positives.

Thus, when applying the criteria for gout, a disease with a relatively low prevalence at the general population level, it is important to keep in mind that the estimated prevalence might be overestimated due to the unintended inclusion of false positives.

\section{Overview of criteria}

In this section, criteria to assess the prevalence of gout in epidemiologic studies are described. For this purpose, PubMed was searched, using the search terms "gout", "incidence", "prevalence" and "epidemiology". Only original articles describing the prevalence and incidence of gout were considered. The EULAR (European League Against Rheumatism) criteria, which are purely diagnostic criteria and intended for use in individual patients with arthritis and not for use in groups, are excluded. 
In 1963, the Rome criteria for gout were proposed during a symposium on population studies (Table 2.1). These and the 1966 New York criteria, which are a modification of the Rome criteria, are based on expert opinion and aimed for application in epidemiologic studies (Table 2.1) ${ }^{18}$. They rely heavily on the presence of tophi and the observation of MSU crystals in synovial fluid, which causes some feasibility issues. This is probably why both criteria sets are rarely used in large epidemiologic studies. The Rome criteria have only been used in two population studies assessing the prevalence or incidence of gout, once as interview ${ }^{20}$ and once as questionnaire $^{21}$, and both times in combination with a physical examination. The New York criteria have been used in several population studies in the same way as the Rome criteria ${ }^{21-24}$.

Table 2.1 Classification criteria for gout.

\begin{tabular}{|c|c|c|}
\hline Rome criteria & New York criteria & $\begin{array}{l}\text { American College of Rheumatology } \\
\text { criteria }\end{array}$ \\
\hline $\begin{array}{l}\text { Two of the following } 4 \text { criteria } \\
\text { must be present to make a } \\
\text { diagnosis of gout: } \\
\text { 1. Serum uric acid level } \\
\geq 7.0 \mathrm{mg} / \mathrm{dl} \text { in men, or } \\
\geq 6.0 \mathrm{mg} / \mathrm{dl} \text { in women } \\
\text { 2. Tophus } \\
\text { 3. Urate crystals in synovial } \\
\text { fluid or tissues } \\
\text { 4. History of attacks of painful } \\
\text { joint swelling of abrupt } \\
\text { onset with remission within } \\
\text { 1-2 week }\end{array}$ & $\begin{array}{l}\text { Urate crystals in synovial fluid or } \\
\text { tissue, or presence of at least } 2 \text { of } \\
\text { the following: } \\
\text { 1. History or observation of at } \\
\text { least } 2 \text { attacks of painful limb } \\
\text { swelling with remission within } \\
\text { 1-2 week } \\
\text { 2. History or observation of } \\
\text { podagra } \\
\text { 3. Presence of tophus } \\
\text { 4. History or observation of a } \\
\text { good response to colchicine } \\
\text { (major reduction in objective } \\
\text { signs of inflammation within } \\
24 \text { h of onset of therapy) }\end{array}$ & $\begin{array}{l}\text { Preliminary criteria for the } \\
\text { classification of the acute arthritis of } \\
\text { primary gout } \\
\text { A Monosodium urate crystals in } \\
\text { synovial fluid, or } \\
\text { B Tophus, or } \\
\text { C Presence of at least } 6 \text { of the } \\
\text { following: } \\
\text { 1. More than } 1 \text { attack of acute } \\
\text { arthritis } \\
\text { 2. Maximal inflammation } \\
\text { developed within } 24 \text { h } \\
\text { 3. Monoarthritis attack } \\
\text { 4. Redness observed over joints } \\
\text { 5. First metatarsophalangeal joint } \\
\text { painful or swollen } \\
\text { 6. Unilateral first } \\
\text { metatarsophalangeal joint attack } \\
\text { 7. Unilateral tarsal joint attack } \\
\text { 8. Tophus (suspected) } \\
\text { 9. Hyperuricemia } \\
\text { 10. Asymmetric swelling within a } \\
\text { joint on radiograph } \\
\text { 11. Joint fluid culture negative for } \\
\text { organisms during attacks }\end{array}$ \\
\hline
\end{tabular}

It should be noted that for use in population surveys, the items that make up criteria likely need to be rephrased into questions that are answerable by patients using questionnaires or participating in interviews. 
Currently, the most frequently used methods to identify people with gout in epidemiologic studies are the ACR criteria, former American Rheumatism Association criteria, using an interview approach and the ICD-9.

The ACR criteria for gout have been developed to achieve a uniform system for reporting and comparing data from studies (Table 2.1$)^{6}$. They have been developed by comparing different sets of criteria among gout patients and patients with classic rheumatoid arthritis of 2 years' or less duration, definite or classic rheumatoid arthritis of more than 2 years' duration, pseudogout, or acute septic arthritis. All have been diagnosed by rheumatologists. As such, the ACR criteria for gout focus on acute arthritis of primary gout and can be used in single patients as well as in population surveys ${ }^{6}$.

In large studies on occurrence of gout, the ACR criteria are often applied by interviewing patients with or without a standardized questionnaire, or by chart review of medical records. Although the ACR criteria were developed for the diagnosis of acute gout, they also have been used to identify so-called chronic gout, when patients fulfil the item tophi or radiographic abnormalities. Compared with the Rome and New York criteria, the ACR criteria rely less on the presence of tophi or identification of MSU crystals and even allow classification based on clinical criteria alone. Malik et al. ${ }^{25}$ applied the ACR, New York, and Rome criteria in patients who had joint effusions in the setting of a rheumatology clinic. They asked patients whether they had experienced any of the clinical features of these three sets of criteria. The researchers found highest specificity (89\%) and PPV (77\%) for the Rome criteria. However, the criteria were slightly less sensitive (67\%). The New York criteria showed sensitivity and PPV of $70 \%$ and specificity of $83 \%$. The ACR criteria ( 6 of 12 clinical items) had $70 \%$ sensitivity and $79 \%$ specificity and a PPV of only $66 \%$. Clearly, one should not extrapolate such findings to an epidemiologic population study, because the PPV varies with the pretest probability, which, as mentioned previously, is highly dependent on the prevalence of the disease. Janssens et al. ${ }^{26}$ compared the ACR criteria with synovial fluid analysis as a gold standard in monoarthritic patients presenting to primary care. Only patients who were suspected of having gout were included in the study. They found a PPV and a sensitivity of $80 \%$, while specificity was $64 \%$. According to Janssens et al. ${ }^{26}$, these findings stress the importance of interpreting with caution the results of gout studies that made use of the ACR criteria.

A common method used to estimate the prevalence of gout is the use of large medical databases that have registered diseases by ICD-9 coding. Examples of databases used in gout research include medical patients' record systems, administrative claims, and insurance programs. Advantages of such databases are the large numbers available at low expenses and the efficient time investment. A disadvantage is that it remains unclear how the diagnosis was made by the variety of health professionals and how to generalize the results because the denominator is often unclear. Malik et al. ${ }^{27}$ evaluated the possibility of documenting the accuracy of ICD-9 code for gout in three databases (National Patient Care Database, Pharmacy 
Benefits Management Database, and the Clinical and Administrative Database) by identifying patients with two ICD-9 coded encounters for gout during 6-year time period. They found that identifying the items of the ACR, New York, or Rome criteria in medical records could not validate the majority of gout diagnoses recorded by ICD- 9 . This discrepancy may be caused by inadequate documentation in medical records, inaccurate diagnostic coding or inappropriateness of current criteria. According to Malik et al. ${ }^{27}$, it is the poor documentation in medical records rather than inaccurate diagnostic coding. Harrold et al. ${ }^{28}$ analyzed a random sample of medical records of patients with two or more coded diagnoses of gout from four managed care plans. The PPV of two or more ambulatory claims (during a time period of 5 years) for a diagnosis of gout was assessed using the investigators' rating of the presence or absence of definite or probable gout as the gold standard. The PPV turned out to be $61 \%$. Substantial improvement in the PPV was not achieved by increasing the number of visits to three or four. Explanations for the disappointing PPV include the ambiguity of a diagnosis of gout compared with, for example, a more firm diagnosis of myocardial infarction; the assignation of an ICD code before the diagnosis was firmly established; the underutilization of synovial fluid analysis; and inadequate documentation in medical records ${ }^{28}$.

Self-reported disease, sometimes completed with information from other medical sources, is often applied in epidemiologic studies of gout. However, it is difficult to distinguish between questionnaires that inquire about physician-diagnosed gout and questionnaires that inquire about manifestations typical of gout based on the existing criteria described above. Furthermore, such questionnaires vary in the time frame in which gout occurred, which can be one or more attacks at some point in the past or several attacks in a specific (limited) period of time preceding the survey. Miller et al. ${ }^{29}$ analyzed the agreement between self-reported diseases and ICD-9 coding. These authors indicated that self-report is fairly reliable. However, only $50 \%$ of self-reported arthritis could be confirmed by ICD coding ${ }^{29}$. Reasons for this lack of agreement may be that responders have interpreted a question in incorrectly or have recalled a diagnosis that was not actually established or was recalled inaccurately. However, if patients are not receiving medication or other treatment, the diagnostic code for a certain condition may not be written down in the record ${ }^{29}$. Miller et al. ${ }^{29}$ pointed out that acute events that occurred in the past and conditions that are episodic in nature are not always captured if the reviewing period is too short.

It should be noted that questionnaires are often operationalized through an interview approach. Although self-completed questionnaires may cover a large population in a relatively short time period at low cost, the downside is a possible low response rate. Using an interview approach, it is possible to ensure all questions are answered in the correct manner. However, this method is more prone to interviewer bias and interviewer variability ${ }^{1}$. Bergman et al. ${ }^{30}$ reported that the agreement between a face-to-face interview and a self-administered questionnaire was moderate $(\kappa, 0.61)$. 
Less serious, less defined, or less persistent diseases such as gout may be perceived by patients as not being important enough to report in questionnaires ${ }^{30}$.

Of interest might be the diagnostic rule for acute gouty arthritis recently developed by Janssens et al. ${ }^{8}$. It is intended to be applied in primary care and obviate joint aspiration. Based on validated clinical variables using synovial fluid analysis as reference test, a multivariate logistic regression model was developed. Hereafter, they developed two models based on external knowledge and availability of the tool in clinical practice. Their final model includes seven variables: male sex, previous patient-reported arthritis attack, onset within 1 day, joint redness, first metatarsophalangeal joint involvement, hypertension, or one or more cardiovascular diseases and serum uric acid level exceeding $5.88 \mathrm{mg} / \mathrm{dl}(0.35 \mathrm{mmol} / \mathrm{l})$. Although developed for use in primary care, the diagnostic rule may be useful in a research setting. However, it is not known how well this model performs in a population study (work in progress).

\section{Interpretation of results}

In addition to the above considerations that are critical in the appraisal of data on the occurrence of disease, several other issues merit consideration when appraising the results of such studies ${ }^{31}$. First is the question of which type of epidemiologic measure of occurrence was applied. The nature of disease will influence the relevant study design and measure of occurrence that is most informative ${ }^{1}$. As acute flares of arthritis mainly characterize gout, the point prevalence estimate (Table 2.2) is not likely of primary interest. In fact, in a cross-sectional population study, the chance that someone will suffer from a gout attack exactly at the time of the survey is low. In this case, the period prevalence, which represents individuals who experienced one or more episodes over a specified period preceding the survey (Table 2.2), will be more informative. Only if chronic gout would be described in terms of persistent joint inflammation, presence of irreversible joint damage, or presence of tophi, would the point-prevalence be interesting.

Another important concept in epidemiologic studies is the incidence or incidence rate, which refers to the number of new cases of gout in a population (Table 2.2). Cumulative incidence refers to new cases of gout per year divided by all members of a cohort (i.e. a closed population) who are at risk (i.e. who never experienced any signs of gout before the observation period). In contrast, incidence density refers to new cases of gout per person-year in a dynamic population, such as the inhabitants of a region or municipality (Table 2.2).

It is also important to carefully consider the population that has been studied ${ }^{2}$. As for any epidemiologic study, the sample should be a correct representation of the population of interest; this requires insight into the sampling frame and participation rate. The participation rate should be at least as high as $80 \%$; however, a rate between 
$60 \%$ and $80 \%$ with a description of the non-responders is often considered acceptable. Furthermore, to guarantee the representativeness of the samples in studies on gout, it is important to take into account sources of (selection) bias, such as the age, sex, and race of the study population. Determining the prevalence in a preponderant older male population will overestimate the occurrence of gout in the general population. One should also be aware of confounding factors such as alcohol consumption, body mass index and comorbidities. Obesity, diabetes, and hypertension are common among patients with gout ${ }^{32}$, and the prevalence of the metabolic syndrome is higher than in patients without gout ${ }^{33,34}$.

Table 2.2 Conceptual framework of incidence and prevalence in studies of gout.

\begin{tabular}{ll}
\hline Incidence & To be assessed in a cohort: number of new cases of gout per year divided by the \\
population at risk (ie, all cohort members who at the initiation of the cohort or \\
at the start of the year of incidence assessment had never experienced any \\
manifestation of gout) \\
To be assessed in a dynamic population (eg, the inhabitants of New York): \\
number of new cases of gout per year divided by the number of person-years of \\
individuals at risk. One person-year is defined as 1 person who is at risk for a 1- \\
year period (eg, if an individual gets gout after 3 months, he or she is counted as \\
0.25 person-years in the denominator). Thus, the denominator of incidence \\
density (ie, the number of person-years in a dynamic population) is not only \\
determined by the changing size of the total population (eg, accounting for \\
individuals entering and leaving the municipality of New York, as well as \\
newborns and deaths) but also by the number of hitherto-healthy individuals \\
who for the first time get gout during the observation period and are therefore \\
(from that moment onwards) no longer "at risk" of newly getting gout \\
Prevalence \\
Point prevalence \\
$\begin{array}{l}\text { Number of cases of gout in the study population at a given point in time divided } \\
\text { by the total study population. This comprises the (usually few) individuals who } \\
\text { suffer from an acute attack of gout at the concerned point in time together with } \\
\text { all those who then have chronic (tophaceous or nontophaceous) gout } \\
\text { Number of cases of gout in the study population during a specified period of } \\
\text { time divided by the mean size of the total study population over the concerned } \\
\text { period. This comprises all individuals who have experienced an acute attack of } \\
\text { gout during that period together with all cases of chronic (tophaceous or non- } \\
\text { tophaceous) gout }\end{array}$ \\
\hline
\end{tabular}

\section{Conclusions}

Although the pathophysiology of gout is relatively well-understood, it is surprisingly difficult to define good classification criteria for use in large population studies to validly assess the prevalence and burden of gout. This is partly due to the nature of the disease, which is typical intermittent, which limits the ability to use MSU crystals as the gold standard in large epidemiologic studies. 
Also challenging is the absence of clear insight into the natural course of the disease, which would require better definitions of the manifestations and stages of gout. Although there is general agreement that gout is likely the result of a longstanding metabolic disorder that eventually leads to clinically manifest gout, it is less clear how many patients will progress to tophaceous gout and develop joint damage.

In view of the aforementioned considerations, literature data on the prevalence of gout are surprisingly consistent. In developed countries estimates vary between $1 \%$ and $2 \%{ }^{35}$. Nevertheless, as discussed previously, different levels of misclassification must have occurred in these studies. This will hamper interpretation of the results, especially in light of risk factors and comorbidities associated with gout. More precise estimates of the prevalence and burden of gout require addressing the validity of classification criteria and proper definitions of the various manifestations and stages of severity of gout.

McAdams et al. ${ }^{36}$ reported recently that self-report of physician-diagnosed gout has good reliability and sensitivity and that this method may seem appropriate for epidemiologic studies. 


\section{References}

1. Silman AJ. Epidemiological studies: a practical guide. Cambridge: Cambridge University Press; 1995.

2. Bouter LM, van Dongen MCJM. Epidemiologisch onderzoek: opzet en interpretatie. Houten: Bohn Stafleu Van Loghum; 1995.

3. Gabriel SE, Michaud K. Epidemiological studies in incidence, prevalence, mortality, and comorbidity of the rheumatic diseases. Arthritis Res Ther. 2009;11:229.

4. Arromdee E, Michet CJ, Crowson CS, O'Fallon WM, Gabriel SE. Epidemiology of gout: is the incidence rising? J Rheumatol. 2002;29:2403-2406.

5. Wallace KL, Riedel AA, Joseph-Ridge N, Wortmann R. Increasing prevalence of gout and hyperuricemia over 10 years among older adults in a managed care population. J Rheumatol. 2004;31:1582-1587.

6. Wallace SL, Robinson H, Masi AT, Decker JL, McCarty DJ, Yu TF. Preliminary criteria for the classification of the acute arthritis of primary gout. Arthritis Rheum. 1977;20:895-900.

7. Pal B, Foxall M, Dysart T, Carey F, Whittaker M. How is gout managed in primary care? A review of current practice and proposed guidelines. Clin Rheumatol. 2000;19:21-25.

8. Janssens HJ, Fransen J, van de Lisdonk EH, van Riel PL, van Weel C, Janssen M. A diagnostic rule for acute gouty arthritis in primary care without joint fluid analysis. Arch Intern Med. 2010;170:1120-1126.

9. Dore RK. The gout diagnosis. Cleve Clin J Med. 2008;75 Suppl 5:S17-21.

10. von Essen R, Holtta AM, Pikkarainen R. Quality control of synovial fluid crystal identification. Ann Rheum Dis. 1998;57:107-109.

11. Selvi E. Needle-shaped crystals are not always urate crystals: comment on the clinical image by Slobodin et al. Arthritis Rheum. 2009;60:3858; author reply 3858.

12. Von Essen R, Holtta AM. Quality control of the laboratory diagnosis of gout by synovial fluid microscopy. Scand J Rheumatol. 1990;19:232-234.

13. Lumbreras B, Pascual E, Frasquet J, Gonzalez-Salinas J, Rodriguez E, Hernandez-Aguado I. Analysis for crystals in synovial fluid: training of the analysts results in high consistency. Ann Rheum Dis. 2005;64:612-615.

14. Taylor WJ, Shewchuk R, Saag KG, et al. Toward a valid definition of gout flare: results of consensus exercises using Delphi methodology and cognitive mapping. Arthritis Rheum. 2009;61:535-543.

15. Schumacher HR, Jr., Edwards LN, Perez-Ruiz F, et al. Outcome measures for acute and chronic gout. $J$ Rheumatol. 2005;32:2452-2455.

16. Choi HK, Mount DB, Reginato AM. Pathogenesis of gout. Ann Intern Med. 2005;143:499-516.

17. Sarkin AJ, Levack AE, Shieh MM, et al. Predictors of doctor-rated and patient-rated gout severity: gout impact scales improve assessment. J Eval Clin Pract. 2010;16:1244-1247.

18. Johnson SR, Goek ON, Singh-Grewal D, et al. Classification criteria in rheumatic diseases: a review of methodologic properties. Arthritis Rheum. 2007;57:1119-1133.

19. Fries JF, Hochberg MC, Medsger TA, Jr., Hunder GG, Bombardier C. Criteria for rheumatic disease. Different types and different functions. The American College of Rheumatology Diagnostic and Therapeutic Criteria Committee. Arthritis Rheum. 1994;37:454-462.

20. Mikkelsen WM, Dodge HJ, Duff IF, Kato H. Estimates of the prevalence of rheumatic diseases in the population of Tecumseh, Michigan, 1959-60. J Chronic Dis. 1967;20:351-369.

21. O'Sullivan JB. Gout in a New England town. A prevalence study in Sudbury, Massachusetts. Ann Rheum Dis. 1972;31:166-169.

22. Chen S, Du H, Wang Y, Xu L. The epidemiology study of hyperuricemia and gout in a community population of Huangpu District in Shanghai. Chin Med J (Engl). 1998;111:228-230.

23. Darmawan J, Valkenburg HA, Muirden KD, Wigley RD. The epidemiology of gout and hyperuricemia in a rural population of Java. J Rheumatol. 1992;19:1595-1599.

24. Wigley RD, Prior IA, Salmond C, Stanley D, Pinfold B. Rheumatic complaints in Tokelau. II. A comparison of migrants in New Zealand and non-migrants. The Tokelau Island migrant study. Rheumatol Int. 1987; 7:61-65.

25. Malik A, Schumacher HR, Dinnella JE, Clayburne GM. Clinical diagnostic criteria for gout: comparison with the gold standard of synovial fluid crystal analysis. J Clin Rheumatol. 2009;15:22-24. 
26. Janssens HJ, Janssen M, van de Lisdonk EH, Fransen J, van Riel PL, van Weel C. Limited validity of the American College of Rheumatology criteria for classifying patients with gout in primary care. Ann Rheum Dis. 2010;69:1255-1256.

27. Malik A, Dinnella JE, Kwoh CK, Schumacher HR. Poor validation of medical record ICD-9 diagnoses of gout in a veterans affairs database. J Rheumatol. 2009;36:1283-1286.

28. Harrold LR, Saag KG, Yood RA, et al. Validity of gout diagnoses in administrative data. Arthritis Rheum. 2007;57:103-108.

29. Miller DR, Rogers WH, Kazis LE, Spiro A, 3rd, Ren XS, Haffer SC. Patients' self-report of diseases in the Medicare Health Outcomes Survey based on comparisons with linked survey and medical data from the Veterans Health Administration. J Ambul Care Manage. 2008;31:161-177.

30. Bergmann MM, Jacobs EJ, Hoffmann K, Boeing H. Agreement of self-reported medical history: comparison of an in-person interview with a self-administered questionnaire. Eur J Epidemiol. 2004;19: 411-416.

31. Sanderson S, Tatt ID, Higgins JP. Tools for assessing quality and susceptibility to bias in observational studies in epidemiology: a systematic review and annotated bibliography. Int J Epidemiol. 2007;36: 666-676.

32. Annemans L, Spaepen E, Gaskin M, et al. Gout in the UK and Germany: prevalence, comorbidities and management in general practice 2000-2005. Ann Rheum Dis. 2008;67:960-966.

33. Choi HK, Atkinson K, Karlson EW, Curhan G. Obesity, weight change, hypertension, diuretic use, and risk of gout in men: the health professionals follow-up study. Arch Intern Med. 2005;165:742-748.

34. Inokuchi T, Tsutsumi Z, Takahashi S, Ka T, Moriwaki Y, Yamamoto T. Increased frequency of metabolic syndrome and its individual metabolic abnormalities in Japanese patients with primary gout. J Clin Rheumatol. 2010;16:109-112.

35. Richette P, Bardin T. Gout. Lancet. 2010;375:318-328.

36. McAdams MA, Maynard JW, Baer AN, et al. Reliability and sensitivity of the self-report of physiciandiagnosed gout in the campaign against cancer and heart disease and the atherosclerosis risk in the community cohorts. J Rheumatol. 2011;38:135-141. 


\section{Chapter}

Determinants of the prevalence of gout in the general population: a systematic review and meta-regression

J.M.A. Wijnands, W. Viechtbauer, K. Thevissen, I.C.W. Arts, P.C. Dagnelie, C.D.A. Stehouwer, Sj. van der Linden, A. Boonen Eur J Epid. 2014; Epub ahead of print 


\section{Abstract}

Studies on the occurrence of gout show a large range in estimates. However, a clear insight into the factors responsible for this variation in estimates is lacking. Therefore, our aim was to review the literature on the prevalence and incidence of gout systematically and to obtain insight into the degree of and factors contributing to the heterogeneity. We searched MEDLINE, EMBASE, and Web of Science (January 1962 to July 2012) to identify primary studies on the prevalence and incidence of gout in the general population. Data were extracted by two persons on sources of clinical heterogeneity, methodological heterogeneity, and variation in outcome reporting. Metaanalysis and meta-regression analysis were performed for the prevalence of gout. Of 1466 articles screened, 77 articles were included, of which 71 reported the prevalence and 12 the incidence of gout. The pooled prevalence $(67$ studies; $\mathrm{N}=12,226,425)$ based on a random effects model was $0.6 \%$ ( $95 \% \mathrm{Cl} 0.4 ; 0.7)$, however there was a high level of heterogeneity $\left(\mathrm{I}^{2}=99.9 \%\right)$. Results from a mixed-effects meta-regression model indicated that age $(p=0.019)$, sex $(p<0.001)$, continent $(p<0.001)$, response rate $(p=0.016)$, consistency in data collection $(p=0.002)$, and case definition $(p<0.001)$ were significantly associated with gout prevalence and jointly accounted for $88.7 \%$ of the heterogeneity. The incidence in the total population ranged from 0.06 to 2.68 per 1000 person-years. In conclusion, gout is a common disease and the large variation in the prevalence data on gout is explained by sex, continent on which the study was performed, and the case definition of gout. 


\section{Introduction}

Gout is an inflammatory arthritis which has been associated with the metabolic syndrome, hypertension, kidney disease, and cardiovascular disease ${ }^{1}$. Partially due to the associated co-morbidity, gout has a substantial impact on a patient's health-related quality of life ${ }^{2}$ and may be a major health issue in affluent countries ${ }^{3}$. Studies on the prevalence and incidence of gout in the general population show a large range in estimates and an increase in these estimates has often been suggested ${ }^{4}$. However, a clear insight into the factors contributing to this variation in estimates is lacking. Metaanalysis and meta-regression are helpful techniques that may shed light on the reasons for the heterogeneity in the findings.

In systematic reviews, two major types of heterogeneity can be distinguished, i.e. clinical and methodological heterogeneity. Clinical heterogeneity refers to differences in patient characteristics or treatment regimen, while methodological heterogeneity refers to variation in study design, outcome measures, and the duration of follow-up. Several sources of heterogeneity emerged from previous studies on the prevalence and incidence of gout, such as age, sex, geographic region (representing ethnic background and susceptibility to gout $)^{5}$, and case definition ${ }^{6-9}$. In contrast to these studies, metaregression can assess and quantify the effect of these factors on the occurrence of gout simultaneously.

The aim of the present study was to review literature on the prevalence and incidence of gout systematically and to perform a meta-analysis including metaregression analysis to obtain insight into the degree of and factors contributing to the heterogeneity.

\section{Methods}

\section{Data sources and searches}

MEDLINE, EMBASE, and Web of Science were searched for primary studies on the prevalence and/or incidence of gout using the free text- and MeSH-search term "gout" with subheading "epidemiology", and the search term "gout" in combination with "epidemiology", "prevalence", and "incidence". Replacing the search term "gout" by the keywords "crystal arthritis" or "crystal arthropathy" did not lead to additional titles.

The search was limited to articles published in English, German, French, Spanish, or Dutch. Letters, comments, and editorial citations were excluded by adding the search term: NOT "letter" [Publication Type] NOT "comment" [Publication Type] NOT "editorial" [Publication Type]. The search was executed on 22 February 2010 and was last updated on 1 July 2012. References were imported in Endnote and duplicates were removed. Finally, hand search of bibliographies of relevant articles was performed. 


\section{Study selection}

Two reviewers (JW, SvL) independently screened titles and (if available) the corresponding abstracts. Studies were included if: 1) the aim of the study was to estimate the prevalence and/or incidence of gout; 2 ) primary data, derived from a new or original research study, were reported; 3 ) the general population was the target. Any disagreement was resolved after consensus between the two reviewers (JW, SvL). Fulltext articles of the selected titles were accessed via PUBMED or were requested from the corresponding authors, after which a full-text review was performed by the first reviewer (JW).

\section{Data extraction}

Data were extracted by two independent reviewers (JW, KT). In case of disagreement, a third reviewer $(A B)$ was consulted and consensus reached. In addition to study identification, data extraction comprised sources of clinical heterogeneity (mean age of the sample, male/female distribution, country, setting), and sources of methodological heterogeneity (year in which data collection began, sampling frame to recruit study population, sampling method, exclusion criteria, response rate, representativeness of study population for the general population, case definition for gout, duration of follow up in case of an incidence study, consistency in case finding and case definition throughout the study). Finally variables related to outcome reporting were extracted (figures on prevalence and/or incidence including its numerator and denominator, confidence intervals, measure of prevalence and/or incidence).

\section{Data synthesis and analysis}

\section{Variables in meta-regression analyses}

With regard to clinical heterogeneity, the percentage of males and the mean age of the sample were included in the analyses as continuous variables. Continent of study execution was subdivided into seven categories: Europe, North America, South America, Africa, Asia, Oceania, and "indigenous people" (composed of Maori, Aboriginals and Inuit). Indigenous people were analysed as a separate category since these individuals represent a unique population in which high gout prevalences are generally found, partly due to a marked genetic predisposition for hyperuricaemia ${ }^{6,10}$. The setting was subdivided into urban, rural, or a combination of both.

With respect to methodological heterogeneity, year in which data collection began (or publication year if not reported) was handled as a continuous variable. The following four variables were scored dichotomously: response rate was deemed appropriate if either $75 \%$ or more of the sampled subjects participated, or if participation was $<75 \%$ but data analysis included a non-responder analysis showing no 
difference in participants' characteristics between responders and non-responders; the sampling method was appropriate if a random selection was used; consistency in data collection was appropriate if the approach was similar across all participants; and representativeness of the study population if the methods used to select the study population were deemed appropriate to obtain a studied sample truly representative of the general population. The following two variables were categorized. The sampling frame was categorized into census list, household register, convenience sample, general practitioner database, hospital database, list of specific group of subjects (employees of a company), and geographic sampling. The case definition of gout was categorized into seven categories. The first two categories comprised a self-reported diagnosis of gout or self-reported symptoms suggestive of gout recorded by a questionnaire or an interview. Categories 3 and 4 involved a 2-step case definition in which a self-reported screening question (as in categories 1 and 2) was followed by a confirmation of cases based on additional clinical criteria, physical exam, or ICD codes. In case health professionals examined all participants the case definition was coded with category 5. Finally, ICD codes/free text search in general practitioner medical records or hospital medical records were coded as categories 6 and 7, respectively.

For outcome reporting, the measure of prevalence was dichotomized as lifetime or period, and the measure of incidence as proportion or incidence rate.

\section{Prevalence studies}

Where possible, data from individual articles were subdivided into independent samples to allow for separate results based on sex, ethnic group, setting, or location (e.g. instead of computing a single prevalence rate for an article, prevalence rates for the male and female subsamples were included in the meta-analysis). To avoid statistical dependence in the estimates, if an article reported the prevalence of a specific population over time, only the most recent estimation was used. The prevalence for each sample was calculated using raw data (i.e. number of cases divided by the sample size). In case of a missing numerator, the number of cases was backcalculated from the reported prevalence rate (\%) and the sample size.

Prevalence rates were transformed with the logit (log odds) transformation before further analysis ${ }^{11,12}$. The sampling distribution of a logit transformed rate is better approximated by a normal distribution, especially when the true prevalence rate is close to zero. For samples with zero cases, we used the standard bias/continuity correction of adding $1 / 2$ to the number of cases and non-cases before computing the logit transformed rates.

To estimate the pooled prevalence, the transformed prevalence rates were combined in a meta-analysis using a random-effects model. The pooled result and the corresponding confidence interval bounds were then back-transformed to yield an estimate of the average prevalence rate. Based on the results from the random-effects model, a $95 \%$ prediction interval was calculated, which provides an estimate of the 
range where future prevalences are expected to fall in $95 \%$ of the individual study settings ${ }^{13}$. The amount of heterogeneity between studies was estimated using the empirical Bayes estimator and reported in terms of the $\mathrm{I}^{2}$-statistic ${ }^{14}$.

A sensitivity analysis, excluding studies with "low study quality", was not performed because of scientific objections to computing a quality rating score or weighting of quality items ${ }^{15}$. Instead, the contribution of methodological and clinical aspects of diversity (including aspects of quality) to the heterogeneity was explored by performing meta-regression analyses using mixed-effects models ${ }^{16}$. Univariable and multivariable models were fitted using the empirical Bayes method to estimate the amount of residual heterogeneity ${ }^{14}$, and model coefficients were tested using the Knapp and Hartung method ${ }^{17}$. Pairwise comparisons were obtained for categorical variables with p-values adjusted by Holm's method ${ }^{18}$. We estimated the amount of heterogeneity accounted for by moderators by computing the proportional reduction in the amount of heterogeneity when the moderators are included in the model ${ }^{16}$.

Sensitivity analyses were performed using two alternative modeling approaches for the multivariable meta-regression analysis, i.e. using a mixed-effects logistic regression model with random effects per observed outcome and a beta-binomial model with logit link function. All analyses were performed with $\mathrm{R}$ using the packages metafor ${ }^{19}, \operatorname{Ime}^{20}$, and VGAM ${ }^{21}$.

\section{Incidence studies}

Due to the small number of articles on the incidence of gout we chose to describe these studies and to inspect the data carefully rather than conducting meta-regression analyses.

\section{Results}

\section{Study selection}

The literature search provided a total of 2126 hits (PubMed: $N=1018$, EMBASE: $N=664$, Web of Science: $\mathrm{N}=444)$. After removing duplicates, 1466 titles, the majority including abstracts, were screened for eligibility, resulting in 86 candidate titles. For 10 studies no full text could be retrieved despite the use of interlibrary loan services and a search for contact details of first authors.

After full text review 12 articles did not meet the inclusion criteria ( 3 titles referred to congress abstracts only, 3 did not provide primary data, and in 6 the target was not the general population). Five further articles were excluded because they reported on the same study population and the paper providing the most complete data on clinical and methodological heterogeneity was considered. The hand search of bibliographies of relevant articles resulted in an additional 7 articles and 11 new articles were included 
after the last update (1 July 2012). Finally, 77 articles were included, of which 71 reported prevalence and 12 incidence (Figure 3.1).

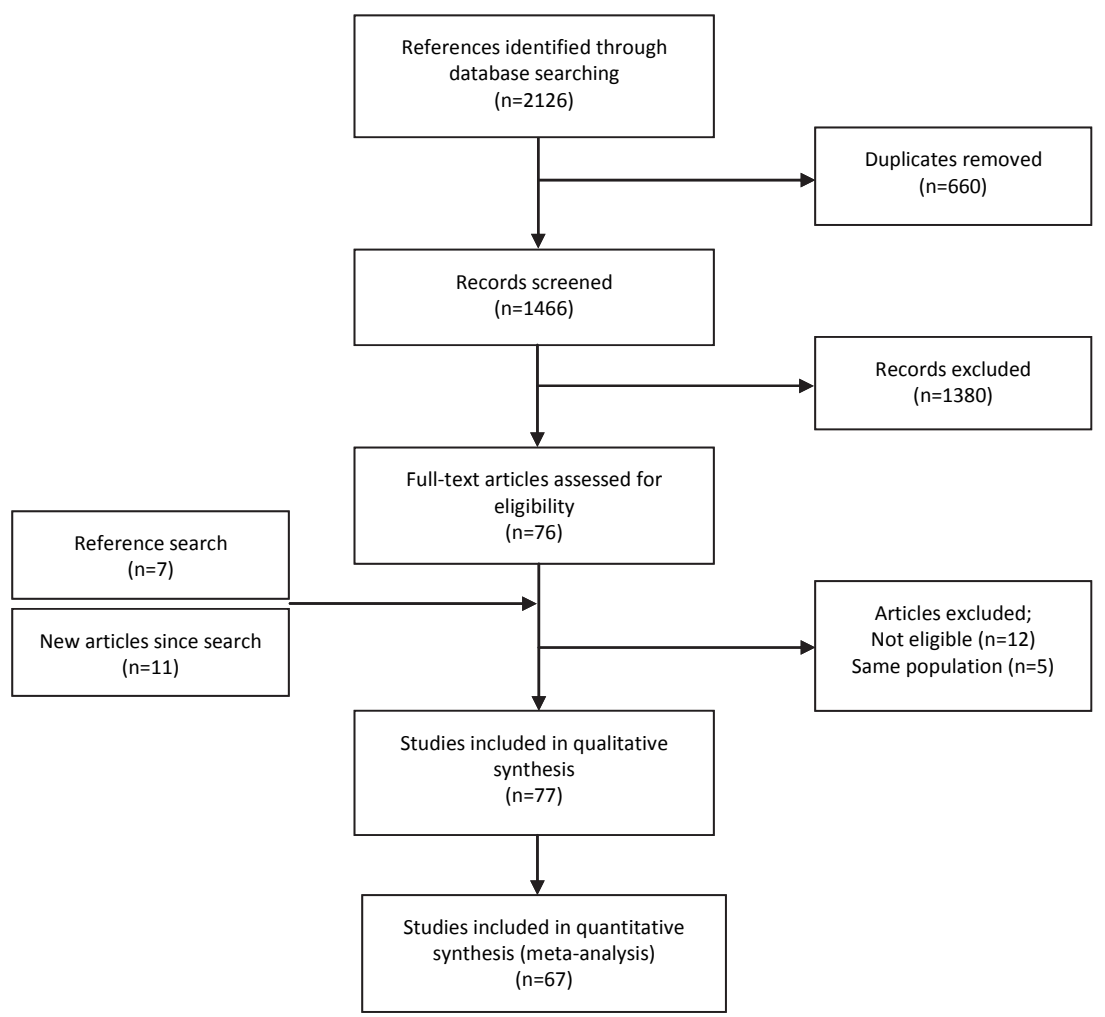

Figure 3.1 Selection of studies for the systematic review of the prevalence and incidence of gout.

\section{Prevalence}

\section{Study characteristics}

In the 71 articles ${ }^{22-92}, 172$ independent samples were identified (please see Appendix 3, Figure S3.1). Table 3.1 presents characteristics of these samples. Studies were carried out between 1950 and 2012.

The total number of individuals in these 71 articles was unknown as denominators were not reported in all studies. Approximately 50.9\% (range: $0-100 \%$ ) of the total population was male with an average age of $\sim 5$ (31-79) years. Studies were mainly conducted in Asia (61 out of 172, 35.5\%) and Europe (48 out of 172, 27.9\%). Fifty-five (38.2\% of 144$)$ studies used a census and 37 (25.7\% of 144$)$ a general practitioner 
database for sampling individuals. The case definition most frequently used was the 2-step approach where self-reported symptoms was followed by further confirmation (52 out of $172,30.2 \%$ ).

Table 3.1 Characteristics of 71 studies reporting the prevalence of gout that were considered as sources of heterogeneity.

\begin{tabular}{|c|c|c|}
\hline Clinical heterogeneity & Methodological heterogeneity & Outcome reporting \\
\hline Mean age $(n=129)$ & Start data collection ( $n=172)$ & Measure of prevalence $(n=166)$ \\
\hline Range 31-79 & Range $1950-2012$ & Lifetime prevalence $(n=141)$ \\
\hline Median 43.0 & Median 1994 & Period prevalence $(n=25)$ \\
\hline \multirow[t]{2}{*}{ Mean 44.4} & Mean 1990 & \\
\hline & Response rate ( $n=172)$ & \\
\hline$\%$ males $(n=165)$ & Adequate: $n=119^{a}$ & \\
\hline Range 0-100 & Non-adequate: $n=53$ & \\
\hline \multicolumn{3}{|l|}{ Median 48.8} \\
\hline Mean 50.9 & $\begin{array}{l}\text { Sampling method ( } n=172 \text { ) } \\
\text { Random: } n=128 \\
\text { Non-random: } n=44\end{array}$ & \\
\hline \multicolumn{3}{|l|}{ Continent $(n=172)$} \\
\hline Europe: $n=48$ & Consistency data collection ( $n=172$ ) & \\
\hline North America: $n=16$ & Approach was similar across all & \\
\hline South America: $n=9$ & participants: $n=157$ & \\
\hline Africa: $n=6$ & Approach was not similar across all & \\
\hline Asia: $n=61$ & participants: $n=15$ & \\
\hline \multicolumn{3}{|l|}{ Oceania: $n=22$} \\
\hline \multirow{5}{*}{$\begin{array}{l}\text { Indigenous people: } \mathrm{n}=10 \\
\text { (composed of Maori, } \\
\text { Aboriginals and Eskimos) }\end{array}$} & Sampling frame $(n=144)$ & \\
\hline & Census: $n=55$ & \\
\hline & Household register: $n=27$ & \\
\hline & Convenience sample: $n=8$ & \\
\hline & General practitioner database: $n=37$ & \\
\hline Setting ( $n=159)$ & Hospital database: $n=4$ & \\
\hline Rural: $n=37$ & List of specific group of subjects: $n=5$ & \\
\hline Urban: $n=54$ & (e.g. employees of a company) & \\
\hline \multirow{12}{*}{$\begin{array}{l}\text { Combination urban en rural: } \\
n=68\end{array}$} & Geographic sampling: $n=8$ & \\
\hline & Representation general population $(n=172)$ & \\
\hline & Yes: $n=26$ & \\
\hline & No: $n=146$ & \\
\hline & Case definition $(n=172)$ & \\
\hline & Self-reported diagnosis: $n=18$ & \\
\hline & Self-reported symptoms: $n=11$ & \\
\hline & 2-step approach diagnosis: $n=10$ & \\
\hline & 2-step approach symptoms: $n=52$ & \\
\hline & Diagnose health professional: $n=46$ & \\
\hline & Medial record general practitioner: $n=31$ & \\
\hline & Medical record hospital: $n=4$ & \\
\hline
\end{tabular}

\footnotetext{
${ }^{a}$ Response rate $\geq 75 \%$ or $<75 \%$ but data analysis included a non-responder analysis
} 


\section{Meta-analysis}

The meta-analysis was conducted based on 165 (95.9\%) samples extracted from 67 studies where the raw prevalence was available or could be computed. In total, the 165 samples comprised 237,464 cases and a sample size of $12,226,425$ individuals. The observed prevalence ranged from $0 \%$ to $26.2 \%$ with an unweighted mean of $1.6 \%$ ( $\mathrm{SD}=3.3 \%$; median=0.3\%). Thirty-two samples (19.4\%) reported a prevalence of $0 \%$. The pooled (back-transformed) estimated average prevalence based on the meta-analysis was $0.6 \%(95 \% \mathrm{Cl} 0.4 ; 0.7)$. The $95 \%$ prediction interval was $0.03-11.16 \%$. Note that 10 samples with sample sizes larger than 100,000 comprised $94.2 \%$ of the total sample size. The $\mathrm{I}^{2}$ statistic indicated a very high level of heterogeneity (99.9\%).

\section{Univariable meta-regression analyses}

Mean age, sex, continent, and case definition were significantly associated with the prevalence, accounting respectively for $8.8 \%, 20.7 \%, 31.2 \%$, and $33.6 \%$ of the heterogeneity (Table 3.2). Start of data collection was not significantly associated with the prevalence of gout $(p=0.719)$. Pairwise comparison showed that in indigenous people (Maori, Aboriginals, Inuit) and Oceania higher prevalences were found compared to Europe $(p=0.004 ; p=0.013)$, South America $(p=0.002 ; p=0.009)$, and Asia $(p<0.001 ; p<0.001)$ (Figure 3.2; please see Appendix 3, Table S3.1). Europe and North America reported higher prevalences in comparison to Asia $(p=0.022 ; p<0.001)$. Within "case definition", self-reported approaches resulted in higher estimates of prevalences compared with: a 2-step approach using gout symptoms as a screening question; diagnoses by a health professional; or ICD code/free text in medical records of general practitioners (range p-values: $<0.001$ to 0.029 ). The 2 -step approach on self-reported diagnosis, diagnosis by a health professional, and ICD code in medical records of general practitioners resulted in a significantly higher prevalence than the 2-step approach based on self-reported symptoms ( $p=0.002 ; p=0.011 ; p=0.039)$. Finally, within the sampling frame, a convenience sample frame estimates higher prevalence compared with geographic sampling $(p=0.048)$. 


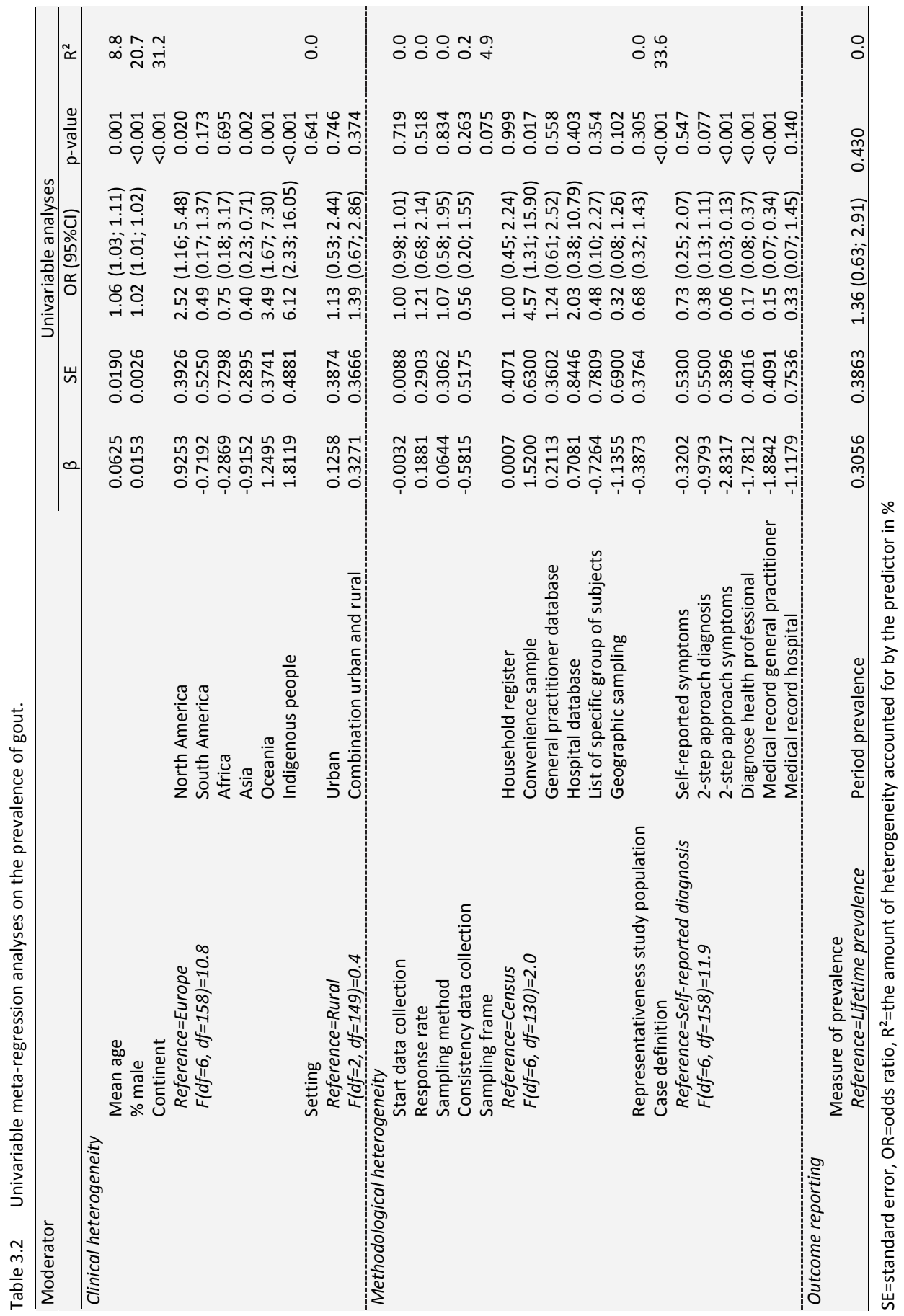



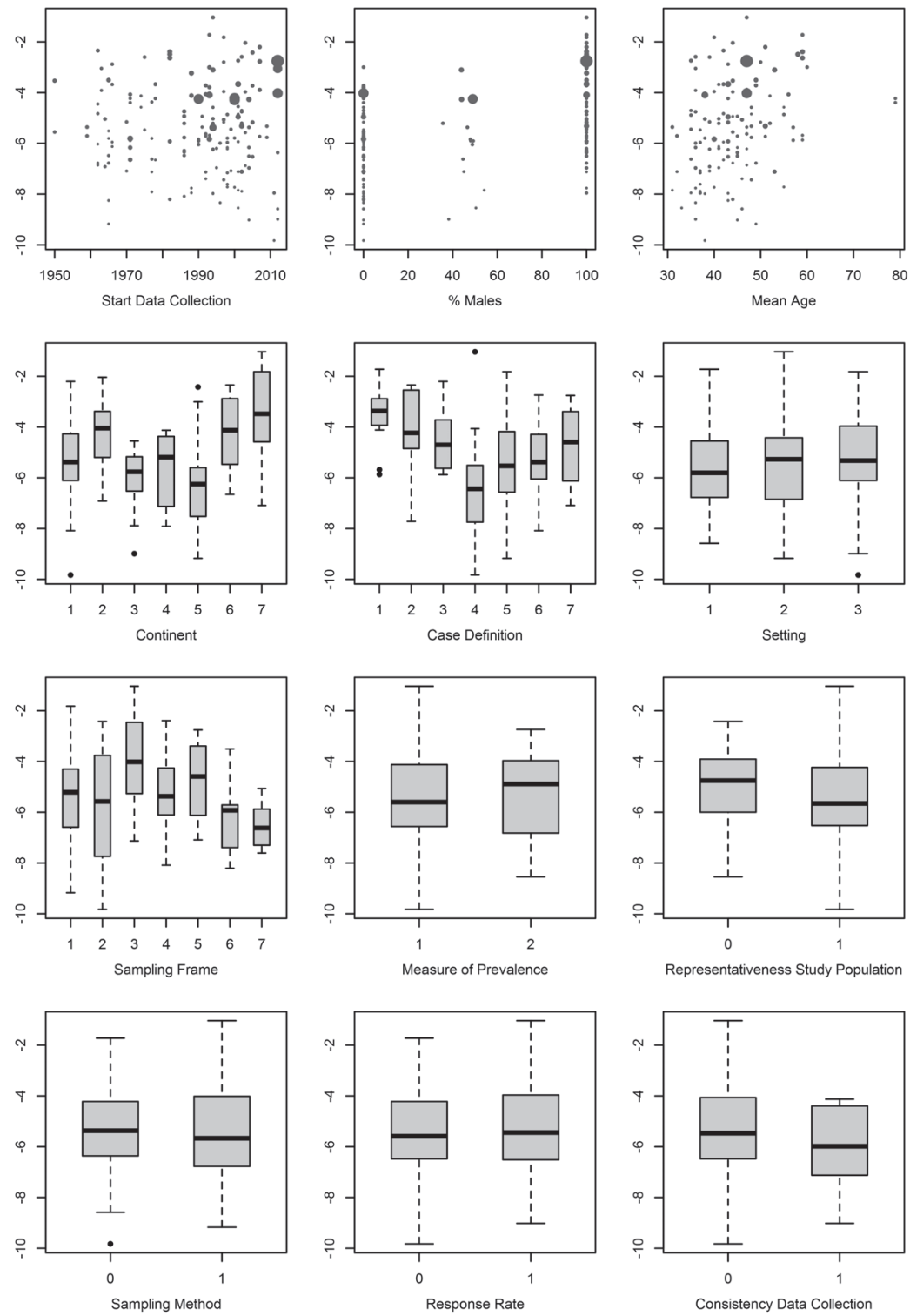

Figure 3.2 Scatterplots for the continuous predictors and boxplots for the categorical predictors with the $y$-axis corresponding to the logit transformed prevalence rates plotted proportional to the sample sizes. Continent (1=Europe, 2=North America, 3=South America, 4=Africa, 5=Asia, 6=Oceania, 7=Indigenous people). Case definition (1=Self-reported diagnosis, 2=Self-reported symptoms, 3=2-step approach diagnosis, 4=2-step approach symptoms, 5=Diagnose health professional, 6=Medial record GP, 7=Medical record hospital). Setting (1=rural, 2=urban, $3=$ combination). Sampling frame (1=Census, $2=$ Household register, $3=$ Convenience sample, $4=$ General practitioner database, $5=$ Hospital database, $6=$ List of specific group of subjects, 7=Geographic sampling). Measure of prevalence (1=lifetime prevalence, 2 =period prevalence). 


\section{Multivariable meta-regression analysis}

Table 3.3 shows the results of the multivariable analysis. Due to collinearity between case definition and sampling frame, the latter was not included in the total model. The multivariable analysis included 109 (63.4\%) samples, comprising a reduced total sample size of $3,813,476$ individuals from 47 studies due to missing data on the sources of clinical and methodological heterogeneity. The variables age $(p=0.019)$, sex $(p<0.001)$, continent $(p<0.001)$, case definition $(p<0.001)$, response rate $(p=0.016)$, and consistency in data collection $(p=0.002)$ were significantly associated with gout prevalence (Table 3.3). Pairwise comparison showed that in indigenous people significantly higher prevalence rates were reported compared to all continents (all $\mathrm{p}<0.01$ ), except for Africa (please see Appendix 3, Table S3.1). Note that results on Africa are based on a small number of samples. Studies performed in Oceania and North America estimated significantly higher gout prevalences compared to: Asia $(p<0.001 ; p<0.001)$; South America $(p=0.001 ; p=0.003)$; and Europe $(p<0.001 ; p=0.002)$. Within "case definition", self-reported symptoms and the 2-step approach based on self-reported diagnosis provided significantly higher prevalences in comparison to a 2 -step approach based on self-reported symptoms $(p=0.001 ; p=0.001)$ or a diagnosis by a health professional $(p<0.001 ; p=0.002)$.

The multivariable model accounted for $88.7 \%$ of the variance. The predicted prevalences based on this model closely corresponded with the observed prevalences in the individuals studies (Figure 3.3). Therefore, the prevalence for any given population may be estimated based on the multivariable model as shown in Table 3.3. For example, a study performed in 2012 in an Asian population (combining both urban and rural area) with a mean age of 44.4 years and $50.9 \%$ males, in which gout is classified using a 2-step approach based on symptoms (representing the population with characteristics that are most frequently reported on), would provide an estimated lifetime prevalence of $0.03 \%(95 \% \mathrm{Cl} 0.01 ; 0.09)$. In contrast, a study performed in 2012 in North America with a similar age and sex distribution, but with a gout diagnosis based on self-reported symptoms, would provide an estimated lifetime prevalence of $1.37 \%(95 \% \mathrm{Cl} 0.43 ; 4.24)$. While a study with similar characteristics as the latter, but with a 20 years older population (mean age $=64.4 \mathrm{yrs}$ ), would result in an estimated prevalence of $2.95 \%(95 \% \mathrm{Cl} 0.94 ; 8.86)$. 


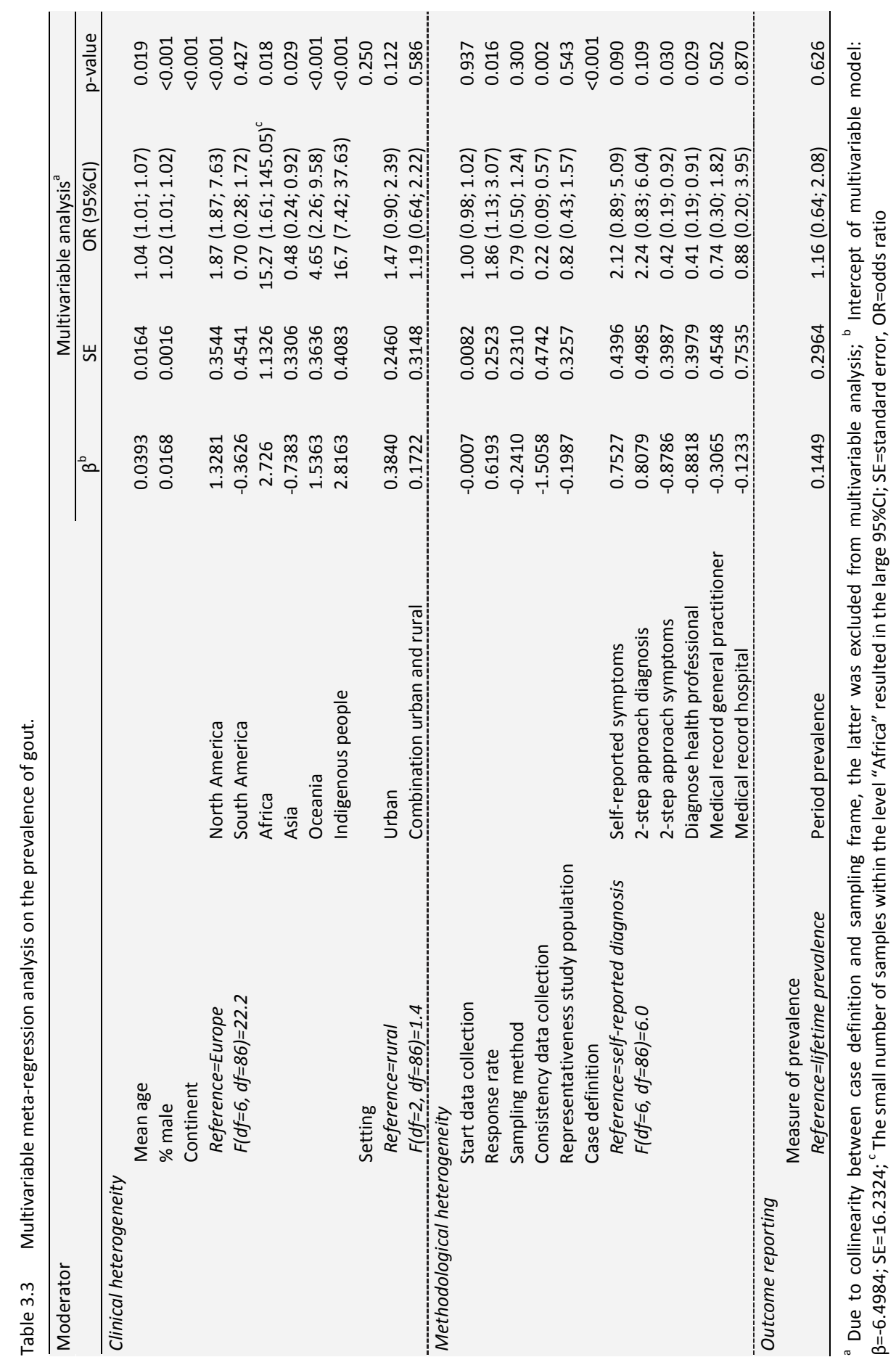




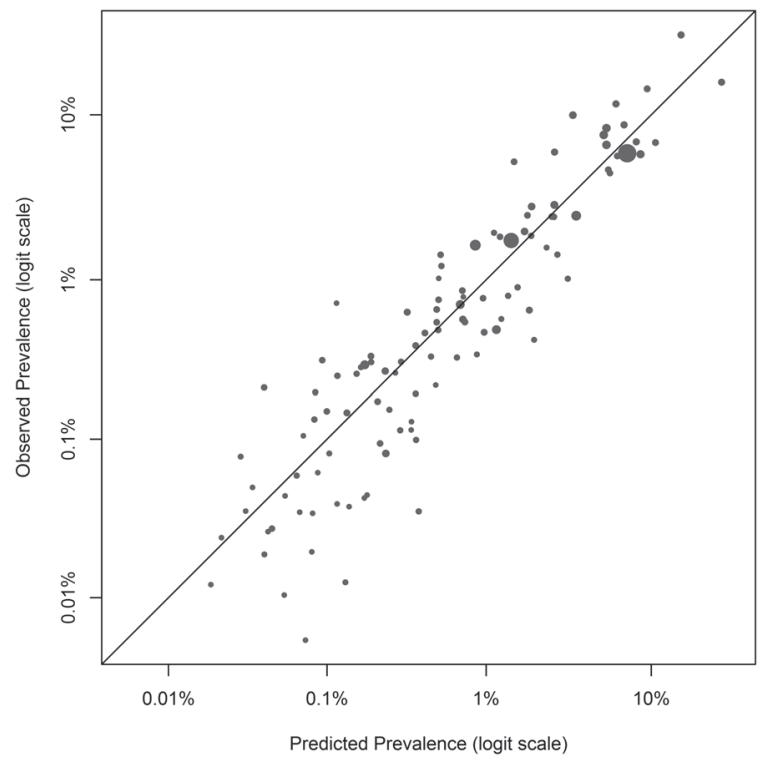

Figure 3.3 Scatterplot for the predicted prevalence based on the multivariable model and the observed prevalence, both on the logit scale.

\section{Sensitivity analyses}

Sensitivity analyses were performed using two alternative modeling approaches for the multivariable regression analysis: (1) using a mixed-effects logistic regression model with random effects per observed outcome and (2) a beta-binomial model with logit link function. The conclusions with respect to the relevant predictors remained largely unchanged. However, using the first alternative method, the prevalence in Asia was no longer different from the one in Europe, whereas the case definition 2-step approach based on self-reported diagnosis was now significantly different from self-reported diagnosis. Using the beta-binomial model, the case definitions self-reported symptoms and the 2-step approach based on self-reported diagnosis were significantly different from self-reported diagnosis, but the 2-step approach based on self-reported symptoms and a diagnose by a health professional were no longer different.

\section{Incidence}

\section{Study characteristics}

Incidence rates were reported in 12 articles ${ }^{34,44,50,54,67,84,93-98}$. Studies were carried out between 1950 and 2012. Due to incomplete method description and missing 
numerators, denominators, or the number of subjects in the study, the measure of incidence (incidence proportion or incidence rate) was not always clear.

\section{Study results}

By scrutinizing extracted data, we observed an influence of duration of follow-up of the cohort on the reported incidence (Table 3.4). Within the studies with a follow-up $\leq 2$ years or in studies reporting annual rates, incidences ranged between $0.06 / 1000$ and $1.80 / 1000$, with higher incidence in men $(0.12 / 1000$ to $1.98 / 1000)$ than in women $(0.0 / 1000$ to $0.74 / 1000)$. Within studies with a longer follow-up (>2 years) an incidence of 2.68/1000 person-years was reported, with incidences varying between $2.8 / 1000$ to $4.42 / 1000$ in men and $1.32 / 1000$ to $1.4 / 1000$ in women. Follow-up periods ranged from 7 to 52 years. In a study performed in Maori with 11 year follow-up, an incidence of $103 / 1000$ in men and 43/1000 in women was reported ${ }^{34}$.

Note that some studies calculated incidence rates or proportions using an unconventional method, that is, by dividing new cases by the number of individuals reexamined after 11 years ${ }^{34}$; by using a denominator based on only the re-examined individuals with hyperuricemia ${ }^{97}$; or by dividing new cases (2002-2003) by census data of 2001, not excluding prevalent cases $^{54}$.

Six articles studied the incidence of gout over time. Four did not find evidence for an increasing or decreasing trend in incidence ${ }^{50,67,84,98}$. However, Currie et al. noted a significant difference between the incidence in 1971-1972 (0.29/1000) and 1974-1975 $(0.35 / 1000)$ in England, but not in Scotland, Wales, and Great Britain as a whole ${ }^{44}$. Arromdee et al. reported that the age and sex adjusted incidence for all gout did not significantly increase $(p=0.10)$ during a 20 -year interval, but found a 2 -fold increase in incidence of primary gout only (subjects not on thiazide or diuretics) ${ }^{93}$. 


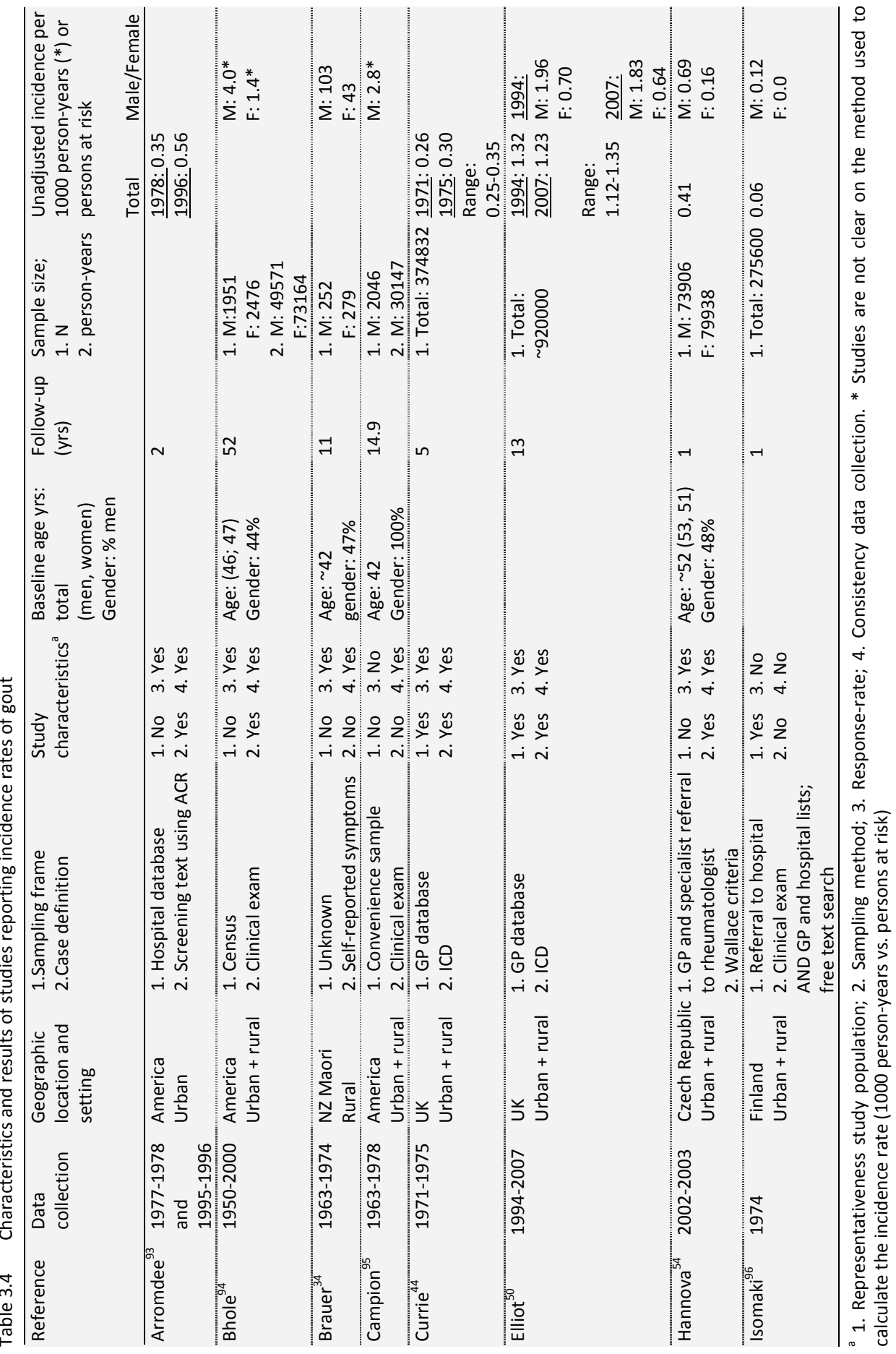




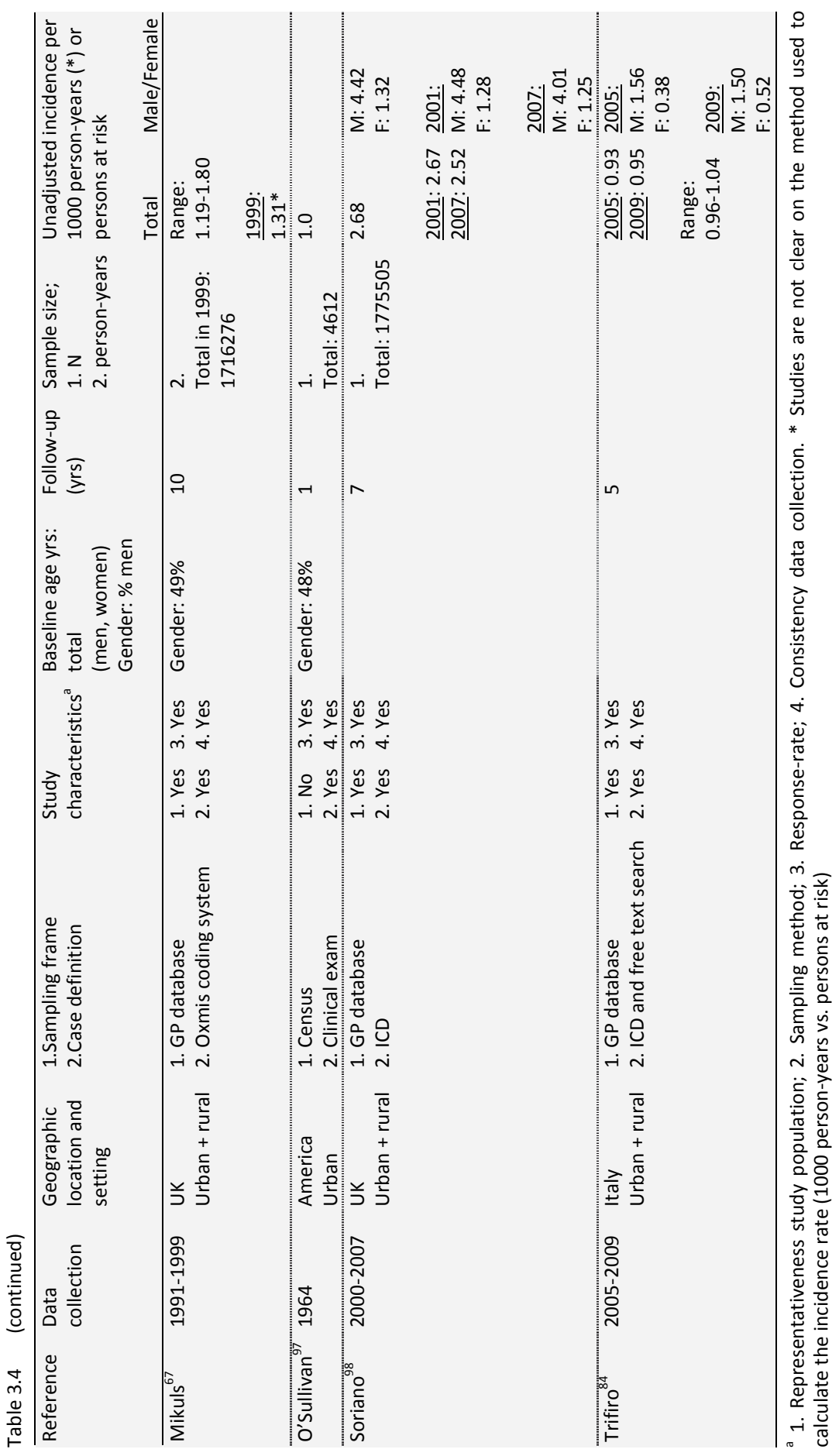




\section{Discussion}

This study was the first to assess the determinants of the worldwide prevalence of gout in the general population in a systematic manner. Our results showed a pooled prevalence of $0.6 \%(95 \% \mathrm{Cl} 0.4 ; 0.7)$ across 67 articles. However, the prevalence estimates were extremely heterogeneous. Therefore, the pooled prevalence should be interpreted with caution. Our multivariable model explained $88.7 \%$ of the heterogeneity and showed an independent influence of age, sex, continent of study execution, consistency in data collection, response rate, but also case definition. In addition, we found that crude incidence rates of gout varied between 0.06/1000 and 2.68/1000 across 12 articles.

The previously reported lower prevalence of gout in females and higher prevalence in Oceania ${ }^{87,99}$, North America ${ }^{5}$, and among indigenous people (Maori, Aboriginals and Inuit) ${ }^{68,87}$ was confirmed in the present study. A higher prevalence in North America was before attributed to the presence of varying ethnic groups on this continent, including Filipinos and African Americans with high gout prevalences ascribed to the shift from a low-purine diet to a high-purine Western diet in case of immigrants ${ }^{100}$ and higher rates of hypertension ${ }^{101}$.

Case definition accounted, in the univariable analysis, for $33.6 \%$ of the heterogeneity. A 2-step approach based on diagnosis and self-reported approaches to define gout resulted in the highest estimates of the prevalence of gout. While a previous study suggested that self-report of physician-diagnosed gout is an adequate proxy of the actual prevalence ${ }^{102}$, we were not able to distinguish this specific selfreported diagnosis from a simple self-reported diagnosis method due to small subsamples. Note that the 2-step approaches were most often used and therefore could have influenced the pooled prevalence.

Because of the limited number of incidence studies a meta-analysis was not possible. Surprisingly, statistical approaches to calculate incidence rates were imprecise and often the exact numerator and denominator were not reported. When incidence rates are assessed over a long time frame, it is assumed that the incidence remains constant during the period of study. However, when assessing a closed cohort, gout incidence will increase with increasing age. This is probably why we found that studies with a long follow-up reported higher incidence rates in comparison to studies reporting an annual incidence.

Among the incidence studies six articles reported incidences across time, of which only two found an increase. Also, our meta-regression analysis of the prevalence rate did not show a significant influence of year of study execution. However, in case a study reported prevalences over time, only the most recent estimation was considered. Nevertheless, only two of the four studies that compared annual prevalence rates for different time points directly ${ }^{43,50,84,90}$ reported the increase to be significant ${ }^{43,90}$. Therefore, based on our results, we suggest that there is insufficient evidence for a 
time trend in the worldwide prevalence and incidence of gout. However, we acknowledge that our finding may represent the absence of evidence, rather than evidence of absence.

Some limitations to this study need to be considered. First, we cannot exclude possible language bias and availability bias in study inclusion as we limited our search to five languages and published articles. Second, due to unavailability of some data from the primary papers, we had to exclude four articles from the meta-analyses. Third, coding the different aspects of clinical and methodological heterogeneity entails some subjectivity, however, coding was independently performed by two reviewers and disagreement resolved by consensus. Fourth, we used mixed-effects logistic regression model for the meta-regression analysis which may have influenced our results. However, sensitivity analyses showed that the impact of the used method was rather small. Finally, associations of the gout prevalence with population averages, such as age and sex, across studies may not reflect findings within studies.

In conclusion, the results of this systematic review show that gout is a common disease. A large part of the heterogeneity between studies on the prevalence of gout can be explained by sources of clinical heterogeneity, such as the world region in which the study was performed, and the percentage of males in the study population, but also by the case definition of gout. Researchers should carefully formulate their case definition to facilitate comparison between studies. In addition, more research is needed to support the possible time trend towards increasing prevalence or incidence of gout in the general population. 


\section{References}

1. Zhu Y, Pandya BJ, Choi HK. Comorbidities of gout and hyperuricemia in the US general population: NHANES 2007-2008. Am J Med. 2012;125:679-687.

2. Roddy $E$, Zhang W, Doherty $M$. Is gout associated with reduced quality of life? A case-control study. Rheumatology. 2007;46:1441-1444.

3. Hamburger M, Baraf HS, Adamson TC, 3rd, et al. 2011 Recommendations for the diagnosis and management of gout and hyperuricemia. Postgrad Med. 2011;123:3-36.

4. Saag KG, Choi H. Epidemiology, risk factors, and lifestyle modifications for gout. Arthritis Res Ther. 2006;8:S2.

5. Singh JA. Racial and gender disparities among patients with gout. Curr Rheumatol Rep. 2013;15:307.

6. Doherty M. New insights into the epidemiology of gout. Rheumatology. 2009;48:2-8.

7. Luk AJ, Simkin PA. Epidemiology of hyperuricemia and gout. Am J Manag Care. 2005;11:S435-S442.

8. Miller DR, Rogers WH, Kazis LE, Spiro A, 3rd, Ren XS, Haffer SC. Patients' self-report of diseases in the Medicare Health Outcomes Survey based on comparisons with linked survey and medical data from the Veterans Health Administration. J Ambul Care Manage. 2008;31:161-177.

9. Malik A, Dinnella JE, Kwoh CK, Schumacher HR. Poor validation of medical record ICD-9 diagnoses of gout in a Veterans Affairs Database. J Rheumatol. 2009;36:1283-1286.

10. Cheng LSC, Chiang SL, Tu HP, et al. Genomewide scan for gout in Taiwanese aborigines reveals linkage to chromosome 4q25. Am J Hum Genet. 2004;75:498-503.

11. Sutton AJ, Abrams KR, Jones DR, Sheldon TA, Song F. Methods for meta-analysis in medical research. New York: Wiley; 2000.

12. Lipsey MW, Wilson DB. Practical meta-analysis. Thousand Oaks, CA: Sage; 2001.

13. Riley RD, Higgins JP, Deeks JJ. Interpretation of random effects meta-analyses. BMJ. 2011;342:d549.

14. Berkey CS, Hoaglin DC, Mosteller F, Colditz GA. A random-effects regression model for meta-analysis. Stat Med. 1995;14:395-411.

15. Greenland S, O'Rourke K. On the bias produced by quality scores in meta-analysis, and a hierarchical view of proposed solutions. Biostatistics. 2001;2:463-471.

16. Raudenbush SW. Analyzing effect sizes: Random-effects models. In: Cooper H, Hedges LV, Valentine JC, eds. The handbook of research synthesis and meta-analysis. 2nd ed. New York: Russell Sage Foundation; 2009:295-315.

17. Knapp G, Hartung J. Improved tests for a random effects meta-regression with a single covariate. Stat Med. 2003;22:2693-2710.

18. Holm S. A simple sequentially rejective multiple test procedure Scand J Statist. 1979;6:65-70.

19. Viechtbauer W. Conducting Meta-Analyses in R with the metafor Package. J Stat Softw. 2010;36:1-48.

20. Bates D, Maechler M, Bolker B, Walker S. Ime4: Linear mixed-effects models using Eigen and S4. R package version 1.1-6 2014; http://CRAN.R-project.org/package=Ime4.

21. Yee TW. The VGAM Package for Categorical Data Analysis. J Stat Softw. 2010;32:1-34.

22. Akizuki S. A population study of hyperuricaemia and gout in Japan--analysis of sex, age and occupational differences in thirty-four thousand people living in Nagano Prefecture. Ryumachi. 1982;22:201-208.

23. Al-Arfaj AS. Hyperuricemia in Saudi Arabia. Rheumatol Int. 2001;20:61-64.

24. Alvarez Nemegyei J, Nuno Gutierrez BL, Alcocer Sanchez JA. Enfermedades reumaticas y discapacidad laboral en poblacion adulta rural. Rev Med Inst Mex Seguro Soc. 2005;43:287-292.

25. Anagnostopoulos I, Zinzaras E, Alexiou I, et al. The prevalence of rheumatic diseases in central Greece: a population survey. BMC Musculoskelet Disord. 2010;11:98.

26. Andrianakos A, Trontzas $P$, Christoyannis $F$, et al. Prevalence of rheumatic diseases in Greece: a crosssectional population based epidemiological study. The ESORDIG Study. J Rheumatol. 2003;30: 1589-1601.

27. Annemans L, Spaepen E, Gaskin M, et al. Gout in the UK and Germany: prevalence, comorbidities and management in general practice 2000-2005. Ann Rheum Dis. 2008;67:960-966.

28. Badley EM, Meyrick JS, Wood PH. Gout and serum uric acid levels in the Cotswolds. Rheumatol Rehabil. 1978;17:133-142. 
29. Beighton P, Solomon L, Soskolne CL, Sweet MB. Rheumatic disorders in the South African Negro. Part IV. Gout and hyperuricaemia. S Afr Med J. 1977;51:969-972.

30. Beighton P, Valkenburg HA. Bone and joint disorders on Tristan da Cunha. S Afr Med J. 1974;48: 743-747.

31. Bergmann MM, Jacobs EJ, Hoffmann K, Boeing $\mathrm{H}$. Agreement of self-reported medical history: comparison of an in-person interview with a self-administered questionnaire. Eur J Epidemiol. 2004;19:411-416.

32. Bergstrom G, Bjelle A, Sorensen LB, Sundh V, Svanborg A. Prevalence of rheumatoid arthritis, osteoarthritis, chondrocalcinosis and gouty arthritis at age 79. J Rheumatol. 1986;13:527-534.

33. Boyer GS, Lanier AP, Templin DW. Prevalence rates of spondyloarthropathies, rheumatoid arthritis, and other rheumatic disorders in an Alaskan Inupiat Eskimo population. J Rheumatol. 1988;15:678-683.

34. Brauer GW, Prior IA. A prospective study of gout in New Zealand Maoris. Ann Rheum Dis. 1978;37: 466-472.

35. Cakir N, Pamuk ON, Dervis E, et al. The prevalences of some rheumatic diseases in western Turkey: Havsa study. Rheumatol Int. 2012;32:895-908.

36. Cardiel MH, Rojas-Serrano J. Community based study to estimate prevalence, burden of illness and help seeking behavior in rheumatic diseases in Mexico City. A COPCORD study. Clin Exp Rheumatol. 2002;20:617-624.

37. Chaiamnuay P, Darmawan J, Muirden KD, Assawatanabodee P. Epidemiology of rheumatic disease in rural Thailand: a WHO-ILAR COPCORD study. Community Oriented Programme for the Control of Rheumatic Disease. J Rheumatol. 1998;25:1382-1387.

38. Chang SJ, Ko YC, Wang TN, Chang FT, Cinkotai FF, Chen CJ. High prevalence of gout and related risk factors in Taiwan's Aborigines. J Rheumatol. 1997;24:1364-1369.

39. Chen SL, Du H, Wang Y, Xu LQ. The epidemiology study of hyperuricemia and gout in a community population of Huangpu District in Shanghai. Chin Med J. 1998;111:228-230.

40. Chopra A, Patil J, Billempelly V, Relwani J, Tandle HS. Prevalence of rheumatic diseases in a rural population in western India: a WHO-ILAR COPCORD Study. J Assoc Physicians India. 2001;49:240-246.

41. Chou CT, Lai JS. The epidemiology of hyperuricaemia and gout in Taiwan aborigines. Br J Rheumatol. 1998;37:258-262.

42. Chou CT, Pei L, Chang DM, Lee CF, Schumacher HR, Liang MH. Prevalence of rheumatic diseases in Taiwan: A population study of urban, suburban, rural differences. $J$ Rheumatol. 1994;21:302-306.

43. Chuang SY, Lee SC, Hsieh YT, Pan WH. Trends in hyperuricemia and gout prevalence: Nutrition and Health Survey in Taiwan from 1993-1996 to 2005-2008. Asia Pac J Clin Nutr. 2011;20:301-308.

44. Currie WJ. Prevalence and incidence of the diagnosis of gout in Great Britain. Ann Rheum Dis. 1979;38:101-106.

45. Dai SM, Han XH, Zhao DB, Shi YQ, Liu Y, Meng JM. Prevalence of rheumatic symptoms, rheumatoid arthritis, ankylosing spondylitis, and gout in Shanghai, China: A COPCORD study. J Rheumatol. 2003;30:2245-2251.

46. Dans LF, TankehTorres S, Amante CM, Penserga EG. The prevalence of rheumatic diseases in a Filipino urban population: A WHO-ILAR COPCORD study. J Rheumatol. 1997;24:1814-1819.

47. Darmawan J, Valkenburg HA, Muirden KD, Wigley RD. The epidemiology of gout and hyperuricemia in a rural population of Java. J Rheumatol. 1992;19:1595-1599.

48. Davatchi F, Jamshidi AR, Banihashemi AT, et al. Effect of ethnic origin (Caucasians versus Turks) on the prevalence of rheumatic diseases: a WHO-ILAR COPCORD urban study in Iran. Clin Rheumatol. 2009;28:1275-1282.

49. Douglas WA. Rheumatic disease in the Australian Aborigine of Cape York Peninsula: A 1965 study. APLAR Journal of Rheumatology. 2004;7:237-241.

50. Elliot AJ, Cross KW, Fleming DM. Seasonality and trends in the incidence and prevalence of gout in England and Wales 1994-2007. Ann Rheum Dis. 2009;68:1728-1733.

51. Farooqi A, Gibson T. Prevalence of the major rheumatic disorders in the adult population of north Pakistan. Br J Rheumatol. 1998;37:491-495.

52. Gardner MJ, Power C, Barker DJ, Padday R. The prevalence of gout in three English towns. Int J Epidemiol. 1982;11:71-75. 
53. Hall AP, Barry PE, Dawber TR, McNamara PM. Epidemiology of gout and hyperuricemia. A long-term population study. Am J Med. 1967;42:27-37.

54. Hanova P, Pavelka K, Dostal C, Holcatova I, Pikhart H. Epidemiology of rheumatoid arthritis, juvenile idiopathic arthritis and gout in two regions of the Czech Republic in a descriptive population-based survey in 2002-2003. Clin Exp Rheumatol. 2006;24:499-507.

55. Haq SA, Darmawan J, Islam MN, et al. Prevalence of rheumatic diseases and associated outcomes in rural and urban communities in Bangladesh: a COPCORD study. J Rheumatol. 2005;32:348-353.

56. Harris CM, Lloyd D, Lewis J. Prevalence and Prophylaxis of Gout in England. J Clin Epidemiol. 1995;48:1153-1158.

57. Hoa TTM, Damarwan J, Le CS, Hung NV, Nhi CT, An TN. Prevalence of the rheumatic diseases in urban Vietnam: A WHO-ILAR COPCORD study. J Rheumatol. 2003;30:2252-2256.

58. Jackson L, Taylor R, Faaiuso S, Ainuu SP, Whitehouse S, Zimmet P. Hyperuricaemia and gout in Western Samoans. J Chronic Dis. 1981;34:65-75.

59. Joshi VL, Chopra A. Is there an urban-rural divide? Population surveys of rheumatic musculoskeletal disorders in the Pune region of India using the COPCORD Bhigwan Model. J Rheumatol. 2009;36: 614-622.

60. Kato H, Duff IF, Russell WJ, et al. Rheumatoid arthritis and gout in Hiroshima and Nagasaki, Japan: A prevalence and incidence study. J Chronic Dis. 1971;23:659-679.

61. Klemp P, Stansfield SA, Castle B, Robertson MC. Gout is on the increase in New Zealand. Ann Rheum Dis. 1997;56:22-26.

62. Kramer HM, Curhan G. The association between gout and nephrolithiasis: The National Health and Nutrition Examination Survey III, 1988-1994. Am J Kidney Dis. 2002;40:37-42.

63. Li R, Sun J, Ren LM, et al. Epidemiology of eight common rheumatic diseases in China: a large-scale cross-sectional survey in Beijing. Rheumatology. 2012;51:721-729.

64. Mahajan A, Jasrotia DS, Manhas AS, Jamwal SS. Prevalence of major rheumatic disorders in Jammu. $J K$ Science. 2003;5:63-66.

65. Miao ZM, Li CG, Chen Y, et al. Dietary and lifestyle changes associated with high prevalence of hyperuricemia and gout in the Shandong coastal cities of Eastern China. J Rheumatol. 2008;35: 1859-1864.

66. Mikkelsen WM, Dodge HJ, Duff IF, Kato H. Estimates of the prevalence of rheumatic diseases in the population of Tecumseh, Michigan, 1959-60. J Chronic Dis. 1967;20:351-369.

67. Mikuls TR, Farrar JT, Bilker WB, Fernandes S, Schumacher HR, Saag KG. Gout epidemiology: results from the UK general practice research database, 1990-1999. Ann Rheum Dis. 2005;64:267-272.

68. Minaur N, Sawyers S, Parker J, Darmawan J. Rheumatic disease in an Australian aboriginal community in North Queensland, Australia. A WHO-ILAR COPCORD survey. J Rheumatol. 2004;31:965-972.

69. Nan HR, Qiao Q, Dong YH, et al. The prevalence of hyperuricemia in a population of the coastal city of Qingdao, China. J Rheumatol. 2006;33:1346-1350.

70. Obregon-Ponce A, Iraheta I, Garcia-Ferrer H, Mejia B, Garcia-Kutzbach A. Prevalence of musculoskeletal diseases in Guatemala, Central America: the COPCORD study of 2 populations. J Clin Rheumatol. 2012;18:170-174.

71. O'Sullivan JB. Gout in a New England town. A prevalence study in Sudbury, Massachusetts. Ann Rheum Dis. 1972;31:166-169.

72. Pelaez-Ballestas I, Sanin LH, Moreno-Montoya J, et al. Epidemiology of the rheumatic diseases in Mexico. A study of 5 regions based on the COPCORD methodology. J Rheumatol. 2011;86:3-8.

73. Picavet HS, Hazes JM. Prevalence of self reported musculoskeletal diseases is high. Ann Rheum Dis. 2003;62:644-650.

74. Popert AJ, Hewitt JV. Gout and hyperuricaemia in rural and urban populations. Ann Rheum Dis. 1962;21:154-163.

75. Portis AJ, Laliberte $\mathrm{M}$, Tatman $\mathrm{P}$, et al. High prevalence of gouty arthritis among the Hmong population in Minnesota. Arthritis Care Res (Hoboken). 2010;62:1386-1391.

76. Prior IA, Rose BS, Harvey HP, Davidson F. Hyperuricaemia, gout, and diabetic abnormality in Polynesian people. Lancet. 1966;1:333-338. 
77. Reyes-Llerena GA, Guibert-Toledano M, Penedo-Coello A, et al. Community-based study to estimate prevalence and burden of illness of rheumatic diseases in Cuba: A COPCORD Study. J Clin Rheumatol. 2009;15:51-55.

78. Rose BS, Prior IA. A survey of rheumatism in a rural New Zealand Maori community. Ann Rheum Dis. 1963;22:410-415.

79. Salaffi F, De Angelis R, Grassi W. Prevalence of musculoskeletal conditions in an Italian population sample: results of a regional community-based study. I. The MAPPING study. Clin Exp Rheumatol. 2005;23:819-828.

80. Sari I, Akar S, Pakoz B, et al. Hyperuricemia and its related factors in an urban population, Izmir, Turkey. Rheumatol Int. 2009;29:869-874.

81. Steven MM. Prevalence of chronic arthritis in four geographical areas of the Scottish Highlands. Ann Rheum Dis. 1992;51:186-194.

82. Sullivan FM, Barber JH, Sturrock RD. Rheumatology at the general practitioner/hospital interface: A study of prevalence and access to specialist care. Ann Rheum Dis. 1990;49:983-985.

83. Taylor W, Smeets L, Hall J, McPherson K. The burden of rheumatic disorders in general practice: consultation rates for rheumatic disease and the relationship to age, ethnicity, and small-area deprivation. N Z Med J. 2004;117:U1098.

84. Trifiro G, Morabito P, Cavagna L, et al. Epidemiology of gout and hyperuricaemia in Italy during the years 2005-2009: a nationwide population-based study. Ann Rheum Dis. 2012;72:694-700.

85. Veerapen K, Wigley RD, Valkenburg H. Musculoskeletal pain in Malaysia: a COPCORD survey. J Rheumatol. 2007;34:207-213.

86. Wigley R, Manahan L, Muirden KD, et al. Rheumatic disease in a Philippine village II: A WHO-ILARAPLAR COPCORD study, phases II and III. Rheumatol Int. 1991;11:157-161.

87. Winnard D, Wright C, Taylor WJ, et al. National prevalence of gout derived from administrative health data in Aotearoa New Zealand. Rheumatology. 2012;51:901-909.

88. Zalokar J, Lellouch J, Claude JR, Kuntz D. Serum uric acid in 23,923 men and gout in a subsample of 4257 men in France. J Chronic Dis. 1972;25:305-312.

89. Zeng QY, Wang QW, Chen R, Xiao ZG, Huang SB, Xu JC. Primary gout in Shantou: a clinical and epidemiological study. Chin Med J. 2003;116:66-69.

90. Zhu Y, Pandya BJ, Choi HK. Prevalence of gout and hyperuricemia in the US general population: the National Health and Nutrition Examination Survey 2007-2008. Arthritis Rheum. 2011;63:3136-3141.

91. Zimmet PZ, Whitehouse S, Jackson L, Thoma K. High prevalence of hyperuricaemia and gout in an urbanised Micronesian population. Br Med J. 1978;1:1237-1239.

92. Lin KC, Lin HY, Chou P. Community based epidemiological study on hyperuricemia and gout in Kin-Hu, Kinmen. J Rheumatol. 2000;27:1045-1050.

93. Arromdee E, Michet CJ, Crowson CS, O'Fallon WM, Gabriel SE. Epidemiology of gout: Is the incidence rising? J Rheumatol. 2002;29:2403-2406.

94. Bhole V, de Vera M, Rahman MM, Krishnan E, Choi H. Epidemiology of female gout: 52-Year follow-up of a prospective cohort. Arthritis Rheum. 2010;62:1069-1076.

95. Campion EW, Glynn RJ, DeLabry LO. Asymptomatic hyperuricemia. Risks and consequences in the Normative Aging Study. Am J Med. 1987;82:421-426.

96. Isomaki H, Raunio J, von Essen R, Hameenkorpi R. Incidence of inflammatory rheumatic diseases in Finland. Scand J Rheumatol. 1978;7:188-192.

97. O'Sullivan JB. The incidence of gout and related uric acid levels in Sudbury, Massachusetts. In: Bennett PH, Wood PHN, eds. Population Studies of the Rheumatic Diseases. Amsterdam: Excerpta Medica; 1968:371-376.

98. Cea Soriano L, Rothenbacher D, Choi HK, Garcia Rodriguez LA. Contemporary epidemiology of gout in the UK general population. Arthritis Res Ther. 2011;13:R39.

99. Robinson P, Taylor W, Merriman T. A systematic review of the prevalence of gout and hyperuricemia in Australia. Intern Med J. 2012;42:997-1007.

100. Torralba TP, Bayani Sioson PS. The Filipino and gout. Semin Arthritis and Rheumatism. 1975;4:307-320.

101. Hochberg MC, Thomas J, Thomas DJ, Mead L, Levine DM, Klag MJ. Racial differences in the incidence of gout. The role of hypertension. Arthritis Rheum. 1995;38:628-632. 
Chapter 3

102. McAdams MA, Maynard JW, Baer AN, et al. Reliability and sensitivity of the self-report of physiciandiagnosed gout in the campaign against cancer and heart disease and the atherosclerosis risk in the community cohorts. J Rheumatol. 2011;38:135-141. 
Appendix 3

Supplemental table and figure 
Chapter 3 


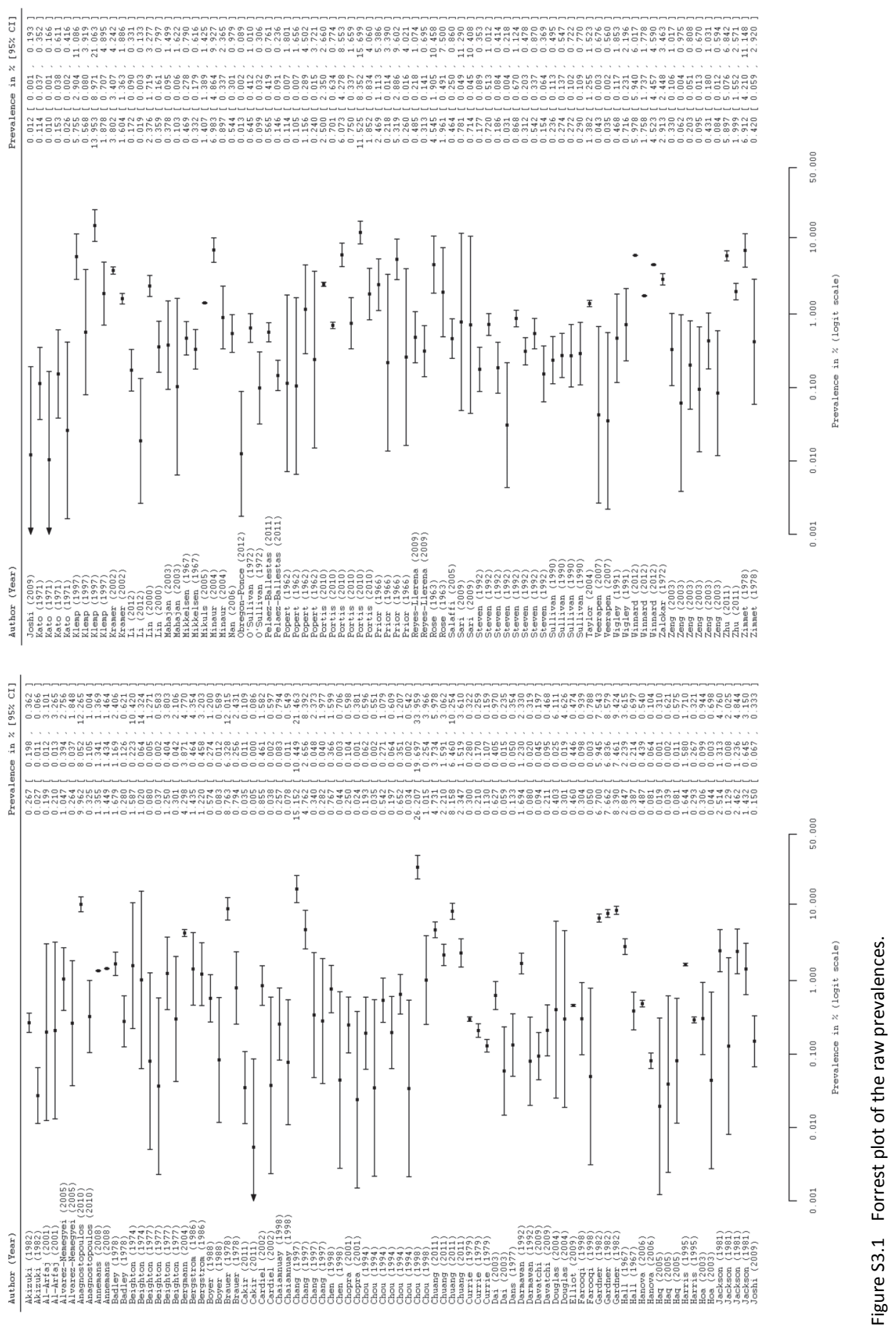




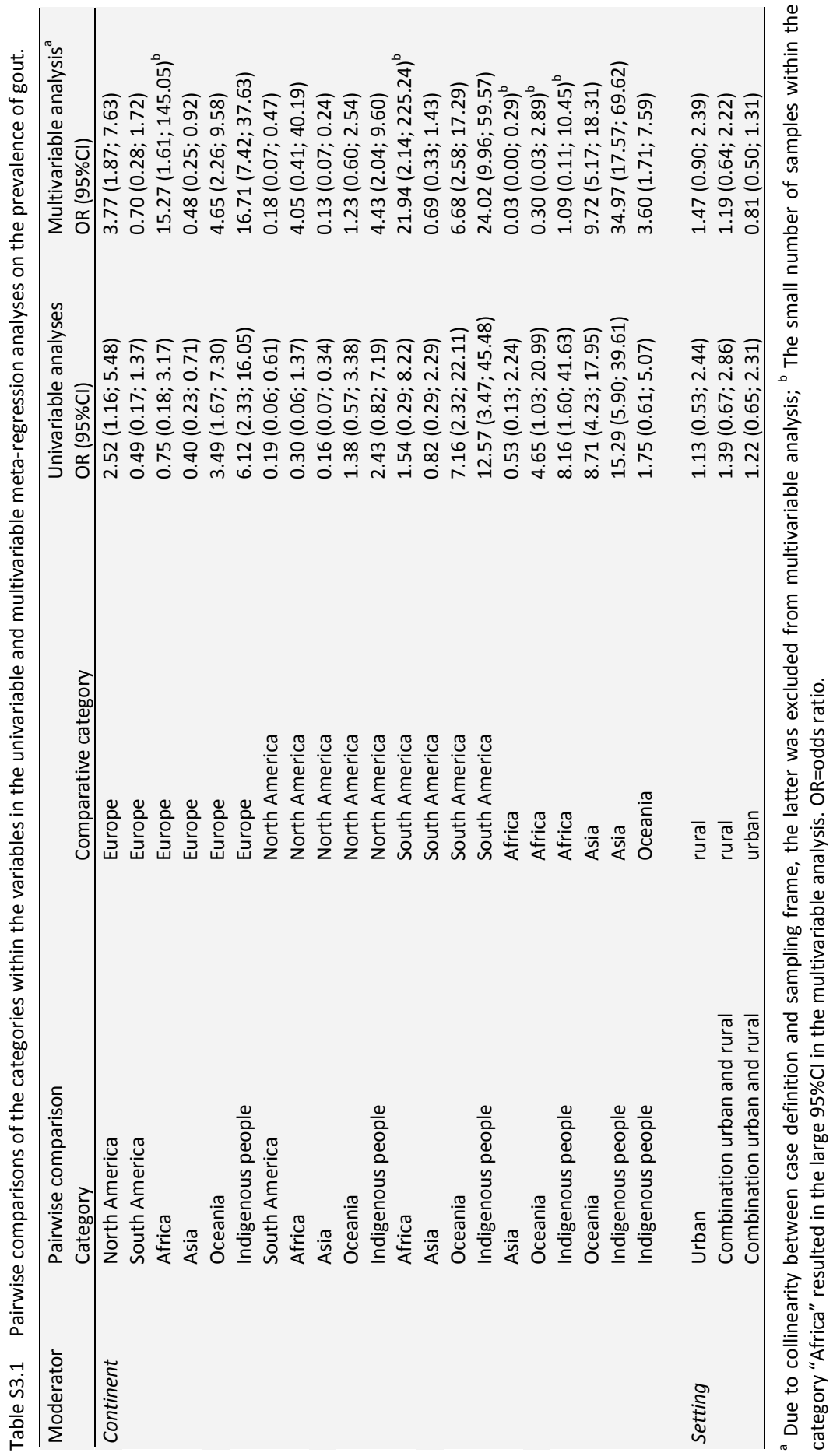




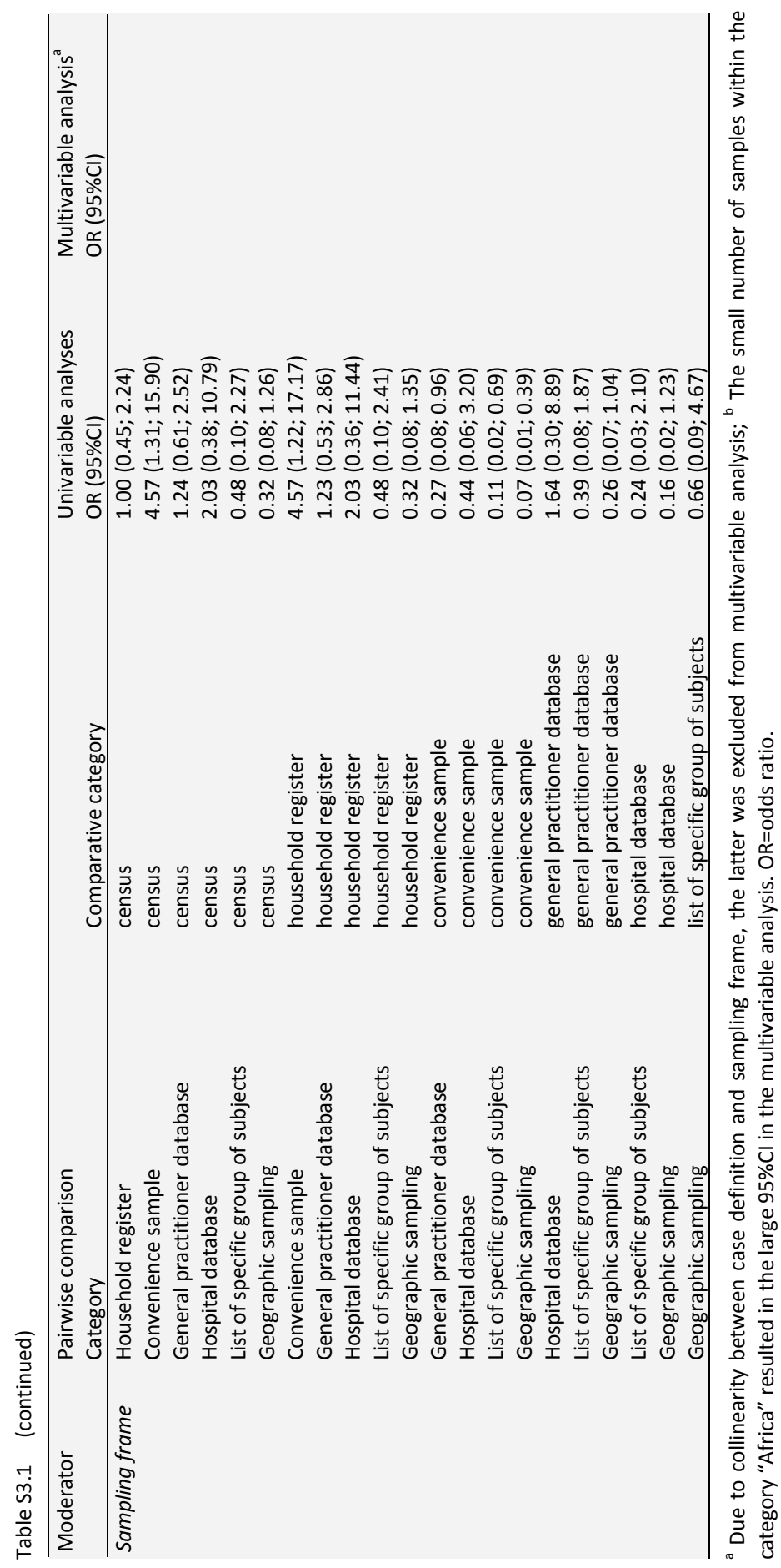




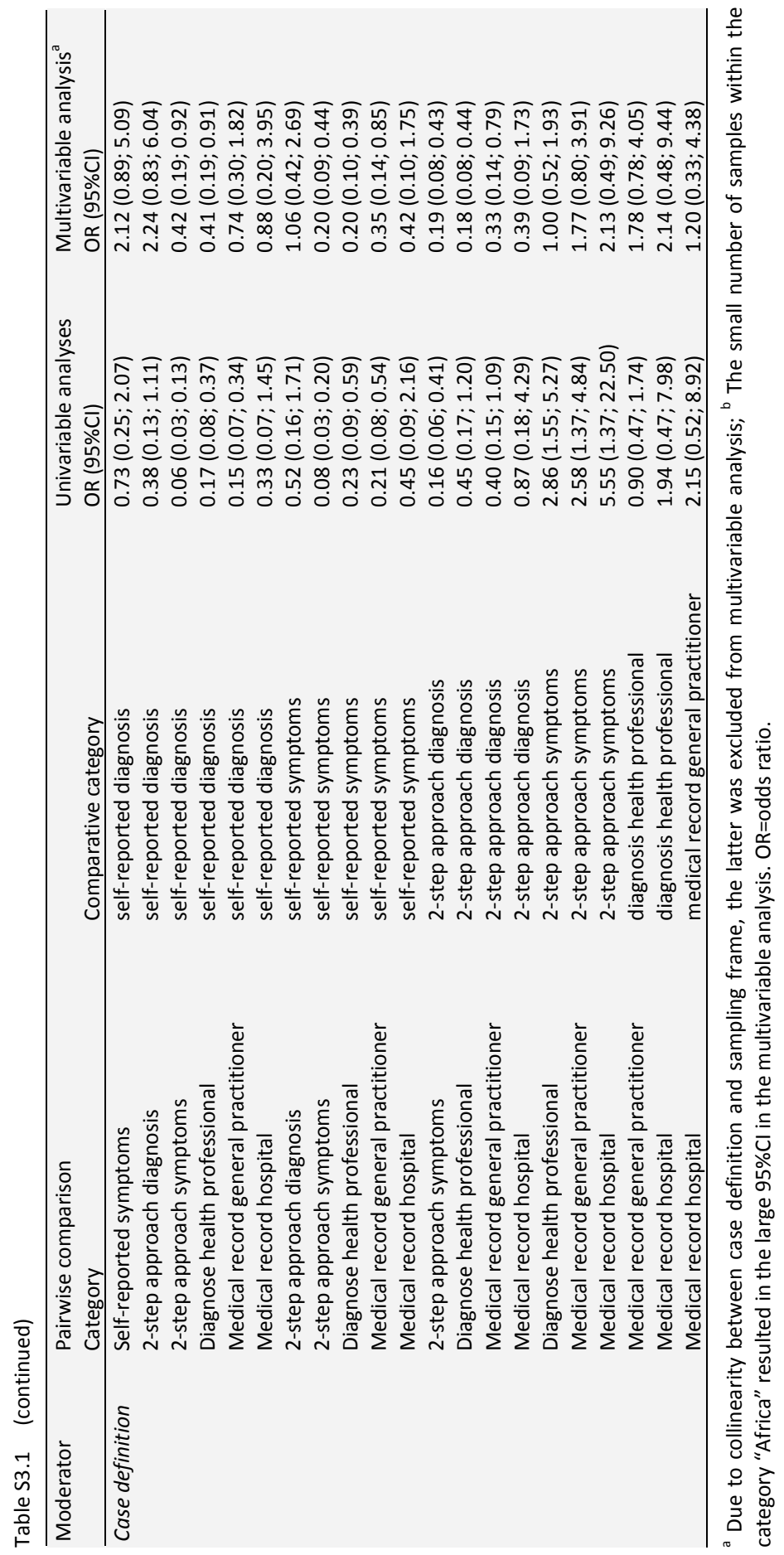




\section{Chapter 4}

Individuals with type 2 diabetes mellitus are at an increased risk of gout but this is not due to diabetes:

a population-based cohort study

J.M.A. Wijnands, C. van Durme, J.H.M. Driessen, C. Klop, H.G.M. Leufkens,

C. Cooper, C.D.A. Stehouwer, A. Boonen, F. de Vries 


\section{Abstract}

\section{Objective}

The relationship between type 2 diabetes mellitus (T2DM) and gout is complex, and previous studies have not clearly delineated the respective roles of diabetes and its comorbidities. The objective of this study was to understand the role of diabetes itself and its comorbidities within the association between T2DM and gout.

\section{Methods}

We conducted a retrospective cohort study using the world's largest primary care database, the UK Clinical Practice Research Datalink (CPRD) GOLD. Persons with T2DM were identified as persons on a non-insulin antidiabetic drug (NIAD) between 2004 and 2012, and matched to one control based on age, sex, and general practice. We estimated gout risk in NIAD users using Cox regression analysis and performed subgroup analyses within these individuals to further explore the role of HbA1c levels. All analyses were stratified for sex.

\section{Results}

221,117 NIAD users and an equal number of non-diabetic controls were identified. Compared with controls, NIAD users had an increased risk of gout [HR=1.48 (95\% Cl 1.41; 1.54)]. This association was stronger in women $[H R=2.23(95 \% \mathrm{Cl} 2.07 ; 2.41)]$ as compared with men [HR=1.19 (95\% Cl 1.13; 1.26)]. However, after adjustments for BMI, eGFR, hypertension, renal transplantation, and the use of thiazide diuretics, loop diuretics, statins, low dose aspirin, cyclosporine, and tacrolimus, the risk disappeared in women [HR=1.01 $(95 \% \mathrm{Cl} 0.92 ; 1.11)]$ and reversed in men $[\mathrm{HR}=0.61(95 \% \mathrm{Cl} 0.58 ; 0.66), \mathrm{p}$ for interaction<0.001]. When stratifying gout risk according to HbA1c in male and female NIAD users, we found an inverse association between $\mathrm{HbA1C}$ and incident gout in men only. Further adjustment gave similar results.

\section{Conclusion}

Individuals with T2DM are at increased risk of gout. This is not due to diabetes itself, which is actually associated with a decreased risk in men, but due to the comorbid conditions found in these individuals. 


\section{Introduction}

Gout is the most common inflammatory joint disease worldwide and affects up to $1-2 \%$ of adults in western societies ${ }^{1}$. The disease has been associated with multiple comorbidities, including type 2 diabetes mellitus (T2DM). However, the relationship between T2DM and gout is complex as several pathophysiological mechanisms that occur in diabetes can have opposite effects on the risk of gout ${ }^{2-5}$.

On the one hand, diabetes may be associated with an increased risk of gout. As compared with the general population, individuals with T2DM generally have a higher $\mathrm{BMI}$, an increased prevalence of hypertension ${ }^{6}$ and a decline in renal function ${ }^{7}$. These comorbid conditions are well known risk factors of gout ${ }^{8,9}$. Indeed, higher prevalences of gout have been identified in individuals with $T 2 \mathrm{DM}^{2,3}$. On the other hand, studies have shown lower uric acid concentrations in individuals with T2DM compared to those without diabetes, suggesting a lower risk of gout ${ }^{10,11}$. Glycosuria, which occurs when blood glucose levels rise above $\sim 10 \mathrm{mmol} / \mathrm{I}^{11}$, has been suggested to be the underlying mechanism for these low concentrations ${ }^{12}$. An impaired inflammatory response in individuals with T2DM may further protect against the development of gout ${ }^{4}$. In agreement, a case-control study in The Health Improvement Network (THIN), a British primary care database, has shown that individuals with T2DM are at a lower risk of gout than controls ${ }^{4}$. This risk was even lower if diabetes was poorly controlled ${ }^{5}$.

In view of the above, the objective of this study was to determine the risk of gout in individuals with T2DM as compared with population-based controls, and to understand the role of diabetes itself and its comorbidities within gout risk. Since it has been suggested that risk factors for gout are more prevalent in women with T2DM than in men $^{13}$, we additionally investigated potential sex-related differences in the association between T2DM and incident gout.

\section{Methods}

\section{Data source}

Using data from the CPRD GOLD, we performed a retrospective cohort study. CPRD GOLD contains computerized medical records of general practitioners in the United Kingdom (UK) and is formerly known as the General Practice Research Database. Currently, the database includes data on more than 13 million individuals from 678 practices in England, Northern Ireland, Scotland and Wales. The data comprises demographic information, data on lifestyle, prescription details, clinical events, specialist referrals, and hospital admissions and major outcomes. In addition, CPRD GOLD contains data on indicators of the Quality and Outcomes Framework (QOF) since 2004. The QOF is an incentive scheme for General Practitioners (GPs) in order to 
increase the quality of recording of indicators of various diseases, including diabetes mellitus. This has resulted in the recording of smoking status and body mass index (BMI) of $90-95 \%$ individuals in CPRD. For persons with diabetes, the QOF awards recent recording of variables such as $\mathrm{HbA1c}$, eGFR, BMI, and smoking status.

\section{Study population}

In order to select individuals with T2DM, we identified all persons aged 18 years or older who received at least one prescription for a non-insulin antidiabetic drug (NIAD) recorded between April $1^{\text {th }} 2004$ and August $31^{\text {th }}$ 2012. NIADs included metformin, sulphonurea derivatives, incretin agents, meglitinides, thiazolidinediones, and acarbose. The index date was defined as the date of the first NIAD prescription since the start of the study period. The study population included, therefore, both prevalent and incident NIAD users. After start of valid data collection, each NIAD user was matched with one control by sex, year of birth (within 5 years), and practice. The controls were individuals without a NIAD or insulin prescription during the whole study period. Every control was assigned the index date of its matched NIAD user. All individuals were then followed-up from their index date until the date of death, end of data collection (August $31^{\text {th }}$ 2012), the date of transfer of the person out of the practice, or the end date of data collection of the practice in CPRD, whichever came first. At baseline, individuals were excluded from the analysis if they had a history of gout, or if they had used colchicine, allopurinol, probenecid, benzbromaron, febuxostat, rasburicase, sulfinpyrazone or pegloticase before or on the index date.

\section{Exposure}

The follow-up time of the NIAD users was divided into intervals based on the length of NIAD prescriptions, i.e. for every prescription a new interval was created. This persontime was classified as "current NIAD use". After a washout period exceeding 90 days, person-time was considered "past NIAD use". When a new NIAD was prescribed, person-time was considered "current NIAD use" again. The follow-up time of controls was divided into intervals of 90 days.

\section{Study outcome and covariates}

Outcome of interest was the first-time clinical diagnosis of gout, identified using READ codes. READ codes are a set of clinical codes used in primary care in the United Kingdom for the registration of clinical diagnosis, processes of care (tests, screening, symptoms, patient administration etc.), and medication. This case definition has previously been validated by analysis of medical records and laboratory results of a sample of 38 anti-ulcer drug exposed subjects with a first-time diagnosis of gout ${ }^{14}$. 
The following variables were assessed in the period prior to the index date: sex, smoking status (never/current/past/unknown), BMI (classified according to the World Health Organization ${ }^{15}$ ), and alcohol use (yes/no/unknown). At each time interval we assessed age, eGFR, and whether individuals had a history of hypertension, underwent a renal transplantation or had a postmenopausal status/oophorectomy. In addition, the following variables were determined 6 months prior to the start of each time interval: the use of insulin, thiazide diuretics, loop diuretics, low dose aspirin ( $\leq 100 \mathrm{mg}$ ), cyclosporine, tacrolimus or statins.

\section{Statistical analysis}

All statistical analyses were performed with SAS 9.2. We estimated incidence rates (IRs) of gout between April 1, 2004 and August 31, 2012 in NIAD and non-NIAD users. IRs were calculated as the number of incident cases divided by the total number of personyears (PYs) at risk. Using time-dependent Cox proportional hazard models we estimated hazard ratios (HRs) for the risk of developing gout in NIAD users (with and without insulin use) versus controls. The age-sex adjusted hazard ratios (model 1) were first adjusted for smoking status, alcohol use, and postmenopausal status/oophorectomy (model 2). Thereafter, we adjusted for variables which theoretically may act as intermediates, i.e. BMI, eGFR, hypertension, and the use of thiazide diuretics, loop diuretics, statins, low dose aspirin $(\leq 100 \mathrm{mg})$, renal transplantation, cyclosporine, and tacrolimus (model 3). In addition, to further examine the gout risk in NIAD users, we performed subgroup analyses by $\mathrm{HbA1c}$. We classified $\mathrm{HbA1c}$ values into the following categories in order to increase comparability with a previous study ${ }^{14}:<6 \%, 6-6.9 \%$, $7-7.9 \%, 8-8.9 \%, \geq 9 \%$ and missing. All analyses were stratified by sex.

In a sensitivity analysis, the definition of gout was restricted to those individuals with a diagnosis of gout and at least one prescription for its treatment: colchicine, allopurinol, non-steroidal anti-inflammatory drug (NSAID), systemic glucocorticoid, probenecid, benzbromaron, febuxostat, rasburicase, sulfinpyrazone or pegloticase, within 14 days before or after a registration of a gout diagnosis. The earliest recording of the gout diagnosis or its treatment after the start of follow-up defined the outcome.

\section{Results}

Table 4.1 shows the baseline characteristics of the study population. Since NIAD users with insulin did not significantly differ from NIAD users without insulin (data not shown), we combined the results of these subgroups into a single NIAD users group. As a result, the cohort encompassed 221,117 NIAD users and a similar number of controls with a mean age of $60.4 \pm 15.4$ years, of whom $50.6 \%$ were women. The mean duration of follow-up was 4.3 years among NIAD users and 4.5 years among controls. On 
average, NIAD users had a higher BMI, suffered more frequently of hypertension, and more often had used statins. As compared with males, female NIAD users had a higher BMI, more often had an eGFR below $60 \mathrm{ml} / \mathrm{min} / 1.73 \mathrm{~m}^{2}$, land more often had hypertension (please see Appendix 4, Table S4.1 and S4.2). HbA1c concentrations were slightly lower in women at baseline. In addition, the differences in mean $\mathrm{BMI}$ and the proportion of individuals with an eGFR below $60 \mathrm{ml} / \mathrm{min} / 1.73 \mathrm{~m}^{2}$ in NIAD users as compared with controls was larger in women.

Table 4.1 Baseline characteristics of NIAD users and matched non-NIAD users.

\begin{tabular}{|c|c|c|}
\hline Characteristics & $\begin{array}{l}\text { NIAD users } \\
N=221,117\end{array}$ & $\begin{array}{c}\text { Non-NIAD users } \\
N=221,117\end{array}$ \\
\hline Mean follow-up time (years, SD) & $4.3 \pm 2.9$ & $4.5 \pm 2.8$ \\
\hline Females & $111,878(50.6 \%)$ & $111,878(50.6 \%)$ \\
\hline \multicolumn{3}{|l|}{ Age } \\
\hline Mean age at index date (years, SD) & $60.4 \pm 15.4$ & $60.4 \pm 15.4$ \\
\hline $18-49$ years & $51,858(23.5 \%)$ & $51,858(23.5 \%)$ \\
\hline $50-59$ years & $46,422(21.0 \%)$ & $46,422(21.0 \%)$ \\
\hline $60-69$ years & $56,055(25.4 \%)$ & $56,055(25.4 \%)$ \\
\hline $70+$ years & $66,782(30.2 \%)$ & $66,782(30.2 \%)$ \\
\hline \multicolumn{3}{|l|}{ BMI } \\
\hline Mean $\mathrm{BMI}$ at index date $\left(\mathrm{kg} / \mathrm{m}^{2}, \mathrm{SD}\right)$ & $31.2 \pm 6.7$ & $26.6 \pm 5.1$ \\
\hline$<24.9 \mathrm{~kg} / \mathrm{m}^{2}$ & $32,887(14.9 \%)$ & $78,419(35.5 \%)$ \\
\hline $25.0-29.9 \mathrm{~kg} / \mathrm{m}^{2}$ & $69.698(31.5 \%)$ & $74,742(33.8 \%)$ \\
\hline $30.0-34.9 \mathrm{~kg} / \mathrm{m}^{2}$ & $59,343(26.8 \%)$ & $29,498(13.3 \%)$ \\
\hline$\geq 35.0 \mathrm{~kg} / \mathrm{m}^{2}$ & $52,325(23.7 \%)$ & $11,902(5.4 \%)$ \\
\hline Missing & $6,864(3.1 \%)$ & $26,556(12.0 \%)$ \\
\hline \multicolumn{3}{|l|}{$\mathrm{HbA1c}$} \\
\hline$<6.0 \%$ & $2,160(1.0 \%)$ & $1,542(0.7 \%)$ \\
\hline $6.0-6.9 \%$ & $9,852(4.5 \%)$ & $1,105(0.5 \%)$ \\
\hline $7.0-7.9 \%$ & $17,622(8.0 \%)$ & $126(0.1 \%)$ \\
\hline $8.0-8.9 \%$ & $10.557(4.8 \%)$ & $12(0.0 \%)$ \\
\hline$\geq 9.0 \%$ & 16.781 (7.6\%) & $6(0.0 \%)$ \\
\hline Missing & $164,145(74.2 \%)$ & $218,326(98.7 \%)$ \\
\hline \multicolumn{3}{|l|}{ eGFR } \\
\hline$\geq 90 \mathrm{ml} / \mathrm{min} / 1.73 \mathrm{~m}^{2}$ & $38,030(17.2 \%)$ & $12,055(5.5 \%)$ \\
\hline $60-89 \mathrm{ml} / \mathrm{min} / 1.73 \mathrm{~m}^{2}$ & $84,450(38.2 \%)$ & $43,885(19.8 \%)$ \\
\hline $30-59 \mathrm{ml} / \mathrm{min} / 1.73 \mathrm{~m}^{2}$ & $29,710(13.4 \%)$ & $16,504(7.5 \%)$ \\
\hline $45-59 \mathrm{ml} / \mathrm{min} / 1.73 \mathrm{~m}^{2}$ & $22,224(10.1 \%)$ & $12,544(5.7 \%)$ \\
\hline $30-45 \mathrm{ml} / \mathrm{min} / 1.73 \mathrm{~m}^{2}$ & $6,450(2.9 \%)$ & $3,093(1.4 \%)$ \\
\hline $15-29 \mathrm{ml} / \mathrm{min} / 1.73 \mathrm{~m}^{2}$ & $1,254(0.6 \%)$ & $537(0.2 \%)$ \\
\hline$<15 \mathrm{ml} / \mathrm{min} / 1.73 \mathrm{~m}^{2}$ & $188(0.1 \%)$ & $99(0.0 \%)$ \\
\hline Missing & $67,485(30.5 \%)$ & 148,037 (66.9\%) \\
\hline \multicolumn{3}{|l|}{ Smoking status } \\
\hline Never & $111,404(50.4 \%)$ & $116,514(52.7 \%)$ \\
\hline Current & 45,797 (20.7\%) & $47,400(21.4 \%)$ \\
\hline Ex & $62,287(28.2 \%)$ & $49,782(22.5 \%)$ \\
\hline Missing & $1,629(0.7 \%)$ & $7,421(3.4 \%)$ \\
\hline
\end{tabular}


Table 4.1 (continued)

\begin{tabular}{lcc}
\hline Characteristics & NIAD users & Non-NIAD users \\
& $\mathrm{N}=221,117$ & $\mathrm{~N}=221,117$ \\
\hline Alcohol use & & \\
No & $65,912(29.8 \%)$ & $40,842(18.5 \%)$ \\
Yes & $141,204(63.9 \%)$ & $152,751(69.1 \%)$ \\
Missing & $14,001(6.3 \%)$ & $27,524(12.4 \%)$ \\
History of diseases & & \\
Hypertension & $85,541(38.7 \%)$ & $46,022(20.8 \%)$ \\
Renal failure acute & $645(0.3 \%)$ & $248(0.1 \%)$ \\
Renal failure chronic & $1,741(0.8 \%)$ & $835(0.4 \%)$ \\
Renal failure total & $2,293(1.0 \%)$ & $1,040(0.5 \%)$ \\
Postmenopausal status & $18,704(8.5 \%)$ & $21,242(9.6 \%)$ \\
Oophorectomy & $5,129(2.3 \%)$ & $4,243(1.9 \%)$ \\
Drug use six months before index date & & \\
Thiazide diuretics & $38,591(17.5 \%)$ & $26,411(11.9 \%)$ \\
Loop diuretics & $21,537(9.7 \%)$ & $10,074(4.6 \%)$ \\
Low dose aspirin & $96(0.0 \%)$ & $39(0.0 \%)$ \\
Statins & $93,729(42.4 \%)$ & $35,120(15.9 \%)$ \\
Cyclosporine & $68(0.0 \%)$ & $60(0.0 \%)$ \\
Tacrolimus & $178(0.1 \%)$ & $100(0.0 \%)$ \\
Diabetes medication six months before index date & & $n$ \\
Metformin & $55,038(24.9 \%)$ & $\mathrm{n} / \mathrm{a}$ \\
Sulfonylureaderivatives & $35,326(16.0 \%)$ & $\mathrm{n} / \mathrm{a}$ \\
Thiazolidinediones & $8,260(3.7 \%)$ & $\mathrm{n} / \mathrm{a}$ \\
Insulin & $18,089(8.2 \%)$ & $\mathrm{n} / \mathrm{a}$ \\
Incretins & $523(0.2 \%)$ & $721(0.3 \%)$ \\
Meglitinides & & \\
\hline
\end{tabular}

\section{Risk of gout in NIAD users as compared with controls}

Table 4.2 shows that current NIAD use was associated with a 1.5 -fold age- and sexadjusted increased risk of gout [HR=1.48 (95\% Cl 1.41; 1.54)] (model 1$)$. This result only slightly changed after adjustment for confounding variables in model 2, including smoking status, alcohol use, and postmenopausal status/oophorectomy $[\mathrm{HR}=1.41(95 \% \mathrm{Cl} 1.35 ; 1.47)]$. However, after full statistical adjustment, current NIAD use was no longer associated with an increased risk, but with a $27 \%$ reduced risk of gout $[\mathrm{HR}=0.73(95 \% \mathrm{Cl} 0.69 ; 0.77)]$ (model 3$)$. The following confounders were mainly responsible for this shift: $\mathrm{BMI}$, the use of statins, the use of loop diuretics, and a history of hypertension.

Sex modified the association between NIAD use and incident gout ( $p$ for interaction $<0.001$ ). Although both male and female users of NIADs had a higher age-adjusted risk of gout in comparison with their controls, the increased risk was more pronounced in women $[\mathrm{HR}=2.23(95 \% \mathrm{Cl} 2.07 ; 2.41)]$ than in men $[\mathrm{HR}=1.19(95 \% \mathrm{Cl} 1.13 ; 1.26)]$ (model 1). After full adjustments in model 3, male NIAD users had an almost $40 \%$ reduced risk of gout $[\mathrm{HR}=0.61(95 \% \mathrm{Cl} 0.58 ; 0.66)]$, whereas in female NIAD users the risk disappeared [HR=1.01 $(95 \% \mathrm{Cl} 0.92 ; 1.11)]$. 
Table 4.2 Risk of gout in NIAD users compared with controls

\begin{tabular}{lcccccc}
\hline & $\begin{array}{c}\text { Number of } \\
\text { gout events }\end{array}$ & Gout & Model 1 & Model 2 & Model 3 & $\begin{array}{c}\text { P-value for } \\
\text { interaction }\end{array}$ \\
\cline { 2 - 7 } & $\mathrm{N}=8322^{\mathrm{a}}$ & $\mathrm{IR}(/ 1000 \mathrm{PY})$ & $\mathrm{HR}(95 \% \mathrm{Cl})$ & $\mathrm{HR}(95 \% \mathrm{Cl})$ & $\mathrm{HR}(95 \% \mathrm{Cl})$ & \\
\hline $\begin{array}{l}\text { By NIAD use } \\
\text { No NIAD use }\end{array}$ & 3594 & 3.60 & Reference & Reference & Reference & \\
$\begin{array}{l}\text { Current NIAD use } \\
\text { By sex }\end{array}$ & 4476 & 5.25 & $1.48(1.41-1.54)$ & $1.41(1.35-1.47)$ & $0.73(0.69-0.77)$ \\
$\quad \begin{array}{l}\text { Males } \\
\text { Females }\end{array}$ & 2630 & 5.99 & $1.19(1.13-1.26)$ & $1.13(1.07-1.19)$ & $0.61(0.58-0.66)$ & \\
\hline
\end{tabular}

a total number of 252 gout events occurred in past NIAD users, who were part of the multivariate model in the analyses; ${ }^{b}$ reference group is no NIAD use with same sex. Model 1: adjusted for sex and age. Model 2: model 1+ additionally adjusted for smoking status, alcohol use, and postmenopausal status/oophorectomy Model 3: model 2 + additionally adjusted for BMI, eGFR, hypertension, renal transplantation, and use of low dose aspirin, statins, tacrolimus, cyclosporine, loop diuretics, and thiazide diuretics. NIAD=non-insulin antidiabetic drug; $\mathrm{IR}=$ =incidence rate; $\mathrm{PY}=$ person years; $\mathrm{HR}=$ hazard ratio; $\mathrm{Cl}=$ confidence interval

\section{Risk of gout among NIAD users by HbA1c}

Exploration of the influence of HbA1c on the risk of gout within NIAD users, showed an inverse association between higher $\mathrm{HbA1C}$ values and gout risk (Table 4.3). As compared to NIAD users with a $\mathrm{HbA} 1 \mathrm{c}<6.0 \%$, the age- and sex-adjusted risk of gout was more than $20 \%$ reduced among those with recent $\mathrm{HbA1C}$ values of $8.0-8.9 \%$ $[\mathrm{HR}=0.75(95 \% \mathrm{Cl} 0.63 ; 0.90)]$ and even almost $40 \%$ reduced among those with recent $\mathrm{HbA} 1 \mathrm{C} \geq 9.0 \%[\mathrm{HR}=0.61(95 \% \mathrm{Cl} 0.51 ; 0.74)]$. Further adjustment in models 2 and 3 gave similar results.

Subgroup analysis by sex, however, showed that higher $\mathrm{HbA} 1 \mathrm{c}$ values were inversely associated with incident gout in male, but not in female NIAD users ( $p$ for interaction $\leq 0.01$ for all categories). As compared to male NIAD users with $\mathrm{HbA} 1 \mathrm{c}<6.0 \%$, the ageadjusted risk of gout was more than $30 \%$ reduced among those with $\mathrm{HbA} 1 \mathrm{c}$ values of 8.0-8.9\% [HR=0.63 $(95 \% \mathrm{Cl} 0.50 ; 0.79)]$ and even 50\% reduced among those with $\mathrm{HbA} 1 \mathrm{C} \geq 9.0 \%$ [HR=0.50 (95\% Cl 0.39; 0.63)] (Table 4.3). Further adjustment in model 2 and 3 gave similar results.

\section{Sensitivity analysis}

After changing the definition of gout from a READ code for gout to a READ code for gout and a prescription for gout-specific medication, the total number of gout events decreased by approximately $25 \%$. Notwithstanding, after full adjustments, NIAD users still had a decreased risk of developing gout [HR=0.67 (95\% $\mathrm{Cl} 0.63 ; 0.72)]$ as compared with controls. Men had a $40 \%$ reduced risk of gout [HR=0.58 (95\% Cl 0.54; 0.63)] whereas this was not the case in women $[\mathrm{HR}=0.92(95 \% \mathrm{Cl} 0.83 ; 1.02)]$. Results were similar for the subgroups analyses according to $\mathrm{HbA} 1 \mathrm{c}$. 


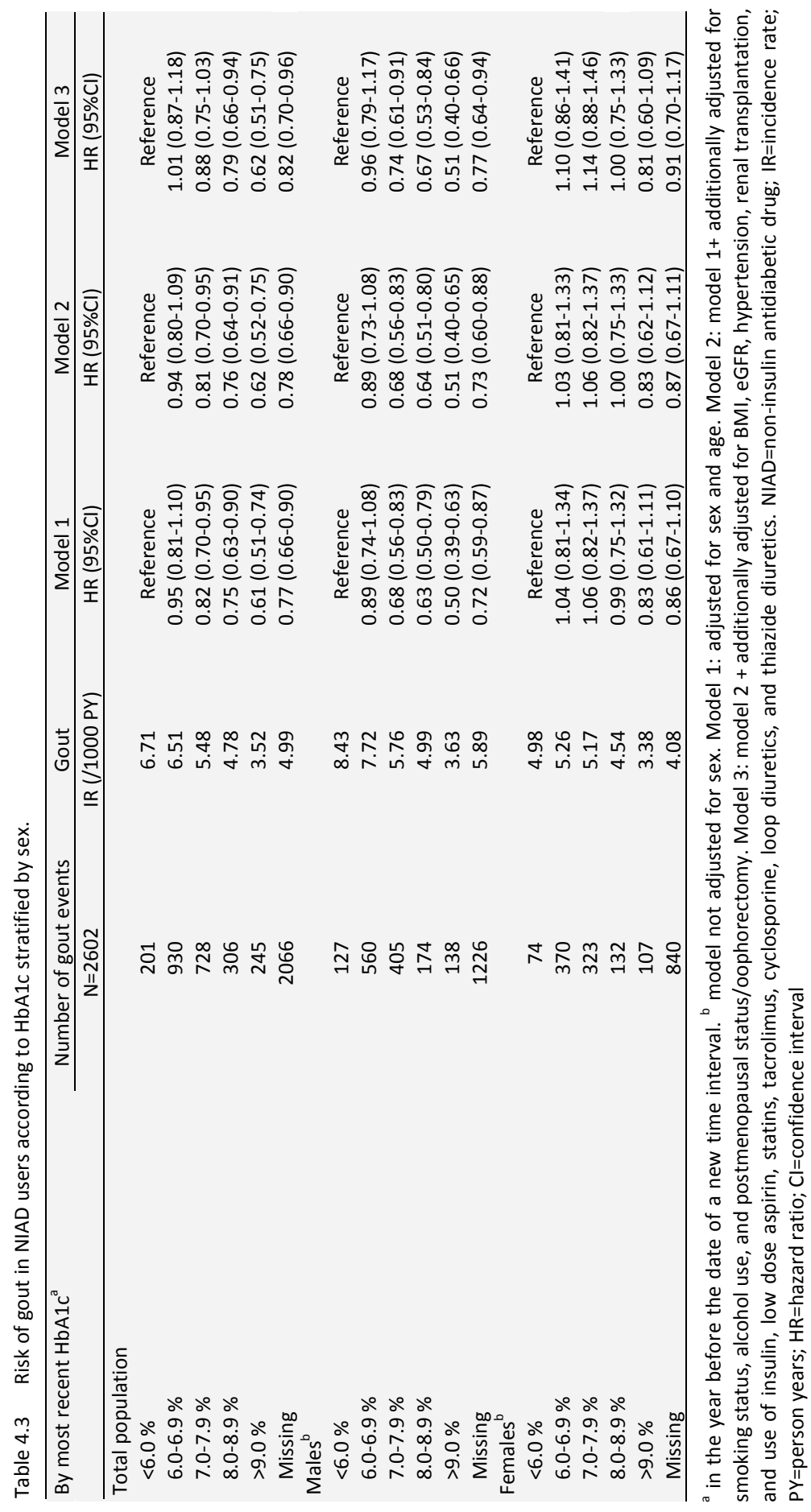




\section{Discussion}

The relationship between T2DM and gout is complex. On the one hand, individuals with T2DM may be at an increased risk of gout, possibly due to T2DM-associated comorbidities. On the other hand, the decreased inflammatory response and the uricosuric effect of glycosuria might protect against the development of gout. This study showed that individuals with T2DM, especially women, had a strongly increased risk to develop gout as compared with controls. However, this risk can be fully attributed to classic risk factors for gout (high BMI, hypertension, reduced renal function). Interestingly, when taking into account these factors, male but not female individuals with T2DM were in fact at lower risk to develop gout as compared to controls. The protective effect of T2DM in men could be attributed to high HbA1c levels.

Our main finding of a $40 \%$ increased risk of gout in individuals with T2DM supports the formerly identified higher prevalence of gout in these individuals as compared with controls $^{2,3}$. Classic risk factors for gout, which may partly mediate the association between T2DM and gout, are likely responsible for this additional risk. When accounting for gout risk factors such as hypertension, we found that individuals with T2DM had a $27 \%$ lower risk to develop gout. This finding is in line with the THIN study 4 . Note that comparison of our unadjusted results with the THIN study was hampered due to the direct adjustment for the number of GP visits in the latter. The number of GP visits is a very non-specific covariate and may reflect the presence or severity of comorbidities, such as hypertension and kidney failure. We want to emphasize that it is difficult to disentangle the role of variables in the association between T2DM and gout. Factors may theoretically acts as a confounder, a mediator, or both. Careful assessment of the respective role may provide a more comprehensive picture of the association between T2DM and gout and can prevent confounded conclusions.

The role of increasing $\mathrm{HbA1c}$ concentrations to explain the reduced risk of gout in individuals with T2DM has been reported in two other studies ${ }^{5,16}$. The risk of gout was almost $40 \%$ reduced among individuals with $\mathrm{T} 2 \mathrm{DM}$ having an $\mathrm{HbA} 1 \mathrm{c} \geq 9 \%$, as compared to those with $\mathrm{HbA} 1 \mathrm{c}$ values below $6.0 \%$. The inverse association between $\mathrm{HbA} 1 \mathrm{c}$ and incident gout may be caused by the uricosuric effect of glycosuria, which occurs when the blood glucose level rise above $\sim 10 \mathrm{mmol} / /(\mathrm{HbA} 1 \mathrm{c} \approx 8 \%)^{11}$. Osmotic diuresis and/or higher filtration rate, induced by glycosuria, may therefore play an important role ${ }^{17}$. An alternative mechanism relates to a newly discovered urate transporter, i.e. hUAT ${ }^{18}$. hUAT can be activated by sugars and could, at least partially, explain low uric acid concentrations in the presence of high glucose concentrations. However, the level of evidence for a role of hUAT in the renal urate transport is still weak.

Of interest are our sex-stratified analyses of the association between T2DM and $\mathrm{HbA1C}$ on the one hand and incident gout on the other. First, we showed that the increased risk of gout was more pronounced in women than in men. In the present 
study, females with T2DM had a higher prevalence of classic risk factors for gout as compared with their male counterparts. Also, the risk difference between individuals with T2DM and controls with regard to gout risk factors such as BMI and the proportion of individuals with an eGFR<60 ml/min $/ 1.73 \mathrm{~m}^{2}$, was greater in women than it was in men. Less favourable CVD risk profiles in female than in male individuals with T2DM have been identified by prior studies ${ }^{19-21}$. Second, we showed that after adjustment for classic risk factors there was no difference in gout risk between women with T2DM and controls, while the risk of gout in men was lower. This difference may be explained by a sex difference in the association between high $\mathrm{HbA1C}$ and incident gout in individuals with T2DM; a significant association between high $\mathrm{HbA1C}$ and a decreased risk of gout in men, but no association in women. It is unclear why HbA1c was only associated with a decreased gout risk in men. A possible hypothesis for this sex difference is a different effect of glucose on uric acid reabsorption in the kidney in men and women. The effect of sex on the association between $\mathrm{HbA1c}$ and incident gout clearly needs further exploration.

Our study had several strengths. First, the findings of this study are likely to be generalizable to the general population as it was performed in a large UK general practice database. Second, a cohort design was used, which is the best observational design for determining the incidence of a certain condition. Third, we used data from 2004 onwards. HbA1c and eGFR recordings have improved dramatically since 2004, because of GP's incentives for routinely recording these data under the QOF. Finally, a validated algorithm (READ codes) for identifying a first-time diagnosis of gout was used $^{14}$. Our study had also several limitations. Despite a substantial number of missing values at baseline, $\mathrm{HbA1c}$ was regularly recorded for the majority of the individuals with T2DM over time. A detection bias may have occurred because persons with T2DM having higher HbA1c values may more often visit their GP as compared to those who are well-controlled. This could increase the likelihood of being diagnosed with gout. However, we found that in individuals with high HbA1c levels the risk of gout is actually lower. Furthermore, we included only persons with T2DM who were treated with NIADs or insulin and therefore our results are not applicable to individuals with T2DM who are not treated with NIADs or insulin.

In conclusion, our data show that individuals with T2DM are at an increased risk of gout, and that this association is stronger in women. The increased risk was not caused by diabetes itself, but by the presence of comorbidities such as hypertension and reduced renal function, which may counterbalance the risk reducing effect of $\mathrm{HbA1c}$ in individuals with T2DM. 


\section{References}

1. Harrold L, Mazor K, Peterson D, Naz N, Firneno C, Yood R. Patients' knowledge and beliefs concerning gout and its treatment: a population based study. BMC Musculoskelet Disord. 2012;13:180.

2. Anagnostopoulos I, Zinzaras E, Alexiou I, et al. The prevalence of rheumatic diseases in central Greece: a population survey. BMC Musculoskelet Disord. 2010;11:98.

3. Suppiah R, Dissanayake A, Dalbeth N. High prevalence of gout in patients with Type 2 diabetes: male sex, renal impairment, and diuretic use are major risk factors. N Z Med J. 2008;121:43-50.

4. Garcia Rodriguez L, Cea Soriano L, Choi H. Impact of diabetes against the future risk of developing gout. Ann Rheum Dis. 2010;69:2090-2094.

5. Bruderer SG, Bodmer M, Jick SS, Meier CR. Poorly controlled type 2 diabetes mellitus is associated with a decreased risk of incident gout: a population-based case-control study. Ann Rheum Dis. 2014;Epub ahead of print (doi:10.1136/annrheumdis-2014-205337).

6. Hu G, Jousilahti P, Tuomilehto J. Joint effects of history of hypertension at baseline and type 2 diabetes at baseline and during follow-up on the risk of coronary heart disease. Eur Heart J. 2007;28:3059-3066.

7. Pavkov ME, Knowler WC, Lemley KV, Mason CC, Myers BD, Nelson RG. Early renal function decline in type 2 diabetes. Clin J Am Soc Nephrol. 2012;7:78-84.

8. Krishnan E. Reduced glomerular function and prevalence of gout: NHANES 2009-10. PloS one. 2012; 7:e50046.

9. McAdams-DeMarco MA, Maynard JW, Baer AN, Coresh J. Hypertension and the risk of incident gout in a population-based study: the atherosclerosis risk in communities cohort. J Clin Hypertens (Greenwich). 2012;14:675-679.

10. Tuomilehto J, Zimmet P, Wolf E, Taylor R, Ram P, King H. Plasma uric acid level and its association with diabetes mellitus and some biologic parameters in a biracial population of Fiji. Am J Epidemiol. 1988;127:321-336.

11. Cook D, Shaper A, THelle D, Whitehead T. Serum uric acid, serum glucose and diabetes: relationships in a population study. Postgrad Med J. 1986;62:1001-1006.

12. Choi HK, Ford ES. Haemoglobin A1c, fasting glucose, serum C-peptide and insulin resistance in relation to serum uric acid levels: the Third National Health and Nutrition Examination Survey. Rheumatology (Oxford). 2008;47:713-717.

13. Meisinger C, Thorand B, Schneider A, Stieber J, Doring A, Lowel H. Sex differences in risk factors for incident type 2 diabetes mellitus: The MONICA Augsburg Cohort study. Arch Intern Med. 2002;162 82-89.

14. Meier CR, Jick H. Omeprazole, other antiulcer drugs and newly diagnosed gout. Br J Clin Pharmacol. 1997;44:175-178.

15. Staub K, Ruhli FJ, Woitek U, Pfister C. BMI distribution/social stratification in Swiss conscripts from 1875 to present. Eur J Clin Nutr. 2010;64:335-340.

16. Liu Q, Gamble G, Pickering K, Morton S, Dalbeth N. Prevalence and clinical factors associated with gout in patients with diabetes and prediabetes. Rheumatology (Oxford, England). 2012;51:757-759.

17. Gilbert RE. Sodium-glucose linked transporter-2 inhibitors: potential for renoprotection beyond blood glucose lowering? Kidney Int. 2013; Epub ahead of print (doi: 10.1038/ki.2013.451).

18. Lipkowitz MS. Regulation of uric acid excretion by the kidney. Curr Rheumatol Rep. 2012;14:179-188.

19. Penno G, Solini A, Bonora E, et al. Gender differences in cardiovascular disease risk factors, treatments and complications in patients with type 2 diabetes: the RIACE Italian multicentre study. $J$ Int Med. 2013;274:176-191.

20. Gouni-Berthold I, Berthold HK, Mantzoros CS, Bohm M, Krone W. Sex disparities in the treatment and control of cardiovascular risk factors in type 2 diabetes. Diabetes Care. 2008;31:1389-1391.

21. Huxley R, Barzi F, Woodward M. Excess risk of fatal coronary heart disease associated with diabetes in men and women: meta-analysis of 37 prospective cohort studies. BMJ. 2006;332:73-78. 


\section{Appendix 4}

Supplemental tables 
Chapter 4 
Table S4.1 Baseline characteristics of male NIAD users and matched male non-NIAD users.

\begin{tabular}{|c|c|c|}
\hline Characteristics & $\begin{array}{l}\text { NIAD users } \\
N=109,239\end{array}$ & $\begin{array}{c}\text { Non-NIAD users } \\
\mathrm{N}=109,239\end{array}$ \\
\hline Mean follow-up time (years, SD) & $4.4 \pm 2.9$ & $4.5 \pm 2.8$ \\
\hline \multicolumn{3}{|l|}{ Age } \\
\hline Mean age at index date (years, SD) & $60.8 \pm 13.1$ & $60.8 \pm 13.1$ \\
\hline $18-49$ years & $22,445(20.5 \%)$ & $22,445(20.5 \%)$ \\
\hline $50-59$ years & $26,581(24.3 \%)$ & $26,581(24.3 \%)$ \\
\hline $60-69$ years & 30,659 (28.1\%) & $30,659(28.1 \%)$ \\
\hline $70+$ years & $29,554(27.1 \%)$ & $29,554(27.1 \%)$ \\
\hline \multicolumn{3}{|l|}{ BMI } \\
\hline Mean $\mathrm{BMI}$ at index date $\left(\mathrm{kg} / \mathrm{m}^{2}, \mathrm{SD}\right)$ & $30.4 \pm 5.8$ & $26.8 \pm 4.4$ \\
\hline$<24.9 \mathrm{~kg} / \mathrm{m}^{2}$ & $16,025(14.7 \%)$ & $33,086(30.3 \%)$ \\
\hline $25.0-29.9 \mathrm{~kg} / \mathrm{m}^{2}$ & $40,094(36.7 \%)$ & $41,602(38.1 \%)$ \\
\hline $30.0-34.9 \mathrm{~kg} / \mathrm{m}^{2}$ & $30,813(28.2 \%)$ & $14,444(13.2 \%)$ \\
\hline$\geq 35.0 \mathrm{~kg} / \mathrm{m}^{2}$ & $19,713(18.0 \%)$ & 4,047 (3.7\%) \\
\hline Missing & $2,594(2.4 \%)$ & $16,060(14.7 \%)$ \\
\hline \multicolumn{3}{|l|}{$\mathrm{HbA1c}$} \\
\hline$<6.0 \%$ & $901(0.8 \%)$ & $772(0.7 \%)$ \\
\hline $6.0-6.9 \%$ & $4,782(4.4 \%)$ & $592(0.5 \%)$ \\
\hline $7.0-7.9 \%$ & $9,038(8.3 \%)$ & $72(0.1 \%)$ \\
\hline $8.0-8.9 \%$ & $5,741(5.3 \%)$ & $6(0.0 \%)$ \\
\hline$\geq 9.0 \%$ & $9,777(9.0 \%)$ & $4(0.0 \%)$ \\
\hline Missing & 79,000 (72.3\%) & 107,793 (98.7\%) \\
\hline \multicolumn{3}{|l|}{ eGFR } \\
\hline$\geq 90 \mathrm{ml} / \mathrm{min} / 1.73 \mathrm{~m}^{2}$ & $22,303(20.4 \%)$ & 6,463 (5.9\%) \\
\hline $60-89 \mathrm{ml} / \mathrm{min} / 1.73 \mathrm{~m}^{2}$ & 44,420 (40.7\%) & $22,073(20.2 \%)$ \\
\hline $30-59 \mathrm{ml} / \mathrm{min} / 1.73 \mathrm{~m}^{2}$ & $10,246(9.4 \%)$ & $5,782(5.3 \%)$ \\
\hline $45-59 \mathrm{ml} / \mathrm{min} / 1.73 \mathrm{~m}^{2}$ & $7,861(7.2 \%)$ & $4,463(4.1 \%)$ \\
\hline $30-45 \mathrm{ml} / \mathrm{min} / 1.73 \mathrm{~m}^{2}$ & $2,002(1.8 \%)$ & 985 (0.9\%) \\
\hline $15-29 \mathrm{ml} / \mathrm{min} / 1.73 \mathrm{~m}^{2}$ & $468(0.4 \%)$ & $203(0.2 \%)$ \\
\hline$<15 \mathrm{ml} / \mathrm{min} / 1.73 \mathrm{~m}^{2}$ & 91 (0.1\%) & 55 (0.1\%) \\
\hline Missing & $31,711(29.0 \%)$ & $74,663(68.3 \%)$ \\
\hline \multicolumn{3}{|l|}{ Smoking status } \\
\hline Never & 44,719 (40.9\%) & $48,303(44.2 \%)$ \\
\hline Current & $25,373(23.2 \%)$ & $26,009(23.8 \%)$ \\
\hline Ex & $38,446(35.2 \%)$ & $29,535(27.0 \%)$ \\
\hline Missing & 701 (0.6\%) & $5,392(4.9 \%)$ \\
\hline \multicolumn{3}{|l|}{ Alcohol use } \\
\hline No & $24,002(22.0 \%)$ & $13,965(12.8 \%)$ \\
\hline Yes & $79,540(72.8 \%)$ & $79,869(73.1 \%)$ \\
\hline Missing & $5,697(5.2 \%)$ & $15,405(14.1 \%)$ \\
\hline \multicolumn{3}{|l|}{ History of diseases } \\
\hline Hypertension & $41,153(37.7 \%)$ & $21,062(19.3 \%)$ \\
\hline Renal failure acute & $349(0.3 \%)$ & $146(0.1 \%)$ \\
\hline Renal failure chronic & $938(0.9 \%)$ & $474(0.4 \%)$ \\
\hline Renal failure total & $1,232(1.1 \%)$ & $591(0.5 \%)$ \\
\hline
\end{tabular}


Table S4.1 (continued)

\begin{tabular}{lcc}
\hline Characteristics & NIAD users & Non-NIAD users \\
& $\mathrm{N}=109,239$ & $\mathrm{~N}=109,239$ \\
\hline Drug use six months before index date & & \\
Thiazide diuretics & $16,525(15.1 \%)$ & $10,307(9.4 \%)$ \\
Loop diuretics & $8,816(8.1 \%)$ & $3,802(3.5 \%)$ \\
Low dose aspirin & $49(0.0 \%)$ & $23(0.0 \%)$ \\
Statins & $49,356(45.2 \%)$ & $19,620(18.0 \%)$ \\
Cyclosporine & $54(0.0 \%)$ & $31(0.0 \%)$ \\
Tacrolimus & $90(0.1 \%)$ & $90(0.1 \%)$ \\
Diabetes medication six months before index date & & \\
Metformin & $27,878(25.5 \%)$ & $\mathrm{n} / \mathrm{a}$ \\
Sulfonylureaderivatives & $4,325(4.0 \%)$ & $\mathrm{n} / \mathrm{a}$ \\
Thiazolidinediones & $18,860(17.3 \%)$ & $\mathrm{n} / \mathrm{a}$ \\
Insulin & $8,772(8.0 \%)$ & $\mathrm{n} / \mathrm{a}$ \\
Incretins & $274(0.3 \%)$ & $\mathrm{n} / \mathrm{a}$ \\
Meglitinides & $380(0.3 \%)$ & \\
\hline
\end{tabular}

Table S4.2 Baseline characteristics of female NIAD users and matched female non-NIAD users.

\begin{tabular}{|c|c|c|}
\hline Characteristics & $\begin{array}{l}\text { NIAD users } \\
\mathrm{N}=111,878\end{array}$ & $\begin{array}{c}\text { Non-NIAD users } \\
N=111,878\end{array}$ \\
\hline Mean follow-up time (years, SD) & $4.4 \pm 2.9$ & $4.5 \pm 2.8$ \\
\hline \multicolumn{3}{|l|}{ Age } \\
\hline Mean age at index date (years, SD) & $59.9 \pm 17.3$ & $59.9 \pm 17.3$ \\
\hline $18-49$ years & $29,413(26.3 \%)$ & $29,413(26.3 \%)$ \\
\hline $50-59$ years & $19,841(17.7 \%)$ & $19,841(17.7 \%)$ \\
\hline $60-69$ years & $25,396(22.7 \%)$ & $25,396(22.7 \%)$ \\
\hline $70+$ years & $37,228(33.3 \%)$ & $37,228(33.3 \%)$ \\
\hline \multicolumn{3}{|l|}{$\mathrm{BMI}$} \\
\hline Mean $\mathrm{BMI}$ at index date $\left(\mathrm{kg} / \mathrm{m}^{2}, \mathrm{SD}\right)$ & $32.0 \pm 7.4$ & $26.5 \pm 5.6$ \\
\hline$<24.9 \mathrm{~kg} / \mathrm{m}^{2}$ & $16,862(15.1 \%)$ & $45,333(40.5 \%)$ \\
\hline $25.0-29.9 \mathrm{~kg} / \mathrm{m}^{2}$ & $29,604(26.5 \%)$ & $33,140(29.6 \%)$ \\
\hline $30.0-34.9 \mathrm{~kg} / \mathrm{m}^{2}$ & $28,530(25.5 \%)$ & $15,054(13.5 \%)$ \\
\hline$\geq 35.0 \mathrm{~kg} / \mathrm{m}^{2}$ & $32,612(29.1 \%)$ & $7,855(7.0 \%)$ \\
\hline Missing & $4,270(3.8 \%)$ & $10,496(9.4 \%)$ \\
\hline \multicolumn{3}{|l|}{$\mathrm{HbA1c}$} \\
\hline$<6.0 \%$ & $1,259(1.1 \%)$ & $770(0.7 \%)$ \\
\hline $6.0-6.9 \%$ & $5,070(4.5 \%)$ & $513(0.5 \%)$ \\
\hline $7.0-7.9 \%$ & $8,584(7.7 \%)$ & $54(0.0 \%)$ \\
\hline $8.0-8.9 \%$ & $4,816(4.3 \%)$ & $6(0.0 \%)$ \\
\hline$\geq 9.0 \%$ & $7,004(6.3 \%)$ & $2(0.0 \%)$ \\
\hline Missing & $85,145(76.1 \%)$ & $110,533(98.8 \%)$ \\
\hline \multicolumn{3}{|l|}{ eGFR } \\
\hline$\geq 90 \mathrm{ml} / \mathrm{min} / 1.73 \mathrm{~m}^{2}$ & 15,727 (14.1\%) & $5,592(5.0 \%)$ \\
\hline $60-89 \mathrm{ml} / \mathrm{min} / 1.73 \mathrm{~m}^{2}$ & $40,030(35.8 \%)$ & $21,812(19.5 \%)$ \\
\hline $30-59 \mathrm{ml} / \mathrm{min} / 1.73 \mathrm{~m}^{2}$ & $19,464(17.4 \%)$ & $10,722(9.6 \%)$ \\
\hline $45-59 \mathrm{ml} / \mathrm{min} / 1.73 \mathrm{~m}^{2}$ & $14,363(12.8 \%)$ & $8,081(7.2 \%)$ \\
\hline $30-45 \mathrm{ml} / \mathrm{min} / 1.73 \mathrm{~m}^{2}$ & $4,448(4.0 \%)$ & $2,108(1.9 \%)$ \\
\hline $15-29 \mathrm{ml} / \mathrm{min} / 1.73 \mathrm{~m}^{2}$ & $786(0.7 \%)$ & $334(0.3 \%)$ \\
\hline$<15 \mathrm{ml} / \mathrm{min} / 1.73 \mathrm{~m}^{2}$ & $97(0.1 \%)$ & $44(0.0 \%)$ \\
\hline Missing & $35,774(32.0 \%)$ & $73,374(65.6 \%)$ \\
\hline
\end{tabular}


Table S4.2 (continued)

\begin{tabular}{|c|c|c|}
\hline Characteristics & $\begin{array}{l}\text { NIAD users } \\
N=111,878\end{array}$ & $\begin{array}{c}\text { Non-NIAD users } \\
N=111,878\end{array}$ \\
\hline \multicolumn{3}{|l|}{ Smoking status } \\
\hline Never & 66,685 (59.6\%) & $68,211(61.0 \%)$ \\
\hline Current & $20,424(18.3 \%)$ & $21,391(19.1 \%)$ \\
\hline Ex & $23,841(21.3 \%)$ & $20,247(18.1 \%)$ \\
\hline Missing & $928(0.8 \%)$ & $2,029(1.8 \%)$ \\
\hline \multicolumn{3}{|l|}{ Alcohol use } \\
\hline No & $41,910(37.5 \%)$ & $26,877(24.1 \%)$ \\
\hline Yes & $61,664(55.1 \%)$ & $72,882(65.1 \%)$ \\
\hline Missing & $8,304(7.4 \%)$ & $12,119(10.8 \%)$ \\
\hline \multicolumn{3}{|l|}{ History of diseases } \\
\hline Hypertension & $44,388(39.7 \%)$ & $24,960(22.3 \%)$ \\
\hline Renal failure acute & $296(0.3 \%)$ & $102(0.1 \%)$ \\
\hline Renal failure chronic & $803(0.7 \%)$ & $361(0.3 \%)$ \\
\hline Renal failure total & $1,061(0.9 \%)$ & $449(0.4 \%)$ \\
\hline Postmenopausal status & $18,704(16.7 \%)$ & $21,242(19.0 \%)$ \\
\hline Oophorectomy & $5,129(4.6 \%)$ & $4,243(3.8 \%)$ \\
\hline \multicolumn{3}{|c|}{ Drug use six months before index date } \\
\hline Thiazide diuretics & $22,066(19.7 \%)$ & $16,104(14.4 \%)$ \\
\hline Loop diuretics & $12,721(11.4 \%)$ & $6,272(5.6 \%)$ \\
\hline Low dose aspirin & $47(0.0 \%)$ & $16(0.0 \%)$ \\
\hline Statins & $44,373(39.7 \%)$ & $15,500(13.9 \%)$ \\
\hline Cyclosporine & $53(0.0 \%)$ & $44(0.0 \%)$ \\
\hline Tacrolimus & $88(0.1 \%)$ & $50(0.0 \%)$ \\
\hline \multicolumn{3}{|c|}{ Diabetes medication 6 months before index date } \\
\hline Metformin & $27,160(24.3 \%)$ & $\mathrm{n} / \mathrm{a}$ \\
\hline Sulfonylureaderivatives & $3,935(3.5 \%)$ & $\mathrm{n} / \mathrm{a}$ \\
\hline Thiazolidinediones & $16,466(14.7 \%)$ & $\mathrm{n} / \mathrm{a}$ \\
\hline Insulin & $9,317(8.3 \%)$ & $\mathrm{n} / \mathrm{a}$ \\
\hline Incretins & $249(0.2 \%)$ & $\mathrm{n} / \mathrm{a}$ \\
\hline Meglitinides & $341(0.3 \%)$ & $\mathrm{n} / \mathrm{a}$ \\
\hline
\end{tabular}


The role of uric acid in the aetiology of
cardiovascular disease The role of uric acid in the aetiology of
cardiovascular disease

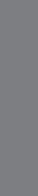 \\ II}

Part II

The role of uric acid in the aetiology of
cardiovascular disease

f

(2)

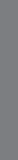

更

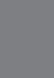

(1)

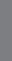




\section{Chapter}

The cross-sectional association between uric acid and atherosclerosis, and the role of low-grade inflammation: the CODAM study

J.M.A. Wijnands, A. Boonen, P.C. Dagnelie, M.M.J. van Greevenbroek, C.J.H. van der Kallen, I. Ferreira, C.G. Schalkwijk, E.J.M Feskens, C.D.A. Stehouwer,

Sj. van der Linden, I.C.W. Arts Rheumatology. 2014; Epub ahead of print 


\section{Abstract}

\section{Objective}

The aims of this study were to investigate (1) associations between uric acid and prevalent cardiovascular disease (CVD), ankle-arm blood pressure index (AAIx) and carotid intima-media thickness (CIMT) in the total population and in predefined subgroups according to glucose metabolism status and (2) the extent to which these associations are explained by low-grade inflammation.

\section{Methods}

Cross-sectional analyses were conducted among 530 individuals $(60.6 \%$ men, mean age $58.9 \pm 6.9 \mathrm{yrs}, 52.6 \%$ normal glucose metabolism (NGM)) at increased risk of CVD from the Cohort of Diabetes and Atherosclerosis Maastricht study. A low-grade inflammation score was computed by averaging the $z$-scores of eight inflammation markers (CRP, TNF- $\alpha$, IL-6, IL-8, serum amyloid A, soluble intercellular adhesion molecule 1 (sICAM-1), ceruloplasmin and haptoglobin).

\section{Results}

After adjustment for traditional CVD risk factors, plasma uric acid (per SD of $81 \mu \mathrm{mol} / \mathrm{l}$ ) was associated with CVD in individuals with NGM [odds ratio $(\mathrm{OR})=1.66(95 \% \mathrm{Cl} 1.06 ; 2.58)$ ], but not with disturbed glucose metabolism (DGM) [OR=0.81 (95\% Cl 0.55; 1.19), $p$ for interaction=0.165]. Uric acid was associated with CIMT in the total population $[\beta=0.024(95 \% \mathrm{Cl} 0.007 ; 0.042)]$ and slightly more strongly in individuals with $\mathrm{NGM}[\beta=0.030(95 \% \mathrm{Cl} 0.006 ; 0.054)]$ than DGM $[\beta=0.018(95 \% \mathrm{Cl}-0.009 ; 0.044), p$ for interaction $=0.443]$. There was no association between uric acid and AAlx in any group ( $p$ for interaction $=0.058$ ). Uric acid was associated with low-grade inflammation in the total population $[\beta=0.074(95 \% \mathrm{Cl} 0.013 ; 0.134), p$ for interaction=0.737]. Adding low-grade inflammation to the models did not attenuate any of the associations.

\section{Conclusion}

The associations for uric acid with CIMT, and with CVD in NGM only, were not explained by lowgrade inflammation. A difference in the strength of the associations between individuals with NGM and DGM was suggested. 


\section{Introduction}

Hyperuricaemia results from the increased production and/or decreased excretion of uric acid and is a major risk factor for gout ${ }^{1}$. Research has also focused on the role of hyperuricaemia in the pathophysiology of cardiovascular diseases (CVD), however the association remains controversial. A meta-analysis of the association between hyperuricaemia and coronary heart disease (CHD) incidence and mortality showed significant, although modest, positive associations independent of other risk factors for $\mathrm{CHD}^{2}$.

Several biological mechanisms have been proposed that may explain the positive, i.e. risk increasing, association between uric acid and CVD. Uric acid can inhibit nitric oxide, which can decrease endothelium-dependent vasorelaxation and subsequent endothelial dysfunction ${ }^{3}$. Moreover, uric acid stimulates the renin-angiotensin system, vascular smooth muscle cell proliferation, and angiotensin II production ${ }^{4}$. Also, inflammation has been put forward as a possible explanation for the association between uric acid and cardiovascular risk factors ${ }^{5}$.

In vitro studies have shown that uric acid contributes to low-grade inflammation ${ }^{6,7}$. In cross-sectional and longitudinal epidemiological studies, serum uric acid was also positively associated with several inflammatory biomarkers ${ }^{8-11}$. Although there is evidence of a relation between uric acid, low-grade inflammation and CVD, low-grade inflammation as an underlying pathway for the association between uric acid and CVD has been studied only sparsely ${ }^{12,13}$.

Interestingly, some evidence suggests that glucose metabolism status affects the association between uric acid and $\mathrm{CVD}^{14}$. The interaction may be caused by the increased uric acid reabsorption due to hyperinsulinaemia, as well as by the bell-shaped association between glucose levels and uric acid ${ }^{15,16}$. This article focuses on the involvement of low-grade inflammation in the associations between uric acid and several measures of atherosclerosis [CVD, ankle-arm blood pressure index (AAIx) and carotid intima-media thickness (CIMT)]. The subjects were part of the Cohort of Diabetes and Atherosclerosis Maastricht (CODAM) study. CODAM is composed of individuals with elevated CVD risk and includes participants with normal glucose metabolism (NGM), impaired glucose metabolism (IGM), and type 2 diabetes mellitus (T2DM), allowing stratification of the analyses according to glucose metabolism status.

\section{Methods}

\section{Study population and design}

The present study reports on cross-sectional analyses of baseline data from CODAM, an ongoing prospective cohort study in the Netherlands ${ }^{17}$. Between 1999 and 2001, 
individuals with an elevated risk for CVD and T2DM were selected from an existing large population-based cohort based on Caucasian ethnicity, aged above 40 years, and at least one of the following: BMI $>25 \mathrm{~kg} / \mathrm{m}^{2}$, positive family history for T2DM, history of gestational diabetes, use of antihypertensive medication, postprandial glucose $>6.0 \mathrm{mmol} / \mathrm{l}$, or glucosuria ${ }^{17}$. In total 574 individuals were included and were extensively characterized with regard to their metabolic, cardiovascular and lifestyle risk profiles during two visits at the University Metabolic Unit. All participants gave written informed consent according to the Declaration of Helsinki and the study was approved by the Medical Ethics Committee of the University Hospital Maastricht and Maastricht University. For the present study we excluded individuals with missing data on serum uric acid $(\mathrm{N}=4)$, one or more of the low-grade inflammation markers $(\mathrm{N}=3)$, and/or other potential confounders $(\mathrm{N}=28)$. Individuals on any uric-acid-lowering drug were excluded $(\mathrm{N}=9)$. The excluded individuals all used allopurinol. In addition, individuals with an $A A \mid x \geq 1.5$, indicating probable arterial calcification $(\mathrm{N}=3)$, were excluded. Therefore analyses on the association between uric acid and CVD or AAIx included 530 individuals and analyses on the association between uric acid and CIMT included 493 of these individuals (37 individuals were missing CIMT data).

\section{Laboratory measurements}

Individuals were asked to stop their lipid-lowering medication 14 days prior to blood sampling and all other medication on the day before. After an overnight fast, venous blood samples were collected. Fasting glucose, fasting insulin, creatinine, total cholesterol, high-density cholesterol, and triglycerides were obtained as described elsewhere ${ }^{18,19}$. Uric acid concentrations were measured in EDTA plasma with an enzymatic colorimetric test (Roche Diagnostics, Almere, The Netherlands) by an automatic analyzer (Hitachi 912) at RIVM (National Institute for Public Health and the Environment, Bilthoven, The Netherlands). Eight markers of low-grade inflammation were measured: CRP, TNF- $\alpha$, IL-6, IL-8, serum amyloid A (SAA), soluble intercellular adhesion molecule 1 (sICAM-1), ceruloplasmin and haptoglobin. These markers were selected because of previous associations with coronary artery disease, AAlx ${ }^{18}$ and $\mathrm{CIMT}^{20}$. CRP, IL-6, SAA, and SICAM were measured by single biomarker techniques ${ }^{18}$ and with a multi-array (MA) detection system ${ }^{21}$. The measures of the single biomarker techniques were realigned to the MA measures as described elsewhere ${ }^{21}$. IL-8 and TNF- $\alpha$ were determined in EDTA plasma on a MA detection system based on electrochemiluminescence technology (SECTOR Imager 2400, Meso Scale Discovery, Rockville, MD, USA). Haptoglobin and ceruloplasmin were measured in serum using Tina-quant haptoglobin assay (haptoglobin) and immunoturbidimetric assay (ceruloplasmin) (Roche Diagnostics) on an automatic analyser. 


\section{Outcomes}

Systolic blood pressures were measured with a standard Doppler device (Mini Dopplex D900, E-Medical, Harmelen, The Netherlands) as described elsewhere ${ }^{18}$. AAlx was calculated for each leg by dividing the highest ankle pressure by the highest brachial pressure. The lowest AAlx of either leg was used in the analyses. CIMT was measured with an ultrasound scanner (Ultramark 4+, Advance Technology Laboratories, Bothel, WA, USA) equipped with a 7.5-MHz linear array probe. An acquisition system and vessel wall movement detector software system was used (Wall Track System 2, Pie Medical, Maastricht, The Netherlands). Based on the radiofrequency signals of the posterior wall, the distance from the leading edge interface between lumen and intima to the leading edge interface between media and adventitia was calculated automatically as the IMT complex. All measurements were repeated up to seven times at both the left and right common carotid artery. The median value of the consecutive measurements on each side was used in the analyses. Higher CIMT values and lower AAIx are indicative of a higher level of atherosclerosis.

Prevalent CVD was defined as self-reported myocardial infarction, stroke, bypass surgery of the coronary arteries, coronary angioplasty, non-traumatic limb amputation, an AAl $x<0.9$ or signs of myocardial infarction or ischemia on a 12-lead electrocardiogram (Minnesota codes 1-1 to 1-3, 4-1 to 4-3, 5-1 to 5-3 or 7-1).

\section{Other covariates}

Body mass index, waist circumference, and blood pressure were measured as previously described ${ }^{18,19}$. Hypertension was defined as a systolic blood pressure $\geq 140 \mathrm{mmHg}$, or diastolic blood pressure $\geq 90 \mathrm{mmHg}$, and/or use of anti-hypertensive medication. Lifetime tobacco smoking was expressed as pack-years (one pack-year $=20$ cigarettes or $20 \mathrm{~g}$ of tobacco smoked per day over the course of 1 year) and was assessed by questionnaire. Alcohol use during the past year was expressed as $\mathrm{g} /$ day and was assessed by a food frequency questionnaire ${ }^{22}$. Habitual physical activity was assessed with a validated questionnaire (SQUASH) ${ }^{23}$, and individuals were subdivided into 3 intensity categories according to the Dutch guidelines for healthy physical activity (NNGB guideline) ${ }^{24}$. Renal function as estimated by glomerular filtration rate (eGFR in $\mathrm{ml} / \mathrm{min} / 1.73 \mathrm{~m}^{2}$ ) was calculated with the short Modification of Diet in Renal Disease (MDRD) equation ${ }^{25}$. All individuals without known T2DM underwent a 75-g (82 g dextrose monohydrate, Avebe, The Netherlands) OGTT test. Following the WHO 1999 criteria, individuals' glucose metabolism status was classified as: NGM in case of fasting plasma glucose levels $<6.1 \mathrm{mmol} / \mathrm{l}$ and $2 \mathrm{~h}$-post glucose levels $<7.8 \mathrm{mmol} / \mathrm{l} ;$ T2DM in case of fasting plasma glucose $\geq 7.0 \mathrm{mmol} / \mathrm{l}$ or $2 \mathrm{~h}$-post glucose $\geq 11.1 \mathrm{mmol} / \mathrm{l}$; and all other individuals, having either impaired fasting glucose, impaired glucose tolerance, or both, were grouped into an IGM category. 


\section{Statistical analyses}

All analyses were performed using IBM SPSS version 19.0 (SPSS, Chicago, IL, USA). Variables (triglycerides, CRP, IL-6, IL-8, SAA, SICAM-1) with a strongly skewed distribution were $\log _{\mathrm{e}}$-transformed prior to analysis. A low-grade inflammation score was computed by averaging the $z$-scores [(individual observed values - population mean)/population standard deviation] of eight inflammation markers (logCRP, TNF- $\alpha$, $\log I L-6, \log I L-8, \log S A A, \log I C A M-1$, ceruloplasmin and haptoglobin). The composite score can be interpreted as eight repeated measurements of the same construct, i.e. inflammation, and thereby may reduce measurement errors ${ }^{26}$. The use of this robust measure of low-grade inflammation prevents multiple testing problems and also reduces the influence of biological variability of each marker if assessed separately ${ }^{26}$.

General characteristics of the study population were compared across tertiles of uric acid levels using analysis of variance (ANOVA) for continuous variables and the chisquared test for discrete variables. Multiple linear or logistic regression analyses were used to determine the association of uric acid, expressed per SD $(81 \mu \mathrm{mol} / \mathrm{l})$, with CVD, AAIX, and CIMT. In the first model, crude results were adjusted for sex and age. The second model was additionally adjusted for smoking, alcohol intake, BMI, waist circumference and physical activity. The third model was also adjusted for hypertension, triglycerides, total:high-density lipoprotein (HDL) cholesterol ratio, fasting plasma insulin, fasting plasma glucose and eGFR. Subsequently, multiple linear regression analyses were performed to explore the association between uric acid and low-grade inflammation. Finally, to further explore whether the association between uric acid and CVD, AAIx and CIMT was (partly) explained by low-grade inflammation, the low-grade inflammation score and the individual low-grade inflammation markers were added to the third model as continuous covariates. Prespecified subgroup analyses were performed according to glucose metabolism status because previous research suggested a difference in the association between uric acid and CVD ${ }^{14}$. A formal test for interaction was performed to assess whether effects differed significantly between these subgroups.

Additionally, since previous studies on the association between uric acid and CVD identified differences according to sex ${ }^{2,27}$, interactions between uric acid and sex were tested in the associations between uric acid, CVD, AAIx and CIMT. Furthermore, the analyses assessing the association between uric acid and AAIx, and CIMT were repeated while excluding individuals with existing CVD, because individuals with prior CVD might have changed their lifestyle and medication use for the better. Likewise, the analyses assessing the association between uric acid and CVD, AAIx and CIMT were repeated while excluding hypertension from the third model since this variable may be in the causal pathway and therefore adjustment may represent overadjustment. Values of $p<0.05$ were considered statistically significant, except for the interaction analyses, where we used $p<0.10$. 


\section{Results}

Table 5.1 shows the general characteristics of the study population according to tertiles of uric acid. Among the 530 participants, with a mean age of $58.9 \pm 6.9$ years, $60.6 \%$ were men and $52.6 \%$ had a NGM. Individuals in higher uric acid tertiles had a worse metabolic profile, higher prevalence of CVD and a higher CIMT and AAIx. Excluded individuals ( $\mathrm{N}=44$ for CVD or AAIx, and $\mathrm{N}=81$ for $\mathrm{CIMT}$ ) were older, more frequently male, had a slightly higher BMI and had slightly higher uric acid and low-grade inflammation levels compared to the individuals included in our analyses (please see Appendix 5, Table S5.1).

\section{The association between uric acid and CVD, AAlx, and CIMT}

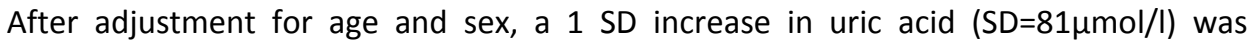
positively associated with CVD [odds ratio $(\mathrm{OR})=1.33(95 \% \mathrm{Cl} 1.06 ; 1.65), \mathrm{p}=0.012$ ] and CIMT [ $\beta=0.028$ (95\% Cl 0.013; 0.043), $p<0.001$ ], but not with AAlx (Table 5.2; model 1). The association between uric acid and CVD became non-significant after additional adjustment for BMI, waist circumference, alcohol intake, smoking, and physical activity. Only the association with CIMT remained significant after full adjustments $[\beta=0.024$ (95\% Cl 0.007; 0.042), p=0.006] (Table 5.2; model 3).

Predefined subgroup analyses for NGM, IGM, and T2DM were performed for all three outcomes. Because the results of the IGM and T2DM subgroups were similar (data not shown), and to increase the power of the analyses, we combined the results of the IGM and T2DM subgroups into disturbed glucose metabolism (DGM). The $p$-value for interaction with glucose metabolism status in model 3 was significant for uric acid with AAIx ( $p=0.058)$, but not with CIMT $(p=0.443)$ or CVD $(p=0.165)$. In the NGM subgroup, uric acid was significantly associated with CVD and CIMT, but not with AAIx (Table 5.2; model 1). Additional adjustments did not change the results [CVD: OR=1.66 (95\% Cl 1.06; 2.58), $p=0.026$; CIMT: $\beta=0.030$ (95\% Cl 0.006; 0.054), $p=0.013$ ] (Table 5.2; model 3). In individuals with DGM, uric acid was not significantly associated with CVD, CIMT, or AAIx in any of the models. 


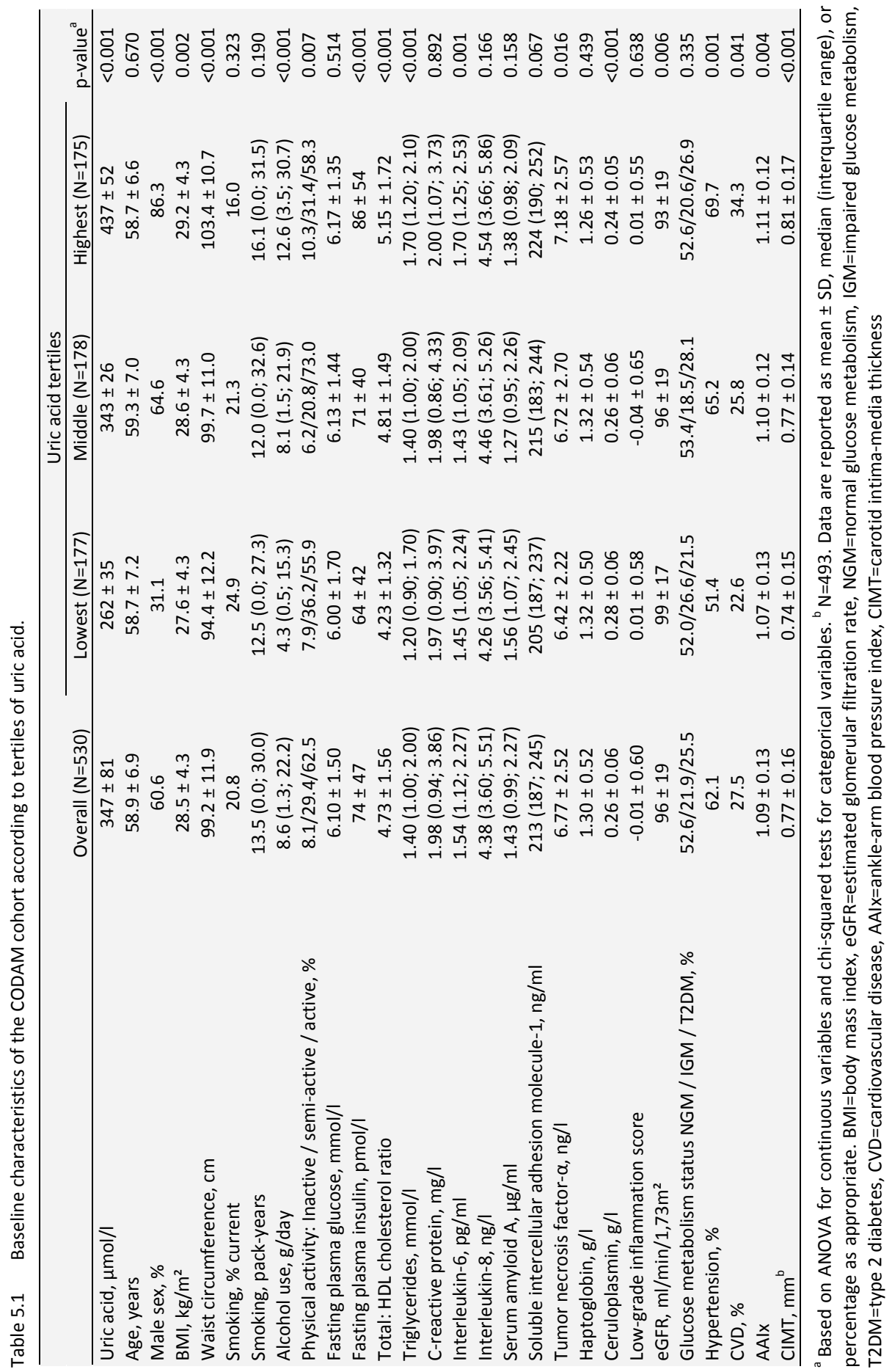




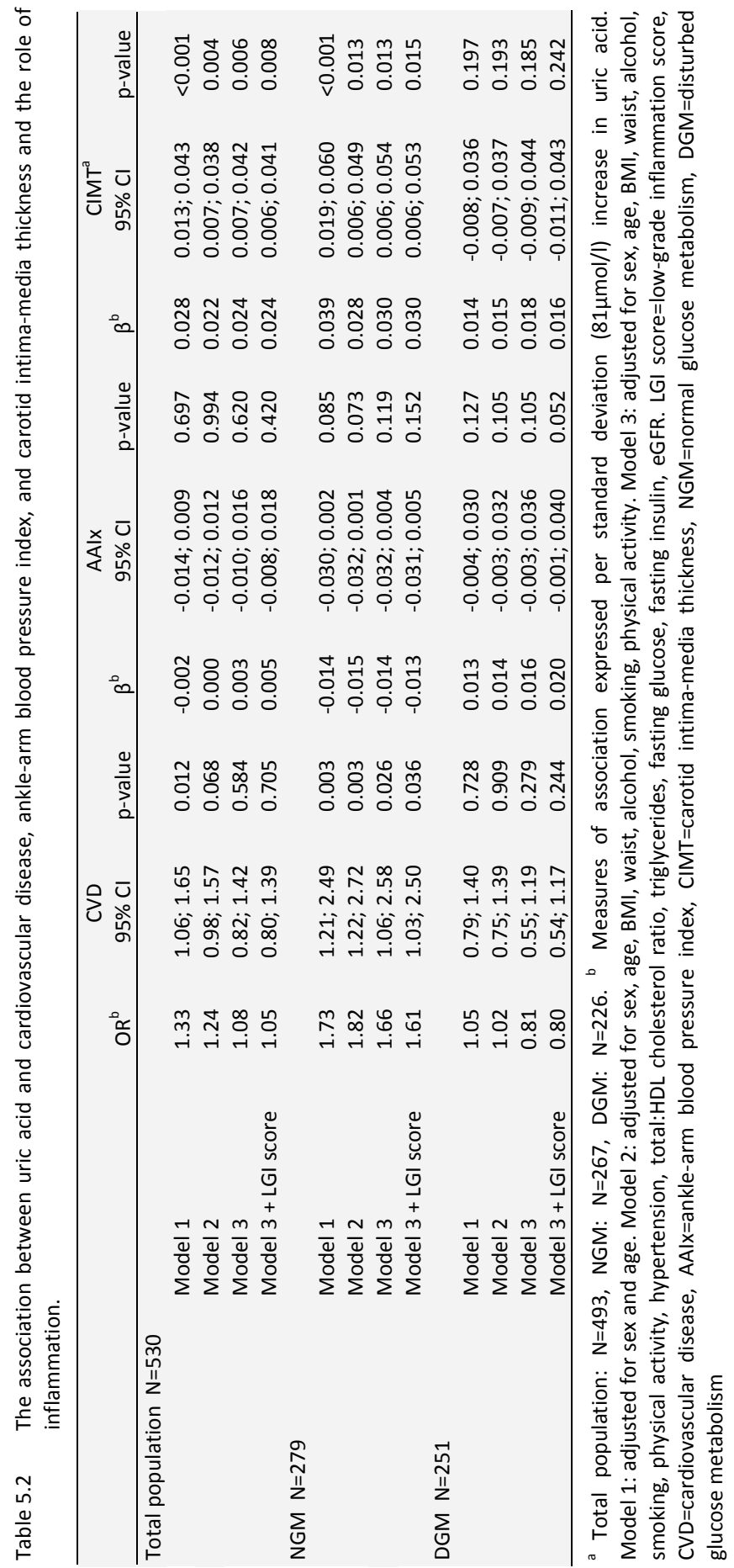




\section{The role of low-grade inflammation in the association between uric acid and CVD, AAIx, CIMT}

Uric acid was positively associated with low-grade inflammation after adjustment for age and sex, and the association remained significant after full adjustments in the total population [ $\beta=0.074$ ( $95 \% \mathrm{Cl} 0.013 ; 0.134), p=0.017$ ] (Table 5.3 ; model 3). Uric acid was also significantly associated with low-grade inflammation in the NGM $[\beta=0.115(95 \% \mathrm{Cl}$ $0.036 ; 0.195), p=0.005]$ and DGM subgroup $[\beta=0.082$ (95\% Cl $0.005 ; 0.160), p=0.038]$ (Table 5.3; model 1). After full adjustments, the association became non-significant in individual with $\mathrm{NGM}[\beta=0.044(95 \% \mathrm{Cl}-0.042 ; 0.131), p=0.316]$, but remained significant in individuals with $D G M[\beta=0.114(95 \% \mathrm{Cl} 0.027 ; 0.201), p=0.011, p$ for interaction=0.737] (Table 5.3; model 3).

Table 5.3 The association between uric acid and the $z$-score of low-grade inflammation.

\begin{tabular}{lcccc}
\hline & & & Low-grade inflammation \\
& & $\beta^{\text {a }}$ & 95\% Cl & p-value \\
\hline Total population N=530 & Model 1 & & & \\
& Model 2 & 0.117 & $0.061 ; 0.172$ & $<0.001$ \\
& Model 3 & 0.064 & $0.009 ; 0.118$ & 0.022 \\
& & 0.074 & $0.013 ; 0.134$ & 0.017 \\
NGM N=279 & & & \\
& Model 1 & & & 0.005 \\
& Model 2 & & & 0.150 \\
& Model 3 & 0.115 & $0.036 ; 0.195$ & 0.316 \\
DGM N=251 & 0.059 & $-0.022 ; 0.140$ & 0.038 \\
& & 0.044 & $-0.042 ; 0.131$ & \\
& Model 1 & & & 0.123 \\
& Model 2 & & & 0.011 \\
\hline
\end{tabular}

\footnotetext{
${ }^{a}$ Uric acid expressed as standard deviation $(81 \mu \mathrm{mol} / \mathrm{I})$. Model 1: adjusted for sex and age. Model 2: adjusted for sex, age, BMI, waist, alcohol, smoking, physical activity. Model 3: adjusted for sex, age, BMI, waist, alcohol, smoking, physical activity, hypertension, total:HDL cholesterol ratio, triglycerides, fasting glucose, fasting insulin, eGFR. NGM=normal glucose metabolism, DGM=disturbed glucose metabolism
}

Adding the overall low-grade inflammation score to the fully adjusted models did not substantially alter the strength of the associations between uric acid and CVD, AAIx or CIMT (Table 5.2). Adjusting model 3 for the single inflammation markers (CRP, TNF- $\alpha$, IL-6, IL-8, SAA, sICAM-1, ceruloplasmin, or haptoglobin) led to comparable results (Table 5.4). 


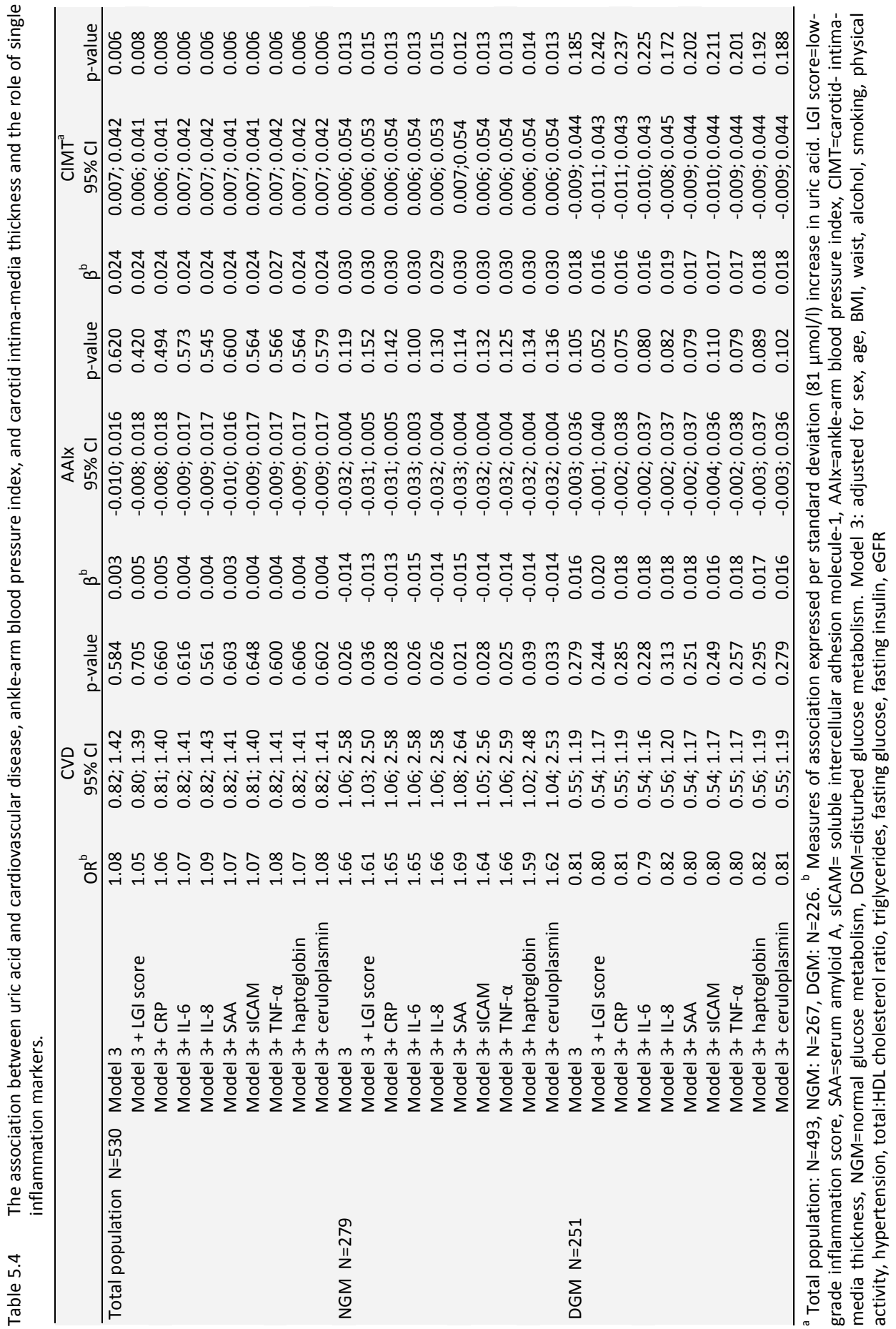




\section{Additional analyses}

No significant interactions between uric acid and sex were identified in the associations between uric acid and CVD ( $p$ for interaction=0.523), AAIx ( $p$ for interaction=0.829) or CIMT ( $p$ for interaction=0.450).

Excluding individuals with prior cardiovascular events did not substantially change the results for AAIX and CIMT. Uric acid was not significantly associated with AAIx in the total population of CVD-free participants ( $N=384)$ [ $\beta$ model $3=-0.006(95 \% \mathrm{Cl}-0.018 ; 0.006)$, $\mathrm{p}=0.357$ ], nor in individuals with NGM ( $\mathrm{N}=217)$ [ $\beta$ model $3=-0.004(95 \% \mathrm{Cl}:-0.023 ; 0.014)$, $\mathrm{p}=0.667$ ] or DGM ( $\mathrm{N}=167)$ [ $\beta$ model $3=-0.003$ (95\% Cl $-0.020 ; 0.014), \mathrm{p}=0.755$ ]. Furthermore, uric acid was significantly associated with CIMT in the total CVD-free population ( $\mathrm{N}=362$ ) [ $\beta$ model $3=0.024(95 \% \mathrm{Cl} 0.003 ; 0.045), p=0.027$ ] and in the NGM subgroup $(\mathrm{N}=211)$ [ $\beta$ model $3=0.033(95 \% \mathrm{Cl} 0.004 ; 0.062), \mathrm{p}=0.025]$, but not in individuals with DGM $(N=151)$ [ $\beta$ model $3=0.014(95 \% \mathrm{Cl}-0.019 ; 0.046), p=0.412]$.

Excluding hypertension from the analyses did not change the results of the associations between uric acid and CVD, AAIx and CIMT (data not shown).

\section{Discussion}

We found that in individuals with an elevated cardiovascular risk: 1) uric acid was modestly associated with CIMT, but not with CVD and AAIx; 2) uric acid was associated with both CIMT and CVD in individuals with NGM, but not in individuals with DGM; and 3 ) these associations were not explained by low-grade inflammation.

Literature on the association between uric acid and CVD shows disparate results, but overall there seems to be a modest positive association in the general population ${ }^{2}$. However, our population comprised individuals at relatively high cardiovascular risk. In line with the present study, uric acid was not an independent predictor of CVD in highrisk overweight or obese individuals ${ }^{28}$. In contrast, an independent association between uric acid and incident CVD was found in a large population with high CVD risk ${ }^{29}$. The authors reported a hazard ratio of $1.56(95 \% \mathrm{Cl} 1.32 ; 1.84)$ for a difference of 2 SD in uric acid levels ${ }^{29}$. Uric acid was also significantly associated with CVD events in individuals with successfully treated hypertension ${ }^{30}$. However, this association varied by risk status, with a more pronounced association among individuals with a lower cardiovascular risk. After stratifying our results for glucose metabolism status, the association between uric acid and CVD was present in individuals with NGM, but not with DGM. Similarly, uric acid was independently associated with CVD in two longitudinal studies in populations without $\mathrm{T}_{2} \mathrm{DM}^{31,32}$, whereas it was not an independent predictor of CVD mortality in two cohort studies of individuals with $\mathrm{T}_{2} \mathrm{DM}^{33,34}$. In contrast, uric acid predicted CVD mortality ${ }^{14}$ and $\mathrm{CHD}^{35}$ in patients with T2DM. 
Few previous studies have investigated the association between uric acid levels and AAIx or peripheral artery disease $(A A \mid x<0.9)$, and these studies showed inconsistent results $^{12,35-39}$. Analogous to studies performed in patients with hypertension ${ }^{36}$, the general population $^{37}$ and in individuals with $\mathrm{T}_{2} \mathrm{DM}^{35,38}$, we found no independent association between uric acid and AAlx. However, an inverse association between uric acid and an AAlx $<0.9$ was found in the general population ${ }^{12}$ and individuals with $\mathrm{T}_{2} \mathrm{DM}^{39}$. Note that the latter study did not adjust for possible confounders. Furthermore, Shankar et al. ${ }^{12}$ performed stratified analyses for individuals with and without diabetes and only found a significant association between uric acid and peripheral artery disease in individuals without diabetes.

We showed that an increase of $1 \mathrm{SD}$ of uric acid $(\mathrm{SD}=81 \mu \mathrm{mol} / \mathrm{l})$ was associated with a $0.024-\mathrm{mm}$ increase in CIMT. A $0.1-\mathrm{mm}$ increment in CIMT has previously been associated with a $10-15 \%$ increased risk of myocardial infarction and a $13-18 \%$ increased risk of stroke ${ }^{40}$. Therefore, an increase of $0.024 \mathrm{~mm}$ can be interpreted as a modest contribution of uric acid to the atherosclerotic process. Our findings contradict with other studies performed in individuals with an increased CVD risk, such as people with the metabolic syndrome ${ }^{41,42}$ or hypertension ${ }^{43,44}$, where no association between uric acid and CIMT was found. Similar to our stratified results, cross-sectional studies showed that uric acid was independently associated with CIMT in individuals without $\mathrm{T}_{2} \mathrm{DM}^{45}$, in individuals with $\mathrm{NGM}^{46}$ and in individuals without the metabolic syndrome ${ }^{41}$. Nevertheless, positive correlations between uric acid and CIMT were also found in patients with $\mathrm{T}_{2} \mathrm{DM}^{39,47}$. Note that these associations were not adjusted for possible confounders.

It is unclear why some studies on the association between uric acid and atherosclerosis seem to show different results in individuals with NGM and DGM. A challenge when exploring the role of uric acid as a potential independent risk factor for atherosclerosis, especially in subjects with DGM, are the correlations between uric acid and many established cardiovascular risk factors such as obesity, hyperlipidaemia, renal disease and hypertension ${ }^{48}$. Moreover, increased uric acid levels due to hyperinsulinaemia ${ }^{16}$ and the bell-shaped association between glucose and uric acid ${ }^{15}$ may not be the only explanation for the difference in association, as these factors were controlled for in the present study. We therefore emphasize the need for replication of our research findings on the identified glucose metabolism-related differences.

Analogous to previous studies, we identified an independent association between uric acid and low-grade inflammation ${ }^{8-10}$. In the CODAM study, low-grade inflammation was found to be associated with CHD or AAlx after adjustment for age, sex and glucose metabolism status ${ }^{18}$. Despite these associations, low-grade inflammation did not explain the association between uric acid and atherosclerosis. This was at least partly due to the non-significant association between uric acid and low-grade inflammation in the fully adjusted model in individuals with NGM. Similar to our results, CRP did not explain the associations between uric acid and $\mathrm{AAIx}^{12}$ and $\mathrm{CIMT}^{13}$. It is likely that 
uric acid contributes to the atherosclerotic process via an alternative mechanism such as a direct effect on the endothelium ${ }^{3}$. Note that after adjustment for low-grade inflammation, the association between uric acid and AAlx seemed stronger among individuals with DGM compared with NGM, the positive association being indicative of a beneficial effect of uric acid on AAlx. However, given the small magnitude of the association, no clear conclusions can be drawn.

Some limitations of the present study have to be taken into account. First, although the results of the prespecified subgroup analyses suggested a difference in strength of the associations, we found no significant $p$-values for the interaction between uric acid and glucose metabolism status in the association with CVD or CIMT. Conclusions on the difference in association should be interpreted with caution, even though it is known that tests for interaction often lack statistical power. Second, the cross-sectional design does not allow conclusions concerning causality. Raised uric acid levels in individuals with vascular damage can be caused by greater endogenous production due to the adenine nucleotide breakdown involved in tissue hypoxia ${ }^{49}$, or may represent a compensatory mechanism functioning as a powerful free radical scavenger to counteract lipid peroxidation ${ }^{50}$. Third, we extensively studied eight markers of inflammation but cannot exclude that additional inflammatory markers might explain the association between uric acid and atherosclerosis. Finally, no formal mediation analysis was performed ${ }^{51}$. However, based on the results of the regression analyses, formal quantification of the mediation was not deemed necessary. The addition of lowgrade inflammation to the adjusted models had no influence at all on any of the coefficients that quantified the associations between uric acid and atherosclerosis.

Strength of this study was the use of an average $z$-score for low-grade inflammation. Uric acid has previously been associated with single inflammation markers ${ }^{8-10}$, however, a low-grade inflammation score has not been considered before. An average $z$-score is a more robust measure for inflammation than the separate biomarkers, although it does not account for the relative importance of the eight single biomarkers. Additionally, the use of CIMT and AAIx, validated measures that are accepted markers of atherosclerosis and correlate with established coronary artery disease $e^{52,53}$, is a strength of this study.

In conclusion, our data suggest that uric acid may play a modest role in the development of atherosclerosis. However, our results do not support the mediation of the association between uric acid and atherosclerosis by the low-grade inflammatory markers measured in this cross-sectional study. In addition, a difference in the strength of the association between individuals with NGM and DGM is suggested, but the precise role of glucose metabolism status in the association between uric acid and atherosclerosis remains to be determined. 


\section{References}

1. Dincer HE, Dincer AP, Levinson DJ. Asymptomatic hyperuricemia: to treat or not to treat. Cleve Clin J Med. 2002;69:594-608.

2. Kim SY, Guevara JP, Kim KM, Choi HK, Heitjan DF, Albert DA. Hyperuricemia and coronary heart disease: a systematic review and meta-analysis. Arthritis Care Res (Hoboken). 2010;62:170-180.

3. Papezikova I, Pekarova $\mathrm{M}$, Kolarova $\mathrm{H}$, et al. Uric acid modulates vascular endothelial function through the down regulation of nitric oxide production. Free Radic Res. 2013;47:82-88.

4. Corry DB, Eslami P, Yamamoto K, Nyby MD, Makino H, Tuck ML. Uric acid stimulates vascular smooth muscle cell proliferation and oxidative stress via the vascular renin-angiotensin system. J Hypertens. 2008;26:269-275.

5. Inaba S, Sautin Y, Garcia GE, Johnson RJ. What can asymptomatic hyperuricaemia and systemic inflammation in the absence of gout tell us? Rheumatology (Oxford). 2013;52:963-965.

6. Kang DH, Park SK, Lee IK, Johnson RJ. Uric acid-induced C-reactive protein expression: implication on cell proliferation and nitric oxide production of human vascular cells. J Am Soc Nephrol. 2005;16: 3553-3562.

7. Kanellis J, Watanabe S, Li JH, et al. Uric acid stimulates monocyte chemoattractant protein-1 production in vascular smooth muscle cells via mitogen-activated protein kinase and cyclooxygenase- 2 . Hypertension. 2003;41:1287-1293.

8. Ruggiero C, Cherubini A, Miller E, 3rd, et al. Usefulness of uric acid to predict changes in C-reactive protein and interleukin-6 in 3-year period in Italians aged 21 to 98 years. Am J Cardiol. 2007;100: 115-121.

9. Ruggiero C, Cherubini A, Ble A, et al. Uric acid and inflammatory markers. Eur Heart J. 2006;27: 1174-1181.

10. Lyngdoh T, Marques-Vidal P, Paccaud F, et al. Elevated serum uric acid is associated with high circulating inflammatory cytokines in the population-based Colaus study. PLoS One. 2011;6:e19901.

11. Grainger R, McLaughlin RJ, Harrison AA, Harper JL. Hyperuricaemia elevates circulating CCL2 levels and primes monocyte trafficking in subjects with inter-critical gout. Rheumatology (Oxford). 2013;52: 1018-1021.

12. Shankar A, Klein BE, Nieto FJ, Klein R. Association between serum uric acid level and peripheral arterial disease. Atherosclerosis. 2008;196:749-755.

13. Gur M, Sahin DY, Elbasan Z, et al. Uric acid and high sensitive C-reactive protein are associated with subclinical thoracic aortic atherosclerosis. J Cardiol. 2013;61:144-148.

14. Kramer CK, von Muhlen D, Jassal SK, Barrett-Connor E. A prospective study of uric acid by glucose tolerance status and survival: the Rancho Bernardo Study. J. Intern. Med. 2010;267:561-566.

15. Wen CP, David Cheng TY, Chan HT, et al. Is high serum uric acid a risk marker or a target for treatment? Examination of its independent effect in a large cohort with low cardiovascular risk. Am J Kidney Dis. 2010;56:273-288.

16. Quinones Galvan A, Natali A, Baldi S, et al. Effect of insulin on uric acid excretion in humans. Am J Physiol. 1995;268:E1-5.

17. Kruijshoop M, Feskens EJ, Blaak EE, de Bruin TW. Validation of capillary glucose measurements to detect glucose intolerance or type 2 diabetes mellitus in the general population. Clin Chim Acta. 2004;341:33-40.

18. Jacobs $\mathrm{M}$, van Greevenbroek MM, van der Kallen $\mathrm{CJ}$, et al. Low-grade inflammation can partly explain the association between the metabolic syndrome and either coronary artery disease or severity of peripheral arterial disease: the CODAM study. Eur J Clin Invest. 2009;39:437-444.

19. Thewissen MM, Damoiseaux JG, Duijvestijn AM, et al. Abdominal fat mass is associated with adaptive immune activation: the CODAM Study. Obesity (Silver Spring). 2011;19:1690-1698.

20. Toprak A, Kandavar R, Toprak D, et al. C-reactive protein is an independent predictor for carotid artery intima-media thickness progression in asymptomatic younger adults (from the Bogalusa Heart Study). BMC Cardiovasc Disord. 2011;11:78. 
21. van Bussel BC, Ferreira I, van de Waarenburg MP, et al. Multiple inflammatory biomarker detection in a prospective cohort study: a cross-validation between well-established single-biomarker techniques and an electrochemiluminescense-based multi-array platform. PloS one. 2013;8:e58576.

22. Ocke MC, Bueno-de-Mesquita HB, Pols MA, Smit HA, van Staveren WA, Kromhout D. The Dutch EPIC food frequency questionnaire. II. Relative validity and reproducibility for nutrients. Int J Epidemiol. 1997;26 Suppl 1:S49-58.

23. Wendel-Vos GC, Schuit AJ, Saris WH, Kromhout D. Reproducibility and relative validity of the short questionnaire to assess health-enhancing physical activity. J Clin Epidemiol. 2003;56:1163-1169.

24. Kemper HCG, Ooijendijk WTM, Stiggelbout M. Consensus over de Nederlandse norm voor gezond bewegen. Tijdschrift voor Gezondheidswetenschappen. 2000;78:180-183.

25. Levey AS, Bosch JP, Lewis JB, Greene T, Rogers N, Roth D. A more accurate method to estimate glomerular filtration rate from serum creatinine: a new prediction equation. Modification of Diet in Renal Disease Study Group. Ann Intern Med. 1999;130:461-470.

26. Wlazlo N, van Greevenbroek MM, Ferreira I, et al. Low-grade inflammation and insulin resistance independently explain substantial parts of the association between body fat and serum C3: the CODAM study. Metabolism. 2012;61:1787-1796.

27. Grayson PC, Kim SY, LaValley M, Choi HK. Hyperuricemia and incident hypertension: a systematic review and meta-analysis. Arthritis Care Res (Hoboken). 2011;63:102-110.

28. Skak-Nielsen $\mathrm{H}$, Torp-Pedersen $\mathrm{C}$, Finer $\mathrm{N}$, et al. Uric acid as a risk factor for cardiovascular disease and mortality in overweight/obese individuals. PloS one. 2013;8:e59121.

29. Thornley S, Marshall RJ, Jackson R, et al. Is serum urate causally associated with incident cardiovascular disease? Rheumatology (Oxford). 2013;52:135-142.

30. Alderman MH, Cohen H, Madhavan S, Kivlighn S. Serum uric acid and cardiovascular events in successfully treated hypertensive patients. Hypertension. 1999;34:144-150.

31. Kivity S, Kopel E, Maor E, et al. Association of Serum Uric Acid and Cardiovascular Disease in Healthy Adults. Am J Cardiol. 2013;111:1146-1151.

32. Niskanen LK, Laaksonen DE, Nyyssonen K, et al. Uric acid level as a risk factor for cardiovascular and allcause mortality in middle-aged men: a prospective cohort study. Arch Intern Med. 2004;164: 1546-1551.

33. Panero F, Gruden G, Perotto M, et al. Uric acid is not an independent predictor of cardiovascular mortality in type 2 diabetes: a population-based study. Atherosclerosis. 2012;221:183-188.

34. Ong G, Davis WA, Davis TM. Serum uric acid does not predict cardiovascular or all-cause mortality in type 2 diabetes: the Fremantle Diabetes Study. Diabetologia. 2010;53:1288-1294.

35. Ito $\mathrm{H}, \mathrm{Abe} \mathrm{M}$, Mifune $\mathrm{M}$, et al. Hyperuricemia is independently associated with coronary heart disease and renal dysfunction in patients with type 2 diabetes mellitus. PLoS One. 2011;6:e27817.

36. Langlois $M$, De Bacquer D, Duprez D, De Buyzere M, Delanghe J, Blaton V. Serum uric acid in hypertensive patients with and without peripheral arterial disease. Atherosclerosis. 2003;168:163-168.

37. Lowe GD, Fowkes FG, Dawes J, Donnan PT, Lennie SE, Housley E. Blood viscosity, fibrinogen, and activation of coagulation and leukocytes in peripheral arterial disease and the normal population in the Edinburgh Artery Study. Circulation. 1993;87:1915-1920.

38. Bianchi C, Penno G, Pancani F, et al. Non-traditional cardiovascular risk factors contribute to peripheral arterial disease in patients with type 2 diabetes. Diabetes Res Clin Pract. 2007;78:246-253.

39. Fukui M, Tanaka M, Shiraishi E, et al. Serum uric acid is associated with microalbuminuria and subclinical atherosclerosis in men with type 2 diabetes mellitus. Metabolism. 2008;57:625-629.

40. Lorenz MW, Markus HS, Bots ML, Rosvall M, Sitzer M. Prediction of clinical cardiovascular events with carotid intima-media thickness: a systematic review and meta-analysis. Circulation. 2007;115:459-467.

41. Takayama S, Kawamoto R, Kusunoki T, Abe M, Onji M. Uric acid is an independent risk factor for carotid atherosclerosis in a Japanese elderly population without metabolic syndrome. Cardiovasc Diabetol. 2012;11:2.

42. Antonini-Canterin F, La Carrubba S, Gullace G, et al. Association between carotid atherosclerosis and metabolic syndrome: results from the ISMIR study. Angiology. 2010;61:443-448. 
43. Gomez-Marcos MA, Recio-Rodriguez JI, Patino-Alonso MC, et al. Relationship between uric acid and vascular structure and function in hypertensive patients and sex-related differences. Am J Hypertens. 2013;26:599-607.

44. Cipolli JA, Ferreira-Sae MC, Martins RP, et al. Relationship between serum uric acid and internal carotid resistive index in hypertensive women: a cross-sectional study. BMC Cardiovasc Disord. 2012;12:52.

45. Zhang Z, Bian L, Choi Y. Serum uric acid: a marker of metabolic syndrome and subclinical atherosclerosis in Korean men. Angiology. 2012;63:420-428.

46. Erdogan D, Gullu H, Caliskan $M$, et al. Relationship of serum uric acid to measures of endothelial function and atherosclerosis in healthy adults. Int J Clin Pract. 2005;59:1276-1282.

47. Li Q, Yang Z, Lu B, et al. Serum uric acid level and its association with metabolic syndrome and carotid atherosclerosis in patients with type 2 diabetes. Cardiovasc Diabetol. 2011;10:72.

48. Johnson RJ, Kivlighn SD, Kim YG, Suga S, Fogo AB. Reappraisal of the pathogenesis and consequences of hyperuricemia in hypertension, cardiovascular disease, and renal disease. Am J Kidney Dis. 1999;33:225-234.

49. Puig JG, Ruilope LM. Uric acid as a cardiovascular risk factor in arterial hypertension. J Hypertens. 1999;17:869-872.

50. Nieto FJ, Iribarren C, Gross MD, Comstock GW, Cutler RG. Uric acid and serum antioxidant capacity: a reaction to atherosclerosis? Atherosclerosis. 2000;148:131-139.

51. Baron RM, Kenny DA. The moderator-mediator variable distinction in social psychological research: conceptual, strategic, and statistical considerations. J Pers Soc Psychol. 1986;51:1173-1182.

52. Davis PH, Dawson JD, Riley WA, Lauer RM. Carotid intimal-medial thickness is related to cardiovascular risk factors measured from childhood through middle age: The Muscatine Study. Circulation. 2001;104:2815-2819.

53. Doobay AV, Anand SS. Sensitivity and specificity of the ankle-brachial index to predict future cardiovascular outcomes: a systematic review. Arterioscler Thromb Vasc Biol. 2005;25:1463-1469. 
Chapter 5 


\section{Appendix 5}

Supplemental table 
Chapter 5 


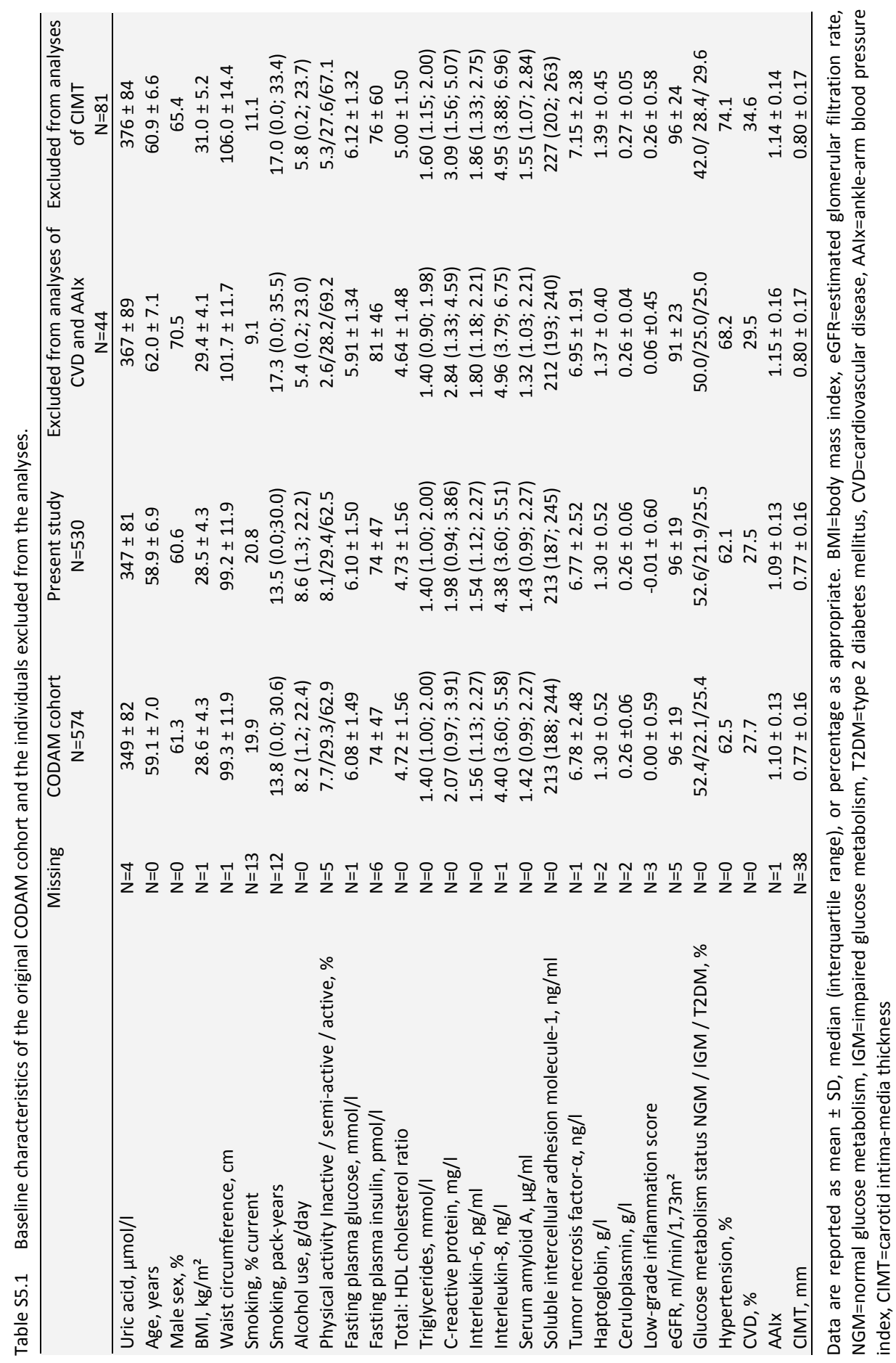




\section{Chapter}

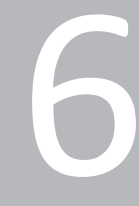

Association between serum uric acid, aortic, carotid and femoral stiffness: The Maastricht Study

J.M.A. Wijnands, A. Boonen, T.T. van Sloten, M.T. Schram, S.J.S. Sep, A. Koster, C.J.H. van der Kallen, R.M.A. Henry, P.C. Dagnelie, C.D.A. Stehouwer, Sj. van der Linden, I.C.W. Arts 


\section{Abstract}

\section{Objective}

Arterial stiffness may be a mechanism to explain the association between uric acid and cardiovascular disease. We aimed to analyse associations between plasma uric acid and regional and local arterial stiffness, and assess potential differences related to sex and glucose metabolism status.

\section{Methods}

A cross-sectional study was performed in 614 adults ( $52.6 \%$ men; mean age $58.7 \pm 8.5$ yrs.; $23.2 \%$ type 2 diabetes (by design)) from The Maastricht Study. Arterial stiffness was assessed by carotidfemoral pulse wave velocity (cfPWV), distensibility and compliance coefficient of the carotid and femoral artery, and carotid artery Young's elastic modulus (YEM).

\section{Results}

Higher uric acid (per SD of $74 \mu \mathrm{mol} / \mathrm{l}$ ) was associated with greater stiffness indicated by a significantly higher cfPWV $[\beta=0.216(95 \% \mathrm{Cl} 0.061 ; 0.372) \quad p=0.006]$ and lower carotid distensibility coefficient $[\beta=-0.458(95 \% \mathrm{Cl}-0.841 ;-0.075) \mathrm{p}=0.019]$ after adjustment for sex, age, and glucose metabolism status. Associations lost significance after adjusting for mean arterial pressure, BMI, waist, smoking status, heart rate, total:HDL cholesterol, triglycerides, eGFR, and lipid-lowering, anti-hypertensive, and diabetes medication. No associations were found between uric acid and carotid compliance coefficient, carotid YEM, or stiffness of the femoral artery. A significant $(p=0.049)$ interaction with glucose metabolism status was found for the carotid distensibility coefficient, with a stronger association among individuals with normal glucose metabolism $[\beta=-0.504(95 \% \mathrm{Cl}-1.098 ; 0.090) p=0.096]$ than among those with impaired glucose metabolism or type 2 diabetes. There was no interaction with sex.

\section{Conclusion}

Uric acid was not significantly associated with stiffness of the aorta, or the carotid or femoral artery. 


\section{Introduction}

The prevalence of hyperuricaemia in the general population has been estimated at $10-20 \%{ }^{1-4}$. There is accumulating evidence that hyperuricaemia is associated with cardiovascular disease (CVD) and its risk factors ${ }^{5}$. The exact mechanisms underlying this association, however, are not completely understood. Arterial stiffness could be a mechanism that links uric acid to CVD.

Arterial stiffness is the loss of elastic properties of the arterial wall and can contribute to CVD through the development of systolic hypertension, left ventricular hypertrophy, and impaired coronary perfusion ${ }^{6}$. Stiffness is affected by endothelial cell function and vascular smooth muscle cell tone ${ }^{7}$. Both underlying processes have been reported to be modified by uric acid ${ }^{8-10}$. Arterial stiffness can be measured at different arterial segments and sites, and by use of different techniques which include regional carotid-femoral pulse wave velocity (cfPWV), brachial-ankle PWV (baPWV), and local carotid and femoral stiffness. Several studies have assessed the association between uric acid and regional arterial stiffness, with conflicting results ${ }^{11-21}$. However, in most of these studies $^{12,14,16-20}$ arterial stiffness was determined via the assessment of baPWV. CfPWV is a more established index of arterial stiffness and is considered the 'gold standard $^{6}$. CfPWV involves a mixture of elastic and muscular arterial parts of the arterial tree and is independently associated with $C V D^{22,23}$. Studies examining the association between uric acid and cfPWV, however, have also shown inconsistent results $^{11,15,21,24-28}$, possibly due to incomplete adjustment for confounding factors such as glucose metabolism status ${ }^{11,24}$, renal function ${ }^{11}$, mean arterial pressure $(\mathrm{MAP})^{26}$, or anti-hypertensive medication ${ }^{25}$, and a large variation in study populations.

Studies that investigated the relation between uric acid and local arterial stiffness indices are scarce ${ }^{29,30}$. However, assessing local carotid stiffness indices may be of importance $^{6}$. The carotid artery is a frequent site of atheroma formation ${ }^{6}$, and combined with greater carotid stiffness, the risk of ischemic stroke may increase ${ }^{31}$. This could be explained by the association between increased pulse pressure and plaque instability $^{32}$. In addition, stiffening of peripheral arteries, such as the femoral artery, may also be important in the development of CVD, because stiffness of these arteries may boost the premature return of reflected pulse waves ${ }^{33}$.

Previous longitudinal studies have reported a stronger relation between uric acid and CVD or mortality in women than in $\operatorname{men}^{34,35}$. In addition, research suggests a difference in the association between uric acid and CVD according to glucose metabolism status ${ }^{36}$, possibly due to a biological interaction between uric acid, glucose, and insulin concentrations ${ }^{37,38}$. In view of these considerations, we investigated whether uric acid is associated with cfPWV, local carotid and/or femoral stiffness. In addition, interactions between uric acid, sex, and glucose metabolism status were assessed. 


\section{Methods}

In this study, we used data from The Maastricht Study, an observational prospective population-based cohort study. The rationale and methodology have been described previously $^{39}$. In brief, the study focuses on the aetiology, pathophysiology, complications and comorbidities of type 2 diabetes mellitus (T2DM) and is characterized by an extensive phenotyping approach. Eligible for participation were all individuals aged between 40 and 75 years and living in the southern part of the Netherlands. Participants were recruited through mass media campaigns and from the municipal registries and the regional Diabetes Patient Registry via mailings. Recruitment was stratified according to known T2DM status for reasons of efficiency. The present report includes cross-sectional data from the first 866 participants, who completed the baseline survey between November 2010 and March 2012. The examinations of each participant were performed within a time window of three months. The study has been approved by the institutional medical ethical committee (NL31329.068.10) and the Netherlands Health Council under the Dutch "Law for Population Studies" (Permit 131088-105234-PG). All participants gave written informed consent.

For the present study we excluded subjects without data on uric acid ( $N=13)$, cfPWV $(\mathrm{N}=43)$, local carotid stiffness $(\mathrm{N}=46)$, local femoral stiffness $(\mathrm{N}=86)$, smoking status $(\mathrm{N}=17)$, BMI $(\mathrm{N}=1)$, waist $(\mathrm{N}=3)$, cholesterol concentrations $(\mathrm{N}=8)$, and/or estimated Glomerular Filtration Rate (eGFR) ( $N=9$ ). We also excluded individuals with type 1 diabetes $(\mathrm{N}=4)$ or a history of CVD $(\mathrm{N}=152)$. A history of CVD was defined as selfreported myocardial infarction; cerebrovascular infarction or haemorrhage; and/or percutaneous artery angioplasty or vascular surgery of the coronary, abdominal, peripheral or carotid arteries according to the Rose questionnaire ${ }^{40}$. Furthermore, individuals taking any uric-acid-lowering medication (i.e. allopurinol or benzbromaron; $\mathrm{N}=21$ ) were excluded. The total study population thus consisted of 614 participants.

\section{Arterial stiffness measurements}

All measurements were done by trained vascular technicians unaware of the participants' clinical or diabetes status, in a dark, quiet, temperature-controlled room $\left(21-23^{\circ} \mathrm{C}\right)$. Participants were asked to refrain from smoking and drinking coffee, tea, or alcoholic beverages three hours prior to the study. Participants were allowed to have a light meal (breakfast and/or lunch). All measurements were performed in the supine position after $10 \mathrm{~min}$ of rest. Talking or sleeping was not allowed during the examination. During the vascular measurements (approximately 45 minutes), brachial systolic, diastolic and MAP were determined every five minutes with an oscillometric device (Accutorr Plus, Datascope Inc., Montvale, NJ, USA). The mean MAP and heart rate (HR) of these measurements were used in the statistical analysis. A three-lead 
electrocardiogram was recorded continuously during the measurements to facilitate automatic signal processing.

\section{Carotid to femoral pulse wave velocity}

CfPWV was determined according to recent guidelines ${ }^{41}$ with the use of applanation tonometry (SphygmoCor, Atcor Medical, Sydney, Australia). Pressure waveforms were determined at the right common carotid and right common femoral arteries. The difference in the time of pulse arrival from the R-wave of the electrocardiogram between the two sites (transit time) was determined with the intersecting tangents algorithm. The pulse wave travel distance was calculated as $80 \%$ of the direct straight distance (measured with an infantometer) between the two arterial sites. The median of three consecutive cfPWV (defined as travelled distance/transit time) recordings was used in the analyses.

\section{Local arterial stiffness}

Data acquisition. Measurements were done at the left common carotid $(10 \mathrm{~mm}$ proximal to the carotid bulb) and the right common femoral (10-20 $\mathrm{mm}$ proximal to the flow divider) arteries, with the use of an ultrasound scanner equipped with a 7.5- $\mathrm{MHz}$ linear probe (MyLab 70, Esaote Europe B.V., Maastricht, the Netherlands). This setup enables the measurement of diameter, distension and intima-media thickness (IMT) as described previously ${ }^{42,43}$. Briefly, during the ultrasound measurements a B-mode image on the basis of $19 \mathrm{M}$-lines was depicted on screen. An online echo-tracking algorithm showed real-time anterior and posterior wall displacements. The M-mode recordings were composed of 19 simultaneous recordings at a frame rate of $498 \mathrm{~Hz}$. The distance between the M-line recording positions was $0.96 \mathrm{~mm}$, thus, a total segment of $18.24 \mathrm{~mm}$ of each artery was covered by the scan plane. For offline processing, the radiofrequency signal was fed into a dedicated PC-based acquisition system (ART.LAB, Esaote Europe B.V. Maastricht, The Netherlands) with a sampling frequency of $50 \mathrm{MHz}$. Data processing was performed in MatLab (version 7.5, Mathworks, Natick, MA, USA). The distension waveforms were obtained from the radiofrequency data with the use of a wall track algorithm ${ }^{42}$. Carotid IMT was defined as the distance of the posterior wall from the leading edge interface between lumen and intima to the leading edge interface between media and adventitia ${ }^{43}$. The median diameter, distension, and IMT of three measurements were used in the analyses. 
Data analysis. Local arterial elastic properties were quantified by calculating the following indices ${ }^{44}$ :

- Distensibility Coefficient (DC)

$$
D C=\left(2 \Delta D \cdot D+\Delta D^{2}\right) /\left(P P \cdot D^{2}\right)
$$

- Young's elastic modulus (YEM) (carotid artery only) YEM = D / (IMT · DC)

- Compliance Coefficient (CC)

$$
C C=\pi \cdot\left(2 D \cdot \Delta D+\Delta D^{2}\right) / 4 P P
$$

$$
\left(10^{-3} \mathrm{kPa}^{-1}\right)
$$

$\left(\mathrm{mm}^{2} \mathrm{kPa}^{-1}\right)$

where $\mathrm{D}$ is arterial diameter; $\Delta \mathrm{D}$ distension; IMT intima-media thickness; and PP brachial pulse pressure (calculated as systolic minus diastolic blood pressure).

DC represents arterial stiffness; YEM, the stiffness of the arterial wall material at operating pressure; and CC, arterial buffering capacity. Note that higher values of cfPWV or carotid YEM and lower values of DC or CC denote greater arterial stiffness, i.e. lower arterial elasticity.

\section{Reproducibility}

Reproducibility was assessed by 2 observers in 12 individuals ( 6 men; $60.8 \pm 6.8$ years; 6 individuals with T2DM) who were examined on two occasions spaced one week apart. The intra- and inter-observer intra-class correlation coefficients were 0.87 and 0.69 for cfPWV; 0.85 and 0.73 for carotid DC; 0.95 and 0.72 for carotid CC; 0.72 and 0.71 for carotid YEM; 0.49 and 0.32 for femoral DC; and 0.41 and 0.67 for femoral CC.

\section{Other covariates}

After an overnight fast, venous blood samples were collected at The Maastricht Study research centre. Plasma glucose was measured with a standard enzymatic hexokinase reference method, and serum total cholesterol, HDL cholesterol, triglycerides, creatinine and uric acid concentrations were measured with standard (enzymatic and/or colourimetric) methods by an automatic analyser (Beckman Synchron LX20, Beckman Coulter Inc., Brea, USA) at Maastricht University Medical Centre (the Netherlands). Measurement of creatinine was based on the Jaffé method traceable to isotope dilution mass spectrometry (Synchron LX20, Beckman Coulter Inc., Brea, USA). Height (in $\mathrm{cm}$ ) was measured with individuals standing upright against a stadiometer. Body weight was measured on an analog scale (Seca 761, Seca). Body mass index (BMI) was calculated as body weight $(\mathrm{kg})$ divided by height squared $\left(\mathrm{m}^{2}\right)$. Waist circumference was measured in duplicate midway between the lower rib margin and the iliac crest at the end of expiration, to the nearest $0.5 \mathrm{~cm}$, with a flexible plastic tape measure (Seca, Hamburg, Germany). Participants were requested to bring all the medication they used at the time of measurement or a list from their pharmacists to the research centre. 
During a medication interview generic name, dose and frequency, and additional overthe-counter (OTC) medication use were registered by trained staff. All participants received an extensive web-based questionnaire in which smoking behaviour (never, former, current) and years of diabetes duration was self-reported. Systolic and diastolic blood pressure was determined three times on the right arm after a 10-minute resting period, using a blood pressure monitor (Omron 705 IT, Japan). The average of the three measurements was calculated. Hypertension was defined as office systolic blood pressure $>140 \mathrm{mmHg}$, or diastolic blood pressure $>90 \mathrm{mmHg}$, and/or current antihypertensive medication use. Renal function as estimated by Glomerular Filtration Rate (in $\mathrm{ml} / \mathrm{min} / 1.73 \mathrm{~m}^{2}$ ) was calculated with the Chronic Kidney Disease Epidemiology Collaboration (CKD-epi) formula ${ }^{45}$. To determine glucose metabolism, all participants (except those who used insulin) underwent a standardized 2-h-75-g oral glucose tolerance test (OGTT) after an overnight fast. For safety reasons, participants with a fasting glucose level above $11.0 \mathrm{mmol} / \mathrm{l}(\mathrm{N}=13)$ were excluded from the OGTT. Glucose metabolism status was classified according to the WHO 2006 criteria $^{46}$ as: normal glucose metabolism (NGM) in case of fasting plasma glucose concentrations $<6.1 \mathrm{mmol} / \mathrm{l}$ and 2-h post-glucose concentrations $<7.8 \mathrm{mmol} / \mathrm{l}$; impaired glucose tolerance (IGT) in case of fasting plasma glucose $<7.0 \mathrm{mmol} / \mathrm{l}$ and 2 -h post-glucose $\geq 7.8 \mathrm{mmol} / \mathrm{l}$ and $<11.1 \mathrm{mmol} / \mathrm{l}$; impaired fasting glucose (IFG) in case of fasting plasma glucose 6.1 to $6.9 \mathrm{mmol} / \mathrm{l}$ and (if measured) 2-h post-glucose $<7.8 \mathrm{mmol} / \mathrm{l}$; and T2DM in case of fasting plasma glucose $\geq 7.0 \mathrm{mmol} / \mathrm{l}$ and/or 2 -h post-glucose $\geq 11.1 \mathrm{mmol} / \mathrm{l}$. For this study, we defined having either IFG or IGT as impaired glucose metabolism (IGM).

\section{Statistical analysis}

All analyses were performed using IBM SPSS version 19.0 (SPSS, Chicago, IL, USA). General characteristics of the study population were compared across tertiles of uric acid concentrations using analysis of variance (ANOVA) for continuous variables and $\chi^{2}$ test for categorical variables. Multivariable linear regression analyses were used to determine the association between uric acid (per +1 standard deviation (SD), $\mathrm{SD}=74 \mu \mathrm{mol} / \mathrm{I}$ ) and arterial stiffness indices (cfPWV, carotid DC, carotid CC, carotid YEM, femoral DC, and femoral (C). The associations were first adjusted for age, sex, and glucose metabolism status (model 1). Additionally, the associations were adjusted for $\mathrm{BMI}$, waist, smoking status, HR (for analyses with cfPWV only), total:HDL cholesterol ratio, triglycerides, eGFR, and use of lipid-lowering, diabetes, renin-angiotensinaldosterone system inhibitors, and other anti-hypertensive medication, including betablockers (model 2).

Arteries become stiffer when they are distended ${ }^{47}$ and therefore stiffness is highly dependent on blood pressure. Elastin fibres bear the load at physiologic pressures, while collagen fibres remain folded ${ }^{48}$. However, with increasing pressures, stiffer collagen fibres are recruited causing an increase in stiffness. In order to disentangle the 
effects of blood pressure from differences in stiffness properties of the arterial wall per se, we additionally adjusted for MAP in models 1 and 2. Interactions between uric acid and sex or glucose metabolism status were tested in model 2+MAP using F change. Additionally, overadjustment by eGFR as a potential intermediate variable in the association between uric acid and arterial stiffness indices was evaluated by excluding eGFR from model $2+\mathrm{MAP}^{49,50}$. A p-value $<0.05$ was considered statistically significant, except for the interaction analyses, where $p<0.10$ was used.

\section{Results}

Table 6.1 shows the general characteristics of the study population according to uric acid tertiles. Of the total population of 614 individuals, 320 (52.4\%) were men. The average age was 58.7 years. A large percentage of individuals had T2DM (23.2\%) or hypertension (50.5\%). Individuals in the third uric acid tertile were significantly older, more frequently male, and more often had T2DM and hypertension. Individuals excluded because of missing data had slightly higher uric acid concentrations, had a higher $\mathrm{BMI}$, and more often had T2DM, hypertension and a kidney function below $60 \mathrm{ml} / \mathrm{min} / 1.73 \mathrm{~m}^{2}$ (please see Appendix 6, Table S6.1).

\section{Uric acid and regional arterial stiffness}

Linear regression analysis, adjusted for age, sex, and glucose metabolism status, showed that a one SD (74 $\mathrm{mol} / \mathrm{l})$ higher plasma uric acid concentration was associated with a higher cfPWV $[\beta=0.216(95 \% \mathrm{Cl} 0.061 ; 0.372), p=0.006]$ (Table 6.2, model 1$)$. After adjustment for MAP the association became non-significant $[\beta=0.108(95 \% \mathrm{Cl}$ -0.031 ; 0.247) $p=0.127$ ]. Additional adjustment for $B M I$, waist, smoking status, HR, total:HDL cholesterol ratio, triglycerides, eGFR, and use of lipid-lowering, diabetes, and anti-hypertensive medication, did not materially change the results $[\beta=0.076(95 \% \mathrm{Cl}$ $-0.089 ; 0.241) \mathrm{p}=0.365$ ] (Table 6.2 , model $2+\mathrm{MAP}$ ). Results of model 2 with or without adjustment for MAP were similar $[\beta=0.092(95 \% \mathrm{Cl}-0.091 ; 0.275) \mathrm{p}=0.324]$ (Table 6.2, model 2). No interaction between uric acid and sex ( $p$ for interaction=0.736) or glucose metabolism status ( $p$ for interaction $=0.124$ ) was identified in the association between uric acid and cfPWV. 


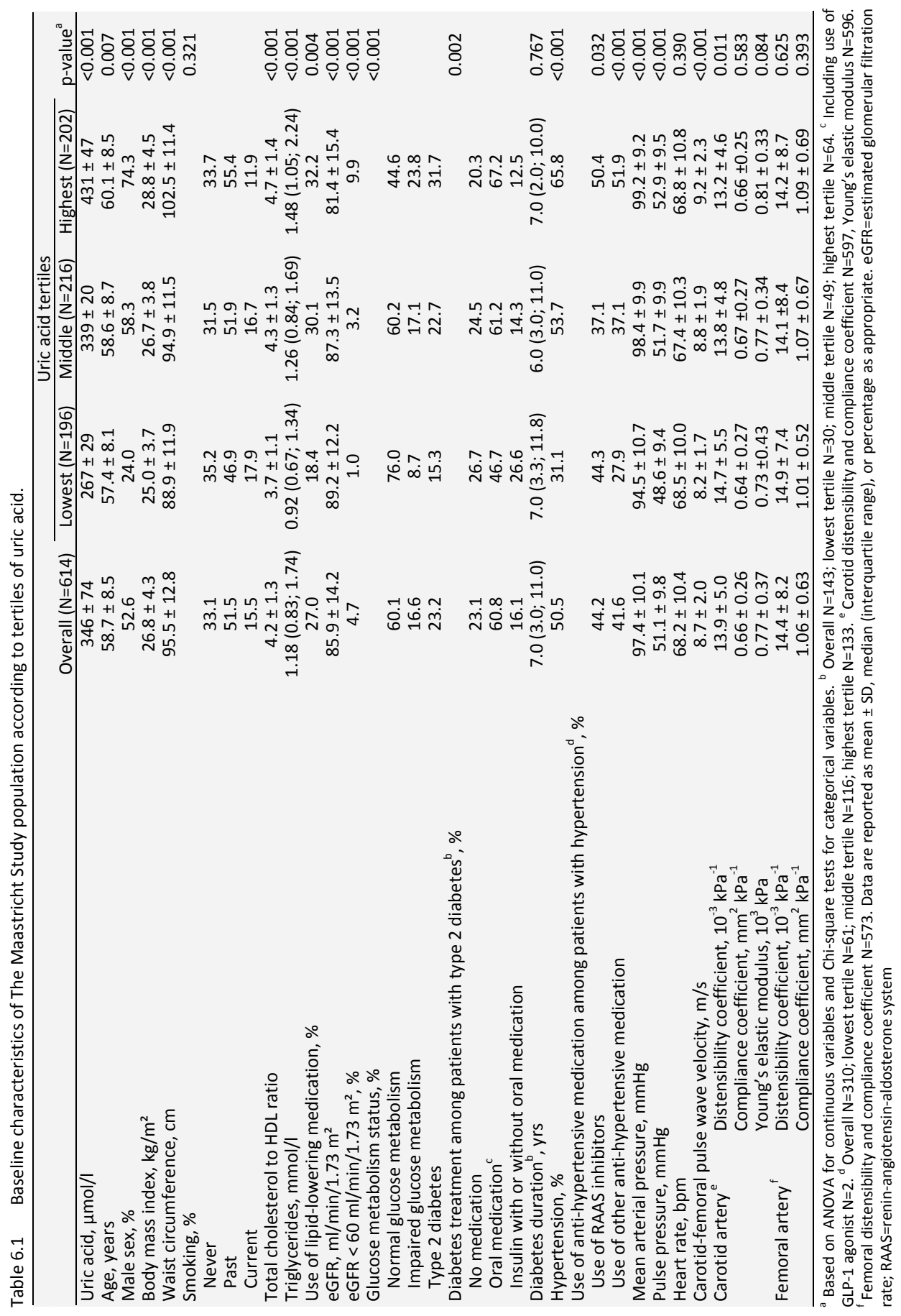


Table 6.2 The association between uric acid and regional stiffness.

\begin{tabular}{lccc}
\hline & \multicolumn{3}{c}{ CfPWV $(\mathrm{m} / \mathrm{s})^{\mathrm{b}}$} \\
\cline { 2 - 4 } & $\beta^{\mathrm{a}}$ & $95 \% \mathrm{Cl}$ & $\mathrm{p}$-value \\
\hline Model 1 & 0.216 & $0.061 ; 0.372$ & 0.006 \\
Model 1+MAP & 0.108 & $-0.031 ; 0.247$ & 0.127 \\
Model 2 & 0.092 & $-0.091 ; 0.275$ & 0.324 \\
Model 2+MAP & 0.076 & $-0.089 ; 0.241$ & 0.365 \\
\hline
\end{tabular}

${ }^{a}$ Uric acid expressed per standard deviation $(74 \mu \mathrm{mol} / \mathrm{l}) .{ }^{\mathrm{b}} \mathrm{N}=614$. Model 1 : adjusted for sex, age, glucose metabolism status. Model 2: model 1 + adjusted for heart rate, BMI, waist, smoking, total:HDL cholesterol, triglycerides, eGFR, use of lipid-lowering, diabetes, and antihypertensive medication. cfPWV=carotid-femoral Pulse Wave Velocity; $\mathrm{Cl}=$ confidence interval; $\mathrm{MAP}=$ mean arterial pressure

\section{Uric acid and local arterial stiffness}

After adjustment for age, sex, and glucose metabolism, higher uric acid was associated with greater stiffness indicated by a significantly lower carotid $D C[\beta=-0.445(95 \% \mathrm{Cl}$ -0.827 ; -0.063) $\mathrm{p}=0.022$ ] (Table 6.3, model 1). Uric acid was not associated with carotid CC, carotid YEM, femoral DC, or femoral CC (Table 6.3, model 1). The significant association with carotid DC was attenuated after adjustment for MAP $[\beta=-0.192(95 \% \mathrm{Cl}$ -0.541 ; 0.156) $\mathrm{p}=0.279$ ] (Table 6.3 , model $1+\mathrm{MAP}$ ). Additional adjustment for the confounding factors in model 2 did not materially change the result $[\beta=-0.084(95 \% \mathrm{Cl}$ -0.497; 0.329) $p=0.691$ ] (Table 6.3 , model $2+M A P)$. Results of model 2 with or without adjustment for MAP were similar $[\beta=-0.133(95 \% \mathrm{Cl}-0.585 ; 0.319) \mathrm{p}=0.563$ ] (Table 6.3, model 2).

No significant interactions between uric acid and sex were identified in the associations between uric acid and any of the local stiffness indices (data not shown). However, glucose metabolism status modified the association between uric acid and carotid DC ( $p$ for interaction=0.047). After full adjustment (model 2+MAP), higher uric acid was more strongly associated with lower carotid DC among individuals with normal glucose metabolism ( $N=370)[\beta=-0.504(95 \% \mathrm{Cl}-1.098 ; 0.090) p=0.096]$, in comparison with individuals with impaired glucose metabolism $(N=100)[\beta=-0.292(95 \%$ $\mathrm{Cl}-1.151 ; 0.568) \mathrm{p}=0.502]$, or with T2DM $(\mathrm{N}=141)[\beta=0.262(95 \% \mathrm{Cl}-0.497 ; 1.022)$ $\mathrm{p}=0.496$ ]. In addition, a trend for effect modification by glucose metabolism status was seen in the association between uric acid and carotid YEM ( $p$ for interaction=0.104). Uric acid was more strongly associated with YEM among individuals with normal glucose metabolism $(N=369)[\beta=0.030(95 \% \mathrm{Cl}-0.004 ; 0.064) \mathrm{p}=0.080]$, in comparison with individuals with impaired glucose metabolism $(\mathrm{N}=98)[\beta=-0.012(95 \% \mathrm{Cl}-0.098$; $0.074) p=0.789]$ or T2DM $(N=141)[\beta=-0.035(95 \% \mathrm{Cl}-0.142 ; 0.072) p=0.522]$. The directions of the associations between uric acid and carotid DC or YEM in individuals with normal glucose metabolism both pointed toward a detrimental effect of uric acid on arterial stiffness. 


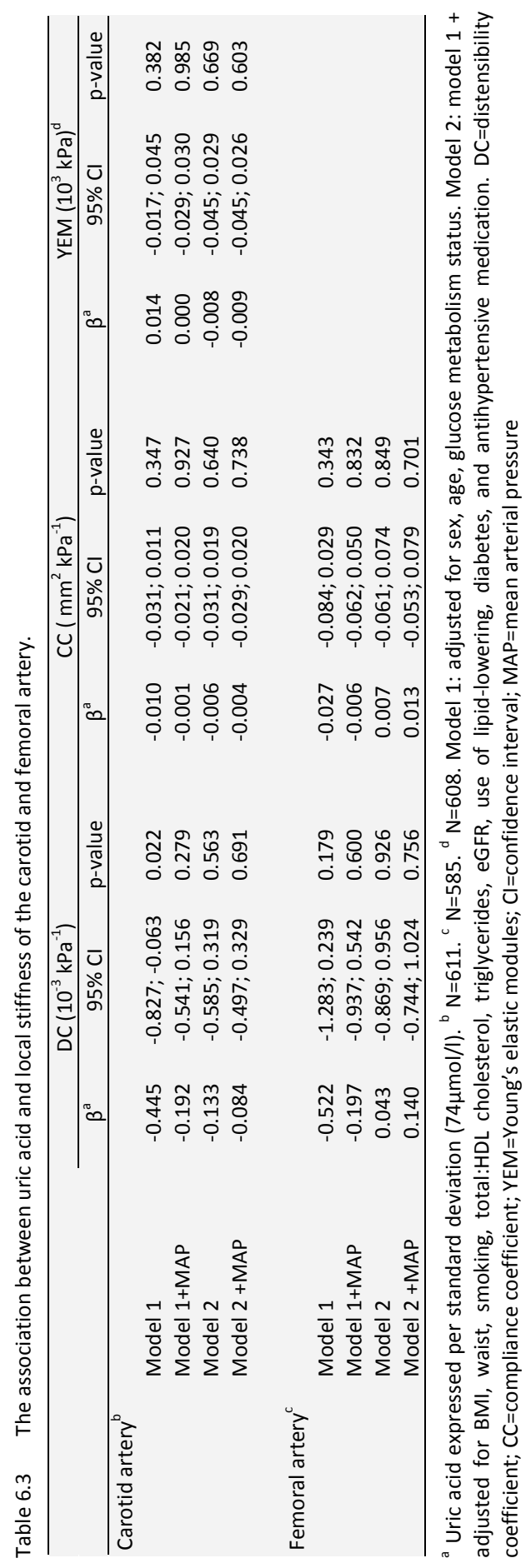




\section{Additional analyses}

After excluding eGFR from the list of confounders in model 2, the association between uric acid and cfPWV became slightly stronger but remained only borderline significant $[\beta=0.172(95 \% \mathrm{Cl}-0.05 ; 0.349) p=0.056]$. Further adjustment for MAP resulted in a nonsignificant association $[\beta=0.137(95 \% \mathrm{Cl}-0.041 ; 0.296) p=0.090]$. Excluding eGFR from the analyses did not change the results of the associations between uric acid and the local stiffness indices (data not shown).

\section{Discussion}

Accumulating evidence suggests that uric acid is associated with $C V D^{5}$. Arterial stiffness, as one of the precursors of CVD, could therefore be among the underlying mechanisms. However, we found no evidence that uric acid was significantly associated with cfPWV or local carotid and femoral arterial stiffness indices in this population-based cohort study (including $23.2 \%$ with T2DM) of adults aged $40-75$ years.

Our findings are in line with those of previous cross-sectional studies showing that uric acid was not associated with cfPWV in normotensive ${ }^{25}$, untreated hypertensive ${ }^{25,27}$, or hypertensive individuals ${ }^{24}$. Similarly, no association was found by Lim et al. in a healthy population free of CVD, diabetes, renal disease, hypertension, or dyslipidaemia $(\mathrm{N}=1276)^{26}$. In contrast, Liang et al. did find a positive association between uric acid and cfPWV in a comparable population $(\mathrm{N}=3772)^{15}$. However, the sample size was about three times larger than the study sample in the study of Lim et al. Independent associations were also found in never-treated hypertensive individuals $(\mathrm{N}=728)^{21}$ and among workers $(\mathrm{N}=940)^{11}$. The reasons for such discrepancies are not apparent, but it is possible that sample size, population characteristics, and the adjustments made for confounding factors such as glucose metabolism status or kidney function, play an important role ${ }^{24}$.

Femoral and carotid arteries differ with regard to structure and function ${ }^{51}$. The muscular femoral artery has more vascular smooth muscle cells and a higher collagen/elastin ratio, and stiffening of this artery is less influenced by age and blood pressure than stiffening of the carotid artery ${ }^{51}$. In the present study we found no difference in the associations between uric acid and femoral stiffness or carotid stiffness. In line with our study, Cipolli et al. did not identify an association between uric acid and carotid YEM or carotid CC in 338 individuals with hypertension ${ }^{29}$. In addition, an association between uric acid and carotid DC was not found among young adults $^{30}$. Our study is the first to evaluate the association between uric acid and the femoral artery and to compare the potential effect of uric acid on both carotid and femoral vessels. 
In our models, we distinguished between effects of blood pressure on arterial stiffness and differences in stiffness properties of the arterial wall per se. After adding MAP to model 1 the $\beta$-coefficients decreased substantially. This suggests that the associations between uric acid, cfPWV, and carotid DC in model 1 were attributable to MAP. However, after adjusting for the confounding factors in model 2, additional adjustment for MAP did not influence our results. MAP is correlated with the confounding factors in model 2, such as kidney function and BMI. Since the independent effects of these factors cannot be disentangled, we cannot draw firm conclusions on the role of MAP in the association between uric acid and arterial stiffness. A previous study found that a one SD increase in age ( $S D=8.5$ years), MAP $(\mathrm{SD}=9.6 \mathrm{~mm} \mathrm{Hg})$, or triglyceride concentrations $(\mathrm{SD}=64.1 \mathrm{mg} / \mathrm{dl})$, was significantly associated with an increase in cfPWV of $1.04 \mathrm{~m} / \mathrm{s}, 0.59 \mathrm{~m} / \mathrm{s}$ and $0.24 \mathrm{~m} / \mathrm{s}$, respectively ${ }^{52}$. In our study a one SD $(74 \mu \mathrm{mol} / \mathrm{l})$ increase in uric acid concentrations was non-significantly $(p=0.365)$ associated with a $0.076 \mathrm{~m} / \mathrm{s}$ higher cfPWV. Therefore, the magnitude of the association found in our study implies a very small, if any, contribution of uric acid to the development of aortic stiffness.

Excluding kidney function from the list of confounders in the additional analyses resulted in a slightly stronger association between uric acid and cfPWV. This may be explained by the association between kidney function and arterial stiffness ${ }^{49}$ and/or the association between kidney function and uric $\operatorname{acid}^{50}$. We cannot conclude whether kidney function acts as a confounder and/or as a mediator.

In our study, we found no sex-related difference in the associations between uric acid and any of the arterial stiffness indices. This is in line with other studies that investigated the association between uric acid and cfPWV in the general population ${ }^{15}$ or in individuals with newly diagnosed hypertension ${ }^{21}$. In contrast, Chen et al. identified a stronger relation between uric acid and arterial stiffness among men ${ }^{11}$. An increase of $100 \mu \mathrm{mol} / \mathrm{l}$ serum uric acid was significantly associated with an increase of $0.15 \mathrm{~m} / \mathrm{s}$ in cfPWV among men, whereas there was no association among women. The authors suggested that the null finding among women may be attributable to the small percentage of women with hyperuricaemia ${ }^{11}$. Although sex differences in the impact of elevated serum uric acid concentrations on CVD have often been observed, explanations for these differences are still lacking.

It has been suggested that uric acid may have a different effect on cardiovascular mortality according to glucose metabolism status ${ }^{36}$, because of the possible biological interaction between uric acid, glucose, and insulin concentrations ${ }^{37,38}$. The Maastricht Study cohort was designed to find potential contrasts between individuals with and without T2DM. In the present study we found a significant interaction between uric acid and glucose metabolism status in the association with carotid DC and a trend for interaction with carotid YEM. Stratified results suggest that the detrimental effect of uric acid in the association with carotid arterial stiffness is more apparent among individuals with normal glucose metabolism than among those with impaired glucose 
metabolism or T2DM. Individuals with T2DM often experience accelerated aging with a higher level of arterial stiffness ${ }^{53}$. In accordance, in the present study individuals with T2DM had stiffer arteries. Therefore, uric acid may play a more prominent role in the early development or less severe stages of arterial stiffness. However, note that none of the stratified associations were significant and the $\beta$-coefficients of the associations were relatively small. Furthermore, the subgroups according to glucose metabolism status differed in size, with a larger number of individuals in the normal glucose metabolism subgroup.

A limitation of this study is the exclusion of a proportion ( $5-10 \%)$ of individuals from the analyses because of missing values on one of the arterial stiffness indices. However, we assumed these missing values to be missing at random because most values were missing due to logistic factors such as the unavailability of a vascular ultrasound technologist. A further limitation is that the cross-sectional design does not allow for conclusions on cause and effect relations.

This study was strengthened by the comprehensive evaluation of arterial stiffness, using both regional as well as local arterial stiffness indices. Moreover, vascular echography data were collected by trained vascular ultrasound technologists and benefited from the high repeatability of the aortic and carotid stiffness measurements. Additionally, due to the extensive phenotyping we were able to adjust for a series of potential confounders.

In conclusion, we found no significant association between uric acid and aortic, carotid or femoral stiffness. The association with carotid stiffness, however, seemed to differ with glucose metabolism status. More research is needed to confirm these results. 


\section{References}

1. Uaratanawong S, Suraamornkul S, Angkeaw S, Uaratanawong R. Prevalence of hyperuricemia in Bangkok population. Clin Rheumatol. 2011;30:887-893.

2. Lohsoonthorn V, Dhanamun B, Williams MA. Prevalence of hyperuricemia and its relationship with metabolic syndrome in Thai adults receiving annual health exams. Arch Med Res. 2006;37:883-889.

3. Conen $D$, Wietlisbach $V$, Bovet $P$, et al. Prevalence of hyperuricemia and relation of serum uric acid with cardiovascular risk factors in a developing country. BMC Public Health. 2004;4:9.

4. Zhu Y, Pandya BJ, Choi HK. Comorbidities of gout and hyperuricemia in the US general population: NHANES 2007-2008. Am J Med. 2012;125:679-687

5. Kanbay M, Segal M, Afsar B, Kang DH, Rodriguez-Iturbe B, Johnson RJ. The role of uric acid in the pathogenesis of human cardiovascular disease. Heart. 2013;99:759-766.

6. Laurent S, Cockcroft J, Van Bortel L, et al. Expert consensus document on arterial stiffness: methodological issues and clinical applications. Eur Heart J. 2006;27:2588-2605.

7. Zieman SJ, Melenovsky V, Kass DA. Mechanisms, pathophysiology, and therapy of arterial stiffness. Arterioscler Thromb Vasc Biol. 2005;25:932-943.

8. Corry DB, Eslami P, Yamamoto K, Nyby MD, Makino H, Tuck ML. Uric acid stimulates vascular smooth muscle cell proliferation and oxidative stress via the vascular renin-angiotensin system. $J$ Hypertens. 2008;26:269-275.

9. Kang $\mathrm{DH}$, Han L, Ouyang $\mathrm{X}$, et al. Uric acid causes vascular smooth muscle cell proliferation by entering cells via a functional urate transporter. Am J Nephrol. 2005;25:425-433.

10. Yu MA, Sanchez-Lozada LG, Johnson RJ, Kang DH. Oxidative stress with an activation of the reninangiotensin system in human vascular endothelial cells as a novel mechanism of uric acid-induced endothelial dysfunction. J Hypertens. 2010;28:1234-1242.

11. Chen X, Li Y, Sheng CS, Huang QF, Zheng Y, Wang JG. Association of serum uric acid with aortic stiffness and pressure in a Chinese workplace setting. Am J Hypertens. 2010;23:387-392.

12. Ishizaka N, Ishizaka Y, Toda E, Hashimoto H, Nagai R, Yamakado M. Higher serum uric acid is associated with increased arterial stiffness in Japanese individuals. Atherosclerosis. 2007;192:131-137.

13. Khan F, George J, Wong K, McSwiggan S, Struthers AD, Belch JJ. The association between serum urate levels and arterial stiffness/endothelial function in stroke survivors. Atherosclerosis. 2008;200:374-379.

14. Kuo CF, Yu KH, Luo SF, et al. Role of uric acid in the link between arterial stiffness and cardiac hypertrophy: a cross-sectional study. Rheumatology (Oxford). 2010;49:1189-1196.

15. Liang J, Li Y, Zhou N, et al. Synergistic effects of serum uric acid and cardiometabolic risk factors on early stage atherosclerosis: the cardiometabolic risk in Chinese study. PLoS One. 2012;7:e51101.

16. Park JS, Kang S, Ahn CW, Cha BS, Kim KR, Lee HC. Relationships between serum uric acid, adiponectin and arterial stiffness in postmenopausal women. Maturitas. 2012;73:344-348.

17. Saijo $\mathrm{Y}$, Utsugi M, Yoshioka E, et al. Relationships of C-reactive protein, uric acid, and glomerular filtration rate to arterial stiffness in Japanese subjects. J Hum Hypertens. 2005;19:907-913.

18. Shin JY, Lee HR, Shim JY. Significance of high-normal serum uric acid level as a risk factor for arterial stiffness in healthy Korean men. Vasc Med. 2012;17:37-43.

19. Tomiyama H, Yamashina A, Arai T, et al. Influences of age and gender on results of noninvasive brachial-ankle pulse wave velocity measurement--a survey of 12517 subjects. Atherosclerosis. 2003; 166:303-309.

20. Tsai WC, Huang YY, Lin CC, et al. Uric acid is an independent predictor of arterial stiffness in hypertensive patients. Heart Vessels. 2009;24:371-375.

21. Vlachopoulos C, Xaplanteris P, Vyssoulis G, et al. Association of serum uric acid level with aortic stiffness and arterial wave reflections in newly diagnosed, never-treated hypertension. Am J Hypertens. 2011;24:33-39.

22. Maldonado J, Pereira T, Polonia J, Silva JA, Morais J, Marques M. Arterial stiffness predicts cardiovascular outcome in a low-to-moderate cardiovascular risk population: the EDIVA (Estudo de DIstensibilidade VAscular) project. J Hypertens. 2011;29:669-675.

23. Willum-Hansen $T$, Staessen JA, Torp-Pedersen $C$, et al. Prognostic value of aortic pulse wave velocity as index of arterial stiffness in the general population. Circulation. 2006;113:664-670. 
24. Gomez-Marcos MA, Recio-Rodriguez JI, Patino-Alonso MC, et al. Relationship between uric acid and vascular structure and function in hypertensive patients and sex-related differences. Am J Hypertens. 2013;26:599-607.

25. Hsu PF, Chuang SY, Cheng HM, et al. Associations of serum uric acid levels with arterial wave reflections and central systolic blood pressure. Int J Cardiol. 2013;168:2057-2063.

26. Lim JH, Kim YK, Kim YS, Na SH, Rhee MY, Lee MM. Relationship between serum uric Acid levels, metabolic syndrome, and arterial stiffness in korean. Korean Circ J. 2010;40:314-320.

27. Tsioufis C, Kyvelou S, Dimitriadis K, et al. The diverse associations of uric acid with low-grade inflammation, adiponectin and arterial stiffness in never-treated hypertensives. J Hum Hypertens. 2011;25:554-559.

28. Cicero AF, Salvi P, D'Addato S, Rosticci M, Borghi C. Association between serum uric acid, hypertension, vascular stiffness and subclinical atherosclerosis: data from the Brisighella Heart Study. J Hypertens. 2014;32:57-64.

29. Cipolli JA, Ferreira-Sae MC, Martins RP, et al. Relationship between serum uric acid and internal carotid resistive index in hypertensive women: a cross-sectional study. BMC Cardiovasc Disord. 2012;12:52.

30. Oikonen M, Wendelin-Saarenhovi M, Lyytikainen LP, et al. Associations between serum uric acid and markers of subclinical atherosclerosis in young adults. The cardiovascular risk in Young Finns study. Atherosclerosis. 2012;223:497-503.

31. Dijk JM, van der Graaf Y, Grobbee DE, Bots ML. Carotid stiffness indicates risk of ischemic stroke and TIA in patients with internal carotid artery stenosis: the SMART study. Stroke. 2004;35:2258-2262.

32. Lovett JK, Howard SC, Rothwell PM. Pulse pressure is independently associated with carotid plaque ulceration. J Hypertens. 2003;21:1669-1676.

33. van de Laar RJ, Ferreira I, van Mechelen W, Prins MH, Twisk JW, Stehouwer CD. Habitual physical activity and peripheral arterial compliance in young adults: the Amsterdam growth and health longitudinal study. Am J Hypertens. 2011;24:200-208.

34. Fang J, Alderman MH. Serum uric acid and cardiovascular mortality the NHANES I epidemiologic followup study, 1971-1992. National Health and Nutrition Examination Survey. JAMA. 2000;283:2404-2410.

35. Culleton BF, Larson MG, Kannel WB, Levy D. Serum uric acid and risk for cardiovascular disease and death: the Framingham Heart Study. Ann Intern Med. 1999;131:7-13.

36. Kramer CK, von Muhlen D, Jassal SK, Barrett-Connor E. A prospective study of uric acid by glucose tolerance status and survival: the Rancho Bernardo Study. J Intern Med. 2010;267:561-566.

37. Padova J, Patchefsky A, Onesti G, Faludi G, Bendersky G. The effect of glucose loads on renal uric acid excretion in diabetic patients. Metabolism. 1964;13:507-512.

38. Quinones Galvan A, Natali A, Baldi S, et al. Effect of insulin on uric acid excretion in humans. Am J Physiol. 1995;268:E1-5.

39. Schram MT, Sep SJS, Kallen van der CJ, et al. The Maastricht Study: An extensive phenotyping study on determinants of type 2 diabetes, its complications and its comorbidities. Eur J Epid.29:439-451.

40. Leng GC, Fowkes FG. The Edinburgh Claudication Questionnaire: an improved version of the WHO/Rose Questionnaire for use in epidemiological surveys. J Clin Epidemiol. 1992;45:1101-1109.

41. Van Bortel LM, Laurent S, Boutouyrie P, et al. Expert consensus document on the measurement of aortic stiffness in daily practice using carotid-femoral pulse wave velocity. J Hypertens. 2012;30: 445-448.

42. Hermeling E, Reesink KD, Kornmann LM, Reneman RS, Hoeks AP. The dicrotic notch as alternative timereference point to measure local pulse wave velocity in the carotid artery by means of ultrasonography. J Hypertens. 2009;27:2028-2035.

43. Willekes C, Hoeks AP, Bots ML, Brands PJ, Willigers JM, Reneman RS. Evaluation of off-line automated intima-media thickness detection of the common carotid artery based on M-line signal processing. Ultrasound Med Biol. 1999;25:57-64.

44. Reneman RS, Meinders JM, Hoeks AP. Non-invasive ultrasound in arterial wall dynamics in humans: what have we learned and what remains to be solved. Eur Heart J. 2005;26:960-966.

45. Levey AS, Stevens LA, Schmid CH, et al. A new equation to estimate glomerular filtration rate. Ann Intern Med. 2009;150:604-612. 
46. WHO. Definition and diagnosis of diabetes mellitus and intermediate hyperglycemia: Report of a who/idf consultation. Geneva, Switzerland: World Health Organization (WHO);2006.

47. Greenwald SE. Ageing of the conduit arteries. J Pathol. 2007;211:157-172.

48. Roach MR, Burton AC. The reason for the shape of the distensibility curves of arteries. Can J Biochem Physiol. 1957;35:681-690.

49. Safar ME, London GM, Plante GE. Arterial stiffness and kidney function. Hypertension. 2004;43: 163-168.

50. Sedaghat S, Hoorn EJ, van Rooij FJ, et al. Serum uric Acid and chronic kidney disease: the role of hypertension. PLoS One. 2013;8:e76827.

51. Benetos A, Laurent S, Hoeks AP, Boutouyrie PH, Safar ME. Arterial alterations with aging and high blood pressure. A noninvasive study of carotid and femoral arteries. Arterioscler Thromb. 1993;13:90-97.

52. Mitchell GF, Parise H, Benjamin EJ, et al. Changes in arterial stiffness and wave reflection with advancing age in healthy men and women: the Framingham Heart Study. Hypertension. 2004;43: 1239-1245.

53. Cruickshank K, Riste L, Anderson SG, Wright JS, Dunn G, Gosling RG. Aortic pulse-wave velocity and its relationship to mortality in diabetes and glucose intolerance: an integrated index of vascular function? Circulation. 2002;106:2085-2090. 
Chapter 6 


\section{Appendix 6}

Supplemental table 
Chapter 6 
Table S6.1 Baseline characteristics of The Maastricht Study population and the individuals excluded from the analyses because of missing values.

\begin{tabular}{|c|c|c|c|}
\hline & $\begin{array}{l}\text { Study population } \\
\qquad \mathrm{N}=614\end{array}$ & Missing & $\begin{array}{c}\text { Excluded because of } \\
\text { missing values } \\
\mathrm{N}=81\end{array}$ \\
\hline Uric acid, $\mu \mathrm{mol} / \mathrm{I}$ & $346 \pm 74$ & 13 & $377 \pm 125$ \\
\hline Age, years & $58.7 \pm 8.5$ & 0 & $60.6 \pm 9.1$ \\
\hline Male sex, \% & 52.6 & 0 & 53.1 \\
\hline Body mass index, $\mathrm{kg} / \mathrm{m}^{2}$ & $26.8 \pm 4.3$ & 1 & $29.0 \pm 5.6$ \\
\hline Waist circumference, $\mathrm{cm}$ & $95.5 \pm 12.8$ & 3 & $100.9 \pm 16.4$ \\
\hline Smoking, \% & & 17 & \\
\hline Never & 33.1 & & 23.4 \\
\hline Past & 51.5 & & 53.1 \\
\hline Current & 15.5 & & 23.4 \\
\hline Total cholesterol to HDL ratio & $4.2 \pm 1.3$ & & $4.3 \pm 1.2$ \\
\hline Triglycerides, mmol/l & $1.18(0.83 ; 1.74)$ & 7 & $1.54(0.99 ; 2.00)$ \\
\hline Use of lipid-lowering medication, \% & 27.0 & 0 & 54.3 \\
\hline eGFR, $\mathrm{ml} / \mathrm{min} / 1.73 \mathrm{~m}^{2}$ & $85.9 \pm 14.2$ & 9 & $80.9 \pm 17.7$ \\
\hline eGFR <60 ml/min/1.73 m², \% & 4.7 & 9 & 18.1 \\
\hline Glucose metabolism status, \% & & 0 & \\
\hline Normal glucose metabolism & 60.1 & & 42.0 \\
\hline Impaired glucose metabolism & 16.6 & & 16.0 \\
\hline Type 2 diabetes & 23.2 & & 42.0 \\
\hline $\begin{array}{l}\text { Diabetes treatment among patients with } \\
\text { type } 2 \text { diabetes }{ }^{a}, \%\end{array}$ & & 0 & \\
\hline No medication & 23.1 & & 23.5 \\
\hline Oral medication $^{\mathrm{b}}$ & 60.8 & & 41.2 \\
\hline Insulin with or without oral medication & 16.1 & & 35.3 \\
\hline Diabetes duration ${ }^{a}$, yrs & $7.0(3.0 ; 11.0)$ & 12 & $9.5(4.0 ; 16.0)$ \\
\hline Hypertension, \% & 50.4 & 2 & 66.7 \\
\hline \multicolumn{4}{|l|}{$\begin{array}{l}\text { Use of anti-hypertensive medication among } \\
\text { patients with hypertension }{ }^{c}, \%\end{array}$} \\
\hline Use of RAAS inhibitors & 44.2 & 0 & 55.6 \\
\hline Use of other anti-hypertensive medication & 41.6 & 0 & 61.1 \\
\hline Mean arterial pressure, $\mathrm{mmHg}$ & $97.4 \pm 10.1$ & 15 & $99.6 \pm 12.0$ \\
\hline Pulse pressure, $\mathrm{mmHg}$ & $51.1 \pm 9.8$ & 15 & $54.6 \pm 11.7$ \\
\hline Heart rate, bpm & $68.2 \pm 10.4$ & 3 & $71.0 \pm 14.4$ \\
\hline Carotid-femoral pulse wave velocity, $\mathrm{m} / \mathrm{s}$ & $8.7 \pm 2.0$ & 43 & $9.7 \pm 2.5$ \\
\hline \multicolumn{4}{|l|}{ Carotid artery $^{d}$} \\
\hline Distensibility coefficient, $10^{-3} \mathrm{kPa}^{-1}$ & $13.9 \pm 5.0$ & 21 & $12.8 \pm 5.9$ \\
\hline Compliance coefficient, $\mathrm{mm}^{2} \mathrm{kPa}^{-1}$ & $0.66 \pm 0.26$ & 21 & $0.62 \pm 0.25$ \\
\hline Young's elastic modulus, $10^{3} \mathrm{kPa}$ & $0.77 \pm 0.37$ & 21 & $0.89 \pm 0.44$ \\
\hline \multicolumn{4}{|l|}{ Femoral artery ${ }^{\mathrm{e}}$} \\
\hline Distensibility coefficient, $10^{-3} \mathrm{kPa}^{-1}$ & $14.4 \pm 8.2$ & 31 & $10.9 \pm 7.2$ \\
\hline Compliance coefficient, $\mathrm{mm}^{2} \mathrm{kPa}^{-1}$ & $1.06 \pm 0.63$ & 31 & $0.78 \pm 0.53$ \\
\hline
\end{tabular}

a Study population $\mathrm{N}=143$; excluded because of missing values $\mathrm{N}=34 .{ }^{\mathrm{b}}$ Including use of $\mathrm{GLP}-1$ agonist $\mathrm{N}=2$. ${ }^{\mathrm{c}}$ Study population $\mathrm{N}=310$; excluded because of missing values $\mathrm{N}=54$. ${ }^{\mathrm{d}}$ Carotid distensibility and compliance coefficient $\mathrm{N}=597$, Young's elastic modulus $\mathrm{N}=596$. ${ }^{\mathrm{e}}$ Femoral distensibility and compliance coefficient $\mathrm{N}=573$ Data are reported as mean \pm SD, median (interquartile range), or percentage as appropriate. eGFR=estimated glomerular filtration rate; RAAS=renin-angiotensin-aldosterone system 


\section{Chapter}

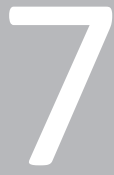

Uric acid and skin microvascular function:

The Maastricht Study

J.M.A. Wijnands, A.J.H.M. Houben, D.M.J. Muris, A. Boonen, M.T. Schram, S.J.S. Sep, C.J.H. van der Kallen, R.M.A. Henry, P.C. Dagnelie, Sj.van der Linden, N.C. Schaper, I.C.W. Arts, C.D.A. Stehouwer 


\section{Abstract}

\section{Objective}

Microvascular dysfunction has been suggested as a possible underlying mechanism for the association between uric acid and various diseases, such as hypertension, renal disease, and cardiomyopathies. We therefore analysed the association between serum uric acid and skin microvascular function, a model of generalized microvascular function.

\section{Methods}

A cross-sectional study was performed in 610 individuals ( $51.8 \%$ men; mean age $58.7 y r s \pm 8.6 y r s ;$ $23.6 \%$ with type 2 diabetes (by design)) from The Maastricht Study. We assessed skin capillary density (capillaries $/ \mathrm{mm}^{2}$ ) by capillaroscopy at baseline, after 4 minutes of arterial occlusion, and after 2 minutes of venous congestion. Capillary recruitment after arterial occlusion and during venous congestion was expressed as the absolute change in capillary density after recruitment and as the percentage change in capillary density from baseline.

\section{Results}

Crude linear regression analyses showed that serum uric acid (per +1 standard deviation (SD) of $74 \mu \mathrm{mol} / \mathrm{l})$ was not associated with baseline capillary density $[\beta=-0.21(95 \% \mathrm{Cl}-1.61 ; 1.19)$ $p=0.765]$, while an inverse association was found between uric acid and absolute change in capillary density after arterial occlusion $[\beta=-1.15(95 \% \mathrm{Cl}-2.36 ; 0.06) p=0.062]$ and during venous congestion $[\beta=-1.41(95 \% \mathrm{Cl}-2.68 ;-0.14) \mathrm{p}=0.029]$. However, after adjustment for sex, age, and glucose metabolism status, these associations were no longer statistically significant. In addition, we found no association between uric acid and percentage capillary recruitment after arterial occlusion $[\beta=-1.66(95 \% \mathrm{Cl}-3.97 ; 0.65) p=0.159]$ or during venous congestion $[\beta=-2.02(95 \% \mathrm{Cl}$ $-4.46 ; 0.42) p=0.104]$ in unadjusted analyses; multivariable analyses gave similar results.

\section{Conclusion}

These results do not support the hypothesis that generalized microvascular dysfunction (as estimated in skin microcirculation) is the underlying mechanism for the association between uric acid and cardiovascular and renal diseases. The possibility that uric acid is associated with microvascular dysfunction in specific end-organs, e.g. heart or kidney, needs further investigation. 


\section{Introduction}

High uric acid concentrations may induce endothelial dysfunction by decreasing nitric oxide availability ${ }^{1}$, and stimulate vascular smooth muscle cell proliferation through activation of the renin-angiotensin system ${ }^{2,3}$. These processes can eventually result in microvascular damage ${ }^{4}$. Therefore, uric acid-mediated microvascular dysfunction has been brought forward as a potential mechanism underlying the association between uric acid and various diseases, such as hypertension ${ }^{5}$, renal disease, and cardiomyopathies $^{7}$, a hypothesis that is supported by animal models ${ }^{8,9}$. However, epidemiological evidence from population-based studies is still scarce.

A limited number of small studies have reported an association between uric acid and coronary microcirculatory function as determined by coronary flow reserve in patients with cardiomyopathy ${ }^{10-12}$. Furthermore, prior work has shown that uric acid was associated with retinal arteriolar narrowing ${ }^{13}$ and the development of microalbuminuria in healthy men after 5 -year follow-up ${ }^{14}$. As microvascular dysfunction may occur in in various vascular beds simultaneously, it has been suggested that microvascular dysfunction is part of a systemic process ${ }^{15}$. The cutaneous microcirculation is considered a representative model of microvascular function in general $^{16}$. An important advantage of the skin is that non-invasive techniques can be used to assess mechanisms of microvascular dilation and constriction ${ }^{16}$. Furthermore, alterations in the cutaneous microcirculation have been identified in patients with type 2 diabetes $(\mathrm{T} 2 \mathrm{DM})^{17}$, chronic heart failure ${ }^{18}$, and hypertension ${ }^{19}$. Although the microcirculation of the skin may be a representative model to study generalized microcirculatory function, only one previous study assessed the association with uric acid ${ }^{20}$. This study showed that higher uric acid concentrations were associated with a reduced endothelium-dependent vasodilator response in patients with type 1 diabetes ${ }^{20}$.

In view of the above, the aim of the present study was to assess the association between serum uric acid concentration and cutaneous microcirculatory function as determined by capillary density. Since it has been suggested that uric acid has a more pronounced detrimental effect in women ${ }^{21}$, younger individuals ${ }^{5,22}$, and individuals with normal glucose metabolism ${ }^{23,24}$, possibly because of the primary involvement of uric acid in the early or less severe stages of cardiovascular diseases ${ }^{22,25}$, we additionally investigated potential differences related to sex, age, and glucose metabolism status. 


\section{Methods}

\section{Study population and design}

In this study, we used data from The Maastricht Study, an observational prospective population-based cohort study. The rationale and methodology have been described previously ${ }^{26}$. In brief, the study focuses on the aetiology, pathophysiology, complications and comorbidities of T2DM and is characterized by an extensive phenotyping approach. Eligible for participation were all individuals aged between 40 and 75 years and living in the southern part of the Netherlands. Participants were recruited through mass media campaigns and from the municipal registries and the regional Diabetes Patient Registry via mailings. Recruitment was stratified according to known T2DM status for reasons of efficiency. The present report includes crosssectional data from the first 866 participants, who completed the baseline survey between November 2010 and March 2012. The examinations of each participant were performed within a time window of three months. The study has been approved by the institutional medical ethical committee (NL31329.068.10) and the Netherlands Health Council under the Dutch "Law for Population Studies" (Permit 131088-105234-PG). All participants gave written informed consent.

For the present study we excluded subjects without data on uric acid $(\mathrm{N}=13)$, capillary density $(\mathrm{N}=44)$, systolic blood pressure $(\mathrm{N}=2), \mathrm{BMI}(\mathrm{N}=1)$, waist $(\mathrm{N}=3)$, cholesterol concentration $(\mathrm{N}=8)$, smoking status $(\mathrm{N}=17)$ and/or estimated glomerular filtration rate (eGFR) ( $N=9$ ). We also excluded individuals with type 1 diabetes $(N=4)$ or a history of cardiovascular disease $(\mathrm{N}=152)$. A history of cardiovascular disease was defined as self-reported myocardial infarction; cerebrovascular infarction or haemorrhage; and/or percutaneous artery angioplasty or vascular surgery of the coronary, abdominal, peripheral or carotid arteries according to the Rose questionnaire $^{27}$. Furthermore, individuals taking any uric-acid-lowering medication (i.e. allopurinol or benzbromaron; $\mathrm{N}=21$ ) were excluded. The total study population thus consisted of 610 participants.

\section{Skin capillaroscopy}

Skin capillaroscopy was conducted as described elsewhere ${ }^{28}$. In short, measurements were performed in a temperature-controlled $\left(24^{\circ} \mathrm{C}\right)$ room after a standardized breakfast or lunch, which included restrictions for caffeine, fatty products, and smoking. A digital video microscope (Capiscope, KK Technology, Honiton UK) was used to record capillaries in the dorsal skin of the distal phalanges of the right-hand third and fourth finger. Capillaries were visualised $4.5 \mathrm{~mm}$ proximal to the terminal row of capillaries in the middle of the nailfold, after which a region of interest of $1 \mathrm{~mm}^{2}$ skin area was selected. Capillary density (mean of two fields) was measured under three 
conditions. First, baseline capillary density was assessed. Second, capillary recruitment after 4 minutes of arterial occlusion was measured. Finally, capillary density after 2 minutes of venous congestion was examined. These measures are thought to reflect functional and/or structural capillary reserve capacity ${ }^{4}$. The number of continuously perfused capillaries within the region of interest was counted with a semi-automatic image analysis application (CapiAna) by two investigators who were both blinded to the characteristics of the participants. As described elsewhere, the intra- and inter-observer variability was $2.5 \%$ and $5.6 \%$, respectively ${ }^{28}$.

\section{Covariates}

After an overnight fast, venous blood samples were collected at The Maastricht Study research centre. Plasma glucose was measured with a standard enzymatic hexokinase reference method, and serum total cholesterol, HDL cholesterol, triglycerides, creatinine and uric acid concentrations were measured with standard (enzymatic and/or colorimetric) methods by an automatic analyser (Beckman Synchron LX20, Beckman Coulter Inc., Brea, USA) at Maastricht University Medical Centre (the Netherlands). Measurement of creatinine was based on the Jaffé method traceable to isotope dilution mass spectrometry (Synchron LX20, Beckman Coulter Inc., Brea, USA). Weight and height were measured without shoes and wearing light clothing using a scale and stadiometer to the nearest $0.5 \mathrm{~kg}$ or $0.1 \mathrm{~cm}$ (Seca, Hamburg, Germany). Body mass index (BMI) was calculated as body weight $(\mathrm{kg})$ divided by height squared $\left(\mathrm{m}^{2}\right)$. Waist circumference was measured in duplicate midway between the lower rib margin and the iliac crest at the end of expiration, to the nearest $0.5 \mathrm{~cm}$, with a flexible plastic tape measure (Seca, Hamburg, Germany). Participants were requested to bring all the medication they used at the time of measurement or a list from their pharmacists to the research centre. During a medication interview generic name, dose and frequency, and additional over-the-counter (OTC) medication use were registered by trained staff. All participants received an extensive web-based questionnaire in which smoking behaviour (never, former, current) and years of diabetes duration was self-reported. Systolic and diastolic blood pressure was determined three times on the right arm after a 10-minute resting period, using a blood pressure monitor (Omron 705 IT, Japan). The average of the three measurements was calculated. Hypertension was defined as office systolic blood pressure $>140 \mathrm{mmHg}$, diastolic blood pressure $>90$ $\mathrm{mmHg}$, and/or current anti-hypertensive medication use. Renal function as estimated by eGFR (in $\mathrm{ml} / \mathrm{min} / 1.73 \mathrm{~m}^{2}$ ) was calculated with the Chronic Kidney Disease Epidemiology Collaboration formula ${ }^{29}$. To determine glucose metabolism, all participants (except those who used insulin) underwent a standardized 2-h, $75 \mathrm{~g}$ oral glucose tolerance test (OGTT) after an overnight fast. For safety reasons, participants with a fasting glucose level above $11.0 \mathrm{mmol} / \mathrm{l}$, as determined by a finger prick, did not undergo the OGTT $(\mathrm{N}=13)$. Glucose metabolism status was classified according to the 
WHO 2006 criteria $^{30}$ as normal glucose metabolism (NGM) in case of fasting plasma glucose concentrations $<6.1 \mathrm{mmol} / \mathrm{l}$ and 2-h post-glucose concentrations $<7.8 \mathrm{mmol} / \mathrm{l}$; impaired glucose tolerance (IGT) in case of fasting plasma glucose $<7.0 \mathrm{mmol} / \mathrm{l}$ and $2-\mathrm{h}$ post-glucose $\geq 7.8 \mathrm{mmol} / \mathrm{l}$ and $<11.1 \mathrm{mmol} /$; impaired fasting glucose (IFG) in case of fasting plasma glucose 6.1 to $6.9 \mathrm{mmol} / \mathrm{l}$ and (if measured) 2-h post-glucose $<7.8$ $\mathrm{mmol} / \mathrm{l}$; and T2DM in case of fasting plasma glucose $\geq 7.0 \mathrm{mmol} / \mathrm{l}$ and/or 2 -h postglucose $\geq 11.1 \mathrm{mmol} / \mathrm{l}$. For this study, we defined having either IFG or IGT as impaired glucose metabolism (IGM).

\section{Statistical analysis}

All analyses were performed using IBM SPSS version 19 (SPSS, Chicago, IL, USA). General characteristics of the study population were compared across tertiles of uric acid concentrations using analysis of variance (ANOVA) for continuous variables and $\chi^{2}$ test for discrete variables. Multivariable linear regression analyses were used to determine the association between uric acid (per +1 standard deviation (SD), $\mathrm{SD}=74 \mu \mathrm{mol} / \mathrm{l})$ and measures of skin microvascular function, i.e. capillary density at baseline (capillaries $/ \mathrm{mm}^{2}$ ) and capillary recruitment after arterial occlusion and during venous congestion. Capillary recruitment after arterial occlusion and during venous congestion was expressed as the absolute change in capillary density after recruitment and as the percentage change in capillary density from baseline. The crude model (model 1) was first adjusted for age, sex and glucose metabolism status (model 2). Subsequently, the associations were adjusted for systolic blood pressure, BMI, waist, smoking habits (current, ever, and never smoker), total cholesterol to HDL cholesterol ratio, triglycerides, eGFR, and use of lipid-modifying and anti-diabetic medication, renin-angiotensin-aldosterone system inhibitors and other anti-hypertensives, including beta-blockers (model 3). Because high blood pressure and (or) low eGFR can theoretically acts as intermediates linking uric acid to microvascular dysfunction, adjustment for these variables may represent overadjustment. We therefore specifically investigated whether model 3 was affected by the inclusion of these variables.

Finally, we tested interactions between uric acid and sex, age, or glucose metabolism status ( 3 categories: NGM, IGM, and T2DM) in model 3, both with and without adjustment for systolic blood pressure and eGFR. A p-value $<0.05$ was considered statistically significant, except for the interaction analyses, where we used p-value $<0.10$. 


\section{Results}

Table 7.1 shows the characteristics of the study population. This study included 610 individuals with a mean age of $58.7 \pm 8.6$ years of which $51.8 \%$ were men. By design, individuals with type 2 diabetes were oversampled (23.6\% of our study population). Mean capillary density at baseline was $73.7 \pm 17.6$ capillaries $/ \mathrm{mm}^{2}$; density increased to $103.8 \pm 17.5$ capillaries $/ \mathrm{mm}^{2}$ after arterial occlusion and to $104.2 \pm 18.0$ capillaries $/ \mathrm{mm}^{2}$ during venous congestion. Consequently, the average percentages of recruitment after arterial occlusion or during venous congestion were $45.5 \pm 29.1 \%$ and $46.2 \pm 30.7 \%$, respectively. Capillary density and percentage of recruitment were not significantly different between uric acid tertiles. However, individuals in the third uric acid tertile were more often male and did have a worse metabolic profile, including significant higher $\mathrm{BMI}$, triglyceride concentrations, and higher total cholesterol to HDL ratio. Individuals excluded due to missing values had higher uric acid concentrations, slightly higher BMI and waist, and more often had T2DM (please see Appendix 7, Table S7.1).

\section{Uric acid and baseline capillary density and capillary recruitment}

Crude linear regression analysis showed that a 1SD (74 $\mu \mathrm{mol} / \mathrm{I})$ higher plasma uric acid concentration was not associated with baseline capillary density $[\beta=-0.21$ (95\% Cl-1.61; 1.19) $\mathrm{p}=0.765$ ] (Table 7.2 , model 1 ). The association remained nonsignificant after adjustment for sex, age, and glucose metabolism status, as well as further adjustments (Table 7.2, models 2 and 3). Excluding systolic blood pressure and eGFR from model 3 did not change the results (data not shown). In contrast, higher uric acid was borderline associated with decreased capillary recruitment expressed as absolute change in density after arterial occlusion $[\beta=-1.15(95 \% \mathrm{Cl}-2.36 ; 0.06)$ $\mathrm{p}=0.062$ ] and significantly associated with change in capillary density during venous congestion $[\beta=-1.41(95 \% \mathrm{Cl}-2.68 ;-0.14) p=0.029$ ] (Table 7.2 , model 1 ) in unadjusted analyses. However, after adjustment for sex, age, and glucose metabolism status, the associations with change in capillary density after arterial occlusion $[\beta=0.01(95 \% \mathrm{Cl}$ -1.32 ; 1.35) $p=0.983]$ and during venous congestion $[\beta=-0.04(95 \% \mathrm{Cl}-1.44 ; 1.36)$ $p=0.952$ ] were no longer statistically significant (Table 7.2, model 2); further adjustment gave similar results (model 3 ). Results did not change after excluding systolic blood pressure and eGFR from model 3 (data not shown).

In unadjusted analyses, no significant association was found between uric acid and the percentage of capillary recruitment after arterial occlusion $[\beta=-1.66$ $(95 \% \mathrm{Cl}-3.97 ; 0.64) p=0.159]$ or during venous congestion $[\beta=-2.02(95 \% \mathrm{Cl}-4.46 ; 0.42)$ $\mathrm{p}=0.104$ ] (Table 7.3, model 1); multivariable analyses gave similar results. Excluding systolic blood pressure and eGFR from model 3 did not change the results (data not shown). 


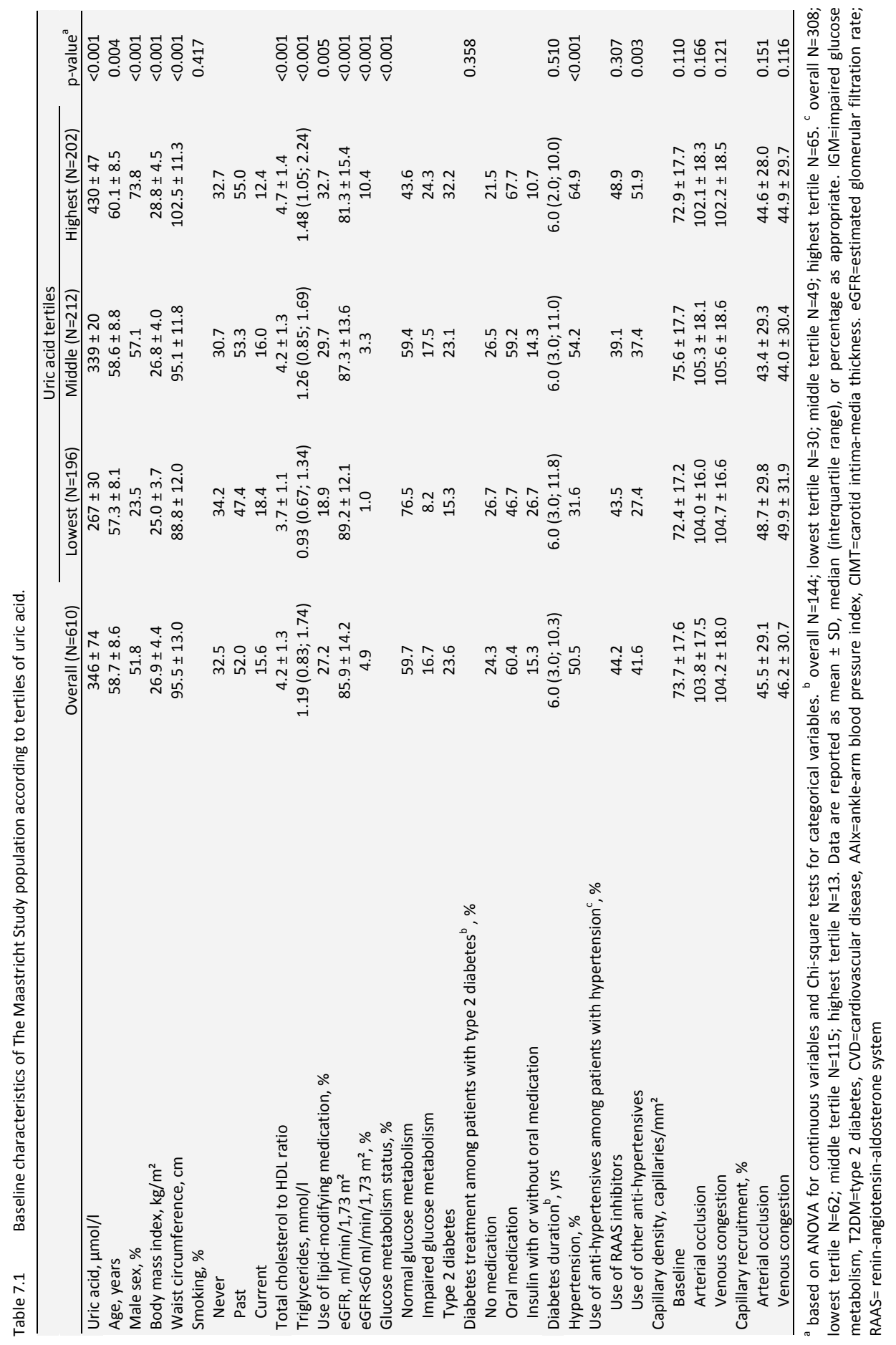




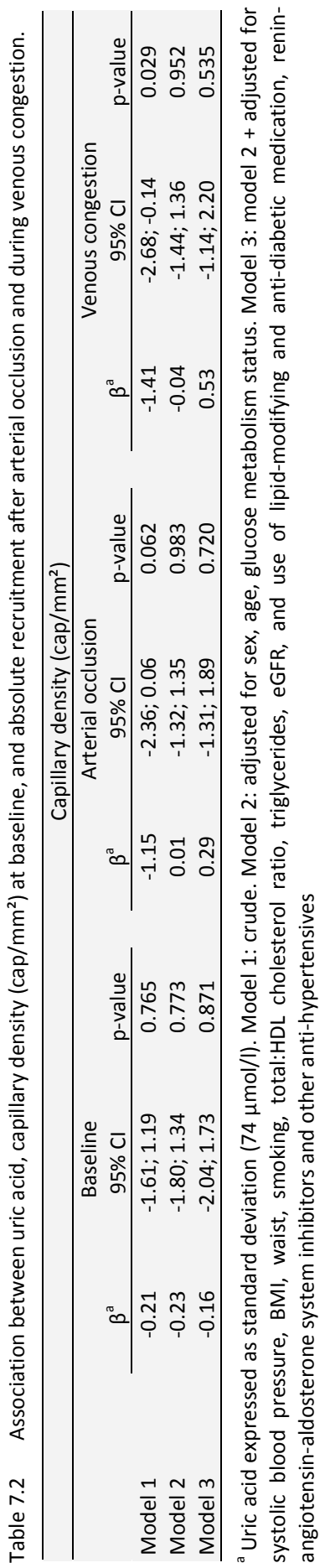


Table 7.3 Association between uric acid and capillary recruitment (\%) after arterial occlusion and during venous congestion.

\begin{tabular}{|c|c|c|c|c|c|c|}
\hline & \multicolumn{6}{|c|}{ Capillary recruitment (\%) } \\
\hline & \multicolumn{3}{|c|}{ Arterial occlusion } & \multicolumn{3}{|c|}{ Venous congestion } \\
\hline & $\beta^{\mathrm{a}}$ & $95 \% \mathrm{Cl}$ & $p$-value & $\beta^{a}$ & $95 \% \mathrm{Cl}$ & p-value \\
\hline Model 1 & -1.66 & $-3.97 ; 0.65$ & 0.159 & -2.02 & $-4.46 ; 0.42$ & 0.104 \\
\hline Model 2 & 0.14 & $-2.43 ; 2.71$ & 0.915 & 0.04 & $-2.67 ; 2.75$ & 0.976 \\
\hline Model 3 & 0.52 & $-2.57 ; 3.60$ & 0.742 & 0.82 & $-2.73 ; 4.06$ & 0.622 \\
\hline
\end{tabular}

${ }^{a}$ Uric acid expressed as standard deviation (74 $\left.\mu \mathrm{mol} / \mathrm{l}\right)$. Model 1: crude. Model 2: adjusted for sex, age, glucose metabolism status. Model 3: model 2 + adjusted for systolic blood pressure, BMI, waist, smoking, total:HDL cholesterol ratio, triglycerides, eGFR, and use of lipid-modifying and anti-diabetic medication, reninangiotensin-aldosterone system inhibitors and other anti-hypertensives

\section{Additional analyses}

Sex modified the association between uric acid and baseline capillary density ( $p$ for interaction=0.007), with an inverse non-significant association among men $[\beta=-2.00$ (95\% Cl -4.46 ; 0.46$) \mathrm{p}=0.110$ ] compared with a positive non-significant association among women $[\beta=1.73(95 \% \mathrm{Cl}-1.26 ; 4.72) p=0.255]$ after full adjustments. Similarly, age modified the association between uric acid and baseline capillary density ( $p$ for interaction=0.092), with an inverse association in the lowest age tertile (mean age $48.7 \pm 4.4$ years) $[\beta=-3.77(95 \% \mathrm{Cl}-6.84 ;-0.71) \mathrm{p}=0.016]$ compared with non-significant associations in the middle (mean age $59.7 \pm 2.2$ years) $[\beta=1.67(95 \% \mathrm{Cl}-1.75 ; 5.10)$ $p=0.337]$ and highest age tertiles (mean age $67.7 \pm 3.0$ years) $[\beta=0.84(95 \% \mathrm{Cl}-2.79 ; 4.47)$ $p=0.648$ ]. Sex and age did not modify the associations between uric acid and any of the other skin microvascular function measures ( $p$ for interaction $>0.10$ ).

No significant interactions between uric acid and glucose metabolism status ( 3 categories: NGM, IGM, and T2DM) were identified in any of the investigated associations ( $p$ for interaction $>0.10$ ).

Finally, excluding systolic blood pressure and eGFR from model 3 gave similar results (data not shown).

\section{Discussion}

The present study showed that, in middle-aged individuals, uric acid was not significantly associated with skin microvascular function as determined by baseline capillary density and capillary recruitment. To the best of our knowledge, this study is the first to assess the relation between uric acid and microvascular function of the skin in the general population. 
Our results are in contrast with prior research on the association between uric acid and markers of microvascular dysfunction in the eye (i.e. retinal arteriolar narrowing) ${ }^{13}$, kidney (i.e. microalbuminuria) ${ }^{14}$, and of the coronary arteries (i.e. coronary flow reserve $)^{10-12}$. These studies showed significant associations between higher uric acid and altered microvascular structure or decreased microvascular function. Reasons for these contrasting findings are not apparent, especially since microvascular dysfunction appears to be part of a systemic process ${ }^{15}$. The contrasting findings may, therefore, be caused by methodological differences, such as demographics and cardiovascular risk profile of the study populations, or the methods used to assess microvascular function.

A possible pathophysiological explanation for our findings may relate to the heterogeneous mechanisms underlying arterial reactivity in various vascular beds ${ }^{31}$. Autoregulation of blood flow is achieved by metabolic, tissue pressure, and myogenic control, but the degree to which they participate in the vascular response may differ ${ }^{32}$. Indeed, it has been suggested that the myogenic response is most pronounced in renal, cerebral, and coronary vessels ${ }^{32,33}$. Animal studies that assessed the underlying mechanism of the association between uric acid and microcirculatory function point towards a primary role of smooth muscle cell proliferation ${ }^{8,9}$. Therefore, it is possible that uric acid mainly affects the kidney and/or coronary microcirculation. However, uric acid has also been associated with endothelial dysfunction ${ }^{34}$. A study in individuals with type 1 diabetes showed that uric acid was associated with a reduced endotheliumdependent vasodilator response, but not with the endothelium-independent response of the skin microcirculation ${ }^{20}$.

We hypothesised that uric acid may have a more pronounced effect in individuals with a lower cardiovascular risk profile ${ }^{22,25}$, i.e. women, younger individuals, and individuals with normal glucose metabolism. However, no strong effect of sex on the association between uric acid and microvascular function could be identified. These data thus seem to contradict previous studies showing a stronger relation between uric acid, cardiovascular disease ${ }^{21}$, and coronary microvascular dysfunction ${ }^{11}$ in women. The effect of sex on the association between uric acid and microvascular function needs further exploration, and also the mechanism of a possible differential effect of sex needs to be elucidated. In addition, we assessed the interaction between uric acid and age, but were unable to clearly confirm the hypothesis of Feig ${ }^{22}$, who suggested that elevated uric acid concentrations may have a more pronounced effect in the young. We did, however, find a significant inverse association between uric acid and baseline capillary density in the lowest age tertile. This result should be interpreted with caution in view of the number of associations we studied. On the other hand, we cannot exclude that uric acid affects microcirculatory function in individuals younger than those we studied (i.e. mean age $=58.7$ years). In addition, we found no support for the hypothesis that uric acid may affect microcirculatory function especially in individuals with normal glucose metabolism ${ }^{23,24}$. These issues deserve further study before firm conclusions can be drawn. 
A limitation of our study may be the mean age of the study population. If uric acid is indeed only associated with microvascular function in young individuals, the age range of our study population may have contributed to the lack of statistical significance of the results of the present study. Furthermore, we used skin microcirculation as model of generalized microvascular function. However, the generalizability to other vascular beds still needs further examination ${ }^{35}$.

In conclusion, our results suggest that the previously reported association between uric acid and various diseases, such as hypertension ${ }^{5}$, renal disease, and cardiomyopathies ${ }^{7}$, cannot be explained by generalized microvascular dysfunction. However, this does not exclude the possibility that uric acid is associated with microvascular dysfunction in specific vascular beds. Especially the association between uric acid and microvascular function of vascular beds in which the myogenic response plays a primary role needs further investigation. 


\section{References}

1. Kanellis J, Kang DH. Uric acid as a mediator of endothelial dysfunction, inflammation, and vascular disease. Semin Nephrol. 2005;25:39-42.

2. Kanbay M, Sanchez-Lozada LG, Franco $M$, et al. Microvascular disease and its role in the brain and cardiovascular system: a potential role for uric acid as a cardiorenal toxin. Nephrol Dial Transplant. 2011;26:430-437.

3. Kang DH, Han L, Ouyang $X$, et al. Uric acid causes vascular smooth muscle cell proliferation by entering cells via a functional urate transporter. Am J Nephrol. 2005;25:425-433.

4. Serne EH, Gans RO, ter Maaten JC, Tangelder GJ, Donker AJ, Stehouwer CD. Impaired skin capillary recruitment in essential hypertension is caused by both functional and structural capillary rarefaction. Hypertension. 2001;38:238-242.

5. Grayson PC, Kim SY, LaValley M, Choi HK. Hyperuricemia and incident hypertension: a systematic review and meta-analysis. Arthritis Care Res (Hoboken). 2011;63:102-110.

6. Hsu CY, Iribarren C, McCulloch CE, Darbinian J, Go AS. Risk factors for end-stage renal disease: 25-year follow-up. Arch Intern Med. 2009;169:342-350.

7. Huang $\mathrm{H}$, Huang $B$, Li $\mathrm{Y}$, et al. Uric acid and risk of heart failure: a systematic review and meta-analysis. Eur J Heart Fail. 2014;16:15-24.

8. Mazzali M, Kanellis J, Han L, et al. Hyperuricemia induces a primary renal arteriolopathy in rats by a blood pressure-independent mechanism. Am J Physiol Renal Physiol. 2002;282:F991-997.

9. Sanchez-Lozada LG, Tapia E, Santamaria J, et al. Mild hyperuricemia induces vasoconstriction and maintains glomerular hypertension in normal and remnant kidney rats. Kidney Int. 2005;67:237-247.

10. Gullu H, Erdogan D, Caliskan M, et al. Elevated serum uric acid levels impair coronary microvascular function in patients with idiopathic dilated cardiomyopathy. Eur J Heart Fail. 2007;9:466-468.

11. Kuwahata S, Hamasaki S, Ishida S, et al. Effect of uric acid on coronary microvascular endothelial function in women: association with eGFR and ADMA. J Atheroscler Thromb. 2010;17:259-269.

12. Erdogan D, Tayyar S, Uysal BA, et al. Effects of allopurinol on coronary microvascular and left ventricular function in patients with idiopathic dilated cardiomyopathy. Can J Cardiol. 2012;28:721-727.

13. Yuan $\mathrm{Y}$, Ikram MK, Jiang $\mathrm{S}$, et al. Hyperuricemia accompanied with changes in the retinal microcirculation in a Chinese high-risk population for diabetes. Biomed Environ Sci. 2011;24:146-154.

14. Oh CM, Park SK, Ryoo JH. Serum uric acid level is associated with the development of microalbuminuria in Korean men. Eur J Clin Invest. 2014;44:4-12.

15. Chade AR, Brosh D, Higano ST, Lennon RJ, Lerman LO, Lerman A. Mild renal insufficiency is associated with reduced coronary flow in patients with non-obstructive coronary artery disease. Kidney Int. 2006;69:266-271.

16. Holowatz LA, Thompson-Torgerson CS, Kenney WL. The human cutaneous circulation as a model of generalized microvascular function. J Appl Physiol (1985). 2008;105:370-372.

17. Barchetta I, Riccieri V, Vasile M, et al. High prevalence of capillary abnormalities in patients with diabetes and association with retinopathy. Diabet Med. 2011;28:1039-1044.

18. Houben AJ, Beljaars JH, Hofstra L, Kroon AA, De Leeuw PW. Microvascular abnormalities in chronic heart failure: a cross-sectional analysis. Microcirculation. 2003;10:471-478.

19. Draaijer P, de Leeuw PW, van Hooff JP, Leunissen KM. Nailfold capillary density in salt-sensitive and salt-resistant borderline hypertension. J Hypertens. 1993;11:1195-1198.

20. Matheus AS, Tibirica E, da Silva PB, de Fatima Bevilacqua da Matta M, Gomes MB. Uric acid levels are associated with microvascular endothelial dysfunction in patients with Type 1 diabetes. Diabet Med. 2011;28:1188-1193.

21. Kawai T, Ohishi M, Takeya $\mathrm{Y}$, et al. Serum uric acid is an independent risk factor for cardiovascular disease and mortality in hypertensive patients. Hypertens Res. 2012;35:1087-1092.

22. Feig DI. The role of uric acid in the pathogenesis of hypertension in the young. J Clin Hypertens (Greenwich). 2012;14:346-352.

23. Shankar A, Klein BE, Nieto FJ, Klein R. Association between serum uric acid level and peripheral arterial disease. Atherosclerosis. 2008;196:749-755. 
24. Wijnands JMA, Boonen A, Dagnelie PC, et al. The cross-sectional association between uric acid and atherosclerosis, and the role of low-grade inflammation: the CODAM study. Rheumatology (Oxford). 2014; ePub ahead of print (doi: 10.1093/rheumatology/keu239).

25. Viazzi F, Parodi D, Leoncini G, et al. Serum uric acid and target organ damage in primary hypertension. Hypertension. 2005;45:991-996.

26. Schram MT, Sep SJ, Kallen van der CJ, et al. The Maastricht Study: An extensive phenotyping study on determinants of type 2 diabetes, its complications and its comorbidities Eur J Epidemiol. 2014;29: 439-451.

27. Leng GC, Fowkes FG. The Edinburgh Claudication Questionnaire: an improved version of the WHO/Rose Questionnaire for use in epidemiological surveys. J Clin Epidemiol. 1992;45:1101-1109.

28. Gronenschild EH, Muris DM, Schram MT, Karaca U, Stehouwer CD, Houben AJ. Semi-automatic assessment of skin capillary density: Proof of principle and validation. Microvasc Res. 2013;90:192-198.

29. Levey AS, Stevens LA, Schmid CH, et al. A new equation to estimate glomerular filtration rate. Ann Intern Med. 2009;150:604-612.

30. WHO. Definition and diagnosis of diabetes mellitus and intermediate hyperglycemia: Report of a who/idf consultation. Geneva, Switzerland: World Health Organization (WHO);2006.

31. Ochodnicky P, Henning RH, Buikema HJ, de Zeeuw D, Provoost AP, van Dokkum RP. Renal vascular dysfunction precedes the development of renal damage in the hypertensive Fawn-Hooded rat. Am J Physiol Renal Physiol. 2010;298:F625-633.

32. Schubert R, Mulvany MJ. The myogenic response: established facts and attractive hypotheses. Clin Sci (Lond). 1999;96:313-326.

33. Habazettl H, Pries AR. Microvascular control of myocardial perfusion. Heart Metab. 2008:5-10.

34. Yu MA, Sanchez-Lozada LG, Johnson RJ, Kang DH. Oxidative stress with an activation of the reninangiotensin system in human vascular endothelial cells as a novel mechanism of uric acid-induced endothelial dysfunction. J Hypertens. 2010;28:1234-1242.

35. Roustit M, Cracowski JL. Assessment of endothelial and neurovascular function in human skin microcirculation. Trends Pharmacol Sci. 2013;34:373-384. 


\section{Appendix}

Supplemental table 
Chapter 7 
Table S7.1 Baseline characteristics of The Maastricht Study population and the individuals excluded from the analyses because of missing values.

\begin{tabular}{|c|c|c|c|}
\hline & $\begin{array}{l}\text { Study population } \\
\qquad N=610\end{array}$ & Missing & $\begin{array}{l}\text { Excluded because } \\
\text { of missing values } \\
\qquad \mathrm{N}=82\end{array}$ \\
\hline Uric acid, $\mu \mathrm{mol} / \mathrm{I}$ & $346 \pm 74$ & 13 & $363 \pm 116$ \\
\hline Age, years & $58.7 \pm 8.6$ & 0 & $59.9 \pm 8.4$ \\
\hline Male sex, \% & 51.8 & 0 & 54.9 \\
\hline Body mass index, kg/m² & $26.9 \pm 4.4$ & 1 & $28.3 \pm 5.2$ \\
\hline Waist circumference, $\mathrm{cm}$ & $95.5 \pm 13.0$ & 3 & $99.5 \pm 15.2$ \\
\hline Smoking, \% & & 17 & \\
\hline Never & 32.5 & & 26.8 \\
\hline Past & 52.0 & & 34.1 \\
\hline Current & 15.6 & & 18.3 \\
\hline Total cholesterol to HDL ratio & $4.2 \pm 1.3$ & 8 & $4.4 \pm 1.1$ \\
\hline Triglycerides, mmol/l & $1.19(0.83 ; 1.74)$ & 7 & $1.36(0.88 ; 1.95)$ \\
\hline Use of lipid-modifying medication, $\%$ & 27.2 & & 42.7 \\
\hline eGFR, $\mathrm{ml} / \mathrm{min} / 1,73 \mathrm{~m}^{2}$ & $85.9 \pm 14.2$ & 9 & $84.6 \pm 16.3$ \\
\hline eGFR<60 ml/min $/ 1,73 \mathrm{~m}^{2}, \%$ & 4.9 & 9 & 9.6 \\
\hline Glucose metabolism status, $\%$ & & 0 & \\
\hline Normal glucose metabolism & 59.7 & & 50.0 \\
\hline Impaired glucose metabolism & 16.7 & & 14.7 \\
\hline Type 2 diabetes & 23.6 & & 34.1 \\
\hline Type 1 diabetes & 0.0 & & 1.2 \\
\hline Diabetes treatment among patients with type 2 & & 0 & \\
\hline \multicolumn{4}{|l|}{ diabetes ${ }^{a}, \%$} \\
\hline No medication & 24.3 & & 21.4 \\
\hline Oral medication & 60.4 & & 35.7 \\
\hline Insulin with or without oral medication & 15.3 & & 42.8 \\
\hline Diabetes duration ${ }^{a}$, yrs & $6.0(3.0 ; 10.3)$ & 10 & $12(7.8 ; 20.0)$ \\
\hline Hypertension, \% & 50.5 & 2 & 58.8 \\
\hline \multicolumn{4}{|l|}{$\begin{array}{l}\text { Use of anti-hypertensives among patients with } \\
\text { hypertension }^{b}, \%\end{array}$} \\
\hline Use of RAAS inhibitors & 44.2 & 0 & 48.9 \\
\hline Use of other anti-hypertensives & 41.6 & 0 & 59.6 \\
\hline \multicolumn{4}{|l|}{ Capillary density, capillaries/mm² } \\
\hline Baseline & $73.7 \pm 17.6$ & 44 & $73.1 \pm 18.9$ \\
\hline Arterial occlusion & $103.8 \pm 17.5$ & 44 & $97.9 \pm 19.1$ \\
\hline Venous congestion & $104.2 \pm 18.0$ & 45 & $97.7 \pm 18.3$ \\
\hline \multicolumn{4}{|l|}{ Capillary recruitment, \% } \\
\hline Arterial occlusion & $45.5 \pm 29.1$ & 44 & $39.2 \pm 31.3$ \\
\hline Venous congestion & $46.2 \pm 30.7$ & 45 & $39.1 \pm 29.0$ \\
\hline
\end{tabular}

${ }^{a}$ study population $\mathrm{N}=144$; Missing $\mathrm{N}=28 .{ }^{\mathrm{b}}$ study population $\mathrm{N}=308$; Missing $\mathrm{N}=47$. Data are reported as mean $\pm \mathrm{SD}$, median (interquartile range), or percentage as appropriate. eGFR=estimated glomerular filtration rate; RAAS=renin-angiotensin-aldosterone system 


\section{Chapter 8}

General discussion 
Chapter 8 


\section{General discussion}

The suggested rise in the prevalence of both gout and hyperuricaemia underlines the need for a better understanding of these conditions and the potential adverse effects of high uric acid concentrations ${ }^{1}$. The objectives of this thesis were to: 1 ) investigate the classification, prevalence, and incidence of gout; and 2) explore the role of uric acid in the aetiology of cardiovascular disease (CVD). This chapter summarizes the main findings of this thesis, along with the discussion of some important methodological considerations. Then we describe our interpretation of the overall results. Finally, the clinical implications are presented and some directions for future research are proposed.

\section{Main findings}

\section{Classification, prevalence and incidence of gout}

Chapter $\mathbf{2}$ summarized the case definitions commonly used in epidemiologic studies of gout. Several classification criteria have been developed to differentiate between individuals with and without gout, e.g. the Rome, New York, and ACR criteria (former American Rheumatism Association criteria) ${ }^{2-4}$. However, these criteria have been validated only to a limited extent ${ }^{5,6}$. Alternative methods to identify people with gout in epidemiologic studies include ICD (International Classification of Diseases) codes, selfreported diagnosis, and self-reported symptoms. Note that the large variation in case definitions limits comparability of research findings. In addition, inconsistent usage of different terms for the various manifestations and stages of gout may further confound results.

In chapter 3 we reported a worldwide gout prevalence of $0.6 \%$ based on a metaanalysis. Since heterogeneity between studies was large (99.9\%), various determinants of gout prevalence were assessed. Univariable regression analysis showed that not only sex $(20.7 \%)$ and continent on which the study was performed (31.2\%), but also case definition (33.6\%), explained a large part of the heterogeneity. The investigated clinical and methodological factors jointly explained $88.7 \%$ of the total heterogeneity.

In chapter 4, using the Clinical Practice Research Datalink (CPRD), we found that individuals with type 2 diabetes mellitus (T2DM), in particular women, had a higher risk of developing gout as compared with those without T2DM. The additional risk could be fully attributed to classic risk factors for gout, i.e. high BMI, hypertension, and/or reduced renal function. Independently of these factors, diabetes itself was associated with a decreased risk of gout in men. The reduced risk in these individuals was probably caused by high $\mathrm{HbA1c}$ levels, which were inversely related to the risk of gout. 


\section{The role of uric acid in the aetiology of cardiovascular disease}

Chapter $\mathbf{5}$ discussed the association between uric acid and measures of atherosclerosis in the Cohort on Diabetes and Atherosclerosis Maastricht (CODAM) study. Uric acid concentrations were not associated with prevalent CVD or ankle-arm blood pressure index (AAIx), but there was a significant relation with carotid intima-media thickness (CIMT). The magnitude of this detrimental association was small. We also showed that the association between uric acid and prevalent CVD was different according to glucose metabolism status, with a positive association in individuals with normal glucose metabolism, but not in those with disturbed glucose metabolism. This difference was independent of other known cardiovascular risk factors. After we adjusted our models for low-grade inflammation, the strength of the associations did not change for any of the observed associations. The results did not support the mediation of the association between uric acid and atherosclerosis by the low-grade inflammatory markers measured in our study.

In chapter 6 we explored the relation between uric acid and arterial stiffness in The Maastricht Study, but were unable to identify a significant association with stiffness of the aorta as determined by carotid-femoral pulse wave velocity (cfPWV). When exploring local stiffness indices of the carotid or femoral artery, also no associations were seen. Excluding hypertension and eGFR from our models to avoid overadjustment did not change these results. In line with the results in chapter 5 , a trend towards a detrimental association between uric acid and carotid arterial stiffness in individuals with normal glucose metabolism was identified, whereas no association was seen in those with impaired glucose metabolism or T2DM.

Chapter $\mathbf{7}$ addressed the relation between uric acid and microvascular function as determined by nailfold capillary density (at baseline, after 4 minutes of arterial occlusion, and after 2 minutes of venous congestion) in The Maastricht Study. No associations were found between uric acid and any of these measurements, and excluding systolic blood pressure and eGFR did not change these results. In addition, no strong effect of sex, age, or glucose metabolism status on the association between uric acid and microvascular function was identified.

\section{Methodological considerations}

\section{Validity and reliability of the determinants and outcomes}

\section{Uric acid}

Uric acid concentrations were measured with an enzymatic colorimetric test. Most routine assays use the same enzymatic methodology, based on the Trinder reaction with uricase 7,8 . There are only small variations in measurements, with between- 
laboratory and between-method coefficients of variation below $5 \%^{7,8}$. Uric acid concentrations were not measured in duplicate, although some degree of biological variability due to diet, diurnal cycles and seasonal rhythms has been reported. While blood values were measured after an overnight fast, variability in uric acid concentrations due to (purine-rich) diet cannot be excluded ${ }^{8}$. Concentrations may also vary during the day, with higher concentrations in the morning ${ }^{9}$. Since in our studies uric acid concentrations were measured in the morning, we may have overestimated the actual concentrations. Variability in levels was minimized by measuring all individuals at the same time of the day. Finally, small seasonal variations in uric acid concentrations have been reported, but these variations are not expected to largely influence our findings ${ }^{10,11}$.

\section{Markers of subclinical vascular damage}

We considered three different processes in the development of CVD, i.e. atherosclerosis, arterial stiffness and microvascular dysfunction. Markers of subclinical atherosclerosis used in chapter $\mathbf{5}$ of this thesis were CIMT and AAIx. CIMT is a recognized marker of carotid atherosclerosis ${ }^{12}$, widely used in clinical and epidemiologic research, and able to predict cardiovascular events ${ }^{13}$. In our study, measurements were repeated up to seven times at both the left and right common carotid artery in order to ensure reliability. AAIx is the ratio of the ankle to the brachial systolic blood pressure and is a simple test to assess lower extremity arterial obstruction $^{14}$. Studies have shown an independent association between low AAlx values and CVD and mortality ${ }^{15}$. However, the low sensitivity of the test $^{16}$ may have contributed to the non-significant association between uric acid and AAIx in our study. Although reliability of AAIx was not tested in the CODAM study, previous studies have shown good intra- and inter-observer reliability ${ }^{17}$.

Markers of arterial stiffness used in chapter 6 include aortic, carotid, and femoral stiffness indices. We measured cfPWV, which is regarded the gold standard of aortic stiffness $^{18}$. A great amount of evidence shows the independent predictive value of cfPWV for cardiovascular events and cardiovascular mortality throughout a large variety of individuals ${ }^{19}$. Carotid stiffness has also been shown to predict $\mathrm{CVD}^{20-23}$. Less is known about the predictive value of femoral stiffness. However, femoral stiffness may be associated with peripheral artery disease ${ }^{24,25}$, which has been associated with increased cardiovascular mortality ${ }^{26}$. Reproducibility of the aortic and carotid stiffness parameters was reasonable to good as the intra- and inter-observer intra-class correlation coefficients for these stiffness indices ranged from 0.72 to 0.95 and from 0.69 to 0.73 , respectively. The femoral stiffness indices had a substantially lower reliability with intra- and inter-observer intra-class correlation coefficients of 0.49 and 0.32 for femoral distensibility coefficient and 0.41 and 0.67 for femoral compliance coefficient. 
The marker of microvascular function used in chapter $\mathbf{7}$ was skin capillary density as determined by nailfold capillaroscopy. The microcirculation of the skin is suggested to be a representative vascular bed for the assessment of generalized systemic microvascular function ${ }^{27}$. Alterations in the cutaneous microcirculation have been identified in patients with $\mathrm{T}_{2} \mathrm{DM}^{28}$, chronic heart failure ${ }^{29}$, and hypertension ${ }^{30}$. However, the exact interpretation of the outcome values was limited by the absence of reference values. Reliability of the measurements was high as the intra- and interobserver coefficients of variation of the parameters were $2.5 \%$ and $5.6 \%$, respectively.

\section{Chronic diseases}

In chapter 4, T2DM was defined as the usage of a non-insulin diabetic drug (NIAD) at baseline to ensure high sensitivity and specificity. A limitation of this case definition is the exclusion of individuals with T2DM who are not treated with a NIAD or insulin. Gout diagnosis in chapter $\mathbf{4}$ was based on Read codes. Read codes are a hierarchical coding system based on ICD codes and is widely used in general practice in the United Kingdom $(U K)^{31}$. The validity of the diagnosis depends on the quality of the computerized information $^{32}$, and may therefore be susceptible to misclassification. However, the Read code for gout has previously been validated by analysis of medical records and laboratory results of a sample of individuals with a first-time diagnosis of gout $^{33}$. Also, our sensitivity analysis in which the definition of gout was restricted to those individuals with a Read code of gout and at least one prescription for its treatment gave similar results.

In chapter 5, prevalent CVD was defined as self-reported myocardial infarction, stroke, bypass surgery of the coronary arteries, coronary angioplasty, non-traumatic limb amputation, an AAlx<0.9, or signs of myocardial infarction or ischemia on a 12-lead electrocardiogram. Prevalent CVD was thus partially based on self-reported cardiovascular events, which may have overestimated the actual prevalence of these events $^{34}$.

\section{Generalizability}

Generalizability is the extent to which research findings can be generalized to other situations and/or other people. First, although the validity and reliability of most of the determinants and outcome measures used in this thesis was reasonable to good, minor limitations may hinder the degree of generalizability of our results. Second, the characteristics of the study populations investigated may limit the extent to which we can generalize our results. These limitations are discussed in this paragraph.

In chapter 3, based on a systematic review, we reported the pooled prevalence of gout as a best possible estimate of the worldwide prevalence of gout. Descriptive studies of disease frequency need to include a study population representative of all variation in determinants of the disease ${ }^{35}$. An important determinant of gout 
prevalence is ethnicity, but the studied population included mainly European, North American and Asian population samples. The number of African or South American population samples was limited. The studied population may therefore not be representative of the whole world.

In chapter 4, we performed a longitudinal study using CPRD, which is the world's largest primary care database. More than $95 \%$ of the British population is registered with a general practitioner, and the data are therefore representative of the British population in terms of age, sex, and geographic distribution ${ }^{36}$. General practitioners participating in CPRD may behave differently than non-participating general practitioners. However, given the large sample size and the many similarities between CPRD and other UK data sources such as the Prescriptions Pricing Authority ${ }^{36-38}$, generalizability of our results is probably not hampered.

In chapters 5-7, we used cross-sectional data of the CODAM study and The Maastricht Study. The sampling procedure of the CODAM study included the selection of individuals aged 40 years and over, with a high risk of (or with prevalent) CVD and/or $\mathrm{T}_{2} \mathrm{DM}^{39}$. The Maastricht Study sampling procedure included the selection of a representative sample of the general population between 40 and 75 years of age, as well as oversampling of individuals with $\mathrm{T}_{2} \mathrm{DM}^{40}$. However, since the study was executed in South Limburg (Maastricht and Heuvelland), a region that is characterized by a low proportion of immigrants and a high number of relatively unhealthy individuals with a poorer lifestyle, the sample may not be representative of the general Dutch population. Generalization of our findings to younger and/or healthier populations, or other ethnicities, should be done with caution. However, it is important to note that in aetiological research, representativeness of the study population is not a primary issue ${ }^{35}$. The use of data from the CODAM study or The Maastricht Study probably does not affect the pathobiological validity of our results.

\section{Complexity of the disease}

Uric acid is part of a large network involving interactions between molecular components, organ systems, conditions, and diseases. Genetic and environmental factors further complicate this network. Some of the associations have extensively been researched, but still there is no agreement on the nature of the relationships. Uric acid may be a consequence of and/or play an active role in the development of certain diseases and conditions. First, uric acid has been found to predict the development of hypertension ${ }^{41}$. However, high blood pressure and antihypertensive medication such as diuretics are known to increase the reabsorption of uric acid ${ }^{42,43}$. Second, literature has shown that uric acid may play a role in the development of insulin resistance ${ }^{44}$, while hyperinsulinaemia can cause hyperuricaemia ${ }^{45}$. Third, accumulating evidence suggest a causal role of uric acid in the development of kidney dysfunction, but low renal function increases uric acid concentrations due to decreased 
excretion ${ }^{46,47}$. Moreover, hypertension, insulin resistance, and kidney function play a role in the development of CVD. All these factors may thus represent confounding factors and/or mediators in the association between uric acid and CVD, and although we carefully assessed these variables in our models overadjustment cannot be excluded. We acknowledge that our studies were cross-sectional in nature, but longitudinal studies will not easily solve this complex methodological issue. Regression analysis assesses individual risk factors in isolation ${ }^{48}$, but in order to comprehend the large network of associations more advanced methods are required. Network analysis may therefore prove to be an interesting technique. This technique is used to model pairwise relations based on mathematical structures which are visualized in a graphical output. Future research using this technique may gain new insight into the pathogenesis of hyperuricaemia, and possibly, its relation with T2DM, cardiovascular and renal disease.

\section{Interpretation of overall results}

Part I of this thesis showed the large influence of case definition on the estimated prevalence of gout. In addition to the impact on prevalence, it is conceivable that the heterogeneity in case definitions may also affect other study outcomes in gout research. This hinders the comparability of research results ${ }^{5}$. Note that classifying gout is complex and that the most appropriate case definition depends on many factors, such as the objective of a study, population of interest, and the available resources. Researchers must be aware of the sensitivity and specificity of the various case definitions and should account for the influence of case definitions when interpreting their results or comparing data between studies. Consensus on the most appropriate case definition for a particular study and clear terms for the various manifestations of gout could improve the quality of research in gout.

In part I we also showed that, independent of known risk factors for gout, diabetes itself was associated with a decreased risk of gout. This may have been caused by the uricosuric effect of glycosuria $^{49}$, as we found an inverse association between high $\mathrm{HbA1c}$ levels and gout risk. Studies have shown that serum uric acid concentrations decrease after administration of sodium-glucose co-transporter-2 (SGLT2) inhibitors, a new class of drugs that promote glycosuria by inhibiting glucose reabsorption in the proximal tubule ${ }^{50}$. It is unclear which aspect of glycosuria can cause the decline in gout risk. Possible explanations include the glycosuria-induced osmotic diuresis and/or higher filtration rate ${ }^{51}$, and the effect of glucose on urate transporters such as hUAT ${ }^{52}$. Interestingly, in our study, $\mathrm{HbA1c}$ levels were only associated with a decreased risk of gout in men. Glycosuria may therefore have a different effect on uric acid concentrations according to sex. It is not known if SGLT2 inhibitors also affect differently uric acid concentrations in men and women. 
In part II of this thesis we studied the association between uric acid and three pathophysiological mechanisms of CVD, i.e. atherosclerosis, arterial stiffness, microvascular dysfunction, but were unable to identify associations of major clinical relevance. If any, evidence for an association between uric acid and atherosclerosis seems to be the strongest. However, a drawback in our conclusion might be that the studies on atherosclerosis and arterial stiffness were performed in different populations. A recent study that did examine the association between uric acid, arterial stiffness and atherosclerosis in a single study population reported a detrimental association between uric acid and CIMT, but not with $\mathrm{cfPWV}^{53}$. In contrast, a study performed in a Korean population found an association between uric acid and brachialankle pulse wave velocity, but not with $\mathrm{CIMT}^{54}$. Note that arterial stiffness and atherosclerosis may be associated ${ }^{55}$. They either reinforce each other or are distinct, but concurrent, processes ${ }^{55}$. Overall, it remains difficult to draw final conclusions about the association between uric acid and the investigated pathophysiological mechanisms of CVD.

We hypothesized that the association between uric acid and CVD may differ according to glucose metabolism status. This hypothesis was supported by our results on the relation with atherosclerosis and arterial stiffness. Two possible mechanisms could explain these differences. First, it has been proposed that uric acid mainly plays an adverse role in the early or less severe stages of $C V D^{56}$. In individuals with T2DM, atherosclerosis and arterial stiffness may already be in an advanced stage. Therefore, uric acid might have a less detrimental effect, if any, in these individuals. Second, the difference in association can relate to the underlying cause of increased uric acid concentrations, i.e. overproduction and/or underexcretion ${ }^{57}$. During the production of uric acid, free radicals are formed, which may result in oxidative stress and an increased risk of $C V D^{58}$. Conceivably, high uric acid concentrations in individuals with a normal glucose metabolism are predominantly caused by overproduction, reflecting xanthine oxidase activity. High uric acid concentrations in individuals with a disturbed glucose metabolism are more likely to result from the underexcretion of uric acid due to a decline in kidney function or high insulin concentrations and are therefore less harmful. However, based on our epidemiologic studies no firm conclusions can be drawn. The influence of glucose metabolism on the association between uric acid and CVD needs further study.

\section{Clinical implications and future research}

Gout is the most common form of inflammatory rheumatic disease affecting $0.6 \%$ of the general population worldwide ${ }^{59}$. In affluent countries higher prevalences are commonly reported ${ }^{60,61}$, and owing to changes in lifestyle, the prevalence in these countries may even be increasing. Although the disease itself is not life-threatening, 
pain and disability contribute to a decrease in the patients' health-related quality of life, while also hindering their functional and work productivity ${ }^{62,63}$. High quality studies are therefore needed to further increase our understanding of gout. In part this may be achieved by a greater degree of homogeneity in case definitions and the use of clear definitions of the various manifestations of gout. An international project is underway to develop new gout classification criteria that closely mimic crystal proven gout, which is the gold standard. These criteria must distinguish between case definitions for use in clinical trials and epidemiologic studies. Such an approach is an important step forward in gout research ${ }^{5}$.

For decades rheumatologists have been raising the question whether there is a need to treat hyperuricaemia in order to decrease cardiovascular risk. If high uric acid concentrations represent an independent risk factor for cardiovascular and kidney disease, treatment can result in large health benefits. Nevertheless, in the 70s and $80 \mathrm{~s}$ clinicians concluded that asymptomatic hyperuricaemia is not considered an issue for preventive clinical care ${ }^{1}$. The reasons being the lack of a clear relation between elevated uric acid concentrations and the risk of developing $\mathrm{CVD}^{64}$, the lack of longterm benefits of uric acid lowering therapy ${ }^{64}$, the cost and risk of prolonged drug use ${ }^{65}$, and the low compliance by patients ${ }^{65}$.

Meanwhile considerable research efforts have been made to identify uric acid as an independent risk factor for CVD. We contributed to that effort by investigating several underlying pathophysiological mechanisms through which uric acid may contribute to the development of CVD. Our results, however, showed no strong relation between uric acid and atherosclerosis, arterial stiffness, or microvascular dysfunction. The causal role of uric acid in the development of CVD remains an ongoing debate and to date no compelling evidence justifies initiation of uric-acid-lowering drugs to decrease cardiovascular risk. The low adherence to gout therapy ${ }^{66,67}$ strengthens the case against treatment of asymptomatic hyperuricaemia, especially since adherence may even be lower if individuals have not been previously diagnosed with gout ${ }^{68}$. Although allopurinol is rather inexpensive, we should not overlook the fact that the treatment itself might be life-long, and may thus constitute a considerable burden to the individual patient and society. To date, uric acid lowering medication should only be started in gout patients with tophi, frequent attacks of acute gouty arthritis, and/or urolithiasis $^{69-71}$. Note that allopurinol is the first-line uric-acid-lowering drugs. As we have shown that glycosuria can decrease the risk of gout, SGLT2 inhibitors which promote this process could also represent an interesting new treatment strategy in individuals with both gout and T2DM. Future studies should determine the effectiveness and possible side-effects of these drugs in the treatment of concurrent gout and T2DM.

Although we were not able to identify a strong association between uric acid and CVD in the total population, an interesting finding was the stronger association between uric acid, atherosclerosis and arterial stiffness in individuals with normal 
glucose metabolism than in those with disturbed glucose metabolism. This difference might reflect the degree of xanthine oxidase activity. Randomized clinical trials assessing the effect of uric-acid lowering medication on cardiovascular and renal outcomes support this hypothesis. Lowering uric acid concentrations with the xanthine oxidase inhibitor allopurinol has been shown to have a beneficial effect on the vasculature $^{72-75}$ and may even reduce mortality ${ }^{76}$, whereas treatment with the uricosuric drugs probenecid ${ }^{77}$ and benzbromaron ${ }^{78}$ had no beneficial effect. Research should therefore focus on the identification of individuals with increased xanthine oxidase activity, not necessary reflected by high uric acid concentrations. In these individuals, health benefits may be gained by inhibiting xanthine oxidase. However, in order to detect long-term benefits of drugs such as allopurinol, adequately sized randomized clinical trials are required ${ }^{1}$. Note that these studies are very expensive and generally require a long follow-up time. Studies also need to determine if the benefits of initiating uric-acid-lowering therapy outweigh the cost and the possible side-effects.

Even if uric-acid-lowering therapy in individuals with asymptomatic hyperuricaemia is not recommended, it is important to screen these individuals for cardiovascular risk $^{79}$. Hyperuricaemia may be a marker of an unfavourable CVD risk profile, and consequently life style changes (i.e. dietary pattern change and more exercise) are wanted. Timely and sustained lifestyle interventions could reduce the future risk of CVD in these individuals. 


\section{References}

1. Neogi T, George J, Rekhraj S, Struthers AD, Choi H, Terkeltaub RA. Are either or both hyperuricemia and xanthine oxidase directly toxic to the vasculature? A critical appraisal. Arthritis Rheum. 2012;64: 327-338.

2. Kellgren JH, Jeffery MR, Ball JF. The epidemiology of chronic rheumatism. Oxford: Blackwell Scientific; 1963.

3. Decker JL. Report from the subcommittee on diagnostic criteria for gout. In: Bennett PH, Wood PHN, eds. Population studies of the rheumatic diseases. Proceedings of the Third International Symposium, New York, June 5-10, 1966. Amsterdam: Excerpta Medica Foundation; 1968:385-387.

4. Wallace SL, Robinson H, Masi AT, Decker JL, McCarty DJ, Yu TF. Preliminary criteria for the classification of the acute arthritis of primary gout. Arthritis Rheum. 1977;20:895-900.

5. Dalbeth N, Fransen J, Jansen TL, Neogi T, Schumacher HR, Taylor WJ. New classification criteria for gout: a framework for progress. Rheumatology (Oxford). 2013;52:1748-1753.

6. Malik A, Schumacher HR, Dinnella JE, Clayburne GM. Clinical diagnostic criteria for gout: comparison with the gold standard of synovial fluid crystal analysis. J Clin Rheumatol. 2009;15:22-24.

7. Miller WG, Myers GL, Ashwood ER, et al. State of the art in trueness and interlaboratory harmonization for 10 analytes in general clinical chemistry. Arch Pathol Lab Med. 2008;132:838-846.

8. Stamp LK, Khanna PP, Dalbeth N, et al. Serum urate in chronic gout: will it be the first validated soluble biomarker in rheumatology? J Rheumatol. 2011;38:1462-1466.

9. Devgun MS, Dhillon HS. Importance of diurnal variations on clinical value and interpretation of serum urate measurements. J Clin Pathol. 1992;45:110-113.

10. Yu KH, Luo SF, Tsai WP, Huang YY. Intermittent elevation of serum urate and 24-hour urinary uric acid excretion. Rheumatology (Oxford). 2004;43:1541-1545.

11. Goldstein RA, Becker KL, Moore CF. Serum urate in healthy men. Intermittent elevations and seasonal effect. N Engl J Med. 1972;287:649-650.

12. Amato $\mathrm{M}$, Montorsi $\mathrm{P}$, Ravani $\mathrm{A}$, et al. Carotid intima-media thickness by B-mode ultrasound as surrogate of coronary atherosclerosis: correlation with quantitative coronary angiography and coronary intravascular ultrasound findings. Eur Heart J. 2007;28:2094-2101.

13. Baldassarre D, Hamsten A, Veglia F, et al. Measurements of carotid intima-media thickness and of interadventitia common carotid diameter improve prediction of cardiovascular events: results of the IMPROVE (Carotid Intima Media Thickness [IMT] and IMT-Progression as Predictors of Vascular Events in a High Risk European Population) study. J Am Coll Cardiol. 2012;60:1489-1499.

14. Hirsch AT, Criqui MH, Treat-Jacobson D, et al. Peripheral arterial disease detection, awareness, and treatment in primary care. JAMA. 2001;286:1317-1324.

15. Heald CL, Fowkes FG, Murray GD, Price JF. Risk of mortality and cardiovascular disease associated with the ankle-brachial index: Systematic review. Atherosclerosis. 2006;189:61-69.

16. Doobay AV, Anand SS. Sensitivity and specificity of the ankle-brachial index to predict future cardiovascular outcomes: a systematic review. Arterioscler Thromb Vasc Biol. 2005;25:1463-1469.

17. Teren A, Beutner F, Wirkner K, Loeffler M, Scholz M. Validity, intra- and inter-observer reliability of automated devices for the assessment of ankle brachial index using photo-plethysmography. BMC Cardiovasc Disord. 2013;13:81.

18. Laurent S, Cockcroft J, Van Bortel L, et al. Expert consensus document on arterial stiffness: methodological issues and clinical applications. Eur Heart J. 2006;27:2588-2605.

19. Laurent S, Boutouyrie P. Arterial stiffness: a new surrogate end point for cardiovascular disease? J Nephrol. 2007;20 Suppl 12:S45-50.

20. Yang EY, Chambless L, Sharrett AR, et al. Carotid arterial wall characteristics are associated with incident ischemic stroke but not coronary heart disease in the Atherosclerosis Risk in Communities (ARIC) study. Stroke. 2012;43:103-108.

21. Dijk JM, Algra A, van der Graaf Y, Grobbee DE, Bots ML. Carotid stiffness and the risk of new vascular events in patients with manifest cardiovascular disease. The SMART study. Eur Heart J. 2005;26: 1213-1220. 
22. Barenbrock M, Kosch M, Joster E, Kisters K, Rahn KH, Hausberg M. Reduced arterial distensibility is a predictor of cardiovascular disease in patients after renal transplantation. J Hypertens. 2002;20:79-84.

23. Blacher J, Pannier B, Guerin AP, Marchais SJ, Safar ME, London GM. Carotid arterial stiffness as a predictor of cardiovascular and all-cause mortality in end-stage renal disease. Hypertension. 1998;32:570-574.

24. Kizu A, Koyama H, Tanaka S, et al. Arterial wall stiffness is associated with peripheral circulation in patients with type 2 diabetes. Atherosclerosis. 2003;170:87-91.

25. Taniwaki $H$, Shoji $T$, Emoto $M$, et al. Femoral artery wall thickness and stiffness in evaluation of peripheral vascular disease in type 2 diabetes mellitus. Atherosclerosis. 2001;158:207-214.

26. Criqui $\mathrm{MH}$, Langer RD, Fronek $\mathrm{A}$, et al. Mortality over a period of 10 years in patients with peripheral arterial disease. N Engl J Med. 1992;326:381-386.

27. Holowatz LA, Thompson-Torgerson CS, Kenney WL. The human cutaneous circulation as a model of generalized microvascular function. J Appl Physiol (1985). 2008;105:370-372.

28. Barchetta I, Riccieri V, Vasile $M$, et al. High prevalence of capillary abnormalities in patients with diabetes and association with retinopathy. Diabet Med. 2011;28:1039-1044.

29. Houben AJ, Beljaars JH, Hofstra L, Kroon AA, De Leeuw PW. Microvascular abnormalities in chronic heart failure: a cross-sectional analysis. Microcirculation. 2003;10:471-478.

30. Draaijer P, de Leeuw PW, van Hooff JP, Leunissen KM. Nailfold capillary density in salt-sensitive and salt-resistant borderline hypertension. J Hypertens. 1993;11:1195-1198.

31. Khan NF, Harrison SE, Rose PW. Validity of diagnostic coding within the General Practice Research Database: a systematic review. Br J Gen Pract. 2010;60:e128-136.

32. Herrett E, Thomas SL, Schoonen WM, Smeeth L, Hall AJ. Validation and validity of diagnoses in the General Practice Research Database: a systematic review. Br J Clin Pharmacol. 2010;69:4-14.

33. Meier $\mathrm{CR}$, Jick H. Omeprazole, other antiulcer drugs and newly diagnosed gout. Br J Clin Pharmacol. 1997;44:175-178.

34. Barr EL, Tonkin AM, Welborn TA, Shaw JE. Validity of self-reported cardiovascular disease events in comparison to medical record adjudication and a statewide hospital morbidity database: the AusDiab study. Intern Med J. 2009;39:49-53.

35. Bouter LM, Dongen van MCJM, Zielhuis GA. Epidemiologische onderzoek: opzet en interpretatie. 6 ed. Houten: Bohn Stafleu van Loghum; 2010.

36. Lawrenson R, Williams T, Farmer R. Clinical information for research; the use of general practice databases. J Public Health Med. 1999;21:299-304.

37. Bashford JN, Norwood J, Chapman SR. Why are patients prescribed proton pump inhibitors? Retrospective analysis of link between morbidity and prescribing in the General Practice Research Database. BMJ. 1998;317:452-456.

38. Donoghue JM, Tylee A. The treatment of depression: prescribing patterns of antidepressants in primary care in the UK. Br J Psychiatry. 1996;168:164-168.

39. Kruijshoop M, Feskens EJ, Blaak EE, de Bruin TW. Validation of capillary glucose measurements to detect glucose intolerance or type 2 diabetes mellitus in the general population. Clin Chim Acta. 2004;341:33-40.

40. Schram M, Sep SJ, Kallen van der CJ, et al. Maastricht Study: An Extensive Phenotyping Study on Determinants of Type 2 Diabetes, its Complications and its Comorbidities. Eur J Epid. 2014;29:439-451.

41. Grayson PC, Kim SY, LaValley M, Choi HK. Hyperuricemia and incident hypertension: a systematic review and meta-analysis. Arthritis Care Res (Hoboken). 2011;63:102-110.

42. McAdams DeMarco MA, Maynard JW, Baer AN, et al. Diuretic use, increased serum urate levels, and risk of incident gout in a population-based study of adults with hypertension: the Atherosclerosis Risk in Communities cohort study. Arthritis Rheum. 2012;64:121-129.

43. Messerli FH, Frohlich ED, Dreslinski GR, Suarez DH, Aristimuno GG. Serum uric acid in essential hypertension: an indicator of renal vascular involvement. Ann Intern Med. 1980;93:817-821.

44. Johnson RJ, Nakagawa T, Sanchez-Lozada LG, et al. Sugar, uric acid, and the etiology of diabetes and obesity. Diabetes. 2013;62:3307-3315. 
45. Facchini F, Chen YD, Hollenbeck CB, Reaven GM. Relationship between resistance to insulin-mediated glucose uptake, urinary uric acid clearance, and plasma uric acid concentration. JAMA. 1991;266: 3008-3011.

46. Feig DI. Uric acid: a novel mediator and marker of risk in chronic kidney disease? Curr Opin Nephrol Hypertens. 2009;18:526-530.

47. Bose B, Badve SV, Hiremath SS, et al. Effects of uric acid-lowering therapy on renal outcomes: a systematic review and meta-analysis. Nephrol Dial Transplant. 2014;29:406-413.

48. Diez D, Wheelock AM, Goto $S$, et al. The use of network analyses for elucidating mechanisms in cardiovascular disease. Mol Biosyst. 2010;6:289-304.

49. Cook DG, Shaper AG, Thelle DS, Whitehead TP. Serum uric acid, serum glucose and diabetes: relationships in a population study. Postgrad Med J. 1986;62:1001-1006.

50. Musso G, Gambino R, Cassader M, Pagano G. A novel approach to control hyperglycemia in type 2 diabetes: sodium glucose co-transport (SGLT) inhibitors: systematic review and meta-analysis of randomized trials. Ann Med. 2012;44:375-393.

51. Gilbert RE. Sodium-glucose linked transporter-2 inhibitors: potential for renoprotection beyond blood glucose lowering? Kidney Int. 2013;Epub ahead of print (doi: 10.1038/ki.2013.451).

52. Lipkowitz MS. Regulation of uric acid excretion by the kidney. Curr Rheumatol Rep. 2012;14:179-188.

53. Cicero AF, Salvi P, D'Addato S, Rosticci M, Borghi C. Association between serum uric acid, hypertension, vascular stiffness and subclinical atherosclerosis: data from the Brisighella Heart Study. J Hypertens. 2014;32:57-64.

54. Bae JS, Shin DH, Park PS, et al. The impact of serum uric acid level on arterial stiffness and carotid atherosclerosis: the Korean Multi-Rural Communities Cohort study. Atherosclerosis. 2013;231:145-151.

55. van Popele NM, Grobbee DE, Bots ML, et al. Association between arterial stiffness and atherosclerosis: the Rotterdam Study. Stroke. 2001;32:454-460.

56. Feig DI. The role of uric acid in the pathogenesis of hypertension in the young. J Clin Hypertens (Greenwich). 2012;14:346-352.

57. Desai RV, Ahmed MI, Fonarow GC, et al. Effect of serum insulin on the association between hyperuricemia and incident heart failure. Am J Cardiol. 2010;106:1134-1138.

58. Hare JM, Johnson RJ. Uric acid predicts clinical outcomes in heart failure: insights regarding the role of xanthine oxidase and uric acid in disease pathophysiology. Circulation. 2003;107:1951-1953.

59. Wijnands JM, Viechtbauer W, Thevissen K, et al. Determinants of the prevalence of gout in the general population: a systematic review and meta-regression Eur J Epid. In Press.

60. Zhu Y, Pandya BJ, Choi HK. Prevalence of gout and hyperuricemia in the US general population: the National Health and Nutrition Examination Survey 2007-2008. Arthritis Rheum. 2011;63:3136-3141.

61. Kuo CF, Grainge MJ, Mallen C, Zhang W, Doherty M. Rising burden of gout in the UK but continuing suboptimal management: a nationwide population study. Ann Rheum Dis. 2014;Epub ahead of print (doi: 10.1136/annrheumdis-2013-204463).

62. Singh JA, Strand V. Gout is associated with more comorbidities, poorer health-related quality of life and higher healthcare utilisation in US veterans. Ann Rheum Dis. 2008;67:1310-1316.

63. Roddy E, Zhang W, Doherty M. Is gout associated with reduced quality of life? A case-control study. Rheumatology (Oxford). 2007;46:1441-1444.

64. Duffy WB, Senekjian HO, Knight TF, Weinman EJ. Management of asymptomatic hyperuricemia. JAMA. 1981;246:2215-2216.

65. Liang MH, Fries JF. Asymptomatic hyperuricemia: the case for conservative management. Ann Intern Med. 1978;88:666-670.

66. De Vera MA, Marcotte G, Rai S, Galo JS, Bhole V. Medication adherence in gout: A systematic review. Arthritis Care Res (Hoboken). 2014;Epub ahead of print (doi: 10.1002/acr.22336).

67. Briesacher BA, Andrade SE, Fouayzi H, Chan KA. Comparison of drug adherence rates among patients with seven different medical conditions. Pharmacotherapy. 2008;28:437-443.

68. Sarawate $\mathrm{CA}$, Brewer $\mathrm{KK}$, Yang $\mathrm{W}$, et al. Gout medication treatment patterns and adherence to standards of care from a managed care perspective. Mayo Clin Proc. 2006;81:925-934.

69. Gutierrez-Macias A, Lizarralde-Palacios E, Martinez-Odriozola P, Miguel-De la Villa F. Fatal allopurinol hypersensitivity syndrome after treatment of asymptomatic hyperuricaemia. BMJ. 2005;331:623-624. 
70. Khanna D, Fitzgerald JD, Khanna PP, et al. 2012 American College of Rheumatology guidelines for management of gout. Part 1: systematic nonpharmacologic and pharmacologic therapeutic approaches to hyperuricemia. Arthritis Care Res (Hoboken). 2012;64:1431-1446.

71. Nuki G. An appraisal of the 2012 American College of Rheumatology guidelines for the management of gout. Curr Opin Rheumatol. 2014;26:152-161.

72. Feig DI, Soletsky B, Johnson RJ. Effect of allopurinol on blood pressure of adolescents with newly diagnosed essential hypertension: a randomized trial. JAMA. 2008;300:924-932.

73. Kanbay $M$, Huddam $B$, Azak A, et al. A randomized study of allopurinol on endothelial function and estimated glomular filtration rate in asymptomatic hyperuricemic subjects with normal renal function. Clin J Am Soc Nephrol. 2011;6:1887-1894.

74. Goicoechea M, de Vinuesa SG, Verdalles U, et al. Effect of allopurinol in chronic kidney disease progression and cardiovascular risk. Clin J Am Soc Nephrol. 2010;5:1388-1393.

75. Siu YP, Leung KT, Tong MK, Kwan TH. Use of allopurinol in slowing the progression of renal disease through its ability to lower serum uric acid level. Am J Kidney Dis. 2006;47:51-59.

76. Dubreuil $M$, Zhu $Y$, Zhang $Y$, et al. Allopurinol initiation and all-cause mortality in the general population. Ann Rheum Dis. 2014; Epub ahead of print (doi: 10.1136/annrheumdis-2014-205269).

77. George J, Carr E, Davies J, Belch JJ, Struthers A. High-dose allopurinol improves endothelial function by profoundly reducing vascular oxidative stress and not by lowering uric acid. Circulation. 2006;114: 2508-2516.

78. Ogino $\mathrm{K}$, Kato $\mathrm{M}$, Furuse $\mathrm{Y}$, et al. Uric acid-lowering treatment with benzbromarone in patients with heart failure: a double-blind placebo-controlled crossover preliminary study. Circ Heart Fail. 2010;3: 73-81.

79. NVR. Richtlijn Jicht. htttp://www.nvr.nl/richtlijnen/richtlijnen2. Accessed 7 July, 2014. 
Samenvatting 


\section{Samenvatting}

Jicht is een reumatische ziekte die wordt veroorzaakt door het neerslaan van urinezuur (in de vorm van kleine naaldvormige kristallen) in en rond de gewrichten. Deze kristallen kunnen een plotselinge ontstekingsreactie veroorzaken. De ontsteking bevindt zich vaak in het basisgewricht van de grote teen. Een hoge urinezuurconcentratie in het bloed, oftewel hyperurikemie, is de voornaamste oorzaak van jicht. Hyperurikemie wordt veroorzaakt door een verhoogde urinezuurproductie en/of een verminderde urinezuurexcretie. Risicofactoren voor deze hoge urinezuurconcentraties zijn alcohol, purinerijke voeding (rood vlees, orgaanvlees, zeevruchten), en fructosehoudende voedingsmiddelen en dranken (frisdrank en vruchtensap). Daarnaast spelen genetische factoren, evenals aandoeningen zoals overgewicht, een verhoogde bloeddruk en een verminderde nierfunctie, een belangrijke rol in het ontstaan van hyperurikemie.

Jicht krijgt in toenemende mate aandacht van clinici en onderzoekers. De reden hiervoor is tweeledig. Ten eerste wordt er gesuggereerd dat het aantal mensen met de ziekte in de laatste decennia is toegenomen en verder zal stijgen. De stijging zou te wijten zijn aan veroudering en de toename in het aantal mensen met overgewicht en een ongezonde leefstijl. Daarom is het belangrijk om meer inzicht te krijgen in hoe vaak jicht voorkomt. Ten tweede hebben mensen met jicht vaak ook andere aandoeningen, waaronder hart- en vaatziekten. Hoewel deze relatie te verklaren is door gemeenschappelijke risicofactoren, zou jicht ook een oorzakelijke rol kunnen spelen in de ontwikkeling van deze aandoeningen. Vermoedelijk zijn de hoge urinezuurconcentraties hierbij van belang. De precieze onderliggende mechanismen voor het verband tussen urinezuur en hart- en vaatziekten zijn vooralsnog onbekend.

In dit proefschrift onderzochten we 1) het classificeren van jicht in wetenschappelijke studies en het vóórkomen van deze ziekte en 2) de relatie tussen urinezuur en drie verschillende processen die kunnen leiden tot hart- en vaatziekten (atherosclerose, vaatstijfheid en disfunctie van de kleine bloedvaten (microcirculatie)).

Hoofdstuk 2 betrof een review over de verschillende methoden waarmee individuen met jicht in epidemiologisch onderzoek geïdentificeerd kunnen worden. We beschreven de formele classificatiecriteria voor jicht (Rome, New York en ACR (American College of Reumatology) criteria) met de bijbehorende beperkingen. Daarnaast gaven we een overzicht van andere vaak gebruikte methoden, zoals ICDcodes (International Classification of Diseases) en zelfrapportage. Als gevolg van de grote variatie in methoden kunnen onderzoeksresultaten moeilijk met elkaar worden vergeleken. Naast deze variatie worden de verschillende termen om de ernst van jicht uit te drukken inconsistent gebruikt zonder een duidelijke definitie. De interpretatie van resultaten kan hierdoor worden belemmerd. 
In hoofdstuk 3 bestudeerden we het percentage van de bevolking dat jicht heeft (prevalentie) en het aantal nieuwe ziektegevallen per jaar (incidentie). We onderzochten dit door op een systematische wijze de literatuur te doorzoeken en deze resultaten vervolgens samen te voegen. We rapporteerden een geschatte wereldwijde prevalentie van 0,6 procent. Echter, de karakteristieken van de diverse studies waren enorm verschillend, oftewel er was een grote mate van heterogeniteit $(99,9 \%)$ tussen de studies. Daarom onderzochten we diverse factoren die deze heterogeniteit zouden kunnen verklaren. We lieten zien dat de man-vrouwverhouding en de variatie in de continenten waar de studies zijn uitgevoerd belangrijke verklarende factoren waren. Daarnaast bevestigden onze resultaten dat de manier waarop jicht geclassificeerd wordt van grote invloed is op de geschatte prevalentie. Alle klinische en methodologische factoren samen verklaarden $88,7 \%$ van de totale heterogeniteit.

In hoofdstuk 4 bestudeerden we het risico op jicht bij mensen met en zonder diabetes type 2 . We vonden dat mensen met diabetes een grotere kans hebben op het ontwikkelen van jicht in vergelijking met mensen zonder diabetes. Dit risico was groter bij vrouwen dan bij mannen met diabetes en was toe te schrijven aan het verhoogd voorkomen van klassieke risicofactoren voor jicht, zoals overgewicht, verhoogde bloeddruk en/of verminderde nierfunctie. Onafhankelijk van deze factoren was diabetes geassocieerd met een verminderd risico op jicht. Dit verlaagde risico zagen we echter alleen bij mannen en was waarschijnlijk toe te schrijven aan een slechte regulatie van de bloedsuikerspiegel. Mogelijk gaat een hoge bloedsuikerspiegel gepaard met een verhoogde urinezuurexcretie en/of verminderde urinezuurreabsorptie in de nier.

Atherosclerose wordt gekenmerkt door vetafzetting op de binnenwand van de slagaders, ook wel atherosclerotische plaques genoemd. Deze plaques kunnen de doorgang van de slagaders vernauwen wat uiteindelijk kan resulteren in een hartinfarct of beroerte. In hoofdstuk $\mathbf{5}$ analyseerden we de mogelijke relatie tussen urinezuur en atherosclerose. Daarnaast onderzochten we of laaggradige ontsteking, een voorspeller van hart- en vaatziekten tevens geassocieerd met urinezuur, het onderliggend mechanisme was voor het verband tussen urinezuur en atherosclerose. We maakten gebruik van markers van atherosclerose en laaggradige ontsteking, zoals gemeten bij deelnemers van de CODAM-studie. In onze studie was er geen verband tussen urinezuur en enkel-arm-index (een maat voor vernauwing in de slagaders van de benen) of al aanwezige hart- en vaatziekten, maar wel met intima-media dikte (een maat voor vaatwanddikte). De sterkte van dit verband was echter gering. Opmerkelijk was dat de onderzochte associaties sterker waren bij mensen met een normale glucosestofwisseling in vergelijking met een gestoorde glucosestofwisseling en diabetes type 2. Onze studie kon niet aantonen dat laaggradige ontsteking het onderliggende mechanisme was voor de gevonden verbanden. 
Vaatstijfheid wordt gekenmerkt door het verlies van de elasticiteit van de vaatwand. Voor het hart wordt het moeilijker om bloed rond te pompen. Daarnaast wordt de kans op vaatwandbeschadigingen vergroot. In hoofdstuk 6 onderzochten we de associatie tussen urinezuur en vaatstijfheid. We maakten gebruik van maten voor verstijving van de aorta, halsslagader en beenslagader, zoals gemeten bij deelnemers van De Maastricht Studie. We toonden aan dat urinezuur met geen enkele marker van vaatstijfheid geassocieerd was. Echter, ook in deze studie zagen we dat er verschillen waren tussen mensen met een normale glucosestofwisseling, gestoorde glucosestofwisseling of diabetes type 2 . De nadelige relatie tussen urinezuur en stijfheid van de halsslagader was sterker bij mensen met een normale glucosestofwisseling.

De microcirculatie zorgt voor de uitwisseling van het bloed en het lichaamsweefsel. Een verminderde werking van de microcirculatie kan daardoor veel verschillende gevolgen hebben. Zo kan het leiden tot schade aan de ogen, nieren, hart en hersenen. Daarnaast verhoogt het de weerstand waartegen het hart pompt met als gevolg een verhoogde bloeddruk. In hoofdstuk 7 bestudeerden we het verband tussen urinezuur en de functie van de microcirculatie in De Maastricht Studie. Hiertoe werd het aantal kleine bloedvaten in het nagelbed van de vingers gemeten in rust en na arteriële en veneuze occlusie. We vonden geen bewijs voor een relatie tussen urinezuur en functionele of structurele afwijkingen van de microcirculatie. Bovendien waren er geen verschillen in de resultaten tussen mannen en vrouwen, leeftijdsgroepen en de status van de glucosestofwisseling.

In hoofdstuk 8 werden de belangrijkste bevindingen gepresenteerd en bediscussieerd in het licht van enkele methodologische beperkingen van onze studies. We benadrukten de complexiteit van de classificatie van jicht en de sterke invloed van de gebruikte classificatiemethode op onderzoeksresultaten. Onderzoekers moeten zich bewust zijn van hoe goed de verschillende methoden meten wat ze moeten meten. We vonden geen sterk bewijs voor een associatie tussen urinezuur en hart- en vaatziekten die klinisch relevant is, noch konden er harde conclusies worden getrokken over een eventueel verschil in associatie tussen urinezuur en de onderzochte pathofysiologische mechanismen van hart- en vaatziekten (atherosclerose, vaatstijfheid en disfunctie van de microcirculatie). Medicamenteuze verlaging van urinezuurconcentraties om het risico op hart- en vaatziekten te verminderen kan op basis van onze resultaten niet worden ondersteund. Echter, we vonden mogelijke verschillen in de associatie tussen urinezuur en hart- en vaatziekten afhankelijk van de glucosestofwisseling. In het proefschrift worden mogelijke verklaringen voor deze bevinding beschreven. 
Valorisation addendum 


\section{Valorisation addendum}

Valorisation is the act of making research results appropriate and useful in order to enhance opportunities for others to use them (cf. definition AWT 2007). This addendum describes the societal relevance of the present findings and the possibilities for valorisation of our results.

\section{Part I Classification, prevalence and incidence of gout}

The quality of research is an essential but sometimes underappreciated starting point of the valorisation process. An important aspect of research quality involves the validity of the case definition used to classify an individual as having a disease. Validity refers to the degree to which a tool measures what it supposed to measure. Low validity may produce biased results and as a consequence, valorisation of these findings will not have the wanted effect. In this thesis we have shown the large effect of the case definition of gout on the estimated prevalence (the number of cases present in a particular population at a given time $)^{1}$. It is possible that the different case definitions applied in the studies reviewed, such as official classification criteria, ICD (International Classification of Diseases) codes and self-reported diagnosis, identify different individuals as having the disease. The manner in which a case is defined can therefore influence the estimated prevalence and limit the comparability of results. In addition to the influence on disease occurrence, it is conceivable that the variation in case definition also affects other study outcomes in gout.

Note that gout is becoming a significant burden on society. In our systematic review we have shown that the worldwide prevalence is considerable, i.e. $0.6 \%{ }^{1}$. Several factors such as population aging, unhealthy lifestyles and obesity are expected to result in an increase in the prevalence of gout in affluent countries. In the United Kingdom, the prevalence increased from $1.52 \%$ in 1997 to $2.49 \%$ in $2012^{2}$. In the USA, the prevalence increased from $2.9 \%$ in $1988-1994$ to $3.9 \%$ in $2007-2008^{3}$. Moreover, insufficiently treated gout may lead to long-term impairment of function, while pain and disability contribute to a decrease in patient's health-related quality of life. In order to reduce the societal burden of this disease, high quality research into gout is greatly needed. This thesis raises awareness for an important issue that may affect the quality of research and by doing so it provides a basis for future advances in gout research. Reaching consensus on the most appropriate case definition, considering the context of application, could improve the quality of research in gout and consequently enhance valorisation efforts. 


\section{Part II The role of uric acid in the aetiology of cardiovascular disease}

Cardiovascular diseases (CVD) affect the heart and/or blood vessels. It is estimated that such diseases are the leading cause of deaths worldwide and a major cause of disability. In 2008 only, the cost in human life was enormous. Approximately 17.3 million people died from complications such as stroke and infarction, which is one third of the global mortality ${ }^{4}$. Moreover, CVD represent a tremendous economic burden to society. Recent studies have estimated that their total annual cost within the European Union is around $€ 169$ billion $^{5}$. Factors that might cause CVD (so called "risk factors") are well known and include obesity, tobacco consumption, physical inactivity, high blood pressure, and elevated glucose concentrations ${ }^{6}$. Several studies suggest that uric acid, the underlying cause of gout, may also contribute to the development of these diseases, independently of other risk factors. Uric acid is produced from the natural breakdown of cells in the body and from dietary products, and is thereafter excreted via the urine and stool. Under normal conditions, the body maintains a balance between uric acid production and excretion so that the uric acid concentration in the blood is nearly constant. However, if uric acid is produced in excess, or not enough is excreted, the concentration of uric acid will rise and can result in hyperuricaemia (high uric acid levels). The prevalence of hyperuricaemia in affluent countries is considerable and estimated at $11.9 \%$ in Italy ${ }^{7}, 21.4 \%$ in the United States ${ }^{3}$, and $25.3 \%$ in China ${ }^{8}$.

The co-occurrence of hyperuricaemia and CVD underlines the need for clarifying the nature of the association between these two conditions. A significant association would advocate for uric acid as a biomarker, i.e. measurable indicator, of CVD. Measurement of this potential biomarker can then help in predicting the development of CVD and consequently have a societal impact. However, contrary to what was expected, no significant independent association was identified. Note that several conditions need to be met for a biomarker to be considered clinically useful: 1) it must be readily accessible and the measurement must be sensitive, specific, and reproducible; 2) it should independently predict the occurrence of a disease and has to add new information on top of traditional risk factors; and 3) it must have a sufficient prevalence in the population and cost-effective ${ }^{9}$. Although uric acid may be easy to measure and hyperuricaemia is relatively prevalent, there has been a long ongoing debate on the predictive value and the additional value on top of known risk factors. So far evidence is not convincing enough to support the use of uric acid as a biomarker for CVD neither to address hyperuricaemia with uric-acid-lowering medication to reduce cardiovascular risk.

Given the many inconsistent results and associated high research costs, we suggest that epidemiological studies into the association between uric acid concentrations and CVD in the general population should be discouraged. However, we have shown that the same increase in the level of uric acid might relate differently to CVD according to certain subgroups of the population. We assumed that not only uric acid level itself, but 
also the degree of uric acid production plays an important role in cardiovascular risk. This might be explained by the fact that during the production of uric acid certain substances are released which may promote the development of CVD. The hypothesis on uric acid production as a cardiovascular risk factor deserves to be elucidated. We acknowledge that the role of uric acid in these subgroups may still be rather small compared with other known cardiovascular risk factors. However, a large number of people have or are at risk of CVD. Even if a risk factor only accounts for a small proportion of the total cardiovascular risk, addressing this factor may still have a relevant contribution to the prevention and/or treatment of CVD and thus have societal impact $^{9}$. 


\section{References}

1. Wijnands JM, Viechtbauer W, Thevissen K, et al. Determinants of the prevalence of gout in the general population: a systematic review and meta-regression. Eur J Epidemiol. 2014; Epub ahead of print (doi: 10.1007/s10654-014-9927-y).

2. Kuo CF, Grainge MJ, Mallen C, Zhang W, Doherty M. Rising burden of gout in the UK but continuing suboptimal management: a nationwide population study. Ann Rheum Dis. 2014;Epub ahead of print (doi: 10.1136/annrheumdis-2013-204463).

3. Zhu Y, Pandya BJ, Choi HK. Prevalence of gout and hyperuricemia in the US general population: the National Health and Nutrition Examination Survey 2007-2008. Arthritis Rheum. 2011;63:3136-3141.

4. Organization WH. Cardiovascular diseases (CVDs). 2013; http://www.who.int/mediacentre/factsheets/ fs317/en/.

5. Leal J, Luengo-Fernandez R, Gray A, Petersen S, Rayner M. Economic burden of cardiovascular diseases in the enlarged European Union. Eur Heart J. 2006;27:1610-1619.

6. Yusuf S, Reddy S, Ounpuu S, Anand S. Global burden of cardiovascular diseases: part I: general considerations, the epidemiologic transition, risk factors, and impact of urbanization. Circulation. 2001;104:2746-2753.

7. Trifiro G, Morabito P, Cavagna L, et al. Epidemiology of gout and hyperuricaemia in Italy during the years 2005-2009: a nationwide population-based study. Ann Rheum Dis. 2013;72:694-700.

8. Nan $\mathrm{H}$, Qiao $\mathrm{Q}$, Dong $\mathrm{Y}$, et al. The prevalence of hyperuricemia in a population of the coastal city of Qingdao, China. J Rheumatol. 2006;33:1346-1350.

9. Stampfer MJ, Ridker PM, Dzau VJ. Risk factor criteria. Circulation. 2004;109:IV3-5. 
Dankwoord 


\section{Dankwoord}

Velen hebben een belangrijke bijdrage geleverd aan de totstandkoming van dit proefschrift, waarvoor mijn dank. Ik wil graag een aantal mensen in het bijzonder bedanken.

Allereerst gaat mijn dank uit naar de leden van mijn promotieteam, prof. dr. A. Boonen, prof. dr. I.C.W. Arts en prof. dr. C.D.A. Stehouwer. Beste Annelies, ik kon altijd bij jou terecht. In je drukke agenda wist je altijd weer een plekje voor mij vrij te maken, zelfs in de weekenden en avonden. Je oprechte interesse in mijn privéleven heb ik altijd zeer gewaardeerd. Beste Ilja, ik heb heel veel van je geleerd, van data-analyse tot het schrijven van een rebuttal. Bedankt voor de leerzame discussies en je enorme betrokkenheid. Beste Coen, zoals beschreven in de vele voorgaande proefschriften van mede-promovendi heb ook ik enorme bewondering voor jouw manier van werken. Het is mij een groot raadsel hoe je, ondanks een overvolle agenda, zo ontzettend snel een manuscript van goed commentaar kan voorzien. Bedankt voor je duidelijke uitleg!

Ik had het grote geluk dat ik naast mijn officiële promotieteam nog twee professoren aan mijn zijde had tijdens mijn promotietraject. Sjef van der Linden en Pieter Dagnelie, jullie hebben een belangrijke rol gespeeld bij de totstandkoming van dit proefschrift. Sjef, jij hebt mij de kans gegeven om te promoveren bij de afdeling reumatologie. Ontzettend bedankt hiervoor! Gelukkig voor mij werd je emiraat telkens nog "eventjes" uitgesteld. Pieter, ik heb je interesse in mijn project altijd erg gewaardeerd. Bedankt voor je kritische blik tijdens alle fasen van het onderzoek.

Ik wil graag de leden van de beoordelingscommissie, prof. dr. C.P. van Schayck, dr. A. Dehghan, prof. dr. M.A.F.J. van de Laar, en dr. K. Reesink, bedanken voor de genomen tijd om mijn proefschrift te lezen en te beoordelen.

Mijn dank gaat ook uit naar alle coauteurs die meewerkten aan de verschillende hoofdstukken van dit proefschrift. Een speciaal woord van dank aan Wolfgang Viechtbauer, Kristof Thevissen, Frank de Vries en Annemariek Driessen voor jullie onmisbare hulp bij de totstandkoming van de hoofdstukken 3 en 4 . Ik wil ook de leden van de CODAM studie bedanken voor het gebruik mogen maken van jullie data en jullie hulp bij het verbeteren van het manuscript.

Tijdens mijn promotie ben ik meerdere malen verhuisd van werkplek. Mijn eerste jaar als promovenda heb ik doorgebracht bij de algemene interne geneeskunde, een leuke en enthousiaste groep onderzoekers. Ik ben blij dat ik die tijd deel uit heb mogen maken van jullie team. Bedankt! 
De start van De Maastricht Studie betekende een nieuwe plek op het onderzoekscentrum. Miranda Schram en Ronald Henry, jullie hebben mij gestimuleerd en de kans geboden om dit onderzoek te verrichten. Ik ben jullie hier erg dankbaar voor. Daarnaast wil ik het managementteam, het projectteam, al het ondersteunend personeel en de deelnemers van De Maastricht Studie bedanken voor het mogelijk maken van deze unieke studie. Mijn tijd bij De Maastricht Studie was nooit zo gezellig geweest zonder mijn mede-Maastricht-Studie-promovendi (Marcelle, Peggy, Pauline, Fleur, Julianne, Louise, Eline, Annemariek, Dennis, Thomas, Stefan, Remy, Jeroen, Frank, Ben) en mijn collega's van de V1 en "de balie" (Joséphine, Karin, Wendy, Mariette, Brigitte, Gilbert, Chantalle, Myriam).

De laatste fase van mijn promotieonderzoek mocht ik doorbrengen bij de reumatologie. Een geweldig team, ik heb me hier altijd thuis gevoeld. In het bijzonder wil ik mijn mede-reumatologie-promovendi (Carmen, Ivette, Lieke, Andrea, Antje, Mayke, Ellis, Bart, Joost, Michiel, Simon) en oud-kamergenoot Dirk bedanken voor het bijgedragen aan een geweldige sfeer op het werk. Succes met jullie promoties! Een speciaal woord van dank aan Ivette. Wat fijn dat je tijdens mijn promoveren naast mij wilt staan. Jouw enthousiasme en positivisme zijn bewonderingswaardig. Bedankt voor je hulp bij het analyseren en interpreteren van data maar vooral ook voor onze fijne gesprekken op het werk, het terras, of tijdens de vele etentjes. Ik kijk nog steeds met veel plezier terug op onze rondreis door Californië.

Mijn vrienden en familie hebben voor de broodnodige ontspanning gezorgd. ledereen bedankt voor de belangstelling in mijn onderzoek. Ik wil in het bijzonder Anke bedanken voor de maandelijkse "dates". Ik ben blij met een vriendin zoals jij. Melanie, I am glad I went to the introduction day for new employees. Thank you for all our conversations, drinks, dinners and nights out!

Lieve pap en mam, zonder jullie had ik dit nooit bereikt. Jullie staan altijd voor ons klaar en hebben ons gestimuleerd om verder te leren, zie hier het resultaat. Bedankt voor alles! Lisette, Rian, Ilse, Roel en Gido, lieve zussen en schoonbroers, fijn dat we het zo goed met elkaar kunnen vinden. Misschien kunnen we de volgende zussendag in Vancouver houden. Ilse, ik ben erg trots op je en ik vind het een eer dat je mijn paranimf wilt zijn.

Lieve Antonio, thank you for always supporting me. I am grateful to have you in my life. 
Curriculum Vitae 


\section{Curriculum Vitae}

José Maria Andreas Wijnands was born on July $16^{\text {th }} 1986$ in Helden, the Netherlands. In 2004 she graduated from secondary school at the Bouwens van der Boijecollege in Helden. Hereafter, she obtained her Master's degree in Public Health at Maastricht University, Maastricht. After graduation she worked as a project member for The Maastricht Study. In November 2009, José started her PhD research at the department of Rheumatology within the School for Public Health and Primary Care (CAPHRI) of Maastricht University. The research was performed under the supervision of prof. dr. A. Boonen, prof. dr. I.C.W. Arts and prof. dr. C.D.A. Stehouwer. Currently José has been appointed as a postdoctoral research fellow at the University of British Columbia in Vancouver, Canada. 
